\title{
Molekulare Mechanismen der Regulation der Glukagon-Gentranskription durch die Pax6-Homöodomäne
}

\author{
DISSERTATION \\ zur Erlangung des Doktorgrades \\ der Mathematisch-Naturwissenschaftlichen Fakultät \\ der Georg-August-Universität zu Göttingen
}

vorgelegt von

MARCEL GRAPP

aus Göttingen

Göttingen 2007 
D 7

Referent:

Prof. Dr. R. Hardeland

Korreferent:

PD Dr. W. Kramer

Tag der mündlichen Prüfung: $\quad$ 11.05.2007 
INHALTSVERZEICHNIS

1 EINLEITUNG 1

1.1 Kontrolle der Gen-Expression. 1

1.2 Der Transkriptionsfaktor Pax6... 2

1.3 Die Struktur der Paired-Domäne und der Homöodomäne von Pax6 ............... 5

1.4 Das Peptidhormon Glukagon .................................................................... 7

1.5 Die Regulation der Glukagon-Genexpression durch Pax6 ........................... 8

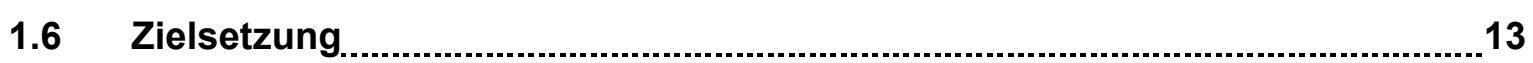

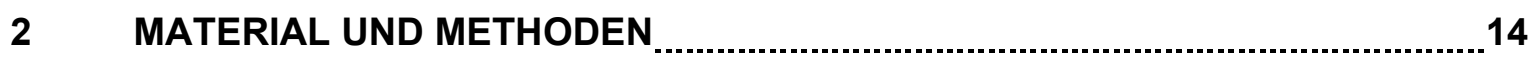

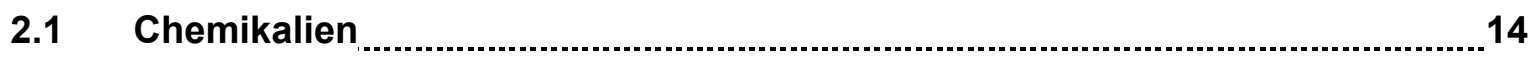

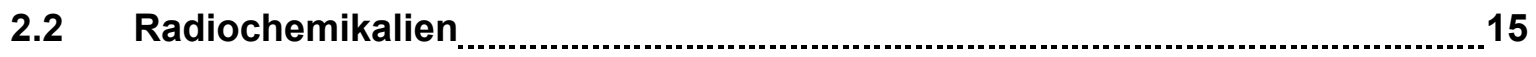

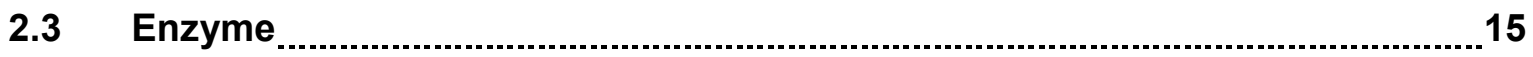

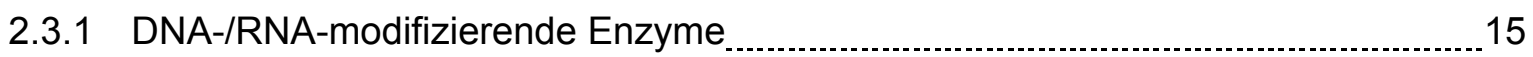

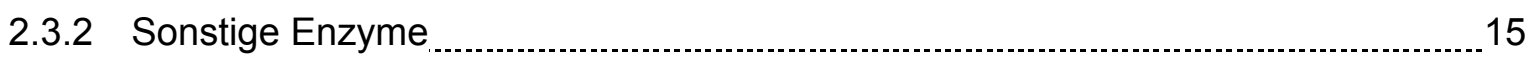

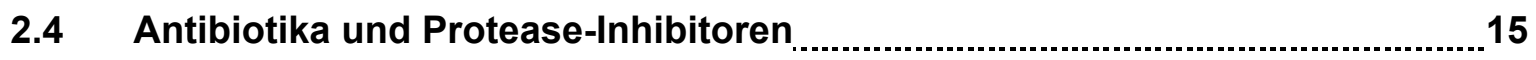

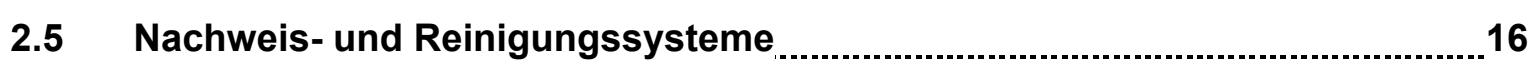

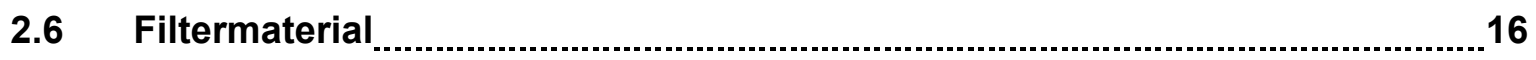

2.7 Materialien zur Anzucht von Bakterien $\ldots 16$

2.8 Material zur Kultivierung eukaryotischer Zelllinien .......................................17

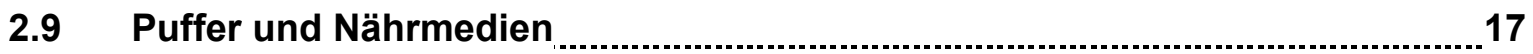

2.10 Medien für die Kultivierung eukaryotischer Zelllinien ...................................19

2.11 Art und Herkunft des biologischen und molekularbiologischen Materials ...20

2.11.1 DNA 20

Synthetische Oligonukleotide für EMSA-Experimente _.................................. 20

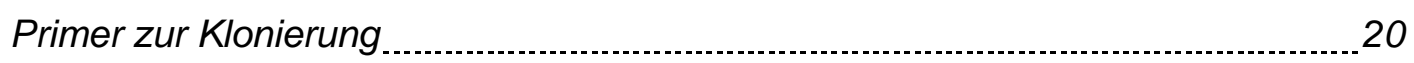

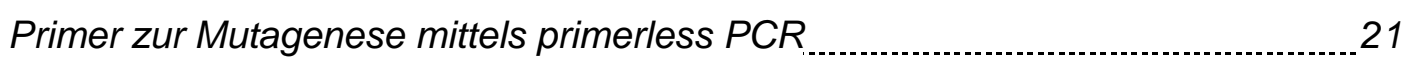

Sequenzierprimer

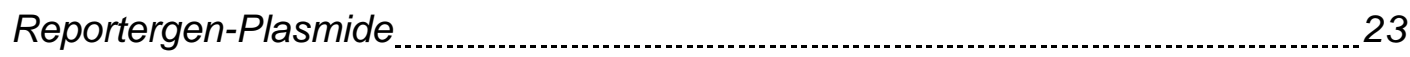

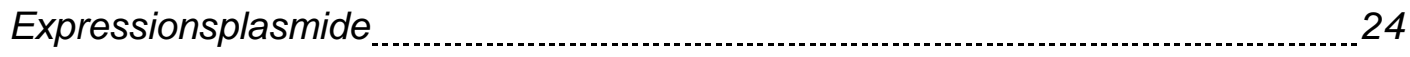

2.11.2 Molekulargewichtstandards 26

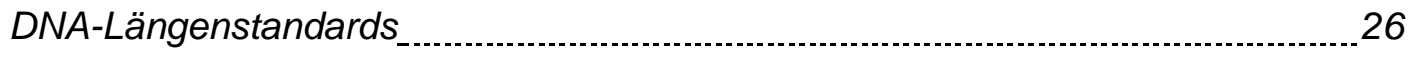


Protein-Molekulargewichtstandards 27

2.11.3 Bakterienstämme 27

2.11.4 Eukaryotische Zelllinien

2.11.5 Antiseren und Antikörper 28

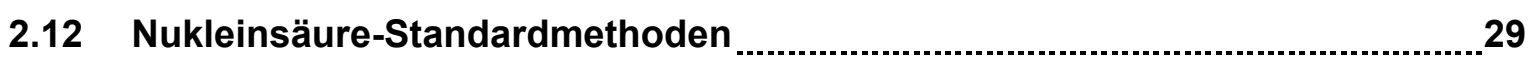

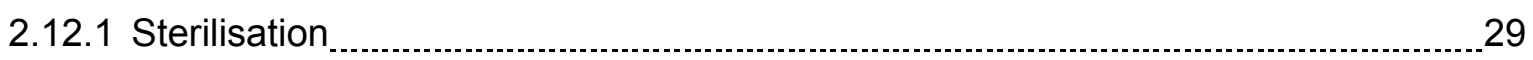

2.12.2 Phenol-Chloroform-Isoamylalkohol-Extraktion (Sambrook et al., 1989).................29

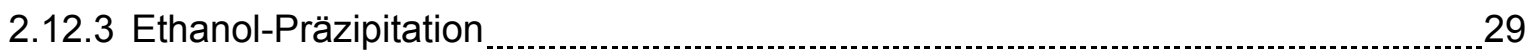

2.12.4 Dialyse von DNA und Proteinen

2.12.5 Konzentrationsbestimmung von Nukleinsäure-Lösungen

(Sambrook et al., 1989) 30

2.12.6 Doppelstrang-Oligonukleotid-Hybridisierung (,,Annealing“) _ _ 30

2.12.7 Radioaktive Markierung von DNA durch die Klenow „Fill-in“-Reaktion (Sambrook et al., 1989)

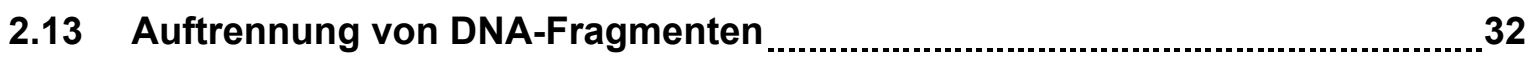

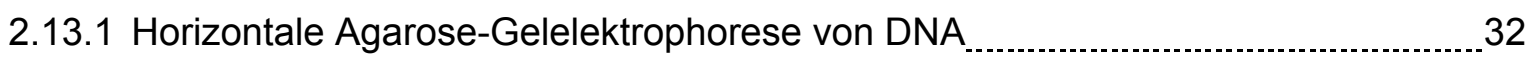

2.13.2 Isolierung von DNA-Fragmenten aus Agarosegelen ........................................... 32

2.14 Nachweis von Nukleinsäuren im analytischen Maßstab................................. 32

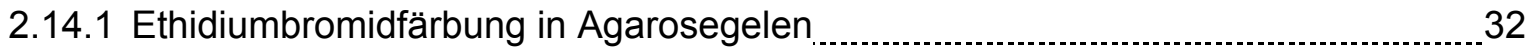

2.14.2 Autoradiographie

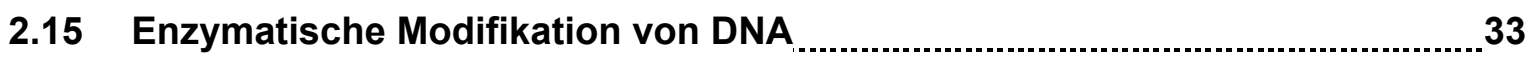

2.15.1 Spaltung von DNA durch Restriktionsendonukleasen .......................................... 33

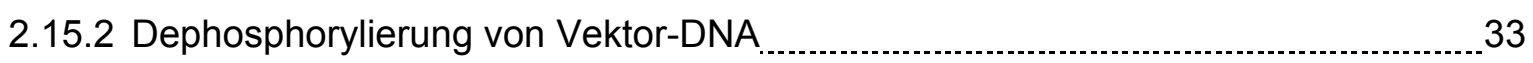

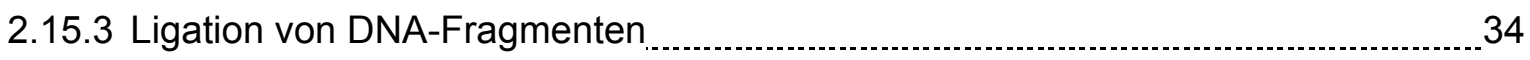

2.16 Polymerase-Kettenreaktion (PCR; Mullis \& Fallona, 1987; Saiki et al., 1988) 34

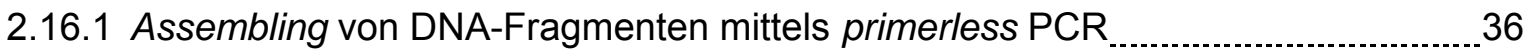

2.16.2 Zielgerichtete Mutagenese mittels primerless PCR 38

2.17 Standardmethoden zur molekularen Klonierung............................................ 39

2.17.1 Herstellung kompetenter E. coli (Dagert \& Ehrlich, 1979)

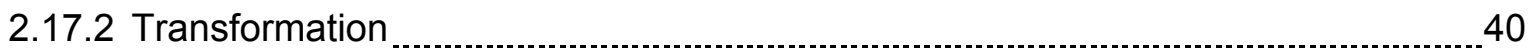

Transformation kompetenter E. coli .................................................................. 40

Transformation kompetenter $\mathrm{DH} 10 \mathrm{Bac}{ }^{\mathrm{TM}}$ E. coli................................................ 40

Identifizierung positiver Klone durch Blau-Weiß-Selektion .................................... 40

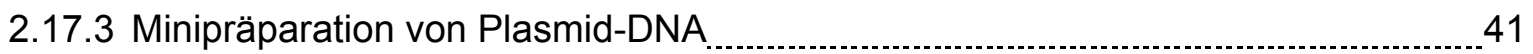

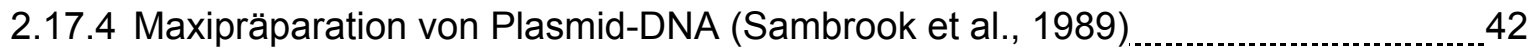

2.17.5 Isolierung rekombinanter Bacmid-DNA

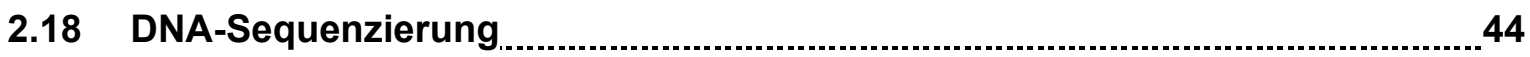


2.19 Proteinbiochemische Methoden 45

2.19.1 In vitro Transkription und Translation $\ldots$

2.19.2 Isolierung von Kernproteinen aus kultivierten Zellen $\ldots \ldots \ldots$

2.19.3 Herstellung von Ganzzellextrakten aus COS-1-Zellen $\ldots . \ldots \ldots$

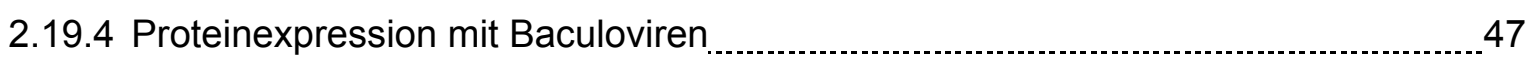

2.19.5 Konzentrationsbestimmung von Proteinlösungen (Bradford, 1976) ........................48

2.19.6 Denaturierende Polyacrylamid-Gelelektrophorese (SDS-PAGE) von Proteinen (Laemmli, 1970). 49

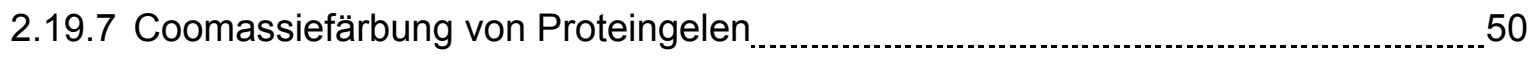

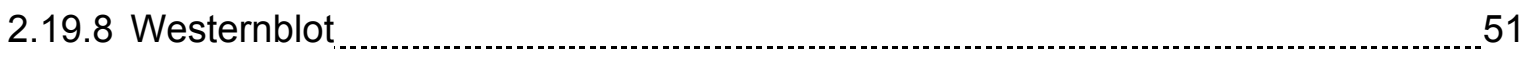

2.19.9 Immundetektion von Proteinen im Westernblot $\ldots$

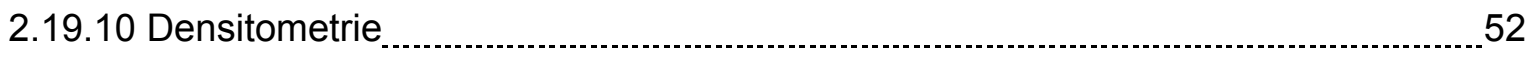

2.20 "Elektrophoretic Mobility Shift Assay" (EMSA)

(Knepel et al. 1990b, modifiziert).............................................................. 52

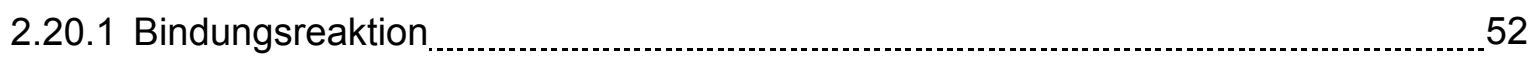

2.20.2 Nicht-denaturierende Auftrennung von Protein-DNA-Komplexen ............................53

2.21 Methoden zur Behandlung eukaryotischer Zellkulturen ................................54

2.21.1 Kultivierung eukaryotischer Zellen ................................................................... 54

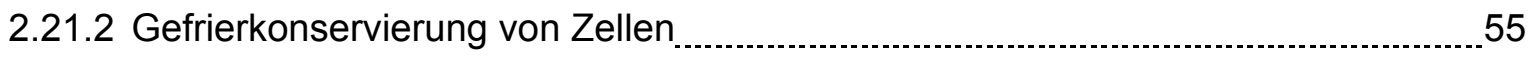

2.21.3 Revitalisierung von Zellen

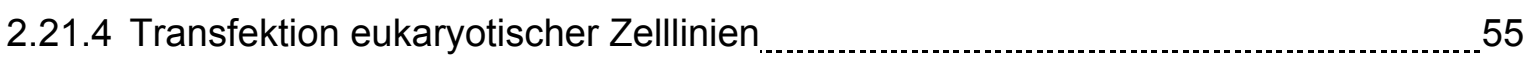

Transfektion mittels DEAE-Dextran (Sambrook et al, 1989, modifiziert)................56

Transfektion mittels Calcium-Phosphat (Ausubel et al, 1987) ..............................57

Transfektion von Insektenzellen _................................................................. 58

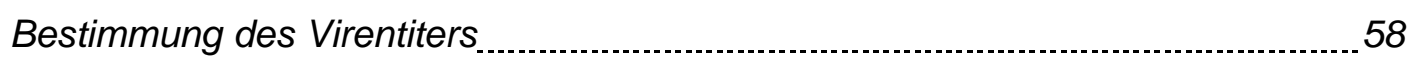

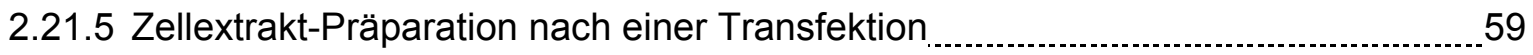

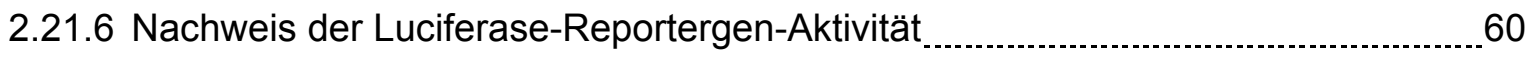

2.21.7 Nachweis der GFP-Reportergen-Aktivität $\ldots 1$

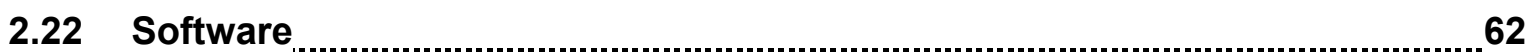

$3 \quad$ ERGEBNISSE

3.1 Hergestellte Reportergen- und Expressionsplasmide ..................................63

3.2 Bedeutung der Pax6-Homöodomäne für die Bindung von Pax6 an den Glukagon-Promotor der Ratte: Untersuchung mit Hilfe von in vitro transkribierten/translatierten Proteinen.

3.2.1 In vitro Transkription und Translation von Pax6-Wildtyp und Pax6-Mutanten und Darstellung der Expressionsprodukte in der SDS-PAGE 
3.2.2 Untersuchung der Bindung von in vitro transkribierten/translatierten Pax6 und Pax6-Mutanten an das G1- und G3-Element des Glukagon-Promotors der Ratte mittels EMSA

Untersuchung der Bindung der Pax6-Paired-Domäne mit Linker an das G1und G3-Element des Glukagon-Promotors

3.3 Bedeutung der Pax6-Homöodomäne für die Bindung von Pax6 an den Glukagon-Promotor der Ratte: Untersuchung mit Hilfe von im Baculovirus-System exprimierten Proteinen 69

3.3.1 Heterologe Proteinexpression in Insektenzellen 69

3.3.2 Optimierung der Expressionsbedingungen für die Expression von Pax6-Wildtyp und der Pax6-Paired-Domäne in Sf9-Insektenzellen

3.3.3 Charakterisierung der Bindung der rekombinanten Pax6-Proteine an das G1und G3-Element des Glukagon-Promotors der Ratte

3.4 Mutation einer putativen Pax6-Homöodomänen-Bindungsstelle im G3und G1- Element des Glukagon-Promotors der Ratte

3.4.1 Annahme einer PH0-artigen („tail-to-tail“) Bindung von Pax6 an das G1- und G3-Element des Glukagon-Promotors

3.4.2 Charakterisierung der Bindung von Pax6 und der Pax6-Paired-Domäne an das G3-Element des Glukagon-Promotors mit den Mutationen PHOmut1 und $\mathrm{PHOmut2}$

3.4.3 Wirkung der Mutationen PHOmut1 und PHOmut2 im G3-Element auf die Aktivierung des Glukagon-Promotors durch endogenes Pax6 in der pankreatischen Inselzelllinie InR1G9

3.4.4 Wirkung der Mutation PHOmut1 und PHOmut2 im G3-Element auf die Aktivierung des Glukagon-Promotors durch Pax6 in der heterologen Zelllinie JEG-3

3.4.5 Charakterisierung der Bindung von Pax6 und der Pax6-Paired-Domäne an das G1-Element des Glukagon-Promotors mit den Mutationen PHOmut1 und $\mathrm{PHOmut2}$

3.4.6 Wirkung der Mutationen PHOmut1 und PHOmut2 im G1-Element auf die Aktivierung des Glukagon-Promotors durch endogenes Pax6 in der pankreatischen Inselzelllinie InR1G9.

3.4.7 Wirkung der Mutationen PHOmut1 und PHOmut2 im G1-Element auf die Aktivierung des Glukagon-Promotors durch Pax6 in der heterologen Zelllinie JEG-3 
3.4.8 Wirkung der Mutationen PHOmut1 und PHOmut2 in G1 auf die Kernproteinbindung in Extrakten aus der pankreatischen Inselzelllinie InR1G9 und der heterologen Zelllinie JEG-3 mittels EMSA

3.5 Bedeutung des $N$-terminalen $\beta$-Faltblatt-Motivs von Pax6 für die Bindung an den Glukagon-Promotor der Ratte

3.5.1 In vitro Transkription/Translation von Pax6wt und Pax6 mit deletierter $\beta$-Faltblattstruktur und Darstellung der Expressionsprodukte in der SDS-PAGE...90

3.5.2 Wirkung der Deletion der $\beta$-Faltblattstruktur von Pax6 auf die Bindung an das G1- und G3-Element des Glukagon-Promotors

3.6 Bedeutung der Pax6-Linkerregion für die Aktivierung des Glukagon-Gens der Ratte durch Pax6

3.6.1 Herstellung, in vitro Transkription/Translation von Pax6-Linkermutanten und Darstellung der Expressionsprodukte in der SDS-PAGE.

3.6.2 Wirkung von Mutationen in der Pax6-Linkerregion auf die Bindung an das G1und G3-Element des Glukagon-Promotors der Ratte

3.6.3 Funktionelle Bedeutung der Pax6-Linkerregion für die Aktivierung des Glukagon-Promotors der Ratte durch Pax6: Wirkung einer Mutation der Pax6Linkerregion auf die Aktivierung des Glukagon-Promotors durch Pax6 in der heterologen Zelllinie JEG-3

3.6.4 Untersuchung des Expressionsgrades von Pax6 und Pax6-Mutanten in cos-1-Zellen

4 DISKUSSION

4.1 Bedeutung der Pax6-Homöodomäne bei der Bindung von Pax6 an das G1- oder G3-Element des Glukagon-Promotors

4.2 Kooperative Bindung der Homöodomäne mit der Paired-Domäne von Pax6 an den Glukagon-Promotor

4.3 Funktion der Pax6-Homöodomäne bei der Aktivierung des

Glukagon-Gens

4.4 Hypothese zur Regulation der Glukagon-Gentranskription durch die Pax6-Homöodomäne

4.5 Die Pax6-Linkerregion zwischen den beiden DNA-Bindedomänen ist für die Aktivierung des Glukagon-Gens durch Pax6 notwendig.

4.6 Vergleichendes Modeling einer PH0-artigen Bindung von Pax6 an das G3-Element des Glukagon-Genpromotors 
6 SUMMARY

7 LITERATURVERZEICHNIS 124 


\section{ABKÜRZUNGSVERZEICHNIS}

A

Abb.

abs.

Ac

Ala

Amp

AP

APS

AS

Asn

ATP

$\beta-M E$

bp

BSA

C

${ }^{\circ} \mathrm{C}$

CA

cAMP

cDNA

$\mathrm{Cdx}$

C/EBP

Chx

$\mathrm{Ci}$

CMV

CRE

CREB

CS

d

dATP

dCTP

dd

DEAE

dGTP
Adenin/Ampère

Abbildung

Absolut

Acetat

Alanin

Ampicillin

Alkalische Phosphatase

Ammoniumpersulfat

Aminosäure

Asparagin

Adenosin-5'-Triphosphat

$\beta$-Mercaptoethanol

Basenpaare

Rinderserumalbumin (bovine serum albumin)

Cytosin

Grad Celsius

Chloramphenicol

zyklisches Adenosin-3‘, 5'-Monophosphat

Copy-Desoxyribonukleinsäure

caudal-type homeobox

CCAAT/EEnhancer-bindendes Protein

C. elegans-like homeobox

Curie

Zytomegalievirus

cAMP-responsives Element

cAMP-responsives Element Bindeprotein

C/EBP-Bindungsstelle

delta (deletiert) oder: desoxy

Desoxyadenosin-5'-Triphosphat

Desoxycytidin-5'-Triphosphat

didesoxy

Diethylaminoethyl

Desoxyguanosin-5'-Triphosphat 


\begin{tabular}{|c|c|}
\hline DMEM & Dulbecco's modified Eagle's medium \\
\hline DMF & Dimethylformamid \\
\hline DMSO & Dimethylsulfoxid \\
\hline DNA & Desoxyribonukleinsäure \\
\hline dNTP & Desoxyribonukleosid-5'-Triphosphat \\
\hline ds & Doppelstrang \\
\hline DTT & Dithiothreitol \\
\hline dTTP & Desoxythymidin-5'-Triphosphat \\
\hline E. coli & Escherichia coli \\
\hline EDTA & Ethylendiamin-Tetra-Acetat \\
\hline EGTA & Ethylenglykol-bis-(2-aminoethylether)-N, N'-Tetra-Acetat \\
\hline EMSA & Electrophoretic Mobility Shift Assay \\
\hline et al. & et alii (und andere) \\
\hline $\mathrm{EtBr}$ & Ethidiumbromid \\
\hline FCS & Fötales Kälberserum (fetal calf serum) \\
\hline g & Gramm \\
\hline G & Guanin \\
\hline G1 & Glukagon-Element 1 \\
\hline G2 & Glukagon-Element 2 \\
\hline G3 & Glukagon-Element 3 \\
\hline G4 & Glukagon-Element 4 \\
\hline G5 & Glukagon-Element 5 \\
\hline GFP & green fluorescent protein \\
\hline GLP & glucagon-like peptide \\
\hline Glu & Glukagon \\
\hline GST & Glutathion-S-Transferase \\
\hline h & Stunde \\
\hline HD & Homöodomäne \\
\hline HeBS & Hepes-gepufferte Salzlösung (Hepes-buffered saline) \\
\hline Hepes & 2-(4-2-Hydroxyethyl)-Piperazinyl-I-Ethansulfonat \\
\hline HOM & Homeotic complex \\
\hline HOX & $\underline{\text { homeobox }}$ \\
\hline IPTG & Isopropyl-b-D-thiogalaktosid \\
\hline $\mathrm{Kb}$ & Kilobasen \\
\hline $\mathrm{KDa}$ & Kilodalton \\
\hline KP-Puffer & Kalium-Phosphat-Puffer \\
\hline
\end{tabular}




\begin{tabular}{|c|c|}
\hline I & Liter \\
\hline $\mathrm{L}$ & Linkerregion \\
\hline LB & Luria Bertani \\
\hline Lhx & $\underline{\text { LIM homeobox }}$ \\
\hline Luc & Luciferase \\
\hline$\mu$ & mikro \\
\hline $\mathrm{m}$ & milli \\
\hline M & Molar \\
\hline $\min$ & Minute \\
\hline $\mathrm{MOI}$ & multiplicity of infection \\
\hline mRNA & Messenger-Ribonukleinsäure \\
\hline MW & Molekulargewicht \\
\hline $\mathrm{n}$ & nano \\
\hline $\mathrm{NaAc}$ & Natriumacetat \\
\hline $\mathrm{NaOH}$ & Natriumhydroxid \\
\hline OD & Optische Dichte \\
\hline $\mathrm{p}$ & Plasmid \\
\hline$\left[{ }^{32} \mathrm{P}\right]$ & Isotop 32 des Phosphors \\
\hline PAGE & Polyacrylamid-Gelelektrophorese \\
\hline pax & paired box \\
\hline Pax6-3Ala & Pax6 mit drei mutierten Aminosäuren in der Homöodomäne \\
\hline Pax6-dHD & Pax6 mit deletierter Homöodomäne \\
\hline Pax6HD & Pax6-Homöodomäne \\
\hline Pax6PD & Pax6-Paired-Domäne \\
\hline Pax6PD-L & Pax6-Paired-Domäne mit Linker \\
\hline Pax6PD-L-HD & Pax6-Paired-Domäne mit Linker und Homöodomäne \\
\hline Pax6Lmut & Pax6 mit mutiertem Linker \\
\hline Pax6PD-Lmut-HD & Pax6-Paired-Domäne mit mutiertem Linker und Homöodomäne \\
\hline Pax6wt & Pax6-Wildtyp \\
\hline PBS & Phosphat-gepufferte Salzlösung (phosphate-buffered saline) \\
\hline pBS & Plasmid Bluescript \\
\hline $\mathrm{Pbx}$ & pre-b-bell-homeobox-protein \\
\hline PCR & Polymerase-Kettenreaktion (polymerase chain reaction) \\
\hline PD & Paired-Domäne \\
\hline PEG & Polyethylenglykol \\
\hline Pfu & Pyrococcus furiosus \\
\hline
\end{tabular}




\begin{tabular}{|c|c|}
\hline pfu & plaque forming units \\
\hline PISCES & pancreatic islet cell-specific enhancer sequence \\
\hline PMSF & Phenylmethyl-Sulfonylfluorid \\
\hline POU & pit oct une \\
\hline PPARy & Peroxisomen-Proliferator(en)-aktivierter Rezeptor $\mathrm{y}$ \\
\hline Prep1 & Pbx-regulating protein 1 \\
\hline $\operatorname{Rax}$ & retina and anterior neural fold homeobox \\
\hline RNA & Ribonukleinsäure \\
\hline RNase & Ribonuklease \\
\hline RT & Raumtemperatur \\
\hline s & Sekunde \\
\hline$\left[{ }^{35} \mathrm{~S}\right]$ & Isotop 35 des Schwefels \\
\hline SDS & Natrium-Dodecylsulfat \\
\hline SEM & Standardfehler des Mittelwerts (standard error of the mean) \\
\hline Ser & Serin \\
\hline Six & 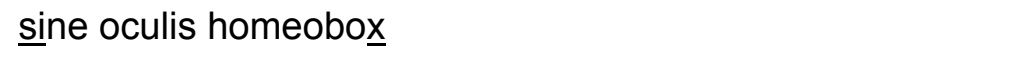 \\
\hline STE & Saccharose-Tris-EDTA \\
\hline SV & simian virus \\
\hline $\mathrm{T}$ & Thymin \\
\hline $\mathrm{T} 7$ & Bakteriophage T7 \\
\hline Tab. & Tabelle \\
\hline TAD & Transaktivierungsdomäne \\
\hline TAE & Tris-Acetat-EDTA \\
\hline TALE & three amino acid loop extension \\
\hline TBE & Tris-Borat-EDTA \\
\hline TBP & TATA-Box-bindendes Protein \\
\hline TE & Tris-EDTA \\
\hline TEMED & $\mathrm{N}, \mathrm{N}, \mathrm{N}^{\prime}, \mathrm{N}^{\prime}$-Tetramethylethylendiamin \\
\hline TK & Thymidin-Kinase \\
\hline $\mathrm{Tm}$ & Schmelztemperatur (melting temperature) \\
\hline TNE & Tris-NaCl-EDTA \\
\hline Tris & Tris-(hydroxymethyl)-aminomethan \\
\hline$U$ & Unit (Enzymeinheiten) \\
\hline ü.N. & über Nacht \\
\hline UpM & Umdrehungen pro Minute \\
\hline UV & ultraviolett \\
\hline
\end{tabular}




$\begin{array}{ll}\text { V } & \text { Volt } \\ \text { Val } & \text { Valin } \\ \text { Vol. } & \text { Volumen } \\ \mathrm{v} / \mathrm{v} & \text { Volumen pro Volumen } \\ \mathrm{wt} & \text { Wildtyp } \\ \mathrm{w} / \mathrm{v} & \text { Masse pro Volumen } \\ \text { X-Gal } & \text { 5-Brom-4-chlor-3-indoxyl- } \beta \text {-D-galactopyranosid }\end{array}$

\section{Einbuchstabencode für Aminosäuren}

$\begin{array}{llll}\text { A } & \text { Alanin } & \text { M } & \text { Methionin } \\ \text { C } & \text { Cystein } & \text { N } & \text { Asparagin } \\ \text { D } & \text { Asparaginsäure } & \text { P } & \text { Prolin } \\ \text { E } & \text { Glutaminsäure } & \text { Q } & \text { Glutamin } \\ \text { F } & \text { Phenylalanin } & \text { R } & \text { Arginin } \\ \text { G } & \text { Glycin } & \text { S } & \text { Serin } \\ \text { H } & \text { Histidin } & \text { T } & \text { Threonin } \\ \text { I } & \text { Isoleucin } & \text { V } & \text { Valin } \\ \text { K } & \text { Lysin } & \text { W } & \text { Tryptophan } \\ \text { L } & \text { Leucin } & \text { Y } & \text { Tyrosin }\end{array}$




\section{EINLEITUNG}

\section{$1.1 \quad$ Kontrolle der Gen-Expression}

Die DNA eines Organismus kodiert für alle RNA- und Proteinmoleküle, die zum Aufbau seiner Zellen notwendig sind. Obwohl die verschiedenen Zelltypen eines höheren Organismus sich oft ganz wesentlich sowohl in ihrer Morphologie als auch in ihrer Funktion unterscheiden, enthalten alle Zellen eines vielzelligen Organismus mit wenigen Ausnahmen dieselbe DNA. Dennoch exprimiert jeder Zelltyp nur eine gewisse Anzahl aller vorhandenen Gene. Somit muss die Umwandlung der in der DNA kodierten biologischen Information in physiologisch aktive Proteine, die Gen-Expression, eng reguliert sein. Für viele Gene ist die Kontrolle des ersten Schritts, die Transkription, von vorrangiger Bedeutung und das Transkriptionsprofil ist tatsächlich ein wichtiger Parameter um einen bestimmten Zelltyp zu identifizieren. Einige Gene werden in allen Zellen zu jeder Zeit exprimiert. Sie stellen die Gruppe der so genannten „housekeeping“ Gene dar, welche für strukturelle Proteine und für Enzyme des basalen Metabolismus kodieren (Calkhoven und Ab, 1996). Andere Gene werden nur in einem oder wenigen Zelltypen exprimiert und üblicherweise nur während bestimmter Phasen der Entwicklung oder unter der Kontrolle von bestimmten extrazellulären und/oder intrazellulären Signalen (Alberts et al., 1994). Die differenzierte Gen-Expression wird durch ein komplexes Netzwerk reguliert, indem spezialisierte DNA-bindende Proteine, die Transkriptionsfaktoren, Signale an spezifische Zielgene weiterleiten (Mitchell und Tijan, 1989; Calkhoven und Ab, 1996). Die Transkriptionsfaktoren, oder wegen ihrer Lokalisation an anderen Stellen im Genom als die Gene die sie beeinflussen, auch trans-regulatorische Faktoren genannt, binden an spezifische regulatorische DNA-Elemente die cis zu den Zielgenen lokalisiert sind. Bei den cis-regulatorischen DNA-Elementen werden die proximalen Promotorelemente, welche innerhalb von 100 - 200 Basenpaaren 5' des Transkriptionsstartpunkts liegen, von den Enhancern und Silencern unterschieden, die über Entfernungen von mehreren tausend Basenpaaren vom Transkriptionsstartpunkt und unabhängig von ihrer Orientierung die transkriptionelle Aktivität beeinflussen können. Dabei ist sowohl eine stromaufwärtige als auch eine stromabwärtige Position des Enhancers oder Silencers von der Transkriptions-Startstelle möglich (Dynan, 1989). Jedes dieser DNA-Elemente wird von einem oder mehreren Transkriptionsfaktoren erkannt und spezifisch gebunden. An der Regulation sind verschiedene Protein-Protein-Wechselwirkungen zwischen den 
regulatorische Proteinen untereinander und/oder zwischen den regulatorischen Proteinen und dem basalen Transkriptionsapparat beteiligt (Alberts et al., 1994).

Transkriptionsfaktoren haben eine modulare Struktur, wobei spezifische Regionen des Moleküls für die DNA-Bindung verantwortlich sind (Latchman, 1997). Die Sekundärstruktur dieser DNA-Bindungsdomänen wird meist zur Klassifizierung von Transkriptionsfaktorfamilien herangezogen. Aufgrund ihrer Strukturähnlichkeit weisen alle Transkriptionsfaktoren einer Familie eine ähnliche aber dennoch distinkte DNABindungsspezifität auf. Andere Regionen üben einen stimulatorischen oder inhibitorischen Effekt auf die Transkription aus und werden als Transaktivierungsdomänen bezeichnet. Die Initiation der Transkription erfolgt nach Bildung des allgemeinen Transkriptionsapparats, einen Multiproteinkomplex am Transkriptionsstartpunkt des Gens, bestehend aus dem TATA-Box-bindenden Protein (TBP), basalen Transkriptionsfaktoren wie TFIIB und TFIID und der RNA-Polymerase II. Nach der Bindung an spezifische DNASequenzen sind Transkriptionsfaktoren in der Lage, mit ihren Transaktivierungsdomänen direkt oder Cofaktor-vermittelt mit spezifischen Komponenten des basalen Transkriptionsapparats zu interagieren und die transkriptionelle Aktivität zu steigern. Dabei beschleunigen die Transkriptionsfaktoren entweder die Zusammenlagerung des basalen Transkriptionsapparats oder verstärken seine Aktivität (Ptashne, 1988; Frankel und Kim, 1991; Johnson und McKnight, 1989; Latchman, 1997).

\subsection{Der Transkriptionsfaktor Pax6}

Pax6 ist ein in der Evolution hoch konservierter Transkriptionsfaktor (Walther und Gruss, 1991a; Simpson und Price, 2002). Von Drosophila bis Mensch übt Pax6 wesentliche Funktionen während der Entwicklung und im ausdifferenzierten Zustand aus. Über die Aktivierung von genetischen Programmen steuert Pax6 die Entwicklung des Auges, der Nase, des Gehirns und der Pankreasinseln.

Das charakteristische Merkmal der Pax-Genfamilie ist das Vorhandensein der so genannten Paired-Box (Pax). Diese 384 Basenpaar lange DNA-Sequenz kodiert für eine 128 Aminosäure lange DNA-Bindedomäne, die Paired-Domäne, welche zuerst in den Segmentierungsgenen paired, gooseberry und gooseberry neuro (Boop et al., 1986; Frigerio et al., 1986) in Drosophila identifiziert wurden. Der Entdeckung der Paired-Box in Drosophila folgte die Suche nach Paired-Box-Genen im Genom von anderen Organismen. In der Maus und im Menschen sind heute neun Paired-Box-Gene bekannt: Pax1 bis Pax9 (zum Überblick, Callaerts et al., 1997; Chalepakis et al., 1993; Mansouri et al, 1999; Underhill, 2000; Walther et al., 1991b). Neben der Paired-Domäne, die immer 
aminoterimal liegt und das längste Strukturmotiv dieser Genfamilie darstellt, enthalten einige der Pax-Gene, ähnlich wie das Gen paired von Drosophila, eine Homöobox. Die in den Paired-Box-Genen enthaltene Homöobox wird als Paired-Typ-Homöobox bezeichnet. Ein weiteres häufiges Motiv in dieser Proteinfamilie ist das Oktapeptid, welches nicht bei allen Pax-Proteinen vorkommt und zwischen der Paired- und der Homöodomäne lokalisiert ist. Anhand ihrer genomischen Organisation, ihrer Struktur sowie ihrer Sequenzähnlichkeit innerhalb der Paired-Domäne, wurden die Pax-Gene in vier Klassen eingeteilt (Stuart et al., 1994; Walther et al, 1991b). Die erste Genklasse besteht aus Pax1 und Pax9, die eine Paired-Domäne und eine hoch konservierte Oktapeptidsequenz kodieren, aber keine Homöodomänensequenz enthalten. Die zweite Klasse wird durch $P a x 3$ und Pax7 vertreten, die zusätzlich zu diesen zwei Sequenzen auch eine vollständige Homöodomäne kodieren. Pax2, Pax5 und Pax8 bilden die dritte Klasse. Die Gene kodieren für je eine Paired-Domäne, ein Oktapeptid und nur partiell für die Homöodomäne. Pax4 und Pax6 aus der vierten Klasse kodieren für die Paired- und die Homöodomäne, aber nicht das Oktapeptid.

Alle Pax6-Gene, die bislang isoliert wurden, kodieren Proteine, die eine 128 Aminosäure lange aminoterminal lokalisierte Paired-Domäne und eine 60 Aminosäure lange PairedTyp-Homöodomäne enthalten (Callaerts et al., 1997). Das Pax6-Gen aus der Maus und dem Menschen kodiert für identische Proteine mit einer Länge von 422 Aminosäuren (Abb. 1.1). Die aminoterminale Paired-Domäne wird nur durch wenige Aminosäuren verlängert. Die Paired-Domäne und die Homöodomäne werden durch eine 78 Aminosäure lange flexible Linkerregion separiert. Die 153 Aminosäure lange Transaktivierungsdomäne von Pax6 befindet sich am Carboxyterminus des Proteins und ist reich an den Aminosäuren $\underline{\text { Prolin, }}$ Serin und Threonin (PST-Region) (Tang et al., 1998).

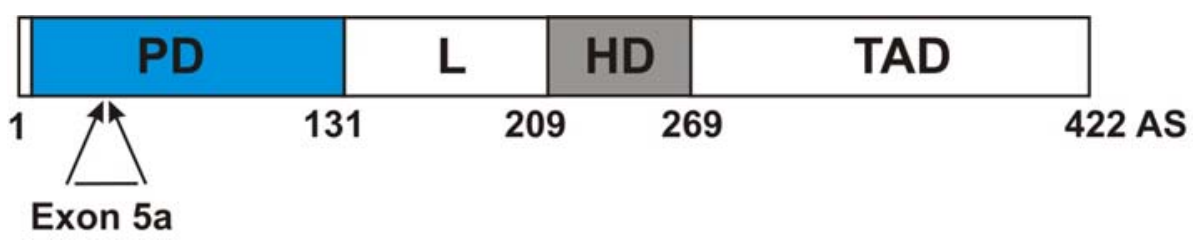

Abb. 1.1: Aufbau des Transkriptionsfaktors Pax6. Das Pax6-Protein ist in unterschiedliche Domänen unterteilt: aminoterminal liegt die Paired-Domäne (PD) und ungefähr in der Mitte des Proteins die paired-Homöodomäne (HD). Eine Glycin- und Glutamin-reiche Linkerregion (L) separiert die beiden DNA-Bindedomänen. Die Prolin-, Serin- und Threonin-reiche Transaktivierungsdomäne (TAD) liegt carboxyterminal. Durch alternatives Spleißen kann es zur Insertion von 14 AS (Exon 5a) kommen. 
Heterozygote Mutationen im Pax6-Gen führen zu dem Phänotyp small eye (sey) in der Maus (Hill et al., 1991) und in der Ratte (Matsuo et al., 1993), der durch Mikroophthalmie gekennzeichnet ist und zu einer Reihe von okularen Defekten führt. Beim Menschen tritt das Aniridie-Syndrom auf (Glaser, et al., 1992; Jordan et al., 1992). Dabei handelt es sich um eine partielle oder vollständige Abwesenheit der Iris, in Kombination mit Defekten in Kornea, Linse, Retina und optischem Nerv (Hittner, 1989; Nelson et al., 1984; Shaw et al., 1960). Homozygote Sey-Mutanten sowie Pax6-/- Mausmutanten (St-Onge et al., 1997) versterben kurz nach der Geburt, unter anderem fehlen innen komplett Augen und Nase. Außerdem besitzen Pax6-/- Mäuse eine stark reduzierte Anzahl glukagonproduzierender a-Zellen in den Pankreasinseln und zeigen eine Desorganisation der Insel-Struktur (St-Onge et al., 1997).

Pax6-homologe Gene wurden aus einer Vielzahl von Organismen isoliert. In Drosophila führen Mutationen im Pax6-Homolog eyeless (ey) zu kleineren Sinnesorganen oder sogar zum Fehlen der Komplexaugen; schwerwiegende homozygote Mutationen sind lethal (Quiring et al., 1994). Die Ähnlichkeit der Phänotypen zwischen der Fliege und den Säugetieren, die nach Funktionsinsuffizienz des ey- bzw. Pax6-Gens entsteht, spricht für die Konservierung der Funktion von Pax6 während der Evolution. Die Universalität der genetischen Mechanismen sowie die Funktion von Pax6 bzw. ey als "master control gene“ der Augenentwicklung (Gehring und Ikeo, 1999) wurde in einer spektakulären Art und Weise demonstriert. Die ektopische Expression von ey in Imaginalscheiben des Kopfes und des Thorax von Drosophila führte zur Entstehung von Augen in diesen Strukturen (Halder et al., 1995). Zum gleichen Effekt führte die ektopische Expression des Pax6-Gens der Maus in Drosophila. Dies zeigt, dass ein einziges Gen in der Lage ist eine genetische Kaskade zu aktivieren, die zur Entwicklung eines komplexen Organs führt.

Bislang sind nur wenige Zielgene des Transkriptionsfaktors Pax6 bekannt (Simpson und Price, 2002): Im Auge wird die Expression von Maf, einem Mitglied der v-Maf-OnkogenFamilie (Blank und Andrews, 1997) und die der Transkriptionsfaktoren Mash1, Math1 und Neurogenin1 (Marquardt et al., 2001; Scardigli et al., 2001) von Pax6 kontrolliert. Ebenso findet eine Expressionsbeeinflussung von Strukturgenen des Auges, wie die der KeratinGene (Liu et al., 1999) statt. Pax6 ist Aktivator der a-Kristallin-Gene der Linse (Cvekl und Piatgorsky, 1996) und gleichzeitig Repressor der ß-Kristallin-Gene (Duncan et al., 1998). Auch außerhalb des Auges reguliert Pax6 die Proteinexpression, wie die des Zelladhäsionsmoleküls L1, einem Mitglied der Immunglobulin-Superfamilie (Meech et al., 1999), oder die der Cadherine, einer Superfamilie von Transmembran- und Zelloberflächen-Molekülen (Matsunami und Takeichi, 1995). 
Zusätzlich wurde für Pax6 ein onkogenes Potential beschrieben: Überexpression von Pax6 in Mäusen induziert Tumorbildung und führt in Zelllinien zur Transformation (Maulbecker und Gruss, 1993).

\subsection{Die Struktur der Paired-Domäne und der Homöodomäne von Pax6}

Die Paired-Domäne von Pax6 setzt sich aus zwei globulären Untereinheiten zusammen, die unterschiedliche Bindungseigenschaften besitzen (Czerny et al., 1993). Die aminoterminale Subdomäne (PD-N, Xu et al., 1999; oder PAI-Domäne, Jun und Desplan, $1996)$ enthält ein antiparalleles $\beta$-Faltblattmotiv mit $\beta$-Hairpin, auf das drei $\alpha$-Helices folgen (Abb. 1.2), deren Tertiärstruktur einer Homöodomänen-Faltung entspricht. Die carboxyterminale Subdomäne (PD-C oder RED-Domäne) besteht aus drei weiteren $\alpha$ Helices (Helices 4, 5 und 6 der Paired-Domäne, Abb. 1.2), deren Faltung ebenfalls der einer Homöodomäne ähnlich ist. Die beiden Untereinheiten sind wiederum über einen Subdomänen-Linker miteinander verbunden. Röntgenkristallstruktur-Untersuchungen zeigen, dass die dritte Helix jeder Subdomäne jeweils an die sich gegenüberliegende große Furche der DNA bindet, wobei der Subdomänen-Linker zur Stabilisierung der Paired-Domänen-Bindung an die DNA beiträgt (Xu et al., 1999).
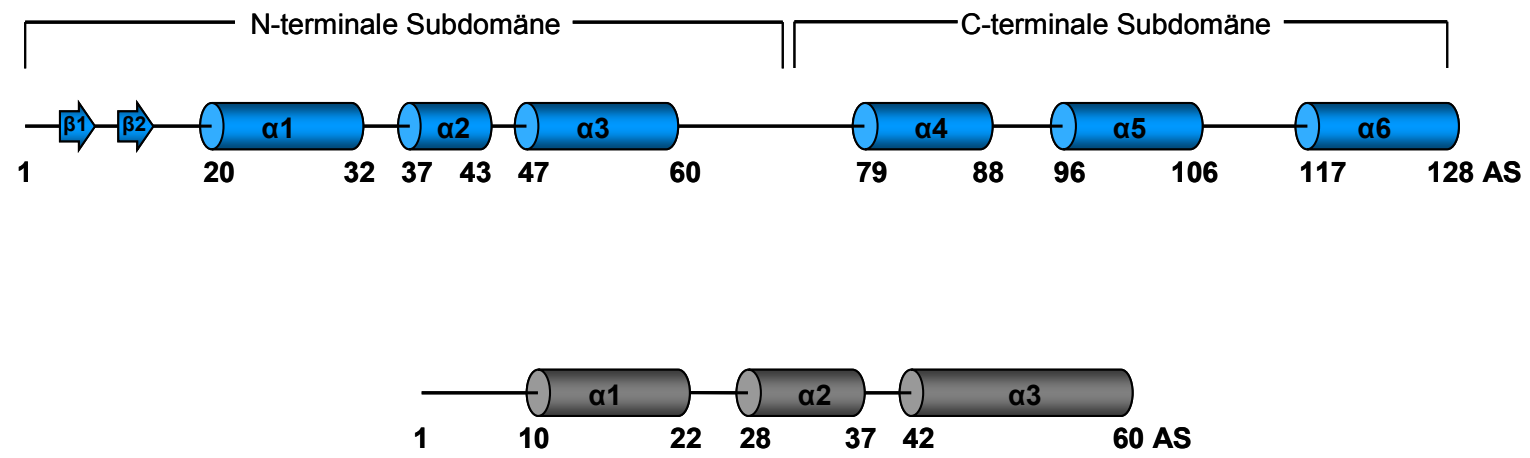

Abb. 1.2: Sekundärstruktur der Paired-Domäne und der Homöodomäne von Pax6. Oben: Sekundärstruktur der Pax6-Paired-Domäne, die sich aus zwei globulären Untereinheiten zusammensetzt: aus der N-terminale Subdomäne (oder PAI-Domäne) und der C-terminale Subdomäne (oder RED-Domäne; PAI + RED = PAIRED, Jun und Desplan 1996). Jede der beiden Subdomänen beinhaltet drei $\alpha$-Helices, wobei jeweils die dritte Helix spezifische Kontakte mit der

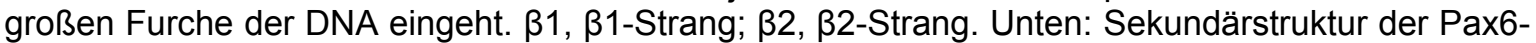
Homöodomäne. Die Pax6-Homöodomäne besteht aus drei $\alpha$-Helices, wobei die dritte Helix die DNA-Erkennungshelix darstellt. 
Da gegenüber jeweils optimalen synthetischen Bindungsstellen die Affinität der Pax6 Paired-Domäne größer ist, als die der Homöodomäne, gilt die Paired-Domäne als die primäre DNA-Bindedomäne von Pax6 (Czerny und Busslinger, 1995). Demgegenüber ist die Bedeutung der Pax6-Homöodomäne weniger klar. Die von der hochkonservierten Homöobox kodierte Pax6-Homöodomäne besteht aus einem flexiblen aminoterminalen Arm sowie aus drei durch Schleifen voneinander getrennten $\alpha$-Helices (Billeter et al., 1990; Phillips et al., 1991; Qian et al., 1994) (Abb. 1.2 und Abb. 1.3). Helix 3 der Homöodomäne dient als DNA-Erkennungshelix und geht bei der Interaktion mit der DNA durch ein Helix-Turn-Helix-Motiv Kontakte mit der großen Furche der DNA ein (Otting et al., 1990; Kissinger et al., 1990; Wilson et al., 1995). Der aminoterminale Arm trägt über eine Interaktion mit der kleinen Furche der DNA zu der Gesamtbindung bei. Homöodomänen des paired-Typ, wie auch die von Pax6, binden mit hoher Affinität als Homo- oder Heterodimere an eine palindromische DNA-Sequenz, die so genannte P3Stelle (Abb. 1.3) mit der Sequenz TAATYNRATTA (mit $Y=C / T, N=A / C / G / T$ und $R=A / G$; Wilson et al., 1993; Wilson et al., 1995), welche das für Homöodomänen-Bindungsstellen typische Tetranukleotid ATTA als Kernsequenz („core“) enthält (Gehring et al., 1994). Der Ausdruck P3 weist auf die drei Basenpaare hin, die die beiden invertierten ATTA Kernsequenzen voneinander trennen (Wilson et al., 1993; Schafer et al., 1994; Czerny und Buslinger, 1995; Underhill et al., 1995). Paired-Homöodomänen unterscheiden sich damit von anderen Homöodomänen-Transkriptionsfaktoren wie z. B. Antennapedia oder Ultrabithorax in Drosophila (Regulski et al., 1985; Calzone et al., 1988), die über die Homöodomäne an ihre Zielsequenzen als Monomere binden. In Bindungsexperimenten konnte gezeigt werden, dass die Bindung von Pax6-Homöodomänen-Dimeren an die P3Sequenz kooperativ erfolgt (Singh et al., 2000). 

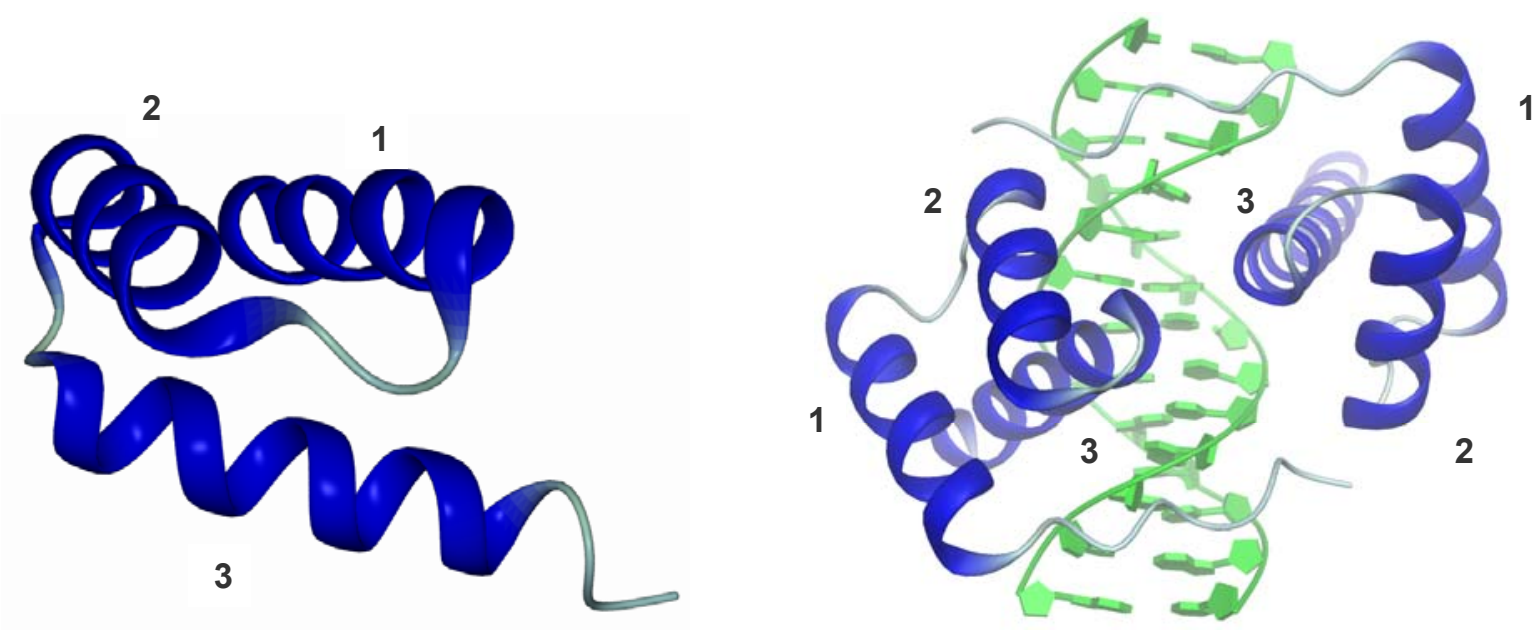

Abb. 1.3: Darstellung der Tertiärstruktur der Pax6-Homöodomäne und die Bindung eines paired-Homöodomänen-Dimers an DNA. (Links) Die Darstellung zeigt die Tertiärstruktur der Homöodomäne von Pax6. Zu erkennen sind drei a-Helices, von denen die dritte Helix, die sog. DNA-Erkennungshelix unten liegt (vergleichendes Modeling nach R. Krätzner, unveröffentlicht). (Rechts) Bindung eines Drosophila paired-Homöodomänen-Dimers an die P3-Sequenz TAATCTGATTA (Wilson et al., 1995). (1) Helix 1; (2) Helix 2; (3) Helix 3.

\subsection{Das Peptidhormon Glukagon}

Das Peptidhormon Glukagon hat eine Größe von 29 Aminosäuren und wird in den Langerhans'schen Inseln des Pankreas von den a-Zellen gebildet (Baum et al., 1962). In den differenzierten phänotypisch unterschiedlichen Pankreasinselzellen werden neben Glukagon noch weitere endo- sowie parakrin wirksame Peptidhormone produziert: Insulin von den $\beta$-Zellen, Somatostatin von den $\delta$-Zellen und das pankreatische Polypeptid von den PP-Zellen (Bonner-Weir, 1991). Im Zentrum der Langerhans'schen Inseln, die 1-2 \% des Pankreasgewebes ausmachen, befinden sich die $\beta$-Zellen, die mit $60 \%$ den größten Anteil der Zellen im endokrinen Pankreas stellen. Die restlichen Zelltypen liegen in der Peripherie verteilt, wobei die a-Zellen $20 \%$ der Inselzellen ausmachen.

Glukagon steigert die Glukoseabgabe aus der Leber und ist damit wichtig für die Aufrechterhaltung ausreichender Blutglukosespiegel in der Hungerphase (Jiang und Zhang, 2003; Gelling et al., 2003). Es steigert die hepatische Glukoseabgabe durch Steigerung der Glykogenolyse und Glukoneogenese, sowie durch Hemmung der Glykogensynthese und Glykolyse in den Leberzellen. Außerdem fördert es die Ketonkörperbildung und Lipolyse. Somit ist Glukagon der biologische Antagonist des Insulins, welches dagegen den Blutglukosespiegel senkt, indem es die Aufnahme von 
Glukose aus dem Blut in Leber-, Muskel- und Fettgewebszellen stimuliert (Ashcroft und Ashcroft, 1992) und in der Leber die Glykogenolyse und die Glukoneogenese hemmt. Da im Ruhezustand Glukagon für etwa $75 \%$ der hepatischen Glukoseproduktion verantwortlich ist, trägt Glukagon wesentlich zur Glukoseversorgung von lebenswichtigen Körperorganen und zur Vermeidung von hypoglykämischen Stoffwechselzuständen bei. Eine isolierte Glukagon-Defizienz konnte bislang nicht nachgewiesen werden, so dass Mutationen des Glukagon-Gens, die zur vollständigen Inaktivierung dieses Gens führen, ein Überleben offensichtlich nicht erlauben (Knepel, 2001).

Störungen in der Glukagon-Biosynthese und -Sekretion tragen zur Pathogenese des Diabetes mellitus bei, der sich durch hyperglykämische Zustände äußert. Insulin hemmt die Glukagon-Produktion und Glukagon-Sekretion (Philippe, 1989). Durch die Insulindefizienz beim Diabetes mellitus kommt es zur Hyperglukagonämie, die zur Hyperglykämie beiträgt (Unger und Orci, 1981a; Unger und Orci 1981b; Lefebvre, 1995).

Das Glukagon-Gen wird nicht nur in den $\alpha$-Zellen der Pankreasinseln exprimiert, sondern auch in enteroendokrinen Zellen des Darms (Habener et al., 1991) sowie in einigen Neuronen des Gehirns (Drucker und Asa, 1988) und im Thymus (Throsby, 1998). In allen Geweben wird ein größeres Vorläufermolekül gebildet, das Proglukagon-Prohormon, welches gewebsspezifisch posttranslational zu verschiedenen Peptiden prozessiert wird, die unterschiedliche Bioaktivitäten zeigen. In den pankreatischen Inseln wird aus Proglukagon neben Glukagon auch zu einem geringeren Anteil das Glukagon-ähnliche Peptid GLP-1 (Glucagon-like peptide 1) gebildet (Habener et al., 1991). In den intestinalen L-Zellen des Darms werden GLP-1, GLP-2, Oxyntomodulin und Enteroglukagon-37 gebildet, welche eine wichtige Rolle bei der Regulation der Insulinsekretion, der Proliferation des Dünndarmepithels bzw. der enteralen Glukoseabsorption spielen (Drucker, 1998; Stümpel et al., 1998).

\subsection{Die Regulation der Glukagon-Genexpression durch Pax6}

Das Glukagon-Gen ist ein „single-copy“-Gen und besteht aus 6 Exons und 5 Introns (Habener et al., 1991). Die Pankreasinsel-spezifische Genexpression wird auf transkriptioneller Ebene kontrolliert. In den letzten Jahren wurden beträchtliche Mengen an Daten erhoben, die zum besseren Verständnis der Regulation der GlukagonGentranskription durch eine Vielzahl von Transkriptionsfaktoren führten. Durch Deletionsstudien, Linker-Scanning-Analysen und DNase I Footprinting-Untersuchungen konnten fünf kritische cis-regulatorische DNA-Kontrollelemente innerhalb der ersten 350 Basenpaare der 5'-flankierenden Region des Glukagon-Gens identifiziert werden, die von 
unterschiedlichen Transkriptionsfaktoren gebunden werden (Knepel, 2001). Die 350 Basenpaare der 5'-flankierenden Region des Glukagon-Gens der Ratte sind ausreichend für die zellspezifische Aktivierung der Transkription in Glukagon-produzierenden Pankreasinsel-Tumorzelllinien (Drucker et al., 1987; Philippe et al., 1988; Knepel, 1993). In transgenen Mäusen sind dagegen 1300 Basenpaare für die Transkriptionsaktivierung in den a-Zellen der Langerhans'schen Inseln notwendig (Efrat et al., 1988).

Abbildung 1.4 zeigt 350 Basenpaare der 5'-flankierenden Region des Glukagon-Gens der Ratte mit den bisher charakterisierten DNA-Kontrollelementen und den damit interagierenden Transkriptionsfaktoren. Die cis-regulatorischen Kontrollelemente werden in zwei Gruppen eingeteilt: In die proximalen Promotorelemente G1 und G4, sowie die mehr distalen Enhancer-artigen Promotorelemente wie G2, G3 und CRE.

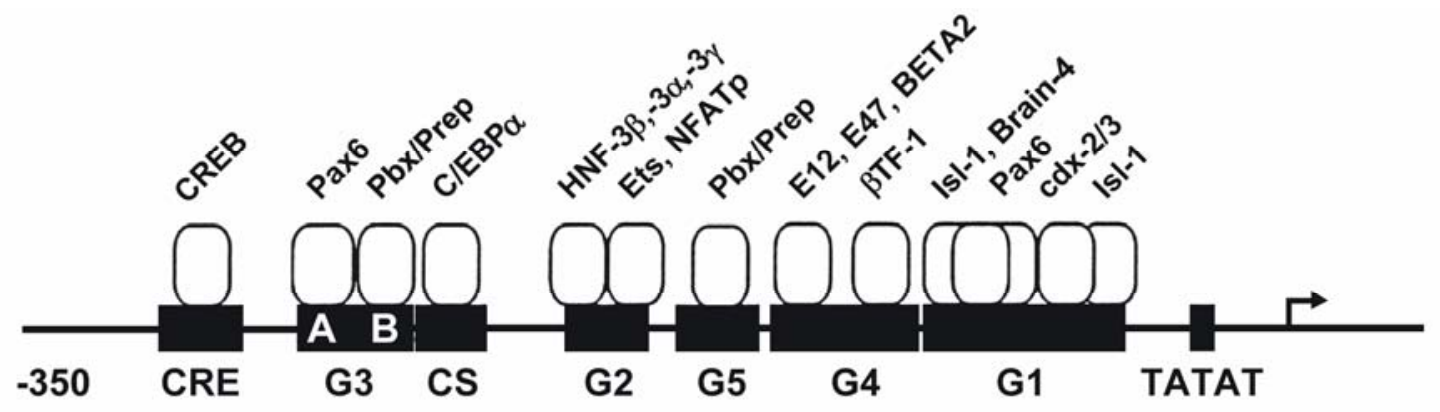

Abb. 1.4: Aktivierung des Glukagon-Gens in den $\alpha$-Zellen des endokrinen Pankreas. Die bisher charakterisierten DNA-Kontrollelemente innerhalb von 350 Basenpaaren der 5'-flankierenden Region des Glukagon-Gens der Ratte und die damit interagierenden Transkriptionsfaktoren. CRE, cAMP-responsives Element; CS, C/EBP-Bindungsstelle; G1, Glukagon-Element 1; G2, Glukagon-Element 2; G3, Glukagon-Element 3; G4, Glukagon-Element 4; G5, Glukagon-Element 5.

Das proximale Promotorelement G1 (entsprechend den Basenpaaren -100 bis -52) hat selbst nur eine geringe transkriptionelle Aktivität, ist aber notwendig um die transkriptionelle Aktivierung über die Elemente G2 und G3 zu vermitteln und scheint für die a-zellspezifische Expression des Glukagon-Gens wichtig zu sein (Philippe et al., 1988; Morel et al., 1995). Das G1-Element enthält zwei nahezu identische AT-reiche Sequenzen, die von Homöodomänen-Transkriptionsfaktoren gebunden werden. Darunter sind der LIM-Homödomänen-Transkriptionsfaktor IsI-1 (Wang und Drucker, 1995), das caudal-verwandte Homöodomänen-Protein Cdx2/3 (Jin und Drucker, 1996; Jin et al., 
1997) und der pit-oct-une (POU) Transkriptionsfaktor Brain-4 (Hussain et al., 1997). Weiterhin interagiert Pax6 entweder als Monomer oder zusammen mit Cdx2/3 mit dem G1-Element (Andersen et al., 1999; Ritz-Laser et al., 1999).

Das Enhancer-Element G3 (entsprechend der Basenpaaren -268 bis -238) besteht aus zwei Abschnitten, der Domäne $A$ und $B$, die von unterschiedlichen Proteinen gebunden werden (Knepel et al., 1990b). Die praktisch ubiquitär exprimierten HomöodomänenTranskriptionsfaktoren der TALE- (Three Amino Acid Loop Exxtension) Familie Pbx/Prep1 (Berthelsen et al., 1998; Monica et al., 1991; Herzig et al., 2000) binden an Domäne B des G3-Elements und hemmen die Glukagon-Genexpression in nicht Glukagonproduzierenden Zelllinien (Herzig et al., 2000).

Pax6 bindet in vitro über seine Paired-Domäne an das Sequenzmotiv PISCES (pancreatic islet cell-specific enhancer sequence), welches sich in Domäne A des G3-Elements befindet (Knepel et al., 1990b). Im Glukagon-Gen kommt das PISCES-Motiv noch im G1Element vor, sowie in zellspezifischen Kontrollelementen des Insulin-I- und SomatostatinGens der Ratte (Sander et al., 1997; Beimesche et al., 1999; Ritz-Laser et al., 1999, Knepel et al., 1991). Das PISCES-Konsensusmotiv besteht aus 12 Basenpaaren und zeigt eine hohe Homologie zu der Pax6-Konsensus-Bindungsstelle der Paired-Domäne (Abb. 1.5).

G1 (-100/-52)

AAAACCCCATTATTTACAGATGAGAAATTTATATTGTCAGCGTAATATC TTTTGGGGTAATAAATGTCTACTCTTTAAATATAACAGTCGCATTATAG

PISCES ASTCCRCAYTTT

Pax6-Konsensus ... . . . . . Y - MKT - ASTWCGCACTT - - A

G3 (-268/-238)

A B TAGTTTTTCACGCCTGACTGAGATTGAAGGG

PISCES TTTYACRCCTSA

Pax6-Konsensus $\ldots \ldots \ldots \ldots$ A - - TTCACGCWTSA-TKM-Y

Abb. 1.5: Sequenzvergleich zwischen dem PISCES-Motiv im G1- und G3-Element des Glukagon-Genpromotors und der Konsensusbindungsstelle für die Pax6-Paired-Domäne. PISCES, pancreatic islet cell-specific enhancer sequence. Die Nummern in Klammern kennzeichnen die Position der Basenpaare stromaufwärts des Transkriptionsstartpunkts des Glukagon-Gens. $\mathrm{W}=\mathrm{A}$ oder $\mathrm{T} ; \mathrm{K}=\mathrm{G} \operatorname{oder} \mathrm{T} ; \mathrm{M}=\mathrm{A} \operatorname{oder} \mathrm{C} ; \mathrm{Y}=\mathrm{T} \operatorname{oder} \mathrm{C} ; \mathrm{R}=\mathrm{A} \operatorname{oder} \mathrm{G} ; \mathrm{S}=\mathrm{G}$ oder C. 
In Pankreasinseln werden zwei Pax6-Isoformen exprimiert, die unterschiedliche DNABindungseigenschaften besitzen (Epstein et al., 1994b). Durch alternatives Spleißen der mRNA kommt es bei der Isoform Pax6-5a zu einer Insertion von 14 Aminosäuren in die Paired-Domäne, dem so genannten Exon 5a, wodurch die DNA-Bindung der N-terminalen Subdomäne der Paired-Domäne unterbunden wird (Walther und Gruss, 1991; Glaser et al., 1992). Die Bindung an das G1- und G3-Element erfolgt in vitro durch die Pax6-Isoform ohne Exon 5a (Beimesche et al., 1999).

Da keiner der bekannten Transkriptionsfaktoren spezifisch in a-Zellen der Pankreasinseln exprimiert wird, muss angenommen werden, dass die a-zellspezifische Aktivierung des Glukagon-Gens durch eine a-zellspezifische Kombination von Transkriptionsfaktoren bestimmt wird. Ein hierfür möglicherweise entscheidender Transkriptionsfaktor ist Pax6.

Untersuchungen in vitro sowie Untersuchungen an Tumorzelllinien geben klare Hinweise darauf, dass Pax6 wesentlich an der zellspezifischen Aktivierung des Glukagon-Gens in den $\alpha$-Zellen der Pankreasinseln beteiligt ist. Ein synthetischer Minienhancer, bestehend aus einer oligomeren Pax6-Bindungsstelle (G3A) besitzt in Pax6-exprimierenden, aus den a-Zellen von Pankreasinseln abgeleiteten Zellinien eine hohe zellspezifische transkriptionelle Aktivität (Beimesche et al., 1999). Weiterhin besitzen in diesen Zelllinien 1300 oder 350 bp der 5'-flankierenden Region des Glukagon-Gens mit den Kontrollelementen G1 und G3 der Ratte hohe zellspezifische Aktivität, welche durch spezifische Mutationen der Pax6-Bindungsstellen in G1 und G3 praktisch vollständig zerstört wird (Teichler, Dissertation 2004). Pax6 wird auch in a-Zellen der Pankreasinsel exprimiert, beginnend etwa am Tag 9,5 des Embryos der Maus und damit zu einem Zeitpunkt, an dem sich auch erstmals die Expression des Glukagon-Gens nachweisen lässt (St-Onge et al., 1997). In ausdifferenzierten Pankreasinseln bleibt die Expression von Pax6 erhalten (St-Onge et al., 1997; Beimesche et al., 1999).

Neben der a-zellspezifischen Aktivierung des Glukagon-Gens, scheint Pax6 auch an der Hemmung des Glukagon-Gens durch Insulin (Grzeskowiak et al., 2000) und durch orale Antidiabetika wie Thiazolidindione (Schinner et al., 2002) beteiligt zu sein. Thiazolidindione wie Rosiglitazon und Pioglitazon sind eine neue Gruppe oraler Antidiabetika, welche ihre antidiabetische Wirkung über die Bindung an den Kernrezeptor PPARy entfalten. Die Zielgene, über welche die antidiabetische Wirkung erreicht wird, sind weitgehend unbekannt. Es konnte gezeigt werden, dass Thiazolidindione über PPARy die Glukagon-Gentranskription hemmen (Schinner et al., 2002). Ohne an den Glukagon-Promotor zu binden hemmt PPARy die transkriptionelle Aktivität von Pax6. Die Hemmung von Pax6 und des Glukagon-Gens scheint damit Teil des Mechanismus zu sein, über welchen Thiazolidindione den Blutzucker bei Diabetes mellitus normalisieren. Dennoch ist der molekulare Mechanismus der Regulation des Glukagon-Gens durch Pax6 
unklar. Bekannt ist, dass die Pax6-Homöodomäne für die Aktivierung des Glukagon-Gens notwendig ist. Es wurde gezeigt, dass die interne Deletion der Homöodomäne, die Deletion der DNA-Erkennungshelix bzw. die Mutation bestimmter Aminosäuren in der DNA-Erkennungshelix die Aktivierung des Glukagon-Promotors durch Pax6 massiv vermindert (Teichler, Dissertation 2004). Jedoch ist der Mechanismus, über welchen die Pax6-Homöodomäne zur Aktivierung des Glukagon-Gens beiträgt, unbekannt (Abb. 1.6). Insbesondere auch die Funktion der Linkerregion zwischen den beiden DNABindedomänen von Pax6 ist weitgehend unklar (Abb. 1.6). Die Aufklärung der molekularen Mechanismen der Pax6-DNA-Bindung und Gen-Aktivierung bildet die Grundlage für ein Verständnis der Zielgenspezifität von Pax6.

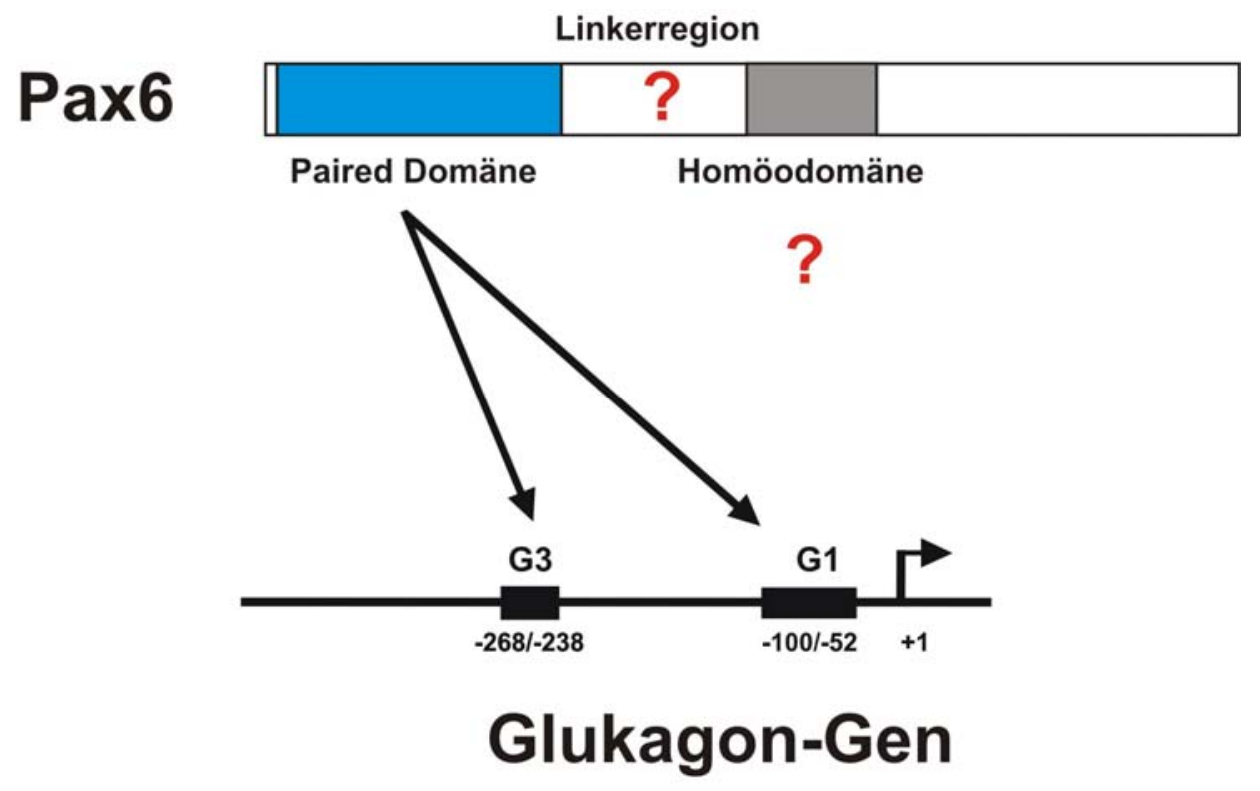

Abb. 1.6: Fragestellungen. Der Transkriptionsfaktor Pax6 bindet in vitro über seine PairedDomäne an zellspezifische Kontrollelemente in der 5'-flankierenden Region des Glukagon-Gens: das proximale Promotorelement G1 (-100/-52) und das mehr distale Enhancer-artige Element G3 (-268/-238). Beide enthalten das Sequenzmotiv PISCES (pancreatic islet cell-specific enhancer sequence). In glukagonproduzierenden Pankreasinselzellinien steigert Pax6 über diese Bindungsstellen die Glukagon-Gentranskription. Fragen: Über welchen molekularen Mechanismus trägt die Homöodomäne zur Bindung und Wirkung von Pax6 am Glukagon-Gen bei? Welche Funktion erfüllt der Linker zwischen den beiden DNA-Bindedomänen? 


\section{$1.6 \quad$ Zielsetzung}

Im Rahmen der vorliegenden Arbeit sollen die molekularen Mechanismen, über die die Pax6-Homöodomäne zur Aktivierung der Glukagon-Gentranskription durch Pax6 beträgt, charakterisiert werden. Untersuchungen zur Pax6-Linkerregion sollen ebenso zu einem besseren Verständnis der Funktion dieser Region zwischen den beiden DNABindedomänen beitragen. Dadurch sollen Einblicke in die Funktion der Pax6Homöodomäne und der Pax6-Linkerregion bei der Regulation der GlukagonGentranskription auf molekularer Ebene gewonnen werden. 


\section{MATERIAL UND METHODEN}

\subsection{Chemikalien}

Sofern nicht anders angegeben, wurden alle aufgeführten Chemikalien des höchsten handelsüblichen Reinheitsgrades von der Firma Applichem (Darmstadt) bezogen. Daneben fanden folgende Chemikalien Verwendung:

Braun, Melsungen

Aqua ad iniectabilia (Ampuwa)

Merck, Darmstadt

Calciumchlorid-Dihydrat

Natriumacetat-Trihydrat

Amersham Biosciences, Freiburg

DEAE-Dextran (MW: $500000 \mathrm{~g} / \mathrm{mol}$ )

Desoxynukleotide (dATP, dCTP, dGTP, dTTP)

Ficoll-400

Serva, Heidelberg

Acrylamid

$\mathrm{N}, \mathrm{N}-$ Methylenbisacrylamid

Sigma, München

$\begin{array}{lll}\text { APS } & \text { Ethidiumbromid } & \text { Triton X-100 } \\ \text { ATP } & \text { Glutathion } & \text { Tween20 } \\ \text { BSA } & \text { IPTG } & \text { X-Gal } \\ \text { Bromphenolblau } & \text { Luciferin } & \text { Xylen Cyanol FF } \\ \text { DMSO } & \text { TEMED } & \end{array}$




\subsection{Radiochemikalien}

[a- $\left.{ }^{32} \mathrm{P}\right]-\mathrm{dCTP}$ (spezifische Aktivitat: $3000 \mathrm{Ci} / \mathrm{mmol}$ ) und $\left[{ }^{35} \mathrm{~S}\right]-$ Methionin (spezifische Aktivität: $1200 \mathrm{Ci} / \mathrm{mmol}$ ) wurden von der Firma Amersham Pharmacia Biotech (Braunschweig) bezogen.

\subsection{Enzyme}

Die verwendeten Restriktionsendonukleasen sowie die DNA-/RNA-modifizierenden Enzyme wurden von der Firma Fermentas (St. Leon Rot) bezogen. Es wurden die jeweils empfohlenen Puffer verwendet.

\subsubsection{DNA-/RNA-modifizierende Enzyme}

Restriktionsendonukleasen

Alkalische Phosphatase (CIAP)

Klenow-Fragment der DNA-Polymerase 1

Pfu DNA-Polymerase

RNase A (aus Rinderpankreas)

T4 DNA-Ligase

\subsubsection{Sonstige Enzyme}

Lysozym (aus Hühnereiweiß)

Sigma (München)

Trypsin/EDTA-Lösung (aus Rinderpankreas)

GIBCO BRL (Karlsruhe)

\subsection{Antibiotika und Protease-Inhibitoren}

Ampicillin

Chloramphenicol

Gentamicin

Kanamycin

Penicillin-Streptomycin- Lösung

(10000 U/ml-10000 $\mu \mathrm{g} / \mathrm{ml}$ )
Roche Diagnostics (Mannheim)

Sigma (München)

GIBCO BRL (Karlsruhe)

GIBCO BRL (Karlsruhe)

GIBCO BRL (Karlsruhe) 
PMSF

Tetracyclin
Roche Diagnostics (Mannheim)

GIBCO BRL (Karlsruhe)

\subsection{Nachweis- und Reinigungssysteme}

Bio-Rad Protein Assay

Easy Pure $®$ DNA Purification Kit

Mini Quick Spin Oligo Columns

TNT Coupled Reticulocyte Lysate System

Pure Yield Plasmid Midiprep System

Wizard Plus Maxiprep DNA Purification System

ECL Detektionsreagenz
Bio-Rad (München)

Biozym Diagnostik (Hess.

Oldendorf)

Pharmacia (München)

Promega (Mannheim)

Promega (Mannheim)

Promega (Mannheim)

Amersham Pharmacia Biotech

\section{$2.6 \quad$ Filtermaterial}

Das Blottingpapier der Firma Schleicher \& Schuell (Dassel) wurde zum Trocknen von SDS- und nicht-denaturierenden Polyacrylamid-Gelen sowie für Westernblots verwendet.

\subsection{Materialien zur Anzucht von Bakterien}

Die verwendeten Substanzen für Nährmedien wurden von der Firma GIBCO BRL (Karlsruhe) bezogen:

Select-Agar

Select-Peptone

Select-Yeast Extract

Die Firma Greiner (Frickenhausen) lieferte die Petrikulturschalen (Durchmesser $10 \mathrm{~cm}$ ), in denen die Anzucht der Plattenkulturen erfolgte. 


\subsection{Material zur Kultivierung eukaryotischer Zelllinien}

Die Zellkulturmedien DMEM, RPMI 1640 und TC-100 wurden von GIBCO BRL (Karlsruhe) bezogen. Dies gilt auch für das verwendete fötale Kälberserum (auf Mykoplasmen getestet). Die Kultivierung der Zellen erfolgte auf Falcon-Zellkulturschalen unterschiedlichen Durchmessers (6/10/15 cm), die von der Firma Becton Dickinson (U. K.) vertrieben werden oder in Zellkulturflachen (EasYFlask, $25 \mathrm{~cm}^{2}$ und $75 \mathrm{~cm}^{2}$ ) der Firma NUNC (Wiesbaden).

\subsection{Puffer und Nährmedien}

Die Lösungen für den Routinegebrauch wurden nach Sambrook et al. (1989) angesetzt. Wenn nicht anders angegeben, wurden die Lösungen mit deionisiertem und destilliertem Wasser hergestellt und bei Raumtemperatur aufbewahrt.

\section{LB-Medium}

Select-Peptone

$1 \%(w / v)$

Select-Yeast Extract $0,5 \%(w / v)$

$\mathrm{NaCl}$ $1 \%(w / v)$

Zur Herstellung von Agarplatten wurde Select-Agar in einer Endkonzentration von 1,5\% (w/v) zugesetzt. Das Medium wurde sofort nach dem Ansetzen autoklaviert.

SOC-Medium

$\begin{array}{ll}\text { Select-Peptone } & 2 \%(w / v) \\ \text { Select-Yeast Extract } & 0,5 \%(w / v) \\ \mathrm{NaCl} & 10 \mathrm{mM} \\ \mathrm{KCl} & 2,5 \mathrm{mM} \\ \mathrm{MgCl}_{2} & 10 \mathrm{mM} \text { (steril filtriert) } \\ \mathrm{MgSO}_{4} & 10 \mathrm{mM} \text { (steril filtriert) } \\ \text { Glucose } & 20 \mathrm{mM} \text { (steril filtriert) }\end{array}$

$\mathrm{pH} 7,5$ mit $\mathrm{NaOH}$

Die steril filtrierten Lösungen wurden nach dem Autoklavieren zugesetzt. 
$\underline{\text { PBS }}$

$\mathrm{NaCl}$

$140 \mathrm{mM}$

$\mathrm{KCl}$

$2,5 \mathrm{mM}$

$\mathrm{Na}_{2} \mathrm{HPO}_{4}$

$8,1 \mathrm{mM}$

$\mathrm{KH}_{2} \mathrm{PO}_{4}$

$1,5 \mathrm{mM}$

Der pH-Wert wurde mit $\mathrm{NaOH}$ auf 7,4 eingestellt.

\section{PBS-T}

PBS-Puffer mit 0,05 (v/v) Tween 20

\section{RNase A-Lösung}
RNase A
$0,1 \mathrm{mg} / \mathrm{ml}$
TRIS, pH 8,0
$5 \mathrm{mM}$

Zur Inaktivierung von DNase-Aktivität wurde die Lösung für 15 min auf $90{ }^{\circ} \mathrm{C}$ erhitzt, aliquotiert und bei $-20{ }^{\circ} \mathrm{C}$ gelagert.

\section{6x Stopp-Mix (EMSA)}

Glycerin

$30 \%(v / v)$

Bromphenol Blau

$0,25 \%(w / v)$

Xylen Cyanol FF

$0,25 \%(w / v)$

6x Stopp-Mix (DNA-Gelelektrophorese)

$\begin{array}{lll}\text { EDTA } & 0,4 & \mathrm{~g} \\ \text { Ficoll400 } & 15 & \mathrm{~g} \\ \text { Glycerin } & 10 & \mathrm{ml} \\ \text { Orange G } & 1 & \text { Spatelspitze }\end{array}$

$\underline{5 \times T B E}$

TRIS, $\mathrm{pH} 8,0$

$450 \mathrm{mM}$

Borsäure

$450 \mathrm{mM}$

EDTA, pH 8,0

$10 \mathrm{mM}$ 
10x TAE

Tris, $\mathrm{pH} 8,0$

$400 \mathrm{mM}$

Eisessig

$200 \mathrm{mM}$

EDTA, pH 8,0

$10 \mathrm{mM}$

$\underline{1 \times T E}$

TRIS, pH 8,0

$10 \mathrm{mM}$

EDTA, pH 8,0

$1 \mathrm{mM}$

Stammlösungen

Ampicillin

$100 \mathrm{mg} / \mathrm{ml} \mathrm{H}_{2} \mathrm{O}$

Chloramphenicol

$34 \mathrm{mg} / \mathrm{ml}$ abs. Ethanol

Gentamicin

$7 \mathrm{mg} / \mathrm{ml} \mathrm{H}_{2} \mathrm{O}$

Kanamycin

$50 \mathrm{mg} / \mathrm{ml} \mathrm{H}_{2} \mathrm{O}$

Tetracyclin

$10 \mathrm{mg} / \mathrm{ml} \mathrm{H}_{2} \mathrm{O}$

IPTG

$100 \mathrm{mM}$ in $\mathrm{H}_{2} \mathrm{O}$

X-Gal

$2 \%(w / v)$ in DMF

Ethidiumbromid

$10 \mathrm{mg} / \mathrm{ml} \mathrm{H}_{2} \mathrm{O}$

\subsection{Medien für die Kultivierung eukaryotischer Zelllinien}

DMEM-Medium (JEG-3- oder COS-1-Zellen)

$\begin{array}{ll}\text { DMEM-Pulver } & 13 \mathrm{~g} \\ \mathrm{NaHCO}_{3} & 3,7 \mathrm{~g} \\ \mathrm{H}_{2} \mathrm{O} & \text { ad } 1000 \mathrm{ml}\end{array}$

RPMI-Medium (InR1G9-Zellen)

RPMI 1640-Pulver

$10 \mathrm{~g}$

$\mathrm{NaHCO}_{3}$

$2 \mathrm{~g}$

$\mathrm{H}_{2} \mathrm{O}$

ad $1000 \mathrm{ml}$

TC100-Medium (Sf9-Zellen)

$\begin{array}{ll}\text { TC100-Pulver } & 19,9 \mathrm{~g} \\ \mathrm{NaHCO}_{3} & 0,35 \mathrm{~g} \\ \mathrm{H}_{2} \mathrm{O} & \text { ad } 1000 \mathrm{ml}\end{array}$


Die angegebenen Mengen DMEM-Pulver, RPMI 1640-Pulver oder TC100-Pulver wurden zunächst in $\mathrm{H}_{2} \mathrm{O}$ gelöst und sterilfiltriert. Der Zusatz des fötalen Kälberserums (10 \% v/v) und der Penicillin-Streptomycin-Lösung (1 $\%$ v/v) erfolgte anschließend unter Sterilbedingungen.

\subsection{Art und Herkunft des biologischen und molekularbiologischen Materials}

\subsubsection{DNA}

Synthetische Oligonukleotide für EMSA-Experimente

Die Oligonukleotide wurden von der Firma MWG-Biotech (Ebersberg) oder Biomers (UIm) bezogen. Die DNA-Sequenzen der kodierenden Stränge sind in Tabelle 2.1 zusammengefasst.

Tab. 2.1: Oligonukleotidsequenzen

\begin{tabular}{|l|l|}
\hline Oligonukleotid & $\begin{array}{l}\text { Sequenz des kodierenden Einzelstrangs } \\
5 '-\end{array}$ \\
\hline G1 & GATCGCATTTGAACAAAACCCATTATTTACAGATGAGAAATTTATATTGTCAG \\
G3 & GATCCTGAAGTAGTTTTTCACGCCTGACTGAGATTGAAGGGTGTAGC \\
G1PH0mut1 & GATCGCATTTGAACAAAACCCCATTATTTACAGATGAGAAAGGTATATTGTCAG \\
G1PH0mut2 & GATCGCATTTGAACAAAACCCCATTATTTACAGATGAGAAGGTTATATTGTCAG \\
G3PH0mut1 & GATCCTGAAGTAGGGTTTCACGCCTGACTGAGATTGAAGGGTGTAGC \\
G3PH0mut2 & GATCCTGAAGTAGTGGTTCACGCCTGACTGAGATTGAAGGGTGTAGC \\
\hline
\end{tabular}

Die Oligonukleotide wurden als Doppelstrang in Electrophoretic Mobility Shift Assays (EMSA, 2.20) als Sonde eingesetzt. Aufgeführt sind die Sequenzen in $5^{\prime}-$ nach $3^{\prime}-$ Richtung. Das PISCESElement ist unterstrichen, die $5^{\prime}$-Überhänge sind fett gedruckt. Die grau unterlegten Nukleotide stellen eingefügte Mutationen dar. 
Primer zur Klonierung

Tab. 2.2: Primer zur Klonierung

\begin{tabular}{|c|c|}
\hline Primer & Sequenz \\
\hline Pax6PDfor & $\begin{array}{l}5^{\prime} \text { - ATAAAGCTTATGCAGAACAGTCACAGCGGAG - } 3^{\prime} \\
\text { (HindIII) }\end{array}$ \\
\hline Pax6PDrev2 & $\begin{array}{l}5^{\prime} \text { - ATAGATATCTTACTGTTGCTTTTCGCTAGCCAGG - 3' } \\
(E C O R V)\end{array}$ \\
\hline Pax6HDfor2 & $5^{\prime}$ - CTGAAGCTTATGCTGCAAAGAAATAGAACATC - $3^{\prime}$ \\
\hline Pax6HDrev & $5^{\prime}$ - ATAGATATCTTATCTTCTCCATTTGGCCCTTCG - 3' \\
\hline Pax6Linker_rev & $5^{\prime}$ - ATAGATATCTTACTTCCGCTTCAGCTGAAG - 3' \\
\hline PDBac_for & $5^{\prime}$ - ATAGGATCCATGCAGAACAGTCACAGCGGAG - 3' \\
\hline PDBac_rev & $5^{\prime}$ - ATACTCGAGTTACTGTTGCTTTTCGCTAGCCAGG - 3' \\
\hline HDBac_for & $5^{\prime}-{\text { CTGGGATCCCTGCAAAGAAATAGAACATC }-3^{\prime}}^{\prime}$ \\
\hline HDBac_rev & $5^{\prime}$ - ATACTCGAGTTATCTTCTCCATTTGGCCCTTCG - 3' \\
\hline Pax6wtBac_rev & $5^{\prime}$ - ATACTCGAGTTACTGTAATCGAGGCCAGTACTG - $3^{\prime}$ \\
\hline Pax6fl-5' & $5^{\prime}$ - GAGTCGGATCCGGAGGCTGCCAACCAGCT - $3^{\prime}$ \\
\hline Pax6fl-3' & $5^{\prime}$ - CGCCGCAAGCTTTTACTGTAATCGAGGCCA-3' \\
\hline
\end{tabular}

Übersicht über die Sequenzen der verwendeten Primer in PCR-Reaktionen (2.16) in 5'- nach 3'Orientierung. Restriktionsschnittstellen sind unterstrichen.

Primer zur Mutagenese mittels primerless PCR

Tab. 2.3: Primer zur Mutagenese mittels primerless PCR

\begin{tabular}{|l|l|}
\hline Primer & Sequenz \\
\hline -350/-150_for & $5^{\prime}$-CGTAGGATCCATGGCCAAATAGCACATCAA-3' \\
& $($ BamHI) \\
\hline
\end{tabular}




\begin{tabular}{|c|c|}
\hline$-350 /-150 \_r e v$ & $\begin{array}{l}5^{\prime} \text { - CGTAAAGCTTACCGGGGTGAGACCTCAG - } 3^{\prime} \\
\frac{\text { (HindIII) }}{}\end{array}$ \\
\hline -350G3mut1_rev & $5^{\prime}$ - TGAAACCCTACTTCAGCTCT - $3^{\prime}$ \\
\hline -350G3mut1_for & $5^{\prime}$ - TAGGGTTTCACGCCTGACTG - $3^{\prime}$ \\
\hline-350 G3mut2_rev & $5^{\prime}$ - TGAACCACTACTTCAGCTCT - $3^{\prime}$ \\
\hline -350G3mut2_for & $5^{\prime}$ - TAGTGGTTCACGCCTGACTG- $3^{\prime}$ \\
\hline$-169 \_$for & $5^{\prime}$ - CGTAGGATCCCTCTGAGGTCTCACCCCGG - 3' \\
\hline$-169 \_r e v$ & $5^{\prime}$ - CGTACTCGAGCAGGTGGAGCTCCTTTGG-3' \\
\hline -169G1mut1_rev & 5' - АTACCTTTCTCATCTGTAAA- $3^{\prime}$ \\
\hline -169G1mut1_for & $5^{\prime}$ - AGAAAGGTATATTGTCAGCG - $3^{\prime}$ \\
\hline -169G1mut2_rev & $5^{\prime}$ - ATAACCTTCTCATCTGTAAA- $3^{\prime}$ \\
\hline -169G1mut2_for & $5^{\prime}$ - AGAAGGTTATATTGTCAGCG - $3^{\prime}$ \\
\hline Pax6LmutAC_rev & 5' - TGCTGGCAGCCATCTTGCGT CTGTTGCTTTTCGCTAGCCA-3' \\
\hline Pax6LmutCB_for & 5' - GACTTCAGCTGAAGCGGAAG ATGGGCGCAGACGGCATGTA-3' \\
\hline Pax6LmutBD_rev & 5' - GATGTTCTATTTCTTTGCAG GGGTTGCCCTGGTACTGAAG - 3' \\
\hline Pax6LmutAC_for & $5^{\prime}$ - TGGCTAGCGAAAAGCAACAG ACGCAAGATGGCTGCCAGCA-3' \\
\hline Pax6LmutCB_rev & 5' - TACATGCCGTCTGCGCCCAT CTTCCGCTTCAGCTGAAGTC - $3^{\prime}$ \\
\hline Pax6LmutBD_for & $5^{\prime}$ - CTTCAGTACCAGGGCAACCC CTGCAAAGAAATAGAACATC - $3^{\prime}$ \\
\hline Pax612aaLmut_rev & $\begin{array}{l}5^{\prime} \text { - ATCTTCAGCCTGCATTCGAAGCTGCAGCTTCCGCTT } \\
\text { CGAGTCTTCTCCGTTAGAAC - } 3^{\prime}\end{array}$ \\
\hline Pax612aaLmut_for & $\begin{array}{l}5^{\prime} \text { - AAGCGGAAGCTGCAGCTTCGAATGCAGGCTGAAGAT } \\
\text { CTGCAAAGAAATAGAACATC - } 3^{\prime}\end{array}$ \\
\hline Pax6LMutAC_rev2 & 5' - TGCTGGCAGCCATCTTGCGT CTGCCCGTTCAACATCCTTA-3' \\
\hline Pax6LMutAC_for2 & $5^{\prime}$ - TAAGGATGTTGAACGGGCAG ACGCAAGATGGCTGCCAGCA-3' \\
\hline Pax6LMutCB_rev3 & 5' - CGTGTGCCCCAGCTTCCGGT CGAGTCTTCTCCGTTAGAAC - 3' \\
\hline Pax6LMutCB_for3 & 5' - GTTCTAACGGAGAAGACTCG ACCGGAAGCTGGGGCACACG - 3' \\
\hline Pax6LMutBD_rev2 & 5' - AGTCGCATCTGAGCTTCATC GGGTTGCCCTGGTACTGAAG-3' \\
\hline Pax6LMutBD_for2 & 5' - CTTCAGTACCAGGGCAACCC GATGAAGCTCAGATGCGACT-3' \\
\hline
\end{tabular}

Unterstrichene Sequenzen stellen Restriktionsschnittstellen dar, mutierte Nukleotide sind grau unterlegt. 
Sequenzierprimer

Tab. 2.4: Sequenzierprimer

\begin{tabular}{|c|c|}
\hline Primer & Sequenz \\
\hline \multirow[t]{2}{*}{ pFastBacHT-B_for } & $5^{\prime}$ - CTATAAATATTCCGGATTATTC - $3^{\prime}$ \\
\hline & Sequenzierprimer für pFastBacHT-B-Konstrukte \\
\hline \multirow[t]{2}{*}{ pFastBacHT-B_rev3 } & $5^{\prime}$ - CAAGTAAAACCTCTACAAATG - $3^{\prime}$ \\
\hline & Sequenzierprimer für pFastBacHT-B-Konstrukte \\
\hline \multirow[t]{2}{*}{ M13_for } & $5^{\prime}$ - GTTTTCCCAGTCACGAC - $3^{\prime}$ \\
\hline & Sequenzier-/PCR-Primer für Bacmide \\
\hline \multirow[t]{2}{*}{ M13_rev } & $5^{\prime}$ - CAGGAAACAGCTATGAC - $3^{\prime}$ \\
\hline & Sequenzier-/PCR-Primer für Bacmide \\
\hline CMV-Promoter & 5' - CAGAGCTGTTTAGTCAACC - 3' \\
\hline T7-Promoter & $5^{\prime}$ - TAATACGACTCACTATAGGG - $3^{\prime}$ \\
\hline pcDNA-r & $5^{\prime}$-AGGCACAGTCGAGGCTGATC-3' \\
\hline
\end{tabular}

Übersicht über die Sequenzen der verwendeten Primer für die Sequenzierung mit dem Sequenziergerät ABI PRISM (2.18).

Reportergen-Plasmide

Die Reportergen-Plasmide für funktionelle Untersuchungen in Tumorzelllinien waren bereits in der Arbeitsgruppe vorhanden und wurden vor dem Einsatz in Transfektionen sowohl durch Restriktionsverdau (2.15.1) als auch durch Sequenzierung (2.18) auf ihre Identiät bzw. Integrität überprüft. In der Tabelle 2.5 sind die in der vorliegenden Arbeit benutzten Reportergen-Plasmide und ihre Herkunft/Referenz aufgelistet. Zusätzlich wurden die Konstrukte -350/-150G3PHOmut1, -350/-150G3PHOmut2, -169G1PH0mut1 und -169G1PH0mut2 mittels primerless PCR, wie unter 2.16.2 beschrieben, hergestellt. Dabei wurden ausgehend von dem Plasmid -350/-150GluLuc Mutationen im G3-Element eingefügt. Für das Plasmid -350/-150G3PH0mut1 kamen die Primerpaare -350/-150_for und -350G3mut1_rev sowie -350G3mut1_for und -350/-150_rev zum Einsatz. Für das Plasmid -350/-150G3PH0mut2 kamen die Primerpaare -350/-150_for und -350G3mut2_rev sowie -350G3mut2_for und -350/-150_rev zum Einsatz. Analog dazu wurden Mutationen im G1-Element eingefügt. Der Ausgangsvektor dafür war -169GluLuc. Die Primerpaare -169_for/-169G1mut1_rev und -169G1mut1_for/-169_rev dienten zur Herstellung des Plasmids -169G1PH0mut1 und die Primerpaare -169_for/ -169G1mut2_rev sowie -169G1mut2_for/-169_rev dienten zur Herstellung des Plasmids -169G1PH0mut2 (vgl. Tab. 2.3). 
Tab. 2.5: Reportergen-Plasmide

\begin{tabular}{|l|l|}
\hline Plasmid & Herkunft/Referenz \\
\hline -350GluLuc & Schwaninger et al.,1993 \\
$-350(G 1 m)$ GluLuc & Teichler, Dissertation 2004 \\
$-350(G 3 A m)$ GluLuc & Teichler, Dissertation 2004 \\
$-350(G 1 \mathrm{~m} /$ G3Am)GluLuc & Teichler, Dissertation 2004 \\
$-350 /-150$ GluLuc & Fürstenau et al., 1997 \\
$-350 /-150 G 3 P H 0 m u t 1$ & Grapp, vorliegende Arbeit \\
$-350 /-150 G 3 P H 0 m u t 2$ & Grapp, vorliegende Arbeit \\
$-169 G l u L u c$ & Fürstenau et al., 1997 \\
$-169 G 1 P H 0 m u t 1$ & Grapp, vorliegende Arbeit \\
$-169 G 1 P H 0 m u t 2$ & Grapp, vorliegende Arbeit \\
pGFPtpz-cmv® control vector & Canberra-Packard (Dreieich) \\
\hline
\end{tabular}

Expressionsplasmide

Die Identität in der Arbeitsgruppe vorhandener Expressionsplasmide wurde vor dem Einsatz in transienten Transfektionen oder in in vitro Transkription/Translationen durch Restriktionsverdau (2.15.1) sowie durch Sequenzierung (2.18) überprüft. Für die Herstellung von in EMSA-Experimenten eingesetzten Proteinen wurde das „TnT Reticulocyte Lysate System“ (Promega, Mannheim) verwendet (2.19.1). Da in diesem System eine T7- oder SP6-RNA-Polymerase verwendet wird, muss die zu transkribierende cDNA in einen Vektor kloniert werden, in dem entweder ein T7- oder SP6-Promotor vor der multiplen Klonierungsstelle liegt. Der Vektor pcDNA3 (Promega, Mannheim) besitzt neben einem prokaryotischen T7- und SP6-Promotor einen eukaryotischen CMV-Promotor und eine Ampicillin-Resistenz. Für die Herstellung der in Tabelle 2.6 aufgeführten Plasmide wurden mittels PCR (2.16) und mit den in Tabelle 2.2 aufgeführten Primern die gewünschten DNA-Fragmente erzeugt. Als Matrizen-DNA diente das Plasmid pcDNA3-Pax6-WT (Tab. 2.6), welches für das Wildtyp Pax6 der Maus kodiert. Die PCR-Produkte wurden gelelektrophoretisch aufgetrennt (2.13.1), aus dem Gel isoliert und dann mit Restriktionsenzymen geschnitten (2.15.1, vgl. Tab. 2.2). Die so präparierten DNA-Fragmente wurden dann in den mit gleichen Restriktionsenzymen geschnittenen Vektor pcDNA3 ligiert (2.15.3). 
Für die Proteinexpression in Sf9-Zellen (2.19.4) wurden die Donorplasmide (Tab. 2.6, pFastBac ${ }^{\text {TM }}$ HT-B-Konstrukte) für die Erzeugung von rekombinanten Baculoviren auf analoge Weise erzeugt. Die mit den Restriktionsenzymen BamHI und Xhol geschnittenen und aus Agarosegelen aufgereinigten PCR-Produkte wurden in den Vektor pFastBac ${ }^{\text {TM }}$ HT-B (Invitrogen, Karlsruhe) ligiert, der ebenfalls zuvor mit BamHI und Xhol geschnitten wurde. Die verwendeten Primer für die PCR-Reaktionen sind in Tabelle 2.2 aufgeführt. Der Vektor pFastBac ${ }^{\mathrm{TM} H T-B}$ besitzt eine Ampicillin-Resistenz, einen starken Polyhedrin-Promotor und erlaubt die Expression von Proteinen mit einem N-terminal fusionierten His-Tag. Der His-Tag erlaubt die Aufreinigung rekombinanter Fusionsproteine mit Nickel-Chelat-Säulen. Der Nachweis rekombinanter Fusionsproteine mittels Westernblot (2.19.8) erfolgte ebenfalls durch einen Antikörper, der gegen den Nterminalen His-Tag gerichtet war (2.11.5).

Das Expressionsplasmid pBAT-Pax6Lmut wurde ausgehend von dem Vektor pBAT14.mPax6, welcher für das Wildtyp Pax6 der Maus kodiert, mittels primerless-PCR erzeugt (2.16.1). In diesem Konstrukt ist der N-terminale und der C-terminale Abschnitt des Linkers zwischen den beiden DNA-Bindedomänen vertauscht. Dabei kamen folgende Primer zum Einsatz: Pax6fl-5', Pax6LmutAC_rev, Pax6LmutCB_for, Pax6LmutBD_rev, Pax6LmutAC_for, Pax6LmutCB_rev, Pax6LmutBD_for und Pax6fl-3' (Tab. 2.2). Nach erfolgreicher Assemblierung der DNA-Abschnitte wurde das PCR-Produkt aus einem Agarosegel isoliert, mit BamHI und HindIII geschnitten und in den Bg/ll/HindIII geschnittenen Vektor pBAT14 ligiert (2.15.3).

Tab. 2.6: Expressionsplasmide

\begin{tabular}{|l|l|}
\hline Plasmid & Herkunft/Referenz \\
\hline pBAT14.mPax6/pBAT-WT & Sander et al.,1997 \\
pBAT-dHD & Teichler, Dissertation 2004 \\
pBAT-3Ala & Teichler, Dissertation 2004 \\
pBAT-Pax6Lmut & Grapp, vorliegende Arbeit \\
pcDNA3-Pax6-WT & Teichler, Dissertation 2004 \\
pcDNA3-dßPax6 & Krätzner, unveröffentlicht \\
pcDNA3-PD-L-HD & Grapp, vorliegende Arbeit \\
pcDNA3-PD & Grapp, vorliegende Arbeit \\
pcDNA3-HD & Grapp, vorliegende Arbeit \\
pcDNA3-PD-L & Grapp, vorliegende Arbeit \\
pcDNA3-PD-Lmut-HD1 & Grapp, vorliegende Arbeit \\
\hline
\end{tabular}




\begin{tabular}{|l|l|}
\hline pcDNA3-PD-Lmut-HD3 & Grapp, vorliegende Arbeit \\
pcDNA3-PD-Lmut-HD4 & Grapp, vorliegende Arbeit \\
pcDNA3-dHD & Teichler, Dissertation 2004 \\
pcDNA3-Pax6Lmut & Grapp, vorliegende Arbeit \\
pcDNA3-6xHisPax6WT & Grapp, vorliegende Arbeit \\
pcDNA3-6xHisPax6dHD & Grapp, vorliegende Arbeit \\
pcDNA3-6xHisPax6Lmut & Grapp, vorliegende Arbeit \\
pFastBacHT-B-Pax6-WT & Grapp, vorliegende Arbeit \\
pFastBacHT-B-PD & Grapp, vorliegende Arbeit \\
pFastBacHT-B-HD & Grapp, vorliegende Arbeit \\
pFastBacHT-B-PD-L-HD & Grapp, vorliegende Arbeit \\
pBluescript & Stratagene, Heidelberg \\
\hline
\end{tabular}

2.11.2 Molekulargewichtstandards

DNA-Längenstandards

Als DNA-Längenstandard wurde der „GeneRuler 1kb-Marker" eingesetzt (Fermentas, St. Leon-Rot), der aus DNA-Fragmenten der folgenden Länge bestand: 10000/8000/6000/5000/4000/3500/3000/2500/2000/1500/1000/750/500/250 bp 


\section{Protein-Molekulargewichtstandards}

Für SDS-Polyacrylamidgele wurden als Protein-Molekulargewichtstandards der „Prestained 7B Marker“ (Sigma, München) oder der „PageRuler Prestained Protein Marker" (Fermentas, St. Leon-Rot) verwendet.

Tab. 2.7: Molekularmassen der Proteine im Proteinstandard 7b

\begin{tabular}{|l|l|}
\hline Protein & Molekularmasse \\
\hline$\alpha$-Galaktosidase & $180 \mathrm{kDa}$ \\
Fruktose-6-Phosphat-Kinase & $84 \mathrm{kDa}$ \\
Pyruvatkinase & $58 \mathrm{kDa}$ \\
Fumarase & $48,5 \mathrm{kDa}$ \\
Lactat-Dehydrogenase & $36,5 \mathrm{kDa}$ \\
Triosephosphat-Isomerase & $26,6 \mathrm{kDa}$ \\
\hline
\end{tabular}

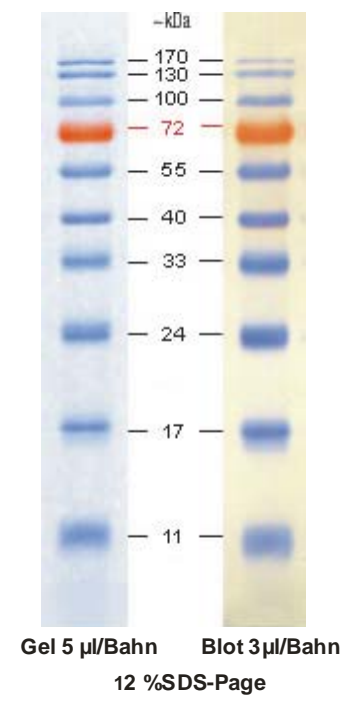

Abb. 2.1: Proteinstandard „Page Ruler Prestained Protein Marker"

\subsubsection{Bakterienstämme}

Escherichia coli $\mathrm{DH} 5 \alpha^{\mathrm{TM}}$ (Invitrogen)

Diese Stämme wurden zur Subklonierung und Vektorvermehrung verwendet. Die mangelnde Fähigkeit zur homologen Rekombination und eine Mutation in der DNAspezifischen Endonuklease I dieser Zellen erhöhten sowohl Transformationseffizienz als auch Ausbeute und Qualität isolierter DNA.

\section{Escherichia coli DH10Bac ${ }^{\mathrm{TM}}$ (Invitrogen)}

Dieser Stamm ist Bestandteil des BAC-TO-BAC Expressionsvektor-Systems. Die Zellen enthalten einen sogenannten Baculovirus-Shuttle-Vektor (Bacmid), in den durch gerichtete Transposition das Zielgen eingeführt wird. Ein zusätzliches Plasmid in den Zellen kodiert für das Enzym Transposase, das die Transposition katalysiert. Das Einfügen des Zielgens unterbricht das LacZa-Peptid, so dass mit einem rekombinanten Bacmid weiße und mit dem Wildtyp-Bacmid blaue Kolonien gebildet werden. Das 
Einbringen dieses rekombinanten Bacmids in Insektenzellen (Transfektion, 2.21.4) führt zur Bildung von infektiösen Baculoviren und Zielprotein.

\subsubsection{Eukaryotische Zelllinien}

Die verwendeten Zelllinien waren bereits im Labor vorhanden.

\section{JEG-3}

JEG-3-Zellen sind eine humane Chorionkarzinom-Zelllinie (Kohler und Bridson, 1971).

\section{InR1G9}

Die pankreatische Goldhamsterlinie InR1G9 imitiert den a-Zell-Phänotyp und synthetisiert überwiegend Glukagon (Takaki et al., 1986).

\section{$\underline{\cos -1}$}

COS-1-Zellen sind fibroblastenähnliche, unpolare Zellen, die durch Transformation von CV-1 Nierenzellen der Affenart Cercopithecus aethiops mit einer „origin“-defekten Mutante des SV40-Virus, die das Wildtyp T-Antigen enthält, hergestellt wurden (Gluzman, 1981).

\section{$\underline{\text { Sfg }}$}

Zur Expression rekombinanter Proteine wurden Sf9-Zellen verwendet. Die Zellen leiten sich ab von Ovarialzellen des „fall army worm“ Spodoptera frugiperda (Lepidoptera) (Vaughn et al., 1977). Eine Starterkultur wurde freundlicherweise vom Zentrum für Physiologie der Universität Göttingen zur Verfügung gestellt.

\subsubsection{Antiseren und Antikörper}

\begin{tabular}{|l|l|}
\hline Antiserum/Antikörper & Herkunft/Referenz \\
\hline $\begin{array}{l}\text { Tetra·His Antibody } \\
\text { Rabbit anti-Pax-QNR-Serum12 }\end{array}$ & $\begin{array}{l}\text { Qiagen, Hilden } \\
\text { Carriere et al., 1995 }\end{array}$ \\
\hline
\end{tabular}




\subsection{Nukleinsäure-Standardmethoden}

\subsubsection{Sterilisation}

Alle hitzestabilen Geräte und Lösungen wurden vor Gebrauch zur Inaktivierung von Mikroorganismen, DNasen sowie Proteasen $20 \mathrm{~min}$ bei $120^{\circ} \mathrm{C}$ und $105 \mathrm{~Pa}$ autoklaviert. Hitzelabile Substanzen (z. B. Antibiotika, SDS, PEG, Lysozym) wurden den sterilen Puffern oder Wasser direkt zugesetzt, bzw. mit Nitrocellulose-Filtern (Minisart $200 \mu \mathrm{m}$, Sartorius, Göttingen) sterilfiltriert.

\subsubsection{Phenol-Chloroform-Isoamylalkohol-Extraktion (Sambrook et al., 1989)}

Durch Extraktion einer DNA-Lösung mit Phenol/Chloroform/lsoamylalkohol (25:24:1 (v/v)) wurden Proteine, Ethidiumbromid oder Reste anderer hydrophober Kontaminationen entfernt. Zur Entfernung des Phenols aus der wässrigen Phase und zur weiteren Denaturierung von Proteinen wurde eine weitere Extraktion mit Chloroform angeschlossen. Die DNA-Lösung wurde mit 1 Vol Phenol/Chloroform/lsoamylalkohol bzw. Chloroform versetzt und gründlich gemischt. Anschließend wurde der Ansatz zur Beschleunigung der Phasentrennung zentrifugiert (Biofuge pico, Heraeus; 1min/RT/14000 UpM). Die obere, wässrige Phase wurde in ein neues Reaktionsgefäß überführt. Zum Schluss wurde die DNA durch eine Ethanol-Präzipitation (2.12.3) konzentriert und so von eventuellen Resten der organischen Lösungsmittel befreit.

\subsubsection{Ethanol-Präzipitation}

Die Ethanol-Präzipitation diente zur Überführung der Nukleinsäuren in neue Puffer, zum Ankonzentrieren der Proben oder als Reinigungsschritt. Die Präzipitation von DNA erfolgte unter Zugabe von 3 Vol eiskaltem 96\%igem Ethanol und 1/10 Vol $3 \mathrm{M}$ Natriumacetat-Lösung ( $\mathrm{pH} \mathrm{4,8).} \mathrm{Nach} \mathrm{gründlicher} \mathrm{Durchmischung} \mathrm{wurde} \mathrm{der} \mathrm{Ansatz} \mathrm{für}$ 20 min bei $-20^{\circ} \mathrm{C}$ gefällt und anschließend 15 min bei $4{ }^{\circ} \mathrm{C}$ und 14000 UpM (Biofuge pico, Heraeus) zentrifugiert. Zur Entfernung von Salzresten wurde das Pellet mit 70 \%igem (v/v) Ethanol gewaschen und erneut zentrifugiert (5 min/RT/14000 UpM). Das DNA-Pellet wurde für 5 min luftgetrocknet und anschließend in dem gewünschten Volumen Wasser oder TE-Puffer (2.9) gelöst. 


\subsubsection{Dialyse von DNA und Proteinen}

DNA-haltige Lösungen und Proteinlösungen wurden zur Überführung in einen neuen Puffer oder zur Abtrennung niedermolekularer, löslicher Substanzen in Dialyseschläuche (GIBCO BRL, Karlsruhe) überführt, die anschließend mit Klemmen (Schütt Labortechnik, Göttingen) abgedichtet wurden. Vor Gebrauch wurden die Schläuche mehrfach mit destilliertem Wasser gespült. Die Dialyse erfolgte über $20 \mathrm{~h}$ bei $4{ }^{\circ} \mathrm{C}$ gegen TE-Puffer (2.9) unter einmaligem Pufferwechsel.

2.12.5 Konzentrationsbestimmung von Nukleinsäure-Lösungen (Sambrook et al., 1989)

Die Konzentrationsbestimmung von Nukleinsäuren in wässrigen Lösungen wurde photometrisch (Shimadzu UV-160-Spektralphotometer, Duisburg) in Quarzküvetten (Hellma, Müllheim) durchgeführt. Dazu wurde die Absorption bei einer Wellenlänge von $260 \mathrm{~nm}\left(\mathrm{OD}_{260}\right)$ gemessen, wobei für die $\mathrm{OD}_{260}$ von 1,0 folgende ReferenzKonzentrationen zugrunde gelegt wurden:

$\begin{array}{ll}\text { Doppelstrang-DNA } & 50 \mu \mathrm{g} / \mathrm{ml} \\ \text { Einzelstrang-Oligonukleotid } & 20 \mu \mathrm{g} / \mathrm{ml} \\ \text { RNA } & 40 \mu \mathrm{g} / \mathrm{ml}\end{array}$

Zusätzlich konnte die Reinheit einer DNA-Lösung durch Bestimmung der optischen Dichte bei einer Wellenlänge von $280 \mathrm{~nm}$ überprüft werden. Für reine DNA gilt:

$$
\mathrm{OD}_{260}: \mathrm{OD}_{280}>1,8 \quad \text { (Sambrook et al., 1989) }
$$

Verunreinigungen durch Proteine oder Phenol sind an einer deutlichen Steigerung der Absorption bei $280 \mathrm{~nm}$ erkennbar. Eine Abschätzung der Nukleinsäure-Konzentration erfolgte auch mittels Agarose-Gelelektrophorese (2.13.1). Der visuelle Vergleich der Intensität einer DNA-Bande mit definierter Größe und Konzentration mit der DNA-Probe erlaubte die Abschätzung der Nukleinsäure-Konzentration.

\subsubsection{Doppelstrang-Oligonukleotid-Hybridisierung (,,Annealing“)}

Zur Herstellung von Doppelstrang-Oligonukleotiden wurden jeweils 100 pmol der komplemetären Oligonukleotid-Einzelstränge (Tab. 2.1) mit $\mathrm{NaCl}$ (Endkonzentration: $10 \mathrm{mM}$ ) und $\mathrm{H}_{2} \mathrm{O}$ auf ein Endvolumen von $50 \mu \mathrm{l}$ gebracht. Die Denaturierung der DNA 
erfolgte durch Inkubation für $1 \mathrm{~min}$ bei $80^{\circ} \mathrm{C}$ im Wasserbad. Durch langsames Abkühlen des Reaktionsansatzes auf RT kam es zur Hybridisierung der Einzelstränge zum Doppelstrang, was durch die Anwesenheit des $\mathrm{NaCl}$ erleichtert wurde.

2.12.7 Radioaktive Markierung von DNA durch die Klenow „Fill-in“-Reaktion (Sambrook et al., 1989)

Die 5'-Überhänge der Doppelstrang-Oligonukleotide wurden unter Anwesenheit von $\left[\alpha^{32} \mathrm{P}\right]$-markiertem dCTP mit Hilfe des Klenow-Fragments der DNA Polymerase I aufgefüllt.

Der Markierungsansatz wurde auf Eis pipettiert und enthielt folgende Komponenten:

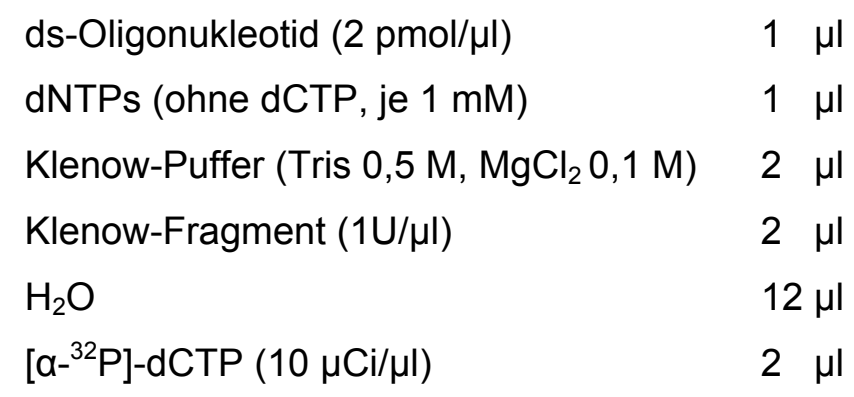

Der Markierungsansatz wurde für 30 min bei RT inkubiert. Zur Entfernung überschüssiger, nicht eingebauter Desoxyribonukleosidtriphosphate wurde der Markierungsansatz nach Reaktionsende auf eine „G-25 mini Quick Spin Oligo-Säule“ (Roche Diagnostics, Mannheim) aufgetragen. Diese wurde gemäß Herstellerangaben vorbereitet durch vortexen (5 s) und Entfernung des Äquilibrierungspuffers durch Zentrifugation (1 min/ RT/3300 UpM; Biofuge 15R Heraeus, Hamburg). Die Säule wurde in ein neues Eppendorf-Gefäß gestellt. Nach Überführung der radioaktiv markierten DNA-Sonde auf die Säule wurde die gereinigte Sonde durch Zentrifugation eluiert (4 min/RT/3300 UpM; Biofuge 15R Heraeus, Hamburg). Die markierten DNA-Fragmente wurden aufgefangen und der radioaktive Einbau mit Hilfe eines Szintillationszählers (Beckmann LS 1801, München) bestimmt. Die Lagerung erfolgte bei $-20^{\circ} \mathrm{C}$. 


\subsection{Auftrennung von DNA-Fragmenten}

\subsubsection{Horizontale Agarose-Gelelektrophorese von DNA}

Zur Analyse oder Präparation von PCR-Produkten und Überprüfung der Identität durch Restriktionsverdau (2.15.1) isolierter DNA-Fragmente, wurden diese in horizontalen Agarosegelen im elektrischen Feld aufgetrennt. Die DNA wurde für analytische und präparative Zwecke in Agarosegelen mit 0,8 - 1,5 \% (w/v) Agarose, 0,5 $\mathrm{\mu g} / \mathrm{ml}$ Ethidiumbromid und TAE als Laufpuffer aufgetrennt. Die DNA-Proben wurden mit einer entsprechenden Menge 6x Stopp-Mix (2.9) versetzt und bei einer konstanten Spannung von 50-100 V elektrophoretisch getrennt. Nach Abschluss der Elektrophorese wurden die DNA-Fragmente unter UV-Licht von $366 \mathrm{~nm}$ Wellenlänge sichtbar gemacht und fotografiert (Herolab E.A.S.Y., Wiesloch).

\subsubsection{Isolierung von DNA-Fragmenten aus Agarosegelen}

Die Isolierung von DNA-Restriktionsfragmenten aus Agarosegelen erfolgte mit Hilfe des Easy Pure ${ }^{\circledR}$ DNA Purification Kit von Biozym (Oldendorf). Diese Methode beruht auf dem von Vogelstein und Gillespie (1979) beschriebenen Prinzip der reversiblen Bindung von

Nukleinsäuren an Partikel einer Anionenaustauschersilikat-Suspension (Glasmilch), abhängig von der lonenstärke des Lösungsmittels. Die gewünschte Bande wurde nach gelelektrophoretischer Auftrennung unter UV-Licht $(366 \mathrm{~nm})$ aus dem Agarosegel ausgeschnitten und die DNA den Herstellerangaben folgend extrahiert.

\subsection{Nachweis von Nukleinsäuren im analytischen Maßstab}

\subsubsection{Ethidiumbromidfärbung in Agarosegelen}

Der Fluoreszenzfarbstoff Ethidiumbromid interkaliert zwischen die Basen von Nukleinsäuren; in ausreichender Menge akkumuliert, können diese somit im UV-Licht indirekt nachgewiesen werden. Der Zusatz des Ethidiumbromids erfolgte direkt bei der Herstellung des Agarosegels (2.13.1). Nach elektrophoretischer Auftrennung der DNAFragmente wurde das DNA-Bandenmuster mit einem UV-Transilluminator $(\lambda=254$ oder 366 nm, UV-Kontaktlampe Chroma 41 bzw. Chroma 42, Vetter GmbH, Wiesloch) sichtbar gemacht und mit Hilfe einer Geldokumentationsanlage (Herolab E.A.S.Y., Wiesloch) ausgewertet. 


\subsubsection{Autoradiographie}

Der Nachweis radioaktiv markierter Nukleinsäuren erfolgte durch Autoradiographie unter Verwendung von Röntgenfilmen (Hyperfilm MP-Röntgenfilme, Amersham, Braunschweig). Getrocknete Polyacrylamid-Gele aus EMSA-Experimenten (2.20) wurden in Röntgenkassetten mit Verstärkerfolie (Kodak X-Omatic, Stuttgart) autoradiographiert. Die Expositionszeit eines Röntgenfilms betrug 3-10 Tage bei $-80{ }^{\circ} \mathrm{C}$. Nach der Exposition wurden die Filme für 1 min entwickelt (Röntgenentwickler LX 24, Kodak, Stuttgart), mit Wasser gespült und für 2 min fixiert (Röntgenfixierbad AL 4, Kodak, Stuttgart). Die Filme wurden intensiv mit Wasser gewaschen und getrocknet. Alternativ wurden die getrockneten Gele mit Hilfe eines Phosphor-Imagers (Fujix BAS-Cassette, BAS Analyzer BAS-1500, Raytest, Straubenhardt) dokumentiert. Die Expositionszeit betrug hier $3 \mathrm{~h}, 6 \mathrm{~h}$ oder $16 \mathrm{~h}$.

\subsection{Enzymatische Modifikation von DNA}

\subsubsection{Spaltung von DNA durch Restriktionsendonukleasen}

Die sequenzspezifische Spaltung von DNA mit Restriktionsendonukleasen liefert lineare Fragmente mit definierten Enden. Sie diente zur Überprüfung der Reinheit und Identität von Plasmiden und wurde zur Umklonierung von DNA-Fragmenten verwendet. Der Restriktionsverdau erfolgte in den vom Hersteller der Restriktionsenzyme mitgelieferten Puffersystemen bei den empfohlenen Temperaturen. In einem Standardansatz wurde der Verdau für $2 \mathrm{~h}$ bei $37{ }^{\circ} \mathrm{C}$ inkubiert, wobei pro $\mu \mathrm{g}$ DNA $2 \mathrm{U}$ des jeweiligen Enzyms eingesetzt wurden. Für den simultanen Verdau mit zwei Restriktionsendonukleasen wurde ein Puffer eingesetzt, der beiden Enzymen eine ausreichende Aktivität erlaubt. Falls eine Inaktivierung der Restriktionsenzyme erforderlich war, wurde der Verdauansatz 15 min bei $65{ }^{\circ} \mathrm{C}$ inkubiert. Die Vollständigkeit der Spaltung wurde mittels AgaroseGelelektrophorese überprüft.

\subsubsection{Dephosphorylierung von Vektor-DNA}

Vor der Ligation von Vektor-DNA mit den zu klonierenden DNA-Fragmenten wurde die 5'-Phosphatgruppe des Vektors mit alkalischer Phosphatase aus Kälberdarm (CIAP, Fermentas, St. Leon Rot) abgespalten. Dadurch sollte die Ligation von VektorFragmenten mit sich selbst oder mit anderen linearen Vektor-Fragmenten verhindert 
werden. Die Dephosphorylierung wurde direkt im Verdauansatz durchgeführt (Greene und Guarente, 1987). Nach der Spaltung des Vektors wurde $1 \mathrm{U}$ alkalische Phophatase pro $\mu \mathrm{g}$ DNA zugegeben und 15 min bei $37^{\circ} \mathrm{C}$ inkubiert. Anschließend wurde erneut $1 \mathrm{U}$ Enzym zugegeben und die Inkubation wiederholt. Abgestoppt wurde die Reaktion durch Hitzeinaktivierung des Enzyms für 20 min bei $65^{\circ} \mathrm{C}$ und durch anschließende Reinigung der DNA mit Glasmilch (2.13.2). Bei Vektor-DNA, die mit zwei unterschiedlichen Restriktionsenzymen verdaut wurde, entfiel die Dephosphorylierung.

\subsubsection{Ligation von DNA-Fragmenten}

Bei der Ligation werden Phosphodiesterbindungen zwischen doppelsträngigen DNAFragmenten geknüpft, die freie 3'-Hydroxylenden und 5'-Phosphatenden aufweisen. Um die Ligationseffizienz zu erhöhen, wurde ein Überschuss an Insert-DNA eingesetzt (Verhältnis Vektor- zu Insert-DNA von 1: 4). Die Ligation erfolgte in einem $20 \mu \mathrm{l}$ Ansatz und in dem vom Hersteller mitgelieferten Puffersystem:

$\begin{array}{lr}\text { Vektor-DNA } & 25-50 \mathrm{ng} \\ \text { Insert-DNA } & 30-120 \mathrm{ng} \\ 10 x \mathrm{~T}_{4} \text {-Ligase-Puffer } & 2 \mu \mathrm{l} \\ \mathrm{T}_{4} \text {-DNA-Ligase }(1 \mathrm{U} / \mu \mathrm{l}) & 1 \mu \mathrm{l} \\ \mathrm{H}_{2} \mathrm{O}_{\text {bidest }} & \text { ad } 20 \mu \mathrm{l}\end{array}$

Die Inkubation der Ansätze erfolgte bei Ligationen von kohäsiven Enden über Nacht bei $16{ }^{\circ} \mathrm{C}$.

\subsection{Polymerase-Kettenreaktion (PCR; Mullis \& Fallona, 1987; Saiki et al., 1988)}

Durch selektive Amplifikation ermöglicht die PCR die Vervielfältigung kleinster Mengen DNA für analytische bzw. präparative Zwecke in vitro. Dabei wird doppelsträngige DNA hitzedenaturiert, so dass zwei kurze Oligonukleotid-Primer bei einer spezifischen Temperatur hybridisieren können (Annealing), die dann von einer thermostabilen DNAPolymerase bei $72{ }^{\circ} \mathrm{C}$ verlängert werden (Extension). Die neu synthetisierten Stränge stehen in der nächsten Amplifikationsrunde ebenfalls als Matrize zur Verfügung. So wird die von den Primern eingerahmte Sequenz idealerweise exponentiell vermehrt. 
Soweit nicht anders erwähnt, wurden jeweils in einem Gesamtvolumen von $100 \mu \mathrm{l} 10$ 20 ng Matrizen-DNA, 20 - 50 pmol der entsprechenden Primer, je 20 pmol dNTPs und 2,5 U der entsprechenden Polymerase in dem vom Hersteller empfohlenen Reaktionspuffer eingesetzt.

Der Ansatz wurde mit Chill-out ${ }^{\mathrm{TM}}$ Wachs überschichtet und in einem PCR-Block inkubiert. Wie in Tabelle 2.8 dargestellt, folgte auf eine initiale Denaturierung bei $94^{\circ} \mathrm{C}$ für 2 min insgesamt 25 bis 30 Zyklen mit jeweils $1 \mathrm{~min}$ Denaturierung bei $94^{\circ} \mathrm{C}, 1 \mathrm{~min}$ Hybridisierung bei der für das Primerpaar spezifischen Temperatur und anschließender Elongation mit $1 \mathrm{~min} / \mathrm{kb}$ bei $72^{\circ} \mathrm{C}$. Die Hybridisierungstemperatur $\mathrm{T}_{\mathrm{M}}$ wurde nach Chester und Marshak (1993) bestimmt; sie berücksichtigt sowohl den GC-Gehalt des Oligonukleotid-Primers als auch dessen Länge:

$T_{M}=69,3+0,41(\% \mathrm{GC}-650 / n)$

$\mathrm{T}_{\mathrm{M}}$ : Schmelztemperatur des Oligonukleotids $\left[{ }^{\circ} \mathrm{C}\right]$

$\mathrm{n}$ : Anzahl der Nukleotide im Oligonukleotid

Die Annealing-Temperatur der Primer war abhängig von der Schmelztemperatur und lag idealerweise $5{ }^{\circ} \mathrm{C}$ tiefer. Um möglichst fehlerfreie DNA-Fragmente für Klonierungen zu amplifizieren, wurde die $\mathrm{Pfu}^{\mathrm{TM}}$-DNA-Polymerase benutzt, welche eine proofreadingAktivität aufweist.

Tab. 2.8: Zusammensetzung des Ansatzes und Bedingungen zur Amplifikation von DNAAbschnitten mittels PCR

\begin{tabular}{|l|l|l|l|l|}
\hline \multicolumn{2}{|l|}{ Reaktionsansatz } & \multicolumn{3}{l|}{ Reaktionsbedingungen } \\
\hline DNA-Matrize & $10-20 \mathrm{ng}$ & Schritt & Temperatur & Dauer \\
\cline { 2 - 5 } Primer A $(100 \mathrm{pmol} / \mu \mathrm{l})$ & $0,5 \mu \mathrm{l}$ & 1. & $94{ }^{\circ} \mathrm{C}$ & $2 \mathrm{~min}$ \\
Primer B $(100 \mathrm{pmol} / \mathrm{\mu l})$ & $0,5 \mu \mathrm{l}$ & 2. & $94{ }^{\circ} \mathrm{C}$ & $1 \mathrm{~min}$ \\
$\mathrm{Pfu}^{\mathrm{TM}}$-Polymerase $(2,5 \mathrm{U} / \mu \mathrm{l})$ & $2 \mu \mathrm{l}$ & 3. & annealing ${ }^{\circ} \mathrm{C}$ & $1 \mathrm{~min}$ \\
$10 \times$ Polymerase-Puffer & $10 \mu \mathrm{l}$ & 4. & $72{ }^{\circ} \mathrm{C}$ & $1 \mathrm{~min} / \mathrm{kb}$ \\
dNTPs (je $10 \mathrm{mM})$ & $2 \mu \mathrm{l}$ & 5. & $72{ }^{\circ} \mathrm{C}$ & $5 \mathrm{~min}$ \\
$\mathrm{H}_{2} \mathrm{O}$ & ad $100 \mu \mathrm{l}$ & \multicolumn{3}{|l|}{ Schritt 2-4 wurden $24-29$ mal wiederholt } \\
\hline
\end{tabular}




\subsubsection{Assembling von DNA-Fragmenten mittels primerless PCR}

Ursprünglich wurde die primerless PCR entwickelt, um ein Gen aus mehreren Oligonukleotiden zu synthetisieren. Bei diesem Verfahren dienen die überlappenden Bereiche der Oligonukleotide als Primer, wodurch sich das Gen über wiederholte Zyklen von Trennung, Annealing und Polymerasereaktionen sukzessive aufbaut (Stemmer et al., 1995).

Die primerless PCR kann auch benutzt werden, um definierte Bereiche eines Gens mit anderen Bereichen auszutauschen. Diese Methode fand Anwendung, um den Pax6Linker in den Konstrukten pcDNA3-PD-Lmut-HD1, 3 und 4 sowie pBAT-Pax6Lmut zu mutieren, d. h. N-terminale Bereiche des Linkers wurden mit C-terminalen Bereichen des Linkers ausgetauscht (pcDNA3-PD-Lmut-HD1 und 4, pBAT-Pax6Lmut), oder es wurden Aminosäureabfolgen invertiert (pcDNA3-PD-Lmut-HD3). Abbildung 2.2 zeigt schematisch die Vorgehensweise am Beispiel des Konstrukts Pax6-PD-Lmut-HD1. In einer ersten PCR (2.16) wurden vier PCR-Produkte erzeugt, die jeweils die Paired-Damäne (PD = Fragment $A)$, die Homöodomäne $(H D=$ Fragment $D)$, den N-terminalen Bereich des Linkers $(\mathrm{LI}=$ Fragment $\mathrm{B})$ und den C-terminalen Bereich des Linkers $(\mathrm{LII}=$ Fragment $\mathrm{C})$ umfassten. Die Primer waren dabei so definiert, dass die DNA-Fragmente jeweils überlappende Bereiche mit dem Fragment haben, mit dem sie assembliert werden sollten (Tab. 2.3). Nach Aufreinigung der PCR-Produkte (2.13.2), wurden in einer primerless PCR die Fragmente $A$ und $C$ oder $B$ und $D$ assembliert. Die Reaktionsbedingungen lassen sich aus Tabelle 2.9 entnehmen. In einer darauf folgenden primed PCR wurden die so erzeugten DNA-Fragmente amplifiziert. Die Reaktionsbedingungen hierfür lassen sich aus Tabelle 2.10 entnehmen. Dieser Vorgang wurde wiederholt, bis das vollständige Gen assembliert war. Das Gen wurde dann in einer letzten primed PCR mit Hilfe von endständigen Primern, die auch die Information für Restriktionsschnittstellen tragen, amplifiziert und konnte daraufhin in einen geeigneten Vektor kloniert werden. 

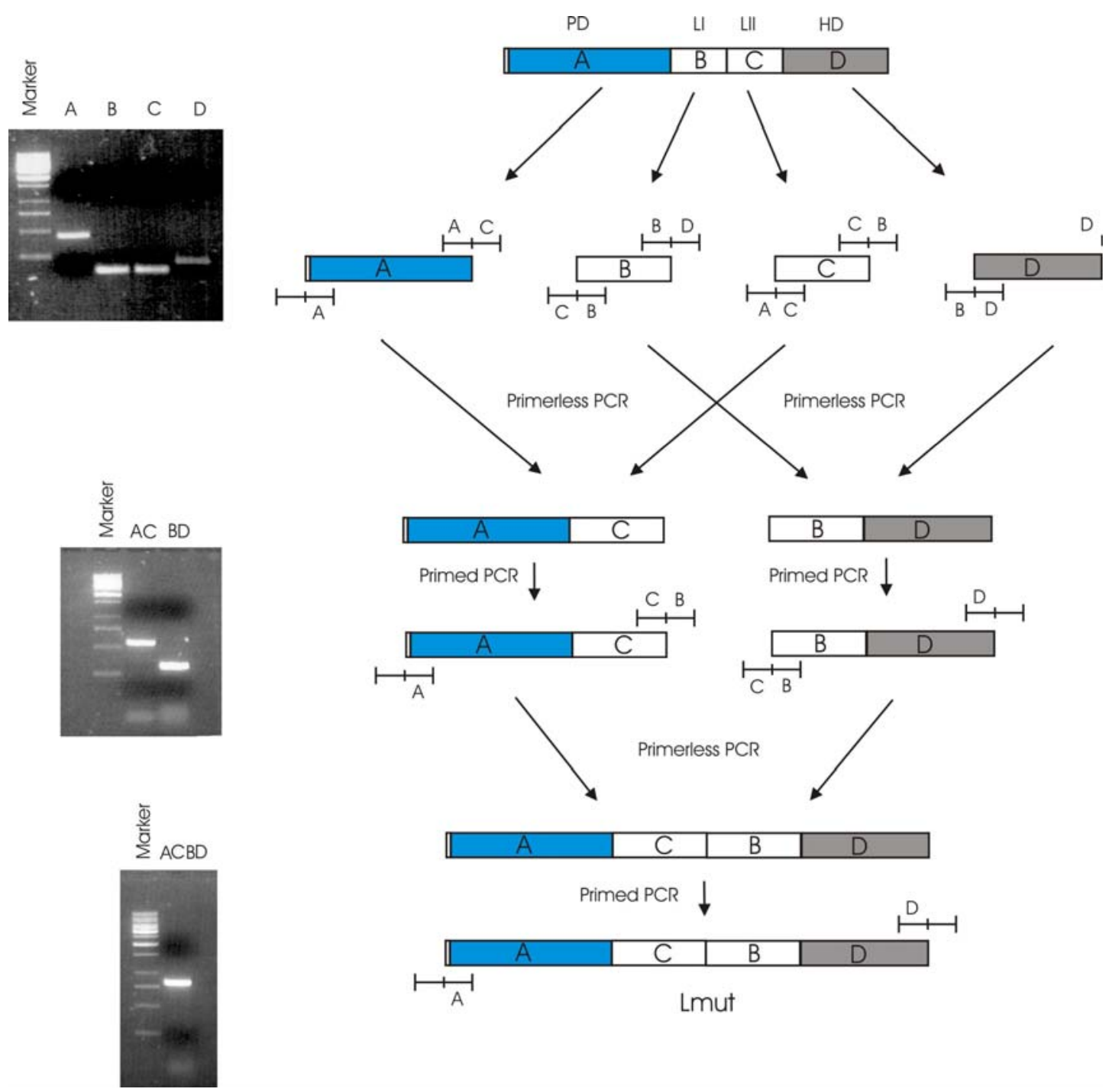

Abb. 2.2: Schematische Darstellung der Assemblierung von Pax6-PD-Lmut-HD1 aus PCRProdukten mittels primerless PCR. PD, Pax6 Paired-Domäne (= Fragment A); LI, N-terminaler Teil des Linkers (= Fragment B); LII, C-terminaler Teil des Linkers (= Fragment C); HD, Pax6Homöodomäne (= Fragment D); Marker, GeneRuler 1kb-Marker (2.11.2),

Tab. 2.9: Zusammensetzung des Ansatzes und Bedingungen zum assembling von DNAFragmenten mittels primerless PCR.

\begin{tabular}{|l|ll|l|l|l|}
\hline \multicolumn{2}{|l|}{ Reaktionsansatz } & \multicolumn{3}{l|}{ Reaktionsbedingungen } \\
\hline PCR-Produkt 1 & $2 \mu \mathrm{l}$ & Schritt & Temperatur & Dauer \\
\cline { 2 - 5 } PCR-Produkt 2 & 2 & $\mu \mathrm{l}$ & 1. & $94^{\circ} \mathrm{C}$ & $2 \mathrm{~min}$ \\
$\mathrm{Pfu}^{\mathrm{TM}}$-Polymerase $(2,5 \mathrm{U} / \mu \mathrm{l})$ & $2 \mu \mathrm{l}$ & 2. & $94^{\circ} \mathrm{C}$ & $30 \mathrm{sec}$ \\
$10 \times$ Polymerase-Puffer & $10 \mu \mathrm{l}$ & 3. & $50^{\circ} \mathrm{C}$ & $30 \mathrm{sec}$ \\
$\mathrm{dNTPs}($ je $10 \mathrm{mM})$ & $2 \mu \mathrm{l}$ & 4. & $72^{\circ} \mathrm{C}$ & $1 \mathrm{~min}$ \\
$\mathrm{H}_{2} \mathrm{O}$ & ad $100 \mu \mathrm{l}$ & 5. & $72{ }^{\circ} \mathrm{C}$ & $10 \mathrm{~min}$ \\
\cline { 3 - 5 } & & \multicolumn{4}{|l|}{ Schritt 2-4 29 wurde mal wiederholt } \\
\hline
\end{tabular}


Tab. 2.10: Zusammensetzung des Ansatzes und Bedingungen zur Amplifikation von DNAAbschnitten über eine primed PCR im Anschluß an eine primerless PCR

\begin{tabular}{|c|c|c|c|c|}
\hline \multicolumn{2}{|l|}{ Reaktionsansatz } & \multicolumn{3}{|c|}{ Reaktionsbedingungen } \\
\hline primerless PCR-Ansatz & $2 \mu \mathrm{l}$ & Schritt & Temperatur & Dauer \\
\hline Primer A (100 pmol/ $/ \mu \mathrm{l})$ & $0,5 \mu \mathrm{l}$ & 1. & $94^{\circ} \mathrm{C}$ & $2 \mathrm{~min}$ \\
\hline Primer B (100 pmol/ $/ \mu \mathrm{l})$ & $0,5 \mu \mathrm{l}$ & 2. & $94^{\circ} \mathrm{C}$ & $1 \mathrm{~min}$ \\
\hline $\mathrm{Pfu}^{\mathrm{TM}}$-Polymerase $(2,5 \mathrm{U} / \mu \mathrm{l})$ & $2 \mu \mathrm{l}$ & 3. & annealing ${ }^{\circ} \mathrm{C}$ & $1 \mathrm{~min}$ \\
\hline 10 x Polymerase-Puffer & $10 \mu \mathrm{l}$ & 4. & $72{ }^{\circ} \mathrm{C}$ & $1 \mathrm{~min} / \mathrm{kb}$ \\
\hline dNTPs (je 10 mM) & $2 \mu \mathrm{l}$ & 5. & $72{ }^{\circ} \mathrm{C}$ & $5 \mathrm{~min}$ \\
\hline $\mathrm{H}_{2} \mathrm{O}$ & ad $100 \mu \mathrm{l}$ & \multicolumn{3}{|c|}{ Schritt 2-4 wurden 24 mal wiederholt } \\
\hline
\end{tabular}

2.16.2 Zielgerichtete Mutagenese mittels primerless PCR

Die in vitro Mutagenese wurde mittels primerless PCR durchgeführt und diente zum Einfügen von Mutationen in die Reportergen-Plasmide -350/150GluLuc und -169GluLuc. Hierbei können ortsgerichtet Mutationen von einem oder mehreren Basenpaaren in die Ziel-DNA eingefügt werden. In einer ersten PCR wurden ausgehend von den Plasmiden -350/-150GluLuc oder-169GluLuc zwei PCR-Fragmente erzeugt (Abb. 2.3). Die Primer hierfür waren so definiert, dass es zu einem Annealing des $3^{\prime}$-Überhangs des ersten Fragments mit einem 5 '-Überhang des zweiten Fragments in einer folgenden primerless PCR kam (Tab. 2.3). Die beiden Überhänge trugen jeweils die gewünschte Mutation (Abb. 2.3, rotes Kreuz). Das mutierte DNA-Fragment wurde dann in einer letzten primed PCR mit Hilfe von endständigen Primern, die auch die Information für Restriktionsschnittstellen tragen, amplifiziert und konnte daraufhin in einen geeigneten Vektor kloniert werden. Die Reaktionsbedingungen für die primerless- und primed PCR können aus Tabelle 2.9 und 2.10 entnommen werden. 


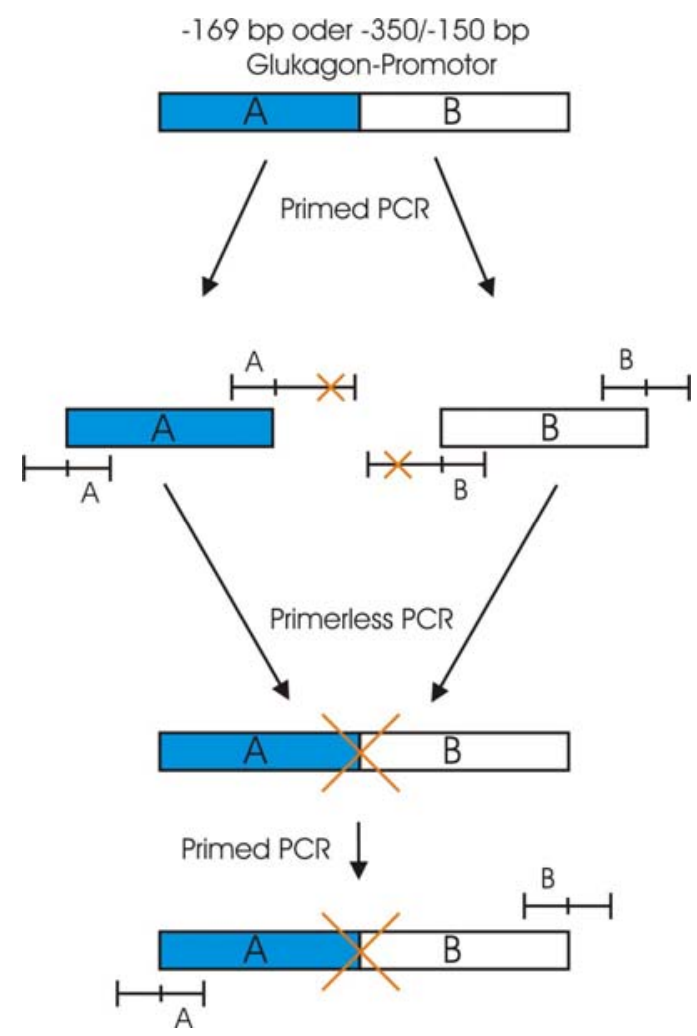

Abb. 2.3: Schematische Darstellung der zielgerichteten Mutagenese mittels primerless PCR.

\subsection{Standardmethoden zur molekularen Klonierung}

2.17.1 Herstellung kompetenter E. coli (Dagert \& Ehrlich, 1979)

Die spontane Aufnahme von in Lösung befindlicher Fremd-DNA durch Bakterien wird als Kompetenz bezeichnet. Durch die Behandlung von E. coli-Bakterien mit $\mathrm{CaCl}_{2}$ und die damit einhergehende Modifikation der Zelloberfläche kann dieser Zustand induziert und die Kompetenz erhöht werden. $100 \mathrm{ml}$ LB-Medium (2.9) wurden mit $10 \mathrm{ml}$ einer Übernachtkultur des jeweiligen E. coli Stammes (DH5a oder DH10Bac) (2.11.3) inokuliert und bei $37^{\circ} \mathrm{C}$ mit 200 UpM im Schüttelinkubator (Inova 4300, NBS, USA) bis zu einer optischen Dichte von $\mathrm{OD}_{600}=0,6$ (UV-160, Shimadzu, Duisburg) inkubiert. Die Bakterien wurden anschließend für $10 \mathrm{~min}$ auf Eis inkubiert und zentrifugiert $\left(10 \mathrm{~min}, 4{ }^{\circ} \mathrm{C}, 3000\right.$ UpM; Beckmann JA-14, München). Der Überstand wurde dekantiert und das Zellpellet mit $50 \mathrm{ml}$ eiskalter, sterilfiltrierter $50 \mathrm{mM} \mathrm{CaCl}_{2}$-Lösung vorsichtig resuspendiert und erneut für 30 min auf Eis inkubiert. Nach einer erneuten Zentrifugation (10 min, $4{ }^{\circ} \mathrm{C}, 3000 \mathrm{UpM}$; Beckmann JA-14, München) wurde das Pellet in $10 \mathrm{ml}$ eiskalter $50 \mathrm{mM} \mathrm{CaCl} / \mathrm{Glycerin}$ (15\% v/v)-Lösung aufgenommen. Die Suspension wurde aliquotiert und in flüssigem Stickstoff schockgefroren. Bis zum Gebrauch wurden die Aliquots bei $-80{ }^{\circ} \mathrm{C}$ gelagert. 


\subsubsection{Transformation}

Transformation kompetenter E. coli

Durch Transformation werden Plasmide in kompetente E. coli-Zellen übertragen. $30 \mu \mathrm{l}$ kompetente DH5a-Bakterien (2.17.1) wurden auf Eis aufgetaut und mit $10 \mu \mathrm{l}$ eines Ligationsansatzes (2.15.3) oder 0,5 $\mathrm{\mu g}$ Plasmid-DNA versehen. Nach 30-minütiger Inkubation auf Eis wurde die Suspension $30 \mathrm{sec}$ bei $42{ }^{\circ} \mathrm{C}$ hitzegeschockt. Die Bakterien wurden für 2 min auf Eis gehalten und nach Zugabe von $500 \mu \mathrm{l}$ LB-Medium (2.9) für $1 \mathrm{~h}$ bei $37{ }^{\circ} \mathrm{C}$ und 250 UpM im Schüttelinkubator (Thermomixer compact, Eppendorf, Köln) inkubiert. Danach wurden $50 \mu \mathrm{l}$ bzw. $120 \mu \mathrm{l}$ der Bakteriensuspension auf LB $_{\text {Amp }}{ }^{-}$ Agarplatten $(100 \mu \mathrm{g} / \mathrm{ml}$ Ampicillin) ausplattiert. Die LB-Agarplatten wurden mindestens $16 \mathrm{~h}$ bei $37^{\circ} \mathrm{C}$ inkubiert.

Transformation kompetenter $\mathrm{DH} 10 \mathrm{Bac}^{\mathrm{TM}}$ E. coli

$100 \mu \mathrm{l}$ kompetenter $\mathrm{DH} 10 \mathrm{Bac}^{\mathrm{TM}}$-Zellen wurden in vorgekühlte PolypropylenRundbodenröhrchen überführt und mit $1 \mathrm{ng}$ der entsprechenden Plasmid-DNA (Tab. 2.6) versetzt. Nach 30-minütiger Inkubation auf Eis wurden die Zellen $45 \mathrm{sec}$ bei $42{ }^{\circ} \mathrm{C}$ hitzegeschockt und danach 2 min auf Eis gehalten. Nach Zugabe von $900 \mu$ SOCMedium (2.9) wurden die Zellen für $4 \mathrm{~h}$ bei $37{ }^{\circ} \mathrm{C}$ und $225 \mathrm{UpM}$ im Schüttelinkubator (Thermomixer compact, Eppendorf, Köln) inkubiert. Die Zellen wurden mit SOC-Medium verdünnt $\left(10^{-1}, 10^{-2}, 10^{-3}\right)$ und $100 \mu$ jeder Verdünnung auf LB-Agarpatten $(50 \mu \mathrm{g} / \mathrm{ml}$ Kanamycin, $7 \mu \mathrm{g} / \mu \mathrm{l}$ Gentamicin, $10 \mu \mathrm{g} / \mathrm{ml}$ Tetracyclin, $100 \mu \mathrm{g} / \mathrm{ml}$ X-Gal, und $40 \mu \mathrm{g} / \mathrm{ml}$ IPTG) ausplattiert. Die Identifizierung positiver Klone erfolgte durch Blau-Weiß-Selektion.

Identifizierung positiver Klone durch Blau-Weiß-Selektion

Die Blau-Weiß-Selektion beruht auf der Spaltung des künstlichen Substrates X-Gal (5-Bromo-4-chloro-3-indolyl- $\beta$-galactopyranosid) durch $\beta$-Galactosidase in den blauen Farbstoff 5-Brom-4-chlorindigo und die Zuckerkomponente Allolactose. Entsprechende Wirtszellen tragen in ihrem Genom lediglich den $\omega$-Abschnitt der $\beta$-Galactosidase. Das in den DH10Bac-Zellen propagierte „Bacmid“ enthält zur Komplementierung des Enzyms den $\alpha$-Abschnitt des Gens in der „mini-attTn7 attachment site“. Die Insertion des Zielgens durch Transpositon in die "mini-attTn7 attachment site“ des Bacmids unterbricht die Bildung der $\beta$-Galactosidase, der Farbstoff kann nicht gespalten werden und die entsprechenden Kolonien erscheinen weiß. Zur Ausbildung des Blau-Weiß-Phänotyps 
wurden die Transformationsansätze auf den entsprechenden LB-Agarplatten (siehe oben) ausplattiert und $48 \mathrm{~h}$ bei $37^{\circ} \mathrm{C}$ inkubiert.

\subsubsection{Minipräparation von Plasmid-DNA}

Die Gewinnung von Plasmid-DNA aus Bakterien im Kleinmaßstab erfolgte durch alkalische Zelllyse und alkoholische Präzipitation (Sambrook et al., 1989).

Zunächst wurden $1,5 \mathrm{ml}$ einer E. coli-Übernachtkultur bei 6000 UpM in einer Tischzentrifuge (Biofuge pico, Heraeus) für 3 min abzentrifugiert und das Pellet in $150 \mu \mathrm{l}$ Lösung M1 resuspendiert. Die Lyse der Zellen erfolgte anschließend nach Zugabe von $150 \mu$ l Lysepuffer M2. Der Ansatz wurde vorsichtig gemischt und 5 min bei RT inkubiert. Die Einhaltung der Inkubationszeit war wichtig, um eine maximale Zelllyse zu gewährleisten und gleichzeitig eine irreversible Denaturierung der Plasmid-DNA zu vermeiden. Nach der Zugabe von $150 \mu$ l der Lösung M3 erfolgte während der zehnminütigen Inkubation auf Eis die Fällung genomischer DNA und der Proteine. Nach dem Abtrennen genomischer DNA und der Proteine durch Zentrifugation $\left(10 \mathrm{~min} / 4{ }^{\circ} \mathrm{C} /\right.$ 1400 UpM; Centrifuge 5417R, Eppendorf, Hamburg), wurde die im Überstand enthaltene Plasmid-DNA mittels Phenol/Chloroform (2.12.2) extrahiert und mit Ethanol gefällt (2.12.3). Zum Abbau bakterieller RNA wurde das DNA-Pellet nach dem Trocknen in $20 \mu \mathrm{l}$ RNaseA-Lösung $(0,1 \mathrm{mg} / \mathrm{ml})$ aufgenommen und $30 \mathrm{~min}$ bei $37{ }^{\circ} \mathrm{C}$ inkubiert. Die so gewonnene Plasmid-DNA wurde durch Restriktionsanalysen überprüft (2.15.1) und konnte zur DNA-Sequenzierung oder Subklonierung eingesetzt werden. Die Lagerung erfolgte bei $-20^{\circ} \mathrm{C}$.

M1

Tris $\quad 50 \mathrm{mM}$

EDTA $\quad 10 \mathrm{mM}$

Der $\mathrm{pH}$ - Wert wurde mit $\mathrm{HCl}$ auf 8,0 eingestellt.

$\underline{\mathrm{M} 2}$

$\mathrm{NaOH} \quad 200 \mathrm{mM}$

SDS $(w / v) \quad 1 \%$

$\underline{\mathrm{M} 3}$

Kaliumacetat $(\mathrm{pH} 5,5) \quad 3,1 \mathrm{M}$ 
2.17.4 Maxipräparation von Plasmid-DNA (Sambrook et al., 1989)

Die Isolierung großer Mengen reiner Plasmid-DNA, z.B. für transiente Transfektionen (2.21.4) oder in vitro Transkription/Translation (2.19.2), erfolgte durch CäsiumchloridDichtegradienten-Zentrifugation eines Plasmid-Rohextraktes. 1 I LB Lmp $_{\text {Ampdium (100 }}$ $\mu \mathrm{g} / \mathrm{ml}$ Ampicillin) wurde mit $25 \mathrm{ml}$ einer aus einer Einzelkolonie inokulierten Übernachtkultur beimpft und bei $37^{\circ} \mathrm{C}$ mit 200 UpM im Schüttelinkubator (Inova 4300, NBS, USA) über Nacht aufgewachsen. Die Kultur wurde auf vier $250 \mathrm{ml}$ Zentrifugenbecher (Beckmann, München) aufgeteilt und für 10 min bei $4{ }^{\circ} \mathrm{C}$ mit $4500 \mathrm{UpM}$ (Beckmann JA-14 Rotor, München) sedimentiert. Das Pellet wurde in $11,25 \mathrm{ml}$ isoosmotischer STE-Lösung resuspendiert, jeweils zwei der Suspensionen in einem $50 \mathrm{ml}$ Zentrifugengefäß vereinigt und zum Abbau der Bakterienzellwand für 20 min auf Eis mit $1,5 \mathrm{ml}$ Lysozymlösung (60 $\mathrm{mg} / \mathrm{ml}$ in STE) versetzt. Die entstandenen Sphäroblasten wurden durch 5-minütige Inkubation mit 1,8 ml einer 0,5 M EDTA-Lösung (pH 8,0) auf Eis und anschließender Zugabe von 14,4 ml Triton-Mix für weitere $30 \mathrm{~min}$ auf Eis unter regelmäßigem Schwenken lysiert. Durch einstündige Zentrifugation der Suspension bei 4 ${ }^{\circ} \mathrm{C}$ und 14000 UpM (Beckmann JA-20 Rotor, München) wurden die Zelltrümmer von der DNA getrennt. Die DNA-haltigen Überstände wurden in einem $250 \mathrm{ml}$ Zentrifugenbecher vereinigt und die DNA durch Zugabe von je 40 ml PEG-6000-Lösung für mindestens $1 \mathrm{~h}$ auf Eis präzipitiert. Nach Zentrifugation für 10 min bei $4{ }^{\circ} \mathrm{C}$ mit 10000 UpM (Beckmann Ja14 Rotor, München) wurde das DNA-Pellet in je $10 \mathrm{ml}$ TNE-Puffer aufgenommen und nach Zugabe von 10,9 g Cäsiumchlorid und $150 \mu$ Ethidiumbromid-Lösung $(10 \mathrm{mg} / \mathrm{ml})$ in Quick-Seal Röhrchen (Beckmann, München) überführt. Die Röhrchen wurden auf 0,05 g genau austariert, verschweißt und für $20 \mathrm{~h}$ bei $20^{\circ} \mathrm{C}$ mit 60000 UpM (Beckmann TI-70.1 Rotor, München) zentrifugiert. Die Interkalation von Ethidiumbromid zwischen die Basen von DNA führt zur Entwindung der DNA-Doppelhelix. Lineare und zirkuläre DNA weisen Unterschiede in der Menge gebundenen Ethidiumbromids auf, was für eine Trennung in der Cäsiumchlorid-Dichtegradienten-Ultrazentrifugation ausgenutzt wird. Die zirkuläre Plasmid-DNA bildet eine distinkte Bande, die unter Verwendung einer Kanüle aus dem Gradienten isoliert wurde. Das Ethidiumbromid wurde über eine Isoamylalkohol-Extraktion aus der DNA-haltigen Lösung entfernt. Durch Dialyse (2.12.4) der DNA-haltigen Lösung gegen TE-Puffer (2.9) wurde das Cäsiumchlorid aus der Präparation beseitigt. Die dialysierte Plasmid-DNA wurde im Restriktionsverdau (2.16.1) überprüft, ihre Konzentration photometrisch bestimmt $(2.12 .5)$ und bei $-20{ }^{\circ} \mathrm{C}$ gelagert. 
STE-Lösung

Tris, $\mathrm{pH} 8,0$

Saccharose

EDTA, pH 8,0

Triton-Mix

Tris, $\mathrm{pH} 8,0$

EDTA, pH 8,0

$50 \mathrm{mM}$

Triton X-100
$50 \mathrm{mM}$

$25 \%(w / v)$

$1 \mathrm{mM}$
PEG-Lösung

PEG 6000

$30 \%(w / v)$

$\mathrm{NaCl}$

$1,5 \mathrm{M}$

\section{TNE-Puffer}

Tris, $\mathrm{pH} 8,0 \quad 10 \mathrm{mM}$

$\mathrm{NaCl} \quad 10 \mathrm{mM}$

EDTA, pH 8,0 $1 \mathrm{mM}$

Alternativ wurden für Maxi- oder Midi-Präparationen von Plasmiden auch Säulen des „Wizard Plus Maxiprep DNA Purification System“ oder „Pure Yield Plasmid Midiprep System“ (2.5, Promega, Mannheim) verwendet. Dabei wurde nach den Angaben des Herstellers verfahren.

\subsubsection{Isolierung rekombinanter Bacmid-DNA}

Die Isolierung rekombinanter Bacmide aus den $\mathrm{DH} 10 \mathrm{Bac}^{\mathrm{TM}}$-Zellen erfolgte nach dem Protokoll des Herstellers (Bac-To-Bac $®$ Baculovirus Expression System Manual, Anhang S. 51, Invitrogen).

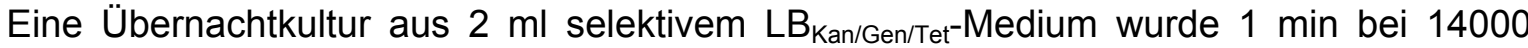
UpM zentrifugiert (Biofuge pico, Heraeus). Das erhaltene Bakterienpellet wurde in $300 \mu \mathrm{l}$ Lösung I resuspendiert, mit $300 \mu$ l Lösung II versetzt und vorsichtig gemischt. Nach einer 5-minütigen Inkubation bei RT wurden 300 Ml $3 \mathrm{M}$ Kaliumacetat $(\mathrm{pH} 5,5)$ zugegeben um Proteine und genomische DNA zu fällen. Nach 10-minütiger Inkubation auf Eis, wurde der Ansatz 10 min bei 14000 UpM zentrifugiert (Biofuge pico, Heraeus) und der Überstand mit $800 \mu \mathrm{l}$ Isopropanol vermischt, gefolgt von einer Inkubationsphase von 10 min auf Eis. Nach erneuter Zentrifugation für 15 min bei RT und 14000 UpM wurde das präzipitierte DNA-Pellet mit $70 \%$ igem Ethanol gewaschen und wiederum abzentrifugiert $(5 \mathrm{~min} /$ RT/14000 UpM). Das getrocknete DNA-Pellet wurde in $40 \mu \mathrm{l}$ TE-Puffer (2.9) aufgenommen und bei $4{ }^{\circ} \mathrm{C}$ gelagert.

Lösung I

Tris, $\mathrm{pH} 8,0$

EDTA, pH 8,0

RNase A
Lösung II

$\begin{array}{ll}\mathrm{NaOH} & 0,2 \mathrm{~N} \\ \mathrm{SDS} & 1 \%(\mathrm{w} / \mathrm{v})\end{array}$




\subsection{DNA-Sequenzierung}

Die DNA-Sequenzierung wurde angewandt, um Klonierungen bzw. das Einfügen von Mutationen in DNA-Abschnitte zu überprüfen. Die DNA-Sequenzierung wurde nach dem Kettenabbruchverfahren (Sanger et al. 1977) mit Fluoreszenzfarbstoff-markierten Didesoxynukleotiden (ddATP, ddGTP, ddCTP und ddTTP) mit Hilfe des Sequenzierungskits Big Dey (Applied Biosystems, Darmstadt) in einem PCR-Block (PTC200 Peltier Thermal Cycler, Biozym) durchgeführt. Hierbei kommt es nach einer statistischen Häufigkeit zum Abbruch der DNA-Synthese, sobald ein ddNTP eingebaut wird, was zur Erzeugung unterschiedlich langer Fragmente führt. Die Nukleotide zum Kettenabbruch werden so in einem Verhältnis mit den Synthesebausteinen gemischt, dass statistisch alle möglichen Fragmentgrößen in Folge des Kettenabbruchs auftreten.

Ein Ansatz der Sequenzierungs-PCR setzte sich wie folgt zusammen:

\begin{tabular}{|c|c|c|c|c|}
\hline \multicolumn{2}{|l|}{ Reaktionsansatz } & \multicolumn{3}{|c|}{ Reaktionsbedingungen } \\
\hline \multirow{2}{*}{$\begin{array}{l}\text { Plasmid-DNA }(100 \mathrm{ng} / \mu \mathrm{l}) \\
\text { Primer }(10 \mathrm{pmol} / \mu \mathrm{l})\end{array}$} & \multirow{7}{*}{$\begin{array}{l}1 \mu \mathrm{l} \\
1 \mu \mathrm{l} \\
2 \mu \mathrm{l} \\
6 \mu \mathrm{l}\end{array}$} & Schritt & Temperatur & Dauer \\
\hline & & 1. & $94{ }^{\circ} \mathrm{C}$ & $2 \min$ \\
\hline Big Dey-Mix* & & 2. & $96{ }^{\circ} \mathrm{C}$ & $15 \mathrm{sec}$ \\
\hline \multirow[t]{4}{*}{$\mathrm{H}_{2} \mathrm{O}$} & & 3. & $56,5^{\circ} \mathrm{C}$ & $15 \mathrm{sec}$ \\
\hline & & 4. & $60{ }^{\circ} \mathrm{C}$ & $15 \mathrm{sec}$ \\
\hline & & 5. & $72{ }^{\circ} \mathrm{C}$ & $4 \min$ \\
\hline & & \multicolumn{3}{|c|}{ Schritt 2-4 wurden 24 mal wiederholt } \\
\hline
\end{tabular}

*: Der Big Dey-Mix (Applied Biosystems, Darmstadt) enthält Fluoreszenz-Farbstoff-gekoppelte ddNTPs, dNTPs, DNA-Polymerase und Puffer

Nach Abschluss der Sequenzierungsreaktion wurde der Sequenzieransatz mit $\mathrm{H}_{2} \mathrm{O}$ auf $40 \mu$ aufgefüllt und über einen Sephadex-Filter (Sephadex G-50, Amersham Biosciences, Freiburg) gereinigt. Die DNA-Fragmente wurden über ein Gelkapillarsystem elektrophoretisch der Größe nach aufgetrennt. Die vier unterschiedlichen FluoreszenzFarbstoffgruppen, die jeweils an ein bestimmtes Nukleotid gekoppelt waren, wurden durch einen Laser angeregt und die Fluoreszenzsignale durch ein Detektorsystem des DNASequenzers (ABI PRISM, 3100 Genetic Analyzer, Applied Biosystems, Darmstadt) anhand ihrer unterschiedlichen Emissionswellenlängen identifiziert und quantifiziert. Die Auswertung der DNA-Sequenzen erfolgte anhand des Computerprogramms Staden Package oder NCBI BLAST Allign Two Sequences (2.22). 


\subsection{Proteinbiochemische Methoden}

\subsubsection{In vitro Transkription und Translation}

Mit dem „TnT Coupled Reticulocyte Lysate System“ (Promega, Mannheim) ist es möglich, Gene in vitro zu transkribieren und die so erzeugte mRNA im Retikulozyten-Lysat zellfrei zu translatieren. In diesen Lysaten aus Kaninchen-Retikulozyten erfolgt mit einer T7-RNAPolymerase in vitro die Transkription und Translation von Protein-kodierenden DNASequenzen, die unter Kontrolle eines prokaryotischen T7-Promoters stehen. Durch Zugabe von $\left[{ }^{35} \mathrm{~S}\right]$-markiertem Methionin wurden die Translationsprodukte radioaktiv markiert und konnten so autoradiographisch (2.14.2) nachgewiesen werden. Die markierten Proteine wurden anschließend im EMSA (2.20) eingesetzt.

Ein $50 \mu \mathrm{l}$ Reaktionsansatz setzte sich aus folgenden Komponenten zusammen:

$\begin{array}{lr}\text { TnT Retikulozyten Lysat } & 25 \mu \mathrm{l} \\ \text { TnT Reaktionspuffer } & 2 \mu \mathrm{l} \\ \text { Plasmid-DNA } & 1 \mu \mathrm{g} \\ \text { TnT T7-RNA-Polymerase } & 1 \mu \mathrm{l} \\ \text { Aminosäure-Mix ohne Methionin }(1 \mathrm{mM}) & 2 \mu \mathrm{l} \\ {\left[{ }^{35} \mathrm{~S}\right]-\text { Methionin }(1200 \mathrm{Ci} / \mathrm{mmol})} & 2 \mu \mathrm{l} \\ \mathrm{H}_{2} \mathrm{O} & \text { ad } 50 \mu \mathrm{l}\end{array}$

Der Reaktionsansatz wurde 90 min bei $30{ }^{\circ} \mathrm{C}$ inkubiert. Nach Ende der Inkubation wurde das Lysat mit $20 \%(\mathrm{v} / \mathrm{v})$ Glycerin versetzt und bei $-20{ }^{\circ} \mathrm{C}$ gelagert. Die Analyse der Translationsreaktion und die Quantifizierung erfolgten durch SDS-PAGE (2.19.6) unter Verwendung von $5 \mu \mathrm{l}$ des Reaktionsansatzes. Nach der SDS-PAGE erfolgte die Detektion $\operatorname{der}\left[{ }^{35} \mathrm{~S}\right]$-markierten in vitro transkribierten/translatierten Proteine durch Autoradiographie mit Hilfe des Phosphor-Imagers (2.14.2). Zur Quantifizierung und densitometrischen Auswertung der Proteinbanden kam das Programm TINA Version 2.09g (Raytest Isotopenmeßgeräte $\mathrm{GmbH}$, Straubenhardt) zum Einsatz.

\subsubsection{Isolierung von Kernproteinen aus kultivierten Zellen}

Für die Kernproteinisolierung aus JEG-3- und InR1G9-Zellen (Schreiber et al., 1989) wurden die Zellen einen Tag vor der Präparation auf $6 \mathrm{~cm}$ Gewebekulturschalen bis zu einer Dichte von ca. $5 \times 10^{5}$ Zellen pro Platte kultiviert. Die Zellen wurden einmal mit TBS 
gewaschen, anschließend in $10 \mathrm{ml}$ TBS mit einem Gummiabzieher von dem Boden der Gewebekulturschale abgelöst, in ein steriles $15 \mathrm{ml}$ Sarstedtgefäß überführt und zentrifugiert (1600 UpM, 2min, RT, Sigma 4K-1, Sigma, Aichach). Dann wurde das Zellsediment in $1 \mathrm{ml}$ TBS resuspendiert und in vorgekühlte Eppendorfgefäße gegeben. Nach einer weiteren Zentrifugation (1600 UpM, 2 min, $4{ }^{\circ} \mathrm{C}$, Centrifuge 5417R, Eppendorf, Hamburg) wurde das Pellet in $400 \mu \mathrm{l}$ Puffer A (vorgekühlt auf $4^{\circ} \mathrm{C}$ ) aufgenommen. Diese Lösung wurde $15 \mathrm{~min}$ auf Eis inkubiert. Danach wurden $25 \mu \mathrm{l} 10 \%$ (w/v) NP-40 zugegeben, die Probe für 10 min gevortext und zentrifugiert (4000 UpM, $1 \mathrm{~min}, 4^{\circ} \mathrm{C}$ ). Der cytoplasmatische Überstand wurde verworfen und die Kernfraktion in $50 \mu \mathrm{l}$ kaltem Puffer $\mathrm{C}$ resuspendiert. Zur Proteinextraktion aus den isolierten Kernen wurde die Probe für 15 min bei $4{ }^{\circ} \mathrm{C}$ geschüttelt (300 UpM, Thermomixer compact, Eppendorf, Hamburg). Nach erneuter Zentrifugation (4000 UpM, $5 \mathrm{~min}, 4^{\circ} \mathrm{C}$ ) wurde der Überstand aliquotiert, in flüssigen Stickstoff eingefroren und bei $-80 \quad{ }^{\circ} \mathrm{C}$ gelagert. Für die Konzentrationsbestimmung der Kernproteine (2.19.5) wurden $2 \mu$ l eingesetzt.

$\underline{\text { TBS }}$

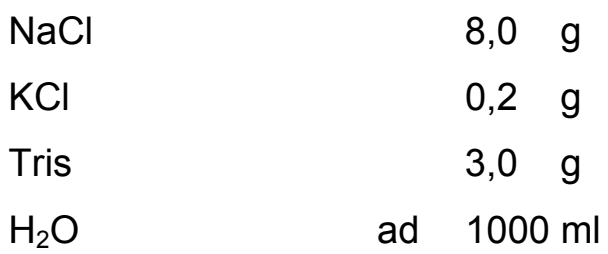

Der $\mathrm{pH}$-Wert wurde mit $\mathrm{HCl}$ auf 7,4 eingestellt.

Puffer A

Hepes $(100 \mathrm{mM}, \mathrm{pH} 7,9) \quad 1,0 \mathrm{ml}$

$\mathrm{KCl}(1 \mathrm{M}) \quad 0,1 \mathrm{ml}$

EDTA $(5 \mathrm{mM}, \mathrm{pH} 8,0) \quad 0,2 \mathrm{ml}$

EGTA $(5 \mathrm{mM}, \mathrm{pH} 7,8) \quad 0,2 \mathrm{ml}$

DTT $(100 \mathrm{mM}) \quad 0,1 \mathrm{ml}$

PMSF (100 mM in EtOH) $50 \mu \mathrm{l}$

$\mathrm{H}_{2} \mathrm{O} \quad$ ad $10 \mathrm{ml}$
Puffer C

Hepes (100 mM, pH 7,9) 2,0 ml $\mathrm{NaCl}(5 \mathrm{M}) \quad 0,8 \mathrm{ml}$

EDTA $(5 \mathrm{mM}, \mathrm{pH} 8,0) \quad 2,0 \mathrm{ml}$

EGTA $(5 \mathrm{mM}, \mathrm{pH} 7,8) \quad 2,0 \mathrm{ml}$

DTT $(100 \mathrm{mM}) \quad 0,1 \mathrm{ml}$

PMSF (100 mM in EtOH) $\quad 0,1 \mathrm{ml}$

$\mathrm{H}_{2} \mathrm{O} \quad$ ad $10 \mathrm{ml}$

\subsubsection{Herstellung von Ganzzellextrakten aus COS-1-Zellen}

COS-1 Zellen wurden mittels DEAE-Dextran transient transfiziert, wie unter 2.21.4 beschrieben. $48 \mathrm{~h}$ nach der Transfektion wurde das Medium abgesaugt und die Zellen mit $2 \mathrm{ml}$ eiskaltem PBS gewaschen. Die Zelllyse erfolgte durch Zugabe von $250 \mu \mathrm{l}$ Cell-Lysis- 
Buffer M (Sigma, München) und Inkubation der Zellen für 15 min auf Eis. Danach wurden die Zellen mithilfe eines Gummischabers von der Schale abgelöst und in ein Eppendorfgefäß gegeben. Nach 10-minütiger Zentrifugation bei $4 \quad{ }^{\circ} \mathrm{C}$ (Eppendorfzentrifuge, 5417 R, Eppendorf Hamburg) wurde der Überstand in eine neues Eppendorfgefäß überführt und konnte im Westernblot (2.19.8) eingesetzt werden.

\subsubsection{Proteinexpression mit Baculoviren}

Die Proteinexpression mit dem BAC-TO-BAC Baculovirus-Exxpressionsvektor-Syystem (BEVS) beruht auf der Infektion von Insektenzellen mit rekombinanten Baculoviren. Das System verwendet eine modifizierte Form des Autographa californica Nuclear Polyhedrosis Virus (AcNPV). Die doppelsträngigen DNA-Baculoviren infizieren spezifisch Insektenzellen und sind für den Menschen ungefährlich, da die Viruspromotoren in Säugetieren weitgehend inaktiv sind (Carbonell et al., 1985). Rekombinante Viren werden durch die Transformation von E. coli DH10Bac-Zellen (2.17.2.2) mit dem rekombinanten Donorplasmid pFastBac ${ }^{\mathrm{TM}} \mathrm{HT}$ (Tab. 2.6) erzeugt. Durch eine spezifische Transposition wird das Zielgen an eine definierte Position in die in den E. coli-Zellen propagierte VirusDNA (Bacmid) eingefügt. Das rekombinante Bacmid kann isoliert (2.17.5) und in Insektenzellen eingebracht werden. Während des folgenden Entwicklungszyklus der Viren kommt es sowohl zur Bildung von rekombinantem Zielprotein als auch zur Bildung neuer rekombinanter Viren, die im Anschluss für weitere Infektionen verwendet werden können. Zur Vorbereitung und Klonierung des Zielgens in das Donorplasmid kamen die unter 2.17 beschriebenen Methoden zur Anwendung, ebenso bei der Transformation und Isolierung des rekombinanten Vektors und Bacmids. Die weitere Durchführung erfolgte nach Herstellerprotokoll. Die Kultivierung und Transfektion der Insektenzellen erfolgte wie unter 2.21.1 und 2.21.4 beschrieben.

Infektion und Proteinexpression in Sf9-Zellen

Um rekombinante Proteine in Sf9-Zellen zu exprimieren, wurden diese mit rekombinanten Baculoviren (2.21.4) infiziert. Dabei wurden Sf9-Zellen aus einer Monolayerkultur auf eine Zellzahl von $1 \times 10^{6}$ Zellen/ml eingestellt. $2 \mathrm{ml}$ dieser Suspension wurden in jeweils eine Vertiefung einer 6-Well-Multischale (NUNC, Wiesbaden) pipettiert. Zur Anheftung der Zellen am Boden wurde die Schale eine Stunde bei $27^{\circ} \mathrm{C}$ inkubiert. Danach wurde das Medium abgesaugt und die Zellen mit $200 \mu$ l einer mit TC-100 Medium verdünnten Viruslösung überschichtet. Die Infektion der Sf9-Zellen erfolgte dann während einer einstündigen Inkubation bei $27{ }^{\circ} \mathrm{C}$. Darauf folgend wurde der virenhaltige Überstand 
abgesaugt und die Zellen mit frischem TC-100 Medium versetzt. Zur Amplifizierung der Viren wurde ein MOI (multiplicity of infection) von 0,1 - 0,4 und eine Infektionsdauer von 2 Tagen angewendet. Sollten rekombinante Proteine erzeugt werden, wurde ein MOI von 1 und eine Infektionsdauer von 3 Tagen angewendet. Um die rekombinanten Proteine zu ernten, wurde zunächst das Medium entfernt und die Zellen in Kalium-Phosphat/NaClPuffer aufgenommen, 2 mal im selben Puffer gewaschen und das Zellpellet dann in $100 \mu \mathrm{l}$ Kalium-Phosphat/NaCl-Puffer aufgenommen. Der Zellaufschluss erfolgte durch dreimaliges Einfrieren in flüssigem Stickstoff und Wiederauftauen bei $37^{\circ} \mathrm{C}$. Nach $5-$ minütiger Zentrifugation bei $4^{\circ} \mathrm{C}$ und 14000 UpM (Centrifuge 5417R, Eppendorf, Hamburg) konnte der Überstand direkt im EMSA (2.20) oder Westernblot (2.19.8) eingesetzt werden.

Das benötigte Volumen des Virusüberstands zur Infektion berechnete sich nach folgender Formel:

Benötigtes Volumen $(\mathrm{ml})=\frac{\text { gewünschter } \mathrm{MOl}(\text { pfu/Zelle }) \times \text { Gesamtzellzahl }}{\operatorname{Virustiter}(\mathrm{pfu} / \mathrm{ml})}$

Kalium-Phosphat/NaCl-Puffer

$\begin{array}{lr}\mathrm{K}_{2} \mathrm{HPO}_{4} & 100 \mathrm{mM} \\ \mathrm{KH}_{2} \mathrm{PO}_{4} & 100 \mathrm{mM} \\ \text { Der pH wurde durch Titrieren der } & \\ \text { beiden Lösungen auf 7,8 eingestellt. } \\ \mathrm{NaCl} & 100 \mathrm{mM} \\ \text { DTT } & 10 \mathrm{mM}\end{array}$

2.19.5 Konzentrationsbestimmung von Proteinlösungen (Bradford, 1976)

Proteinkonzentrationen wurden unter Verwendung des "Bio-Rad Protein Assays" (2.5) bestimmt. Der Bio-Rad-Farbstoff (Coomassie Brilliant blue G-250) wurde mit $\mathrm{H}_{2} \mathrm{O}$ 1:5 verdünnt und über Minisart-Einmalfilter (0,2 $\mu \mathrm{m}$, Sarstedt, Göttingen) filtriert. Zur Konzentrationsbestimmung wurden $20 \mu \mathrm{l}$ einer 1:40-, 1:20- und 1:4-Verdünnung der Proteinlösung hergestellt und mit $280 \mu \mathrm{l}$ der verdünnten Farbreagenz versetzt. Durch die Bindung des Farbstoffes an Proteine verschiebt sich das Absorptionsspektrum des Farbstoffes von $\lambda=465 \mathrm{~nm}$ nach $\lambda=595 \mathrm{~nm}$. Die Proben wurden zur Bildung des Farbkomplexes für 5 min bei RT inkubiert und die Extinktion bei einer Wellenlänge von $\lambda=$ $595 \mathrm{~nm}$ (Molecular Devices, Kinetic microplate reader) gegen den Pufferleerwert photometrisch ermittelt. Die Bestimmung der Proteinkonzentration erfolgte anhand einer 
BSA-Eichkurve, die bei jeder Messung durch eine definierte Verdünnungsreihe mit BSA (2.1) erhalten wurde. Die Eichkurve wurde mit BSA-Konzentrationen von 0-100 $\mu \mathrm{g} / \mathrm{ml}$ erstellt.

2.19.6 Denaturierende Polyacrylamid-Gelelektrophorese (SDS-PAGE) von Proteinen (Laemmli, 1970)

Proteine wurden gelelektrophoretisch in einem diskontinuierlichen System unter denaturierenden Bedingungen auf SDS-haltigen Polyacrylamidgelen größenabhängig aufgetrennt. Das Gelsystem setzte sich aus einem 4\%igen Sammelgel sowie einem 8 15\%igem Trenngel zusammen. Die Trenngellösung wurde zunächst pipettiert, sofort in die Gießkammer (Mighty Small-System, SE 250, Hoefer, San Francisco, USA) mit den zusammengesetzten Einzelgelkammern gegeben und mit Butanol überschichtet. Nach der Polymerisation wurde das Butanol abgesaugt und die Sammelgellösung auf das Trenngel gegossen. Nach dem sofortigen Einsetzen des Kammes war das Gel nach etwa $1 \mathrm{~h}$ Polymerisation gebrauchsfertig und konnte in eine Gelelektrophoresekammer eingespannt werden (SE 250, Hoefer, San Francisco, USA). Die Elektrodenkammer wurde mit 1x SDS-Laufpuffer gefüllt und die Proteinproben nach ihrer Denaturierung in die Geltaschen pipettiert. Die elektrophoretische Auftrennung der Proteine erfolgte bei einer konstanten Stromstärke von $25 \mathrm{~mA}$ und konnte durch mitlaufende ProteinMolekulargewichtsstandards (2.11.2) verfolgt werden. Die Gele wurden anschließend mit Coomassieblau-Lösung angefärbt (2.19.7) oder im Westernblot (2.19.8) eingesetzt. Die Proteinproben wurden vor dem Gelauftrag mit 2x Lämmli-Probenpuffer versetzt und 5 min bei $95^{\circ} \mathrm{C}$ denaturiert.

\section{$\underline{\text { 2x Lämmli Probenpuffer }}$}

Tris, $\mathrm{pH} 8,0$

SDS

Glycerin

Bromphenolblau

$\beta$-Mercaptoethanol

\section{SDS Laufpuffer}

Tris $25 \mathrm{mM}$

Glycin $\quad 192 \mathrm{mM}$

SDS $\quad 0,1 \%$

Acrylamidlösung $30 \%(w / v)$

Acrylamid

$29,2 \mathrm{~g}$

Bisacrylamid

$0,8 \mathrm{~g}$

$\mathrm{H}_{2} \mathrm{O}$

ad $100 \mathrm{ml}$ 
Sammelgel $4 \%$

Acrylamidlösung

Tris, $\mathrm{pH} 6,8(0,5 \mathrm{M})$

SDS (10\%)

$\mathrm{H}_{2} \mathrm{O}$

APS (10 \%)

TEMED
$620 \mu \mathrm{l}$

$1,25 \mathrm{ml}$

$50 \mu \mathrm{l}$

$3,13 \mathrm{ml}$

$50 \mu \mathrm{l}$

$7,5 \mu \mathrm{l}$
Trenngel $10 \%$

Acrylamidlösung $\quad 3,3 \mathrm{ml}$

Tris, $\mathrm{pH} 8,8(1,5 \mathrm{M}) \quad 2,5 \mathrm{ml}$

$\operatorname{SDS}(10 \%) \quad 100 \mu \mathrm{l}$

$\mathrm{H}_{2} \mathrm{O} \quad 4,2 \mathrm{ml}$

APS $(10 \%) \quad 100 \mu l$

TEMED $\quad 15 \mu \mathrm{l}$

\subsubsection{Coomassiefärbung von Proteingelen}

Zum Nachweis von Proteinen im SDS-Polyacrylamidgel (2.19.6) wird die Eigenschaft von blauem Coomassie-Farbstoff ausgenutzt, unlösliche Farbstoff-Protein-Komplexe zu bilden.

Nach der Elektrophorese wurden die Gele zum Anfärben für 20 min in der Färbelösung geschwenkt (2,5 Zyklen/min, Mini Rocking Platform, Biometra, Göttingen). Zum Entfernen des nicht an Proteine gebundenen Farbstoffs, wurden die Gele in Entfärber bei mehrfachem Wechsel der Lösung geschwenkt, bis sich die Proteinbanden deutlich vom Hintergrund abhoben. Die Dokumentation erfolgte mittels einer Geldokumentationsanlage (E.A.S.Y store, Herolab, Wiesloch). Zur Lagerung wurden die Gele luftblasenfrei in Zellophanpapier eingeschlagen, zwischen zwei Plexiglasplatten gelegt und 5 Tage bei RT getrocknet.

\section{Färbelösung}

Coomassie Brilliant Blue R-250

$0,25 \%(w / v)$

Essigsäure

$10 \%(v / v)$

Methanol

$45 \%(v / v)$

\section{Entfärber}

Essigsäure

$10 \%(\mathrm{v} / \mathrm{v})$

Methanol

$45 \%(v / v)$ 


\subsubsection{Westernblot}

Für den Transfer von Proteinen aus SDS-Gelen auf Nitrozellulose-Membranen (Hybond$E C L^{\mathrm{TM}}$, Amersham, Biosciences) wurden Westernblots nach dem Semi-Dry-Verfahren durchgeführt. Dazu wurde eine auf das Gel zugeschnittene Nitrozellulose-Membran in Blotpuffer B für 10 min äquilibriert. Der Blot-Sandwich wurde folgendermaßen aufgebaut: Nach dem Anfeuchten der unteren Elektrodenplatte (Anode) wurden zwei Lagen in Blottpuffer A getränkte Filterpapiere (1,2 mm Dicke, Schleicher und Schüll, Dassel) aufgelegt. Auf weitere zwei in Blotpuffer B getränkte Filterpapiere wurde die Nitrozellulose-Membran, folgend von dem zuvor in Blotpuffer C getränktem SDS-Gel luftblasenfrei aufgelegt. Den Abschluss bildeten vier in Blotpuffer C getränkte Filterpapiere. Auf diesen Stapel wurde die Kathodenplatte vorsichtig aufgesetzt. Der Transfer der Proteine erfolgte für $75 \mathrm{~min}$ bei $1,2 \mathrm{~mA} / \mathrm{cm}^{2}$. Der Proteintransfer konnte im Anschluss durch eine reversible Färbung mit Ponceau S-Lösung (AppliChem, Darmstadt) überprüft werden.

Blotpuffer A

Tris, $\mathrm{pH} \mathrm{11,3}$

Methanol

\section{Blotpuffer C}

Tris-Borat $\mathrm{pH} \mathrm{9,0}$

Methanol
Blotpuffer B

$$
300 \mathrm{mM}
$$

$20 \%(v / v)$

Tris, $\mathrm{pH} \mathrm{10,5}$

$25 \mathrm{mM}$

Methanol $\mathrm{pH}$

\subsubsection{Immundetektion von Proteinen im Westernblot}

Für die Immundetektion wurde die Membran in 5 \% (w/v) Magermilchpulver in PBS-T (2.9) $1 \mathrm{~h}$ unter Schwenken inkubiert (2,5 Zyklen/min, Mini Rocking Platform, Biometra, Göttingen), um unspezifische Bindungsstellen zu blocken. Die Membran wurde dann mit einer entsprechenden Verdünnung des Primärantikörpers in $5 \%(\mathrm{w} / \mathrm{v})$ Magermilchpulver in PBS-T über Nacht bei $4{ }^{\circ} \mathrm{C}$ unter schwenken inkubiert. Dann wurde die Membran dreimal mit PBS-T gewaschen, gefolgt von einer einstündigen Inkubation mit dem Sekundärantikörper (Verdünnung 1:10000; HRP: Horseradish-Peroxidase-gekoppelt) in $5 \%(w / v)$ Magermilch in PBS-T unter Schwenken bei RT. Darauf folgten fünf Waschschritte mit PBS-T für 5 min. Die Detektion erfolgte durch Chemilumineszenz, die 
durch die Enzym-Substrat-Reaktion der HRP mit dem ECL-Reagenz (Amersham Pharmacia Biotech) entsteht, gemäß den Angaben des Herstellers.

\subsubsection{Densitometrie}

Zur Quantifizierung von Bandenintensitäten auf Filmen (Autoradiographien 2.14.2 oder Immundetektionen 2.19.9) wurden die Filme eingescannt (HP Scanjet 3770) und mit dem Programm BioDocAnalyzer (Biometra, Göttingen) ausgewertet.

\subsection{0 "Elektrophoretic Mobility Shift Assay" (EMSA) (Knepel et al. 1990b, modifiziert)}

Mit Hilfe des "Electrophoretic Mobility Shift Assays" werden Protein-DNAWechselwirkungen untersucht. Proteingebundene DNA migriert in einem nichtdenaturierenden Polyacrylamid-Gel langsamer als freie, ungebundene DNA-Fragmente. Die verlangsamte Wanderungsgeschwindigkeit eines Protein-DNA-Komplexes (Retardierung) ist in der Elektrophorese durch eine abweichende Bandenposition („Bandshift“) gekennzeichnet.

In dieser Arbeit wurde der EMSA verwendet, um die Bindungseigenschaften von in vitro transkribierten/translatierten Proteinen (2.19.1), von heterolog exprimiertem Pax6 (2.19.4) und von Kernproteinen aus JEG-3- und InR1G9-Zellen (2.19.2) an [ $\left.\alpha^{32} P\right]-d C T P-$ markierten Oligonukleotiden (2.12.7) zu charakterisieren.

\subsubsection{Bindungsreaktion}

Die Bindungsreaktion wurde mit 3 bis $12 \mu$ in vitro transkribierten/translatierten Proteinen (2.19.1), mit Zellextrakten aus Sf9-Insektenzellen (2.19.4) oder mit 5 bzw. $20 \mu \mathrm{g}$ Kernextrakten (2.19.2) sowie mit 5-10 fmol (15000-30000 cpm) radioaktiv markierter DNA (2.12.7) in $20 \mu \mathrm{l}$ durchgeführt. Die Ansätze wurden auf Eis pipettiert und nach Zugabe der radioaktiv markierten Oligonukleotid-Sonde für $15 \mathrm{~min}$ auf Eis inkubiert. Die Bindungsansätze wurden anschließend mit $4 \mu \mathrm{l} 6 \mathrm{x}$ Stopp-Mix (2.9) versetzt und auf einem nativen Polyacrylamid-Gel aufgetrennt (2.20.2). 


\begin{tabular}{|c|c|}
\hline Hepes, $\mathrm{pH} 7,9$ & $80 \mathrm{mM}$ \\
\hline $\mathrm{KCl}$ & $560 \mathrm{mM}$ \\
\hline EDTA, pH 8,0 & $4 \mathrm{mM}$ \\
\hline DTT & $2 \mathrm{mM}$ \\
\hline Glycerin & $40 \%(v / v)$ \\
\hline
\end{tabular}

Nach Zusatz von $2 \mu \mathrm{g}$ Poly ( $\mathrm{dl} / \mathrm{dC}$ ) pro Ansatz, wurden die Proben $10 \mathrm{~min}$ auf Eis inkubiert. Erst danach wurde die radioaktiv markierte Sonde zugegeben.

\subsubsection{Nicht-denaturierende Auftrennung von Protein-DNA-Komplexen}

Zur Erhaltung der nativen Proteinstruktur erfolgte die elektrophoretische Auftrennung der Protein-DNA-Komplexe aus den Bindungsreaktionen (2.20.1) unter nicht-denaturierenden Bedingungen in vertikalen 5\%igen Polyacrylamidgelen. Die Elektrophorese wurde mit Gelplatten (18 cm x $16 \mathrm{~cm} \times 3 \mathrm{~mm}$ ) in Elektrophoresekammern der Firma Hoefer (SE 600, Hoefer, San Francisco, USA) durchgeführt.

Nach Fertigstellung der Gellösung wurde diese luftblasenfrei zwischen zwei mit Ethanol gereinigten Glasplatten gegossen. Der Teflonkamm für die Auftragstaschen wurde unverzüglich eingesetzt. Nach der Polymerisation wurde das Gel in die Elektrophoresekammer eingesetzt und die Geltaschen wurden gründlich gespült. Vor dem Beladen des Gels mit den Proben erfolgte eine Vorelektrophorese für $1 \mathrm{~h}$ bei RT und konstanter Spannung von $180 \mathrm{~V}$ mit 1x TBE-Laufpuffer (2.9). Nach dem Auftragen der Proben wurde die elektrophoretische Auftrennung der Protein-DNA-Komplexe unter identischen Bedingungen durchgeführt. Abschließend wurde das Gel auf Blottingpapier (2.6) überführt, unter Vakuum getrocknet (Vakuumtrockner G 200, Fröbel Blaufeld) und autoradiographiert (2.14.2).

Polyacrylamid-Gellösung, 5\% (Knepel et al. 1990b)

$\begin{array}{ll}38 \% \text { / } 2 \% \text { Acrylamid/Bisacrylamid } & 6,25 \mathrm{ml} \\ 5 \times \text { TBE } & 5 \mathrm{ml} \\ \mathrm{H}_{2} \mathrm{O} & 38,5 \mathrm{ml} \\ \text { APS }(10 \%) & 0,5 \mathrm{ml} \\ \text { TEMED } & 50 \mathrm{\mu l}\end{array}$




\subsection{Methoden zur Behandlung eukaryotischer Zellkulturen}

Sämtliche Arbeiten in der Zellkultur erforderten sterile Bedingungen. Unter einer sterilen Werkbank (Baker, Labotect GmbH, Göttingen) wurden daher ausschließlich sterile, vor Benutzung auf $37{ }^{\circ} \mathrm{C}$ vorgewärmte Kulturmedien (2.10) und Pufferlösungen (2.9) verwendet. Die Gefäße und Pipettenspitzen wurden vor der Verwendung trocken sterilisiert $\left(4 \mathrm{~h}\right.$ bei $180^{\circ} \mathrm{C}$ ) und direkt vor Benutzung unter der Werkbank abgeflammt. Wenn nicht anders angegeben, erfolgten alle Zentrifugationsschritte für 2 min bei RT mit 1300 UpM (Megafuge 1.0, Hereaus Sepatech GmbH, Hamburg).

\subsubsection{Kultivierung eukaryotischer Zellen}

Die Kultivierung von JEG-3-, InR1G9- und COS-1-Zellen (2.11.4) erfolgte in $30 \mathrm{ml}$ des jeweiligen Kulturmediums (2.10) in $15 \mathrm{~cm}$-Kulturschalen (2.8). Die Zellen wurden bei $37{ }^{\circ} \mathrm{C}, \mathrm{CO}_{2}$-Begasung (5\%) und 93\% relativer Luftfeuchtigkeit im Brutschrank (Steri-Kult Inkubator, Labotect $\mathrm{GmbH}$, Göttingen) kultiviert. Nach Erreichen einer Konfluenz von 80\% wurden die Zellen passagiert. Nach Absaugen des Kulturmediums wurden die Zellen mit $10 \mathrm{ml}$ 1x PBS-Puffer gewaschen. Das Ablösen der Zellen erfolgte unter Zugabe von $3 \mathrm{ml}$ Trypsin/EDTA (GIBCO BRL, Karlsruhe) und 2-3 min Inkubation im Brutschrank. Der Trypsinverdau wurde durch Zugabe von $7 \mathrm{ml}$ des entsprechenden Kulturmediums abgestoppt. Die Zellsuspension wurde zentrifugiert, das Sediment in $10 \mathrm{ml}$ Kulturmedium aufgenommen und erneut zentrifugiert. Auf frische $15 \mathrm{~cm}$-Kulturschalen wurden jeweils $25 \mathrm{ml}$ des Kulturmediums verteilt und mit je $5 \mathrm{ml}$ des resuspendierten Zellpellets auf $30 \mathrm{ml}$ Endvolumen aufgefüllt, so dass eine Teilungsrate von 1:7 (JEG-3), 1:6 (InR1G9-Zellen) bzw. 1:11 (COS-1-Zellen) erfolgte. Nach einer Wachstumsphase von 3-5 Tagen im Brutschrank wurden die Zellen erneut passagiert oder in transienten Transfektionen (2.21.4) eingesetzt.

\section{Kultivierung von Insektenzellen}

Die Haltung der Spodoptera frugiperda (Sf9-) Zellen (2.11.4) erforderte andere Bedingungen. Die Kultivierung der Zellen als Monolayer erfolgte in $75 \mathrm{~cm}^{2}$ Zellkulturflaschen (EasYFlask, NUNC, Wiesbaden) in $15 \mathrm{ml}$ TC-100 Medium (2.10) bei $27{ }^{\circ} \mathrm{C}$ ohne weitere $\mathrm{CO}_{2}$-Begasung im Brutschrank (Modell 3164, Labotect $\mathrm{GmbH}$, Göttingen). Alle 3 bis 4 Tage oder bei einer Zelldichte von 2 bis $3 \times 10^{6}$ Zellen $/ \mathrm{ml}$ erfolgte die Subkultivierung der Zellen. Dazu wurde das Medium abgesaugt und durch $15 \mathrm{ml}$ frisches TC-100 Medium (auf $27{ }^{\circ} \mathrm{C}$ vorgewärmt) ersetzt. Durch vorsichtiges Auf- und 
Abpipettieren des Mediums wurden die Zellen vom Boden der Kulturflasche abgelöst und resuspendiert. Die Zellsuspension wurde zentrifugiert (5 min, 800 UpM, RT, Universalzentrifuge 16R, Hettich, Tutlingen) und das Zellpellet in $15 \mathrm{ml}$ frisches Medium aufgenommen. In eine neue $75 \mathrm{~cm}^{2}$-Zellkulturflasche wurden $12 \mathrm{ml}$ Medium vorgelegt und $3 \mathrm{ml}$ der Zellsuspension gegeben. Die Teilungsrate betrug so 1:5.

\subsubsection{Gefrierkonservierung von Zellen}

Zur langfristigen Lagerung von eukaryotischen Kulturzellen wurden Gefrierstocks angelegt, die bei $-196{ }^{\circ} \mathrm{C}$ in flüssigem Stickstoff konserviert wurden. Die Zellen wurden nach Ablösen von der Kulturschale zentrifugiert und mit DMSO-haltigem (10 \% (v/v)) Kulturmedium gewaschen. Der Zusatz von DMSO (2.1) diente beim Einfriervorgang als Schutz der Zellen gegen Eiskristalle. Nach nochmaliger Zentrifugation wurde das Zellpellet in $10 \mathrm{ml}$ des DMSO-haltigen Mediums aufgenommen, in Kryoröhrchen (Nalgene, Hereford, U.K.) zu je $1 \mathrm{ml}$ aliquotiert und für $24 \mathrm{~h}$ bei $-80{ }^{\circ} \mathrm{C}$ in einem Styroporbehälter gelagert. Die Langzeitlagerung erfolgte in einem Stickstofftank (GT 140, Schütt Labortechnik, Göttingen) bei $-196{ }^{\circ} \mathrm{C}$.

\subsubsection{Revitalisierung von Zellen}

Die Revitalisierung der Zellen wurde zügig durchgeführt, um die durch den Konservierungsstoff DMSO (2.1) auftretenden toxischen Effekte auf die Zellen zu vermeiden. Ein Kryoröhrchen mit eingefrorenen Zellen wurde in einem $37^{\circ} \mathrm{C}$ Wasserbad geschwenkt, bis nur noch ein kleiner Eiskern sichtbar war. Die Zellen wurden in $15 \mathrm{ml}$ vorgewärmtes Kulturmedium aufgenommen, zentrifugiert und mit 1x PBS gewaschen. Das Zellsediment wurde nach erneuter Zentrifugation in $10 \mathrm{ml}$ Kulturmedium resuspendiert, auf eine $10 \mathrm{~cm}$-Kulturschale gebracht und im Brutschrank bei $37{ }^{\circ} \mathrm{C}$ kultiviert. Nach $12 \mathrm{~h}$ wurde das Medium gewechselt, um restliches DMSO, tote Zellen und Zelltrümmer zu entfernen. Nach 3-5 Tagen Kultivierung wurden die Zellen zur weiteren Vermehrung auf $15 \mathrm{~cm}-$ Kulturschalen verteilt.

\subsubsection{Transfektion eukaryotischer Zelllinien}

Eukaryotische Zellen sind in der Lage, unverpackte exogene DNA aufzunehmen und zu exprimieren. Die Expression transfizierter DNA kann allerdings nur bis zu $72 \mathrm{~h}$ nach der Transfektion nachgewiesen werden, da die Zellen die exogene DNA nach einer Kinetik 
erster Ordnung wieder abbauen. Versuche dieser Art werden daher als „transiente Transfektionen" bezeichnet.

Für die transiente Transfektion stehen verschiedene chemische Methoden zur Verfügung. Die Transfektion von InR1G9- und COS-1-Zellen erfolgte mit dem kationischen Polymer DEAE-Dextran (2.1). Bei dieser Transfektionsmethode wird die DNA im Komplex mit DEAE-Dextran mittels Endocytose über einen noch nicht geklärten Mechanismus aufgenommen. JEG-3-Zellen wurden mit Hilfe der Calcium-Phosphat-Methode transfiziert. Dabei wird die DNA in Form feinkörniger Calcium-Phosphat-Präzipitate auf die Zellen aufgebracht und von diesen vermutlich über Phagocytose aufgenommen. Die Präparation der Zellextrakte (2.21.5) wurde in allen Fällen 48-55 h nach Transfektion vorgenommen.

Transfektion mittels DEAE-Dextran (Sambrook et al, 1989, modifiziert)

Nachdem die InR1G9- oder COS-1-Zellen auf einer $15 \mathrm{~cm}$-Schale zu $80 \%$ konfluent gewachsen waren, wurden sie durch eine Trypsin/EDTA-Behandlung (2.21.1) von der Kulturschale abgelöst. Die Reaktion wurde durch Zugabe von $7 \mathrm{ml}$ des entsprechenden, inkompletten Mediums (Medium ohne Serum, 2.10) gestoppt, und die Zellsuspension anschließend zentrifugiert. Das Zellpellet wurde in $10 \mathrm{ml}$ TD-Puffer gewaschen, zentrifugiert und die Zellen in dem gewünschten Volumen TD-Puffer aufgenommen. Standardmäßig wurden die Zellen einer $15 \mathrm{~cm}$-Schale auf $126 \mathrm{~cm}$-Schalen aufgeteilt. Dazu wurden sie in $12 \mathrm{ml}$ TD-Puffer aufgenommen, mit $60 \mu \mathrm{l}$ DEAE-Dextran (5 $\mu \mathrm{l}$ DEAEDextran/6 cm-Kulturschale) versetzt und leicht geschwenkt. Je $1 \mathrm{ml}$ dieser Suspension wurde auf 12 Polypropylenröhrchen verteilt, in welche bereits die zu transfizierenden Reportergen-Plasmide (je $2 \mu \mathrm{g}$ ) für InR1G9-Zellen oder Expressionsvektoren (je 0,5 $\mu \mathrm{g}$ ) für COS-1-Zellen vorgelegt worden waren. Die Ansätze wurden durch Schwenken gut durchmischt und für 15 min bei RT inkubiert. In dieser Zeit erfolgte die Aufnahme der DNA in die Zellen. Anschließend wurde den Ansätzen jeweils $1 \mathrm{ml}$ Kulturmedium zugefügt, die Zellen zentrifugiert und mit je $2 \mathrm{ml}$ Kulturmedium gewaschen. Nach erneuter Zentrifugation wurden die Zellsedimente in $1 \mathrm{ml}$ Kulturmedium aufgenommen und die Zellen auf $6 \mathrm{~cm}$-Kulturschalen, in denen zuvor $4 \mathrm{ml}$ Medium vorgelegt wurde, ausgesät. Die Schalen wurden nach $48 \mathrm{~h}$ Inkubation bei $37^{\circ} \mathrm{C}$ zur Zellextraktpräparation (2.21.5) geerntet. Anschließend wurde die Luciferase-Reportergen-Aktivität der Zellextrakten bestimmt (2.21.6). Durch Cotransfektion von $0,5 \mu \mathrm{g} / 6 \mathrm{~cm}-$ Kulturschale des pGFPtpzcmv® control vector-Plasmids (Tab. 2.5) wurden die Transfektionseffizienz sowie der Einfluss unspezifischer Effekte auf das Luciferase-Reportergen („Squelching“) überprüft. 
$\underline{\text { TD-Puffer }}$

Tris, $\mathrm{pH} 7,4$

$\mathrm{NaCl}$

$\mathrm{KCl}$

$\mathrm{K}_{2} \mathrm{HPO}_{4}$

\section{DEAE-Dextran}

$60 \mathrm{mg} / \mathrm{ml}$ $140 \mathrm{mM}$

$5 \mathrm{mM}$

$0,7 \mathrm{mM}$
Die Lösung wurde sterilfiltriert.

Transfektion mittels Calcium-Phosphat (Ausubel et al, 1987)

Die Aufnahme exogener DNA in eukaryotische Zellen wird deutlich gesteigert, sofern die Nukleinsäure als Co-Präzipitat mit Calcium-Phosphat vorliegt. Die Präzipitate werden an der Zelloberfläche angelagert und durch Phagozytose in die Zellen eingeschleust.

Nach Erreichen einer 80 \%igen Konfluenz der Zellen auf einer $15 \mathrm{~cm}$-Kulturschale wurden JEG-3-Zellen 16-20 h vor einer Transfektion auf $126 \mathrm{~cm}$-Kulturschalen (5 ml Medium/6 $\mathrm{cm}$-Kulturschale) aufgeteilt und bis zur Transfektion bei $37{ }^{\circ} \mathrm{C}, 5 \% \mathrm{CO}_{2}$ und $93 \%$ relativer Luftfeuchtigkeit im Brutschrank (Steri-Kult Inkubator, Labotect $\mathrm{GmbH}$, Göttingen) kultiviert. Zur Herstellung der Präzipitate wurden je $3 \mu \mathrm{g}$ Reportergen-Plasmid/6 cm-Kulturschale mit $207 \mathrm{ng}$ der jeweiligen Expressionsplasmide (Tab. 2.6) in einem Gesamtvolumen von $150 \mu \mathrm{H}_{2} \mathrm{O}$ aufgenommen und mit $150 \mu \mathrm{l}$ 0,5 $\mathrm{M} \mathrm{CaCl}_{2}$-Lösung zu einem Endvolumen von $300 \mu \mathrm{l}$ aufgefüllt. Dieser Ansatz wurde unter permanentem Schütteln tropfenweise zu $300 \mu \mathrm{l} 2 x$ HeBS pipettiert und anschließend zur Präzipitatbildung 20-30 min bei RT inkubiert. Anschließend wurden je $590 \mu \mathrm{l}$ des Ansatzes auf eine $6 \mathrm{~cm}$-Kulturschale mit JEG-3-Zellen aufgetropft, durch leichtes Schwenken der Schale gemischt und bei $37{ }^{\circ} \mathrm{C}$ im Brutschrank inkubiert. Nach 4-5 h wurde das Kulturmedium abgesaugt, die Zellen zur Entfernung nicht-aufgenommener DNA-Präzipitate zweimal mit 1x PBS gespült und mit $5 \mathrm{ml}$ frischem DMEM-Medium (2.10) überschichtet. Die Zellen wurden für weitere $48 \mathrm{~h}$ bei $37{ }^{\circ} \mathrm{C}$ im Brutschrank kultiviert, zur Zellextrakt-Präparation (2.21.5) geerntet und die Luciferase- und GFP-Aktivitäten (2.21.6 und 2.21.7) bestimmt. Die Kontrolle der Transfektionseffizienz erfolgte bei JEG-3-Zellen durch Cotransfektion von 50 ng pGFPtpz$\mathrm{cmv} \circledast$ control vector-Plasmid/6 cm-Kulturschale (Tab. 2.5).

\section{$\underline{2 x \mathrm{HeBS}}$}

Hepes

$50 \mathrm{mM}$

$\mathrm{NaCl}$

$140 \mathrm{mM}$

$\mathrm{Na}_{2} \mathrm{HPO}_{4}$

$1,5 \mathrm{mM}$

Der pH-Wert wurde mit $\mathrm{NaOH}$ auf 7,05 - 7,12 eingestellt. 


\section{Transfektion von Insektenzellen}

Die Transfektion von Sf9-Insektenzellen (2.11.4) mit rekombinanter Virus-DNA (Bacmid) erfolgte mittels des kationischen Lipidreagenz CellFectin (Invitrogen, Karlsruhe). Das Herstellerprotokoll wurde leicht verändert. Die Zellen einer Sf9-Monolayerkultur (2.21.1) mit einer Zelldichte von $9 \times 10^{5}$ bis $2 \times 10^{6}$ Zellen/ml wurden in frischem TC-100-Medium (2.10) vorsichtig resuspendiert und die Zelldichte der Suspension anschließend auf 4,5 $\mathrm{x}$ $10^{5}$ Zellen/ml Medium eingestellt. $2 \mathrm{ml}$ dieser Suspension wurden in jeweils eine Vertiefung einer 6-Well-Multischale (NUNC, Wiesbaden) pipettiert. Zur Anheftung der Zellen am Boden wurde die Schale eine Stunde bei $27^{\circ} \mathrm{C}$ inkubiert. In der Zwischenzeit wurden folgende Transfektionslösungen hergestellt:

$$
\begin{array}{ll}
\text { Lösung A: } & 1 \mu \mathrm{g} \text { rekombinante Bacmid-DNA } \\
& 100 \mu \mathrm{l} \text { TC-100 Insektenmedium (ohne Serum) }
\end{array}
$$

Lösung B: $6 \mu$ l CellFectin-Reagenz $100 \mu \mathrm{l}$ TC-100 Insektenmedium (ohne Serum)

Die Lösungen $A$ und $B$ wurden vereinigt und nach 45-minütiger Inkubation bei Raumtemperatur mit $800 \mu \mathrm{l}$ TC-100 Insektenmedium (ohne Serum) auf ein Volumen von $1 \mathrm{ml}$ aufgefüllt. Der serumhaltige Überstand der am Boden haftenden Sf9-Zellen wurde mit einer Pipette vorsichtig abgenommen, und durch $1 \mathrm{ml}$ Transfektionslösung ersetzt. Von jeder Transfektion wurde ein Doppelansatz durchgeführt. Während der folgenden 5stündigen Inkubation bei $27^{\circ} \mathrm{C}$ erfolgte die Aufnahme der Bacmid-DNA in die Zellen. Anschließend wurde die Transfektionslösung mit einer Pipette abgezogen und durch $2 \mathrm{ml}$ TC-100-Komplettmedium ersetzt. Zur Bildung von Viruspartikeln wurden die Zellen 3 - 4 Tage bei $27^{\circ} \mathrm{C}$ inkubiert. Der Viruspartikel-haltige Überstand wurde abgenommen und stand dann für weitere Infektionen zur Verfügung. Er konnte bei $4{ }^{\circ} \mathrm{C}$ bis zu einem Jahr gelagert werden.

\section{Bestimmung des Virentiters}

Zur gezielten Infektion der Sf9-Zellkulturen mit Baculoviren zur Virusamplifizierung oder Proteinproduktion war die Kenntnis der Virenkonzentration (Titer) nötig. Hierzu wurde mit einer Sf9-Monolayerkultur (Kap. 2.21.1), die eine Zelldichte von $9 \times 10^{5}$ bis $2 \times 10^{6}$ Zellen/ml besaß ein „Plaque-Assay“ durchgeführt. Die Zellen wurden in frischem TC-100 Medium resuspendiert und die Zellzahl auf $4 \times 10^{5}$ Zellen/ml eingestellt. Je $500 \mu \mathrm{l}$ dieser 
Zellsuspension wurden in die Vertiefungen einer 24-Well-Multischale (NUNC, Wiesbaden) pipettiert und zur Anheftung der Zellen am Boden $1 \mathrm{~h}$ bei $27{ }^{\circ} \mathrm{C}$ inkubiert. In der Zwischenzeit wurden Verdünnungen des Virusüberstandes zwischen $10^{-2}$ und $10^{-8}$ in TC100 Medium hergestellt. Anschließend wurde der Mediumüberstand der Zellen durch $100 \mu \mathrm{l}$ der verdünnten Viruslösungen ersetzt. Nach einstündiger Inkubation bei Raumtemperatur unter gelegentlichem leichten Schütteln wurde der Virusüberstand schließlich abgenommen und die Zellen vorsichtig mit $500 \mu \mathrm{l}$ Topagar überschichtet. Nach dem Aushärten des Agars (etwa 1 Stunde bei Raumtemperatur) wurden die 24-WellMultischalen 6 Tage bei $27^{\circ} \mathrm{C}$ inkubiert. Nach 6 Tagen Inkubation wurden die Ansätze zur besseren Detektion der Virusplaques mit $100 \mu$ l einer Lösung von Neutralrot $(1 \mathrm{mg} / \mathrm{ml}$ in $\mathrm{H}_{2} \mathrm{O}$ ) versetzt und bei $27^{\circ} \mathrm{C}$ weiter inkubiert. Nach $2 \mathrm{~h}$ oder am nächsten Tag konnten die sich hell vom rötlichen Hintergrund absetzenden Virusplaques ausgezählt werden. Der Virustiter als Zahl der Plaques bildenden Einheiten (plaque forming unit, pfu) pro ml ergab sich unter Berücksichtigung der Verdünnung des Virusstocks nach folgender Formel:

Titer $(\mathrm{pfu} / \mathrm{ml})=$ Anzahl der Plaques $\mathrm{x}$ Verdünnungsfaktor $\mathrm{x}$

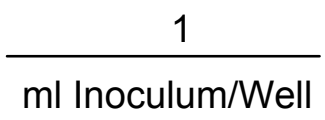

$\begin{array}{ll}\text { Topagar } & \\ \text { TC-100 Medium doppelt konzentriert (ohne Serum) } & 20 \mathrm{ml} \\ \text { fötales Kälberserum } & 4 \quad \mathrm{ml} \\ \text { Agarose (4\%, low-melting-point, Invitrogen) } & 12,5 \mathrm{ml} \\ \mathrm{H}_{2} \mathrm{O} & 12,5 \mathrm{ml}\end{array}$

Die Agarose wurde in einem $70{ }^{\circ} \mathrm{C}$ Wasserbad geschmolzen und bis zur Verwendung bei $40{ }^{\circ} \mathrm{C}$ warm gehalten. Erst unmittelbar vor Gebrauch wurde dem Medium das Serum zugegeben.

\subsubsection{Zellextrakt-Präparation nach einer Transfektion}

Nach einer Inkubation von $48-55$ h bei $37^{\circ} \mathrm{C}$ im Brutschrank wurden die transfizierten Zellen geerntet. Das Kulturmedium wurde abgesaugt, die Zellen mit 1x PBS (2.9) gewaschen und in 1,5 ml Kratzpuffer mit einem Gummischaber von der Schale abgelöst. Die Zellsuspension wurde in ein Eppendorfgefäß überführt und für 4 min bei $4{ }^{\circ} \mathrm{C}$ mit 7000 UpM (Eppendorfzentrifuge, 5417 R, Eppendorf Hamburg) zentrifugiert. Das Zellsediment wurde in $150 \mu \mathrm{l}$ Kaliumphosphat-Puffer aufgenommen und zum Zellaufschluß in flüssigem 
Stickstoff eingefroren, bei $37^{\circ} \mathrm{C}$ wieder aufgetaut und unter starkem Schütteln (VF2, IKALabortechnik, Staufen i. Br.) resuspendiert. Dieser Vorgang wurde dreimal wiederholt. Zur Beseitigung von Zelltrümmern wurde die Suspension für 5 min bei $4{ }^{\circ} \mathrm{C}$ mit $14000 \mathrm{UpM}$ (Eppendorfzentrifuge $5417 \mathrm{R}$ ) zentrifugiert und je $50 \mu \mathrm{l}$ des Überstandes für die Bestimmung von Luciferase- und GFP-Reportergen-Aktivitäten (2.21.6 und 2.21.7) eingesetzt.

Kratzpuffer

Tris, $\mathrm{pH} 7,5$

$\mathrm{NaCl}$

EDTA
$40 \mathrm{mM}$
$150 \mathrm{mM}$
$1 \mathrm{mM}$

\section{Kalium-Phosphatpuffer}

$\begin{array}{ll}\mathrm{K}_{2} \mathrm{HPO}_{4} & 100 \mathrm{mM} \\ \mathrm{KH}_{2} \mathrm{PO}_{4} & 100 \mathrm{mM}\end{array}$

Der $\mathrm{pH}$ wurde durch Titrieren auf 7,8 eingestellt.

2.21.6 Nachweis der Luciferase-Reportergen-Aktivität

Das Luciferase-Enzym ist in der Lage, unter ATP-Verbrauch und in Anwesenheit von $\mathrm{Mg}^{2+}$-Ionen mit Luciferin einen Luciferase-Luciferyl-AMP-Komplex zu bilden. Dieser Komplex wird in einem weiteren Reaktionsschritt oxidativ decarboxyliert und es entsteht unter Emission von Licht freie Luciferase, Oxyluciferin, AMP sowie $\mathrm{CO}_{2}$ (De Wet et al., 1987). Steht das Luciferase-Substrat (Luciferin) im Überschuss zur Verfügung, so ist die Lichtemission proportional zur Luciferasekonzentration und kann im Luminometer quantifiziert werden. Die so in Zellextrakten transfizierter Zellen (2.21.4) quantifizierte Menge Luciferase erlaubt damit Rückschlüsse auf die Aktivität und Stärke des Promotors transfizierter Plasmide, die ein Luciferase-Reportergen tragen.

Zur Bestimmung der Luciferase-Aktivität transfizierter Zellen wurden $50 \mu \mathrm{l}$ des präparierten Zellextraktes (2.21.5) zu $368 \mu$ l gekühltem Luciferase-Assay-Mix in ein Luminometerröhrchen (Sarstedt, Nürnbrecht) gegeben. Zu diesem Ansatz wurden im Luminometer (AutoLumat LB 953, E\&G Berthold, Bad Wildbach) automatisch $200 \mu \mathrm{l}$ gekühlte Luciferin-Lösung injiziert. Die Lichtemission der Luciferase-katalysierten Reaktion wurde bei einer Wellenlänge von $560 \mathrm{~nm}$ über einen Zeitraum von $20 \mathrm{sec}$ gemessen und als Luciferase-Einheit dargestellt. Reine Luciferin-Lösung diente als Referenz- bzw. Nullwert. 
Luciferase-Assay-Mix

KP-Puffer (2.21.5)

Glycylglycin-Puffer

DTT

ATP

Glycylglycin-Puffer

Glycylglycin pH 7,8

$\mathrm{MgSO}_{4}$

EDTA pH 8,0
$16,5 \mathrm{mM}$

$82,4 \mathrm{mM}$

$1,1 \mathrm{mM}$

$2,2 \mathrm{mM}$
Luciferin-Lösung

Luciferin

$1 \mathrm{mM}$

DTT

$10 \mathrm{mM}$

in Glycylglycin-Puffer

\subsubsection{Nachweis der GFP-Reportergen-Aktivität}

Das "Green Fluorescent Protein“ (GFP) ist ein Protein mit Autofluoreszenz, welches aus der Quallenart Aequoria victoria stammt. Unter aeroben Bedingungen wird durch Oxidation und Protonierung spezifischer Aminosäurereste des Proteins die Fluoreszenz erzeugt (Cubitt et al., 1995; Heim et al., 1994). Im pGFPtpz-cmv® control vector Reportergenplasmid (Canberra-Packard) steht die Expression des GFP unter der Kontrolle eines CMV-Promotors und wurde routinemäßig in transienten Transfektionen cotransfiziert (2.21.4). Die Transfektionseffizienz sowie die Stärke unspezifischer Effekte auf die Luciferase-Reportergen-Aktvität („Squelching“) durch die Expression cotransfizierter Plasmide wurde durch die Stärke des Fluoreszenzsignals aus präparierten Zellextrakten (2.21.5) abgeschätzt. Zur Fluoreszenzbestimmung wurden $50 \mu \mathrm{l}$ Zellextrakt in Rundboden-Mikrotiterplatten (96 K, Greiner $\mathrm{GmbH}$, Frickenhausen) pipettiert. Die Fluoreszenz wurde bei einer Anregungswellenlänge von $485 \mathrm{~nm}$ und einer Emissionswellenlänge von $530 \mathrm{~nm}$ mit Software-Unterstützung (Plate Reader Software version 3.0, Packard Inc., Meriden, USA) mit einem Fluorocount-Fluorometer bestimmt (Fusion, Canberra Packard, Dreieich). Routinemäßig wurde eine Signalverstärkung von $1100 \mathrm{~V}$ und eine Messdauer von je $1 \mathrm{sec}$ verwendet. 


\subsection{Software}

\begin{tabular}{|c|c|c|}
\hline Name & Anwendung & Version/Internetadresse \\
\hline Staden Package & Sequenzauswertung & Version 1999.0 \\
\hline $\mathrm{NCBI}$ & $\begin{array}{l}\text { Sequenzauswertung/ } \\
\text { Homologiesuche (blast) }\end{array}$ & www.ncbi.nlm.nih.gov \\
\hline ClustalW & $\begin{array}{l}\text { Sequenzvergleiche (multiple } \\
\text { sequence alignment program) }\end{array}$ & www.ebi.ac.uk/clustalw/ \\
\hline ExPASy & $\begin{array}{l}\text { Swiss Institute of } \\
\text { Bioinformatics }\end{array}$ & www.expasy.org \\
\hline ProtParam & $\begin{array}{l}\text { Vorhersage verschiedener } \\
\text { physikalischer und chemischer } \\
\text { Eigenschaften eines Proteins }\end{array}$ & www.expasy.org/tools/protparam.html \\
\hline TINA & $\begin{array}{l}\text { Quantifizierung von } \\
\text { Bandenintensitäten mithilfe } \\
\text { des Phospor-Imagers (2.14.2) }\end{array}$ & $\begin{array}{l}\text { Version } 2.09 \mathrm{~g} \\
\text { raytest Isotopenmessgeräte } \mathrm{GmbH}\end{array}$ \\
\hline BioDocAnalyser & $\begin{array}{l}\text { Quantifizierung von } \\
\text { Bandenintensitäten auf } \\
\text { eingescannten Filmen }\end{array}$ & $\begin{array}{l}\text { Version 2.23.7.4 } \\
\text { Biometra Göttingen }\end{array}$ \\
\hline NEBcutter V2.0 & $\begin{array}{l}\text { Vorhersage von } \\
\text { Restriktionsschnittstellen und } \\
\text { ORFs in DNA-Sequenzen }\end{array}$ & $\begin{array}{l}\text { http://tools.neb.com/NEBcutter2 } \\
\text { /index.php }\end{array}$ \\
\hline
\end{tabular}




\section{ERGEBNISSE}

\subsection{Hergestellte Reportergen- und Expressionsplasmide}

Es wurden die folgenden Konstrukte hergestellt (vgl. 2.11.1; Tab. 2.5 und 2.6):

$$
\begin{aligned}
& \text {-350/-150G3PH0mut1 } \\
& -350 /-150 G 3 P H 0 m u t 2 \\
& -169 G 1 P H 0 m u t 1 \\
& \text {-169G1PH0mut2 } \\
& \text { pBAT-Pax6Lmut } \\
& \text { pcDNA3-PD } \\
& \text { pcDNA3-HD } \\
& \text { pcDNA3-PD-L-HD } \\
& \text { pcDNA3-PD-L } \\
& \text { pcDNA3-PD-Lmut-HD1 } \\
& \text { pcDNA3-PD-Lmut-HD3 } \\
& \text { pcDNA3-PD-Lmut-HD4 } \\
& \text { pcDNA3-Pax6Lmut } \\
& \text { pcDNA3-6xHisPax6WT } \\
& \text { pcDNA3-6xHisPax6dHD } \\
& \text { pcDNA3-6xHisPax6Lmut } \\
& \text { pFastBacHT-B-Pax6-WT } \\
& \text { pFastBacHT-B-PD } \\
& \text { pFastBacHT-B-HD } \\
& \text { pFastBacHT-B-PD-L-HD }
\end{aligned}
$$

Nach der Herstellung wurde die Identität der Konstrukte durch Restriktionsverdau (2.15.1) und durch Sequenzierung (2.18) bestätigt. 


\subsection{Bedeutung der Pax6-Homöodomäne für die Bindung von Pax6 an den Glukagon-Promotor der Ratte: Untersuchung mit Hilfe von in vitro transkribierten/translatierten Proteinen}

Es wurden verschiedene Pax6-Mutanten erzeugt und im „Electrophoretic Mobility Shift Assay“ (EMSA, 2.20) eingesetzt. Dazu wurden mittels PCR (2.16) ausgehend von dem Plasmid pcDNA3-Pax6wt, welches für das gesamte Pax6 der Maus kodiert, Pax6Mutanten erzeugt und zur in vitro Transkription/Translation (2.19.1) in den Vektor pcDNA3 kloniert. In Abbildung 3.1 sind die Pax6-Varianten schematisch gezeigt: Pax6wt kodiert für das gesamte Pax6 der Maus mit der Wildtyp-Sequenz. Pax6PD-L-HD umfasst die PairedDomäne mit Linker und Homöodomäne von Aminosäure 1 bis 268. Pax6PD kodiert für die isolierte Paired-Domäne von Aminosäure 1 bis 136. Pax6HD kodiert für die Homöodomäne von Aminosäure 210 bis 268. Pax6PD-L umfasst die Paired-Domäne inklusive Linker von Aminosäure 1 bis 209.

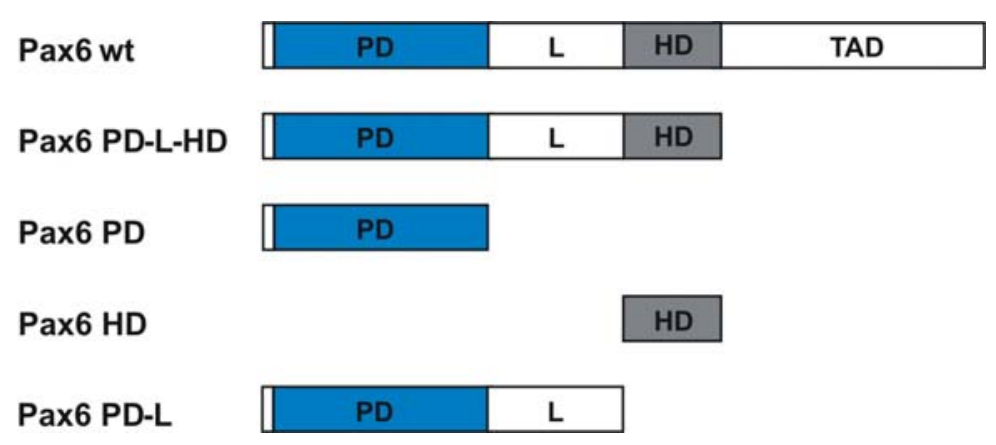

Abb. 3.1: Schematische Darstellung von Pax6 und der generierten Pax6-Mutanten. Pax6wt (Pax6 Wildtyp); Pax6PD-L-HD (Pax6 Paired-Domäne mit Linker und Homöodomäne); Pax6PD und Pax6HD (isolierte Paired-Domäne und Homöodomäne); Pax6PD-L (Paired-Domäne mit Linker). PD, Paired-Domäne; L, Linker; HD, Homöodomäne; TAD, Transaktivierungsdomäne. 
3.2.1 In vitro Transkription und Translation von Pax6 Wildtyp und Pax6-Mutanten und Darstellung der Expressionsprodukte in der SDS-PAGE

Zur Herstellung der Proteine Pax6wt, Pax6PD, Pax6HD, Pax6PD-L und Pax6PD-L-HD wurden die Expressionsplasmide pcDNA3-Pax6-WT, pcDNA3-PD, pcDNA3-HD, pcDNA3PD-L und pcDNA3-PD-L-HD (2.11.1; Tab. 2.6) in zellfreien Kaninchen-RetikulozytenLysaten unter Verwendung der T7-RNA-Polymerase in vitro transkribiert/translatiert (2.19.1). Die Abbildung 3.2 stellt die Expressionsprodukte in der SDS-PAGE (2.19.6) dar. Die in vitro transkribierten/translatierten Proteine Pax6wt, Pax6PD-L-HD und Pax6PD-L migrierten bei den berechneten Größen von 46,5 kDa, 30 kDa und 22,8 kDa (Abb. 3.2, Bahn 2, 3 und 5). Zusätzlich wurden niedermolekulare Degradationsprodukte nachgewiesen. Aufgrund der Markierung mit $\left[{ }^{35}\right.$ S]-Methionin (2.19.1) konnte die Expression von Pax6PD nicht nachgewiesen werden (Abb. 3.2, Bahn 4). Dieses Proteinfragment enthält nur ein Methionin als Startaminosäure und ist aufgrund der zu geringen Menge an Radioaktivität mit dem angewendeten Verfahren nicht detektierbar. Die Expression von Pax6HD konnte aus dem gleichen Grund nicht nachgewiesen werden (Daten nicht gezeigt).

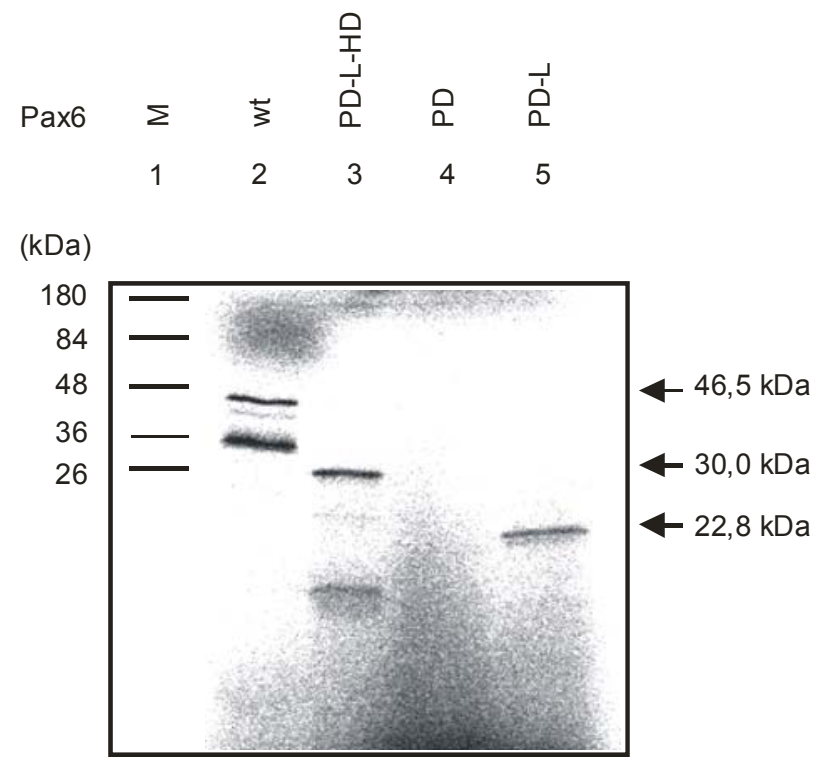

Abb. 3.2: In vitro Transkription/Translation von Pax6wt, Pax6PD-L-HD, Pax6PD und Pax6PD-L in zellfreien Retikulozyten-Lysaten. Für die in vitro Transkription/Translation in Kaninchen-Retikulozyten-Lysaten wurde je $1 \mu \mathrm{g}$ der Expressionsplasmide pcDNA3-Pax6-WT, pcDNA3-PD-L-HD, pcDNA3-PD, und pcDNA3-PD-L unter Verwendung von $\left[{ }^{35}\right.$ S]-Methionin eingesetzt. Je $5 \mathrm{\mu l}$ der Reaktionsansätze (Bahn 2-5) wurden zusammen mit einem Molekulargewichtsstandard (Bahn 1) mittels SDS-PAGE aufgetrennt. Die Detektion der Proteinbanden erfolgte durch Autoradiographie. Die Beschriftung entspricht den unter Abbildung 3.1 erklärten Abkürzungen. 
3.2.2 Untersuchung der Bindung von in vitro transkribierten/translatierten Pax6 und Pax6-Mutanten an das G1- und G3-Element des Glukagon-Promotors der Ratte mittels EMSA

Retikulozyten-Lysate mit in vitro transkribierten/translatierten Pax6wt, Pax6PD, Pax6HD oder Pax6PD-L-HD wurden mit radioaktiv markierten G1- oder G3-Oligonukleotid-Sonden (2.11.1; Tab. 2.1) inkubiert. Um sicherzustellen, dass gleiche Mengen der Proteine eingesetzt wurden, wurden die Intensitäten der Proteinbanden im SDS-Gel mit Hilfe des Phosphor-Imagers und des Programms TINA (2.22) zunächst densitometrisch quantifiziert. Des Weiteren wurde bei der Mengenkalkulation die Anzahl der eingebauten radioaktiv markierten Aminosäure Methionin berücksichtigt. Bei Inkubation der Proteine Pax6wt und Pax6PD-L-HD mit der G1- und der G3-Oligonukleotid-Sonde kam es zu einer verlangsamten Bandenmigration sowohl mit dem G1-Element als auch mit dem G3Element (Abb. 3.3A, Bahn 3, 4, 9 und 10). Dabei waren die Bandenintensitäten aus den Pax6PD-L-HD-DNA-Komplexen stärker als die mit dem Pax6wt-Protein. Bei der Inkubation der G1- oder der G3-Sonde mit der isolierten Pax6 Paired-Domäne (PD) oder der Paired-Domäne und der Homöodomäne zusammen, (PD + HD) konnte nur ein spezifischer Protein-DNA-Komplex mit dem G3-Element nachgewiesen werden (Abb. 3.3A, Bahn 5, 6, 7 und 8). Die gleiche Migration des Protein-DNA-Komplexes nach Inkubation der G3-Sonde mit der Pax6 Paired-Domäne oder der Paired-Domäne und der Homöodomäne zusammen, deutete darauf hin, dass nur die Paired-Domäne einen Komplex mit dem G3-Element formte. Als Spezifitätskontrolle dienten Ansätze in denen Retikulozyten-Lysat ohne Expressionsplasmid mit den Sonden inkubiert wurde (Abb. 3.3A, Bahn 11 und 12). Die in vitro transkribierte/translatierte Pax6-Homöodomäne zeigte keine Bindung an das G1- oder G3-Element (Abb. 3.3B, Bahn 5 und 6). 
G1 5’'-GATCGCATTTGAACAAAACCCCATTATTTACAGATGAGAAATTTATATTGTCAG - 3 ’

G3 5' - GATCCTGAAGTAGTTTTTCACGCCTGACTGAGATTGAAGGGTGTAGC - 3'

A

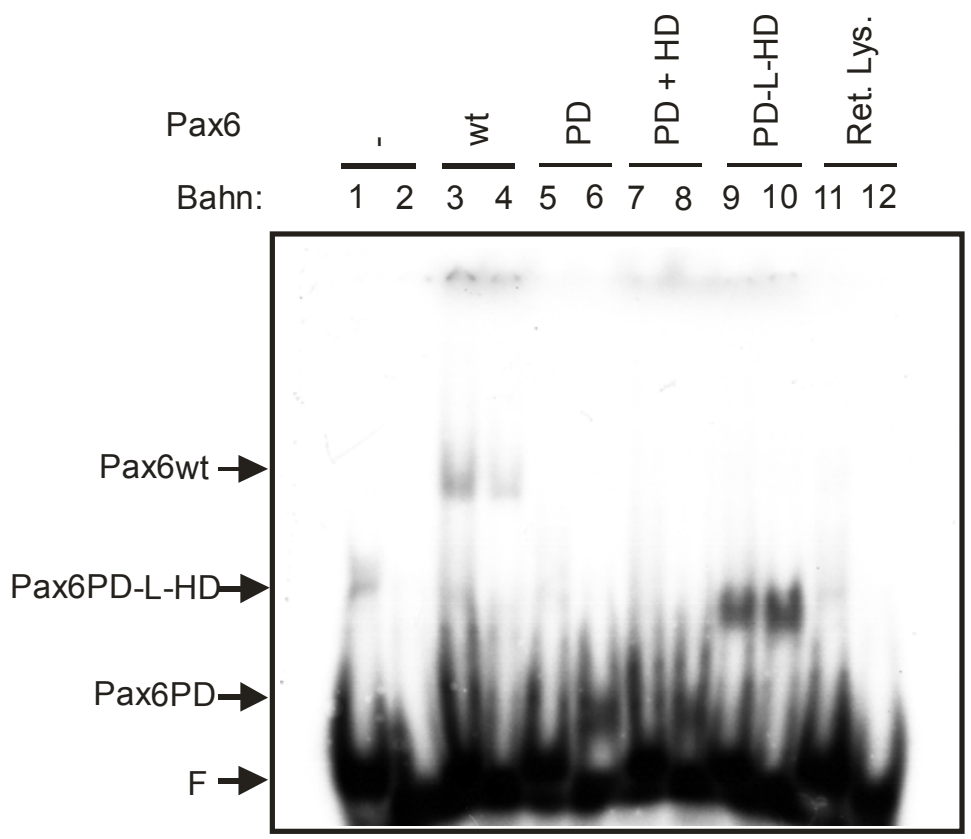

G1 G3 G1 G3 G1 G3 G1 G3 G1 G3 G1 G3
B

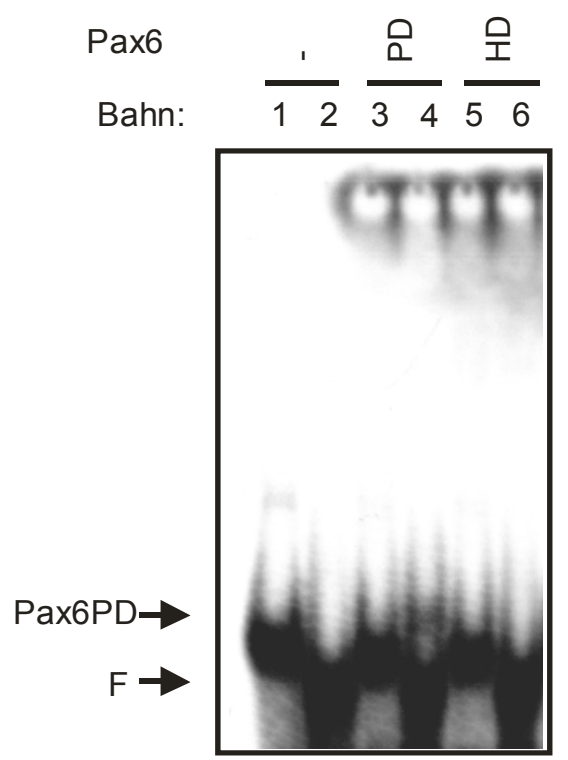

G1 G3 G1 G3 G1 G3

Abb. 3.3: In vitro transkribiertes/translatiertes Pax6wt und die Pax6-Paired-Domäne mit Linker und Homöodomäne zeigen im EMSA eine Bindung an das G1- und G3-Element des Glukagon-Promotors, wohingegen die Paired-Domäne alleine nur einen Komplex mit dem G3-Element formt. Für die in vitro transkribierte/translatierte Pax6-Homöodomäne konnte keine Bindung nachgewiesen werden. (A) Radioaktiv markierte G1- und G3-OligonukleotidSonden wurden mit gleichen Mengen in vitro transkribierten/translatierten Pax6wt, Pax6PD-L-HD, Pax6PD und Pax6PD + Pax6HD oder mit einem Kontrolllysat ohne Expressionsplasmid (Ret. Lys.) inkubiert. Die Reaktionsansätze wurden auf einem 5 \%igen Polyacrylamidgel unter nicht denaturierenden Bedingungen aufgetrennt. Radioaktiv markierte DNA wurde anschließend autoradiographisch detektiert. Die Pfeile markieren die spezifischen DNA-bindenden Pax6Proteinkomplexe. F, freie Sonde. (B) Für die Inkubation der isolierten Pax6-Homöodomäne (Pax6HD) mit den radioaktiv markierten Sonden konnte keine verlangsamte Bandenmigration nachgewiesen werden (Bahn 5 und 6). Im oberen Teil der Abbildung sind die Sequenzen der eingesetzten Sonden dargestellt. Das PISCES-Motiv ist unterstrichen, die 5'-Überhänge sind fett gedruckt. 
Untersuchung der Bindung der Pax6-Paired-Domäne mit Linker an das G1- und G3Element des Glukagon-Promotors

Um zu testen, ob auch der Pax6-Linker zwischen den beiden DNA-Bindedomänen einen Beitrag zu der Bindung an das G1- und G3-Element leistet, wurde Retikulozyten-Lysat mit in vitro transkribiertem/translatiertem Pax6PD-L (Abb. 3.1) mit der radioaktiv markierten G1- oder der G3-Oligonukleotid-Sonde inkubiert. Ein spezifischer Protein-DNA-Komplex konnte mit dem G3-Element nachgewiesen werden, nicht aber mit dem G1-Element (Abb. 3.4, Bahn 9 und 10). Zur Bindung an das G1-Element ist demnach die Pax6Homöodomäne notwendig und muss in einem Molekül mit der Paired-Domäne vorliegen.

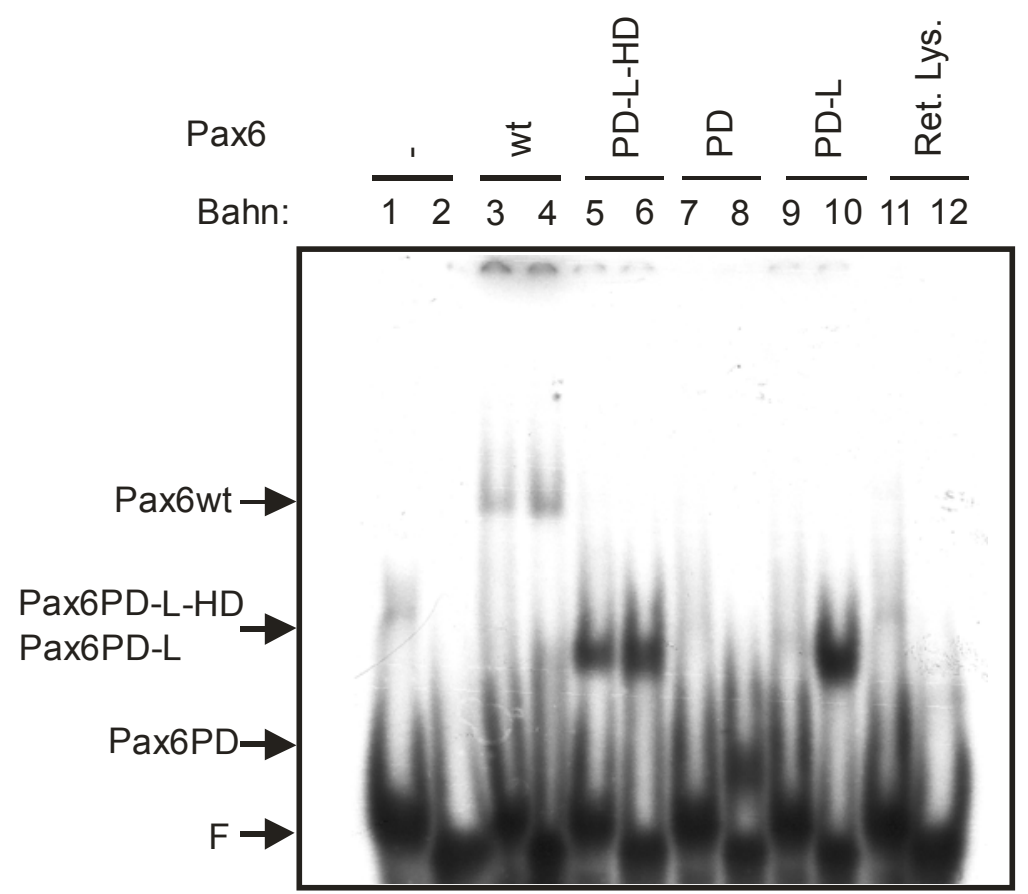

G1 G3 G1 G3 G1 G3 G1 G3 G1 G3 G1 G3

Abb. 3.4: Die in vitro transkribierte/translatierte Pax6-Paired-Domäne mit Linker bindet an das G3-Element, nicht aber and das G1-Element des Glukagon-Promotors. EMSA: Radioaktiv markierte G1- und G3-Oligonukleotid-Sonden wurden mit gleichen Mengen in vitro transkribierten/translatierten Pax6wt, Pax6PD-L-HD, Pax6PD und Pax6PD-L oder mit einem Kontrolllysat ohne Expressionsplasmid (Ret. Lys.) inkubiert. Die Reaktionsansätze wurden auf einem 5 \%igen Polyacrylamidgel unter nicht denaturierenden Bedingungen aufgetrennt. Radioaktiv markierte DNA wurde anschließend autoradiographisch detektiert. Die Pfeile markieren die spezifischen DNA-bindenden Pax6-Proteinkomplexe. F, freie Sonde. 


\subsection{Bedeutung der Pax6-Homöodomäne für die Bindung von Pax6 an den Glukagon-Promotor der Ratte: Untersuchung mit Hilfe von im Baculovirus- System exprimierten Proteinen}

Pax6 in voller Länge und die Pax6-Paired-Domäne wurden als rekombinante Proteine in der Insektenzellinie Sf9 exprimiert. Dabei fand das Baculovirus-ExpressionsvektorSystem (BEVS) Anwendung. Ziel war es, Pax6 im größeren Maßstab in einer eukaryotischen Zelllinie zu exprimieren, da sich die bakterielle Überexpression von Pax6 in voller Länge in der Vergangenheit als schwierig herausgestellt hatte.

Weil Insektenzellen zur heterologen Proteinexpression in der Abteilung bisher nicht verwendet wurden, musste die Kultivierung der Zellen und die Proteinexpression mit dem BEVS zunächst etabliert werden.

\subsubsection{Heterologe Proteinexpression in Insektenzellen}

Die Insektenzelllinie Sf9 leitet sich ab von Ovarialzellen des „fall army worm“ Spodoptera frugiperda (Vaughn et al., 1977). Die Kulturführung erfolgte wie unter 2.21.1 beschrieben. Die typische Morphologie der fakultativ adhärenten Zellen ist in Abbildung 3.5C gezeigt. Die Herstellung rekombinanter Baculoviren erfolgte durch die Transformation von E. coli $\mathrm{DH} 10 \mathrm{Bac}^{\mathrm{TM}}$-Zellen (2.17.2.2) mit den rekombinanten Donorplasmiden pFastBacHT-BPax6wt und pFastBacHT-B-PD wie unter 2.19.4 beschrieben. Positive Klone wurden über ein Blau-Weiß-Screening (2.17.2.3) identifiziert und die rekombinanten Bacmide BacPax6wt und Bac-PD isoliert (2.17.5). Zusätzlich wurde das Vorhandensein der Zielgene in den Bacmiden über PCR mit dem Primerpaar M13_for/M13_rev (Tab. 2.4) verifiziert. Durch Transfektion von Sf9-Zellen mit den rekombinanten Bacmiden wurden die Virenstocks erzeugt (2.21.4). Durch erneute Infektion der Zellen mit den Baculoviren wurde der Virustiter erhöht oder rekombinantes Protein exprimiert (2.19.4).

Um zu testen, ob eine Infektion der Sf9-Zellen mit den angewendeten Methoden generell möglich ist und es zur Expression von rekombinanten Proteinen kommt, wurden die Insektenzellen mit Baculoviren infiziert, die zur Expression eines GFP-Fusionsproteins führen (der Virenstock wurde freundlicherweise vom Zentrum Physiologie der Universität Göttingen zur Verfügung gestellt). Die Autofluoreszenz des GFP-Fusionsproteins konnte $24 \mathrm{~h}$ nach der Infektion mikroskopisch nachgewiesen werden (Abb. 3.5A). Kontrollzellen, die mit dem Wildtyp Baculovirus infiziert wurden, zeigten keine Autofluoreszenz (Abb. $3.5 B)$. 
Zur reproduzierbaren Optimierung des Systems war die genaue Kenntnis des Virustiters notwendig. Die Bestimmung des Virustiters erfolgte mit einem sog. „Plaque-Assay“ wie unter 2.21.4 beschrieben. Abbildung 3.5D zeigt das typische Aussehen rekombinanter Plaques, die sich deutlich vom dunkleren Zellhintergrund abhoben. Der Virustiter der zur Proteinexpression eingesetzten Virenstocks lag bei ca. $2 \times 10^{7} \mathrm{pfu} / \mathrm{ml}$ (plaque forming units/ml).

A

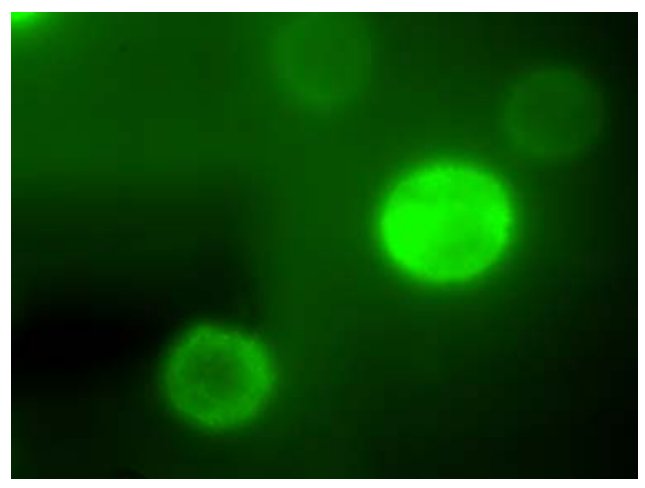

B

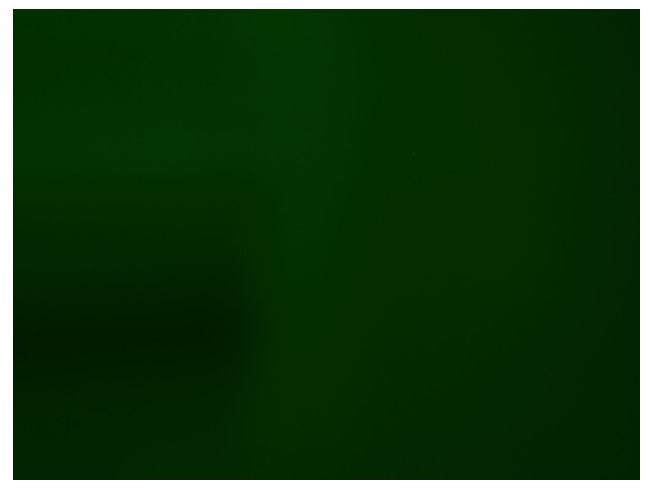

C

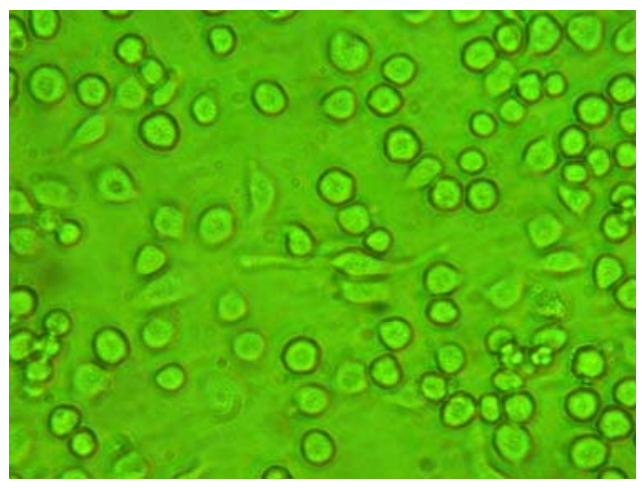

D

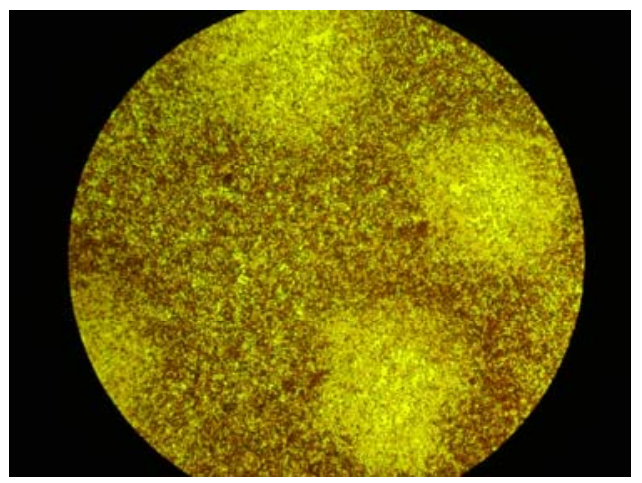

Abb. 3.5: (A) Sf9-Zellen exprimieren ein GFP-Fusionsprotein, dessen Autofluoreszenz $24 \mathrm{~h}$ nach der Infektion mit rekombinanten Baculoviren nachgewiesen werden konnte. (B) Die Kontrollzellen wurden mit dem Wildtyp Baculovirus infiziert. (C) Typische Morphologie von Sf9-Zellen bei einer Konfluenz von ca. $50 \%$, die als Monolayer-Kultur in TC100-Medium wachsen. Das Medium wurde mit 10\% FCS (2.10), $100 \mathrm{unit} / \mathrm{ml}$ Penicillin und $100 \mu \mathrm{g} / \mathrm{ml}$ Streptomycin supplementiert. (D) Rekombinante virale Plaques (occlusion negative, vgl. Page und Rodgers, 1995)

3.3.2 Optimierung der Expressionsbedingungen für die Expression von Pax6-Wildtyp und der Pax6-Paired-Domäne in Sf9-Insektenzellen

Die Proteinausbeute wird zum einen von der Infektionsdauer und zum anderen von der Menge der eingesetzten Viren beeinflusst. Um die optimalen Bedingungen für die Expression von Pax6 festzulegen, wurden Sf9-Zellen mit dem rekombinanten Virusstock 
Bac-Pax6wt mit einem MOI (multiplicity of infection, Anzahl der Viruspartikel pro Zelle) von 1 bzw. 0,17 infiziert. Nach 24 h, 48 h, 72 h und 96 h wurden Zellextrakte hergestellt (2.19.4) und mittels Westernblot auf die Expression von Pax6wt überprüft.

A

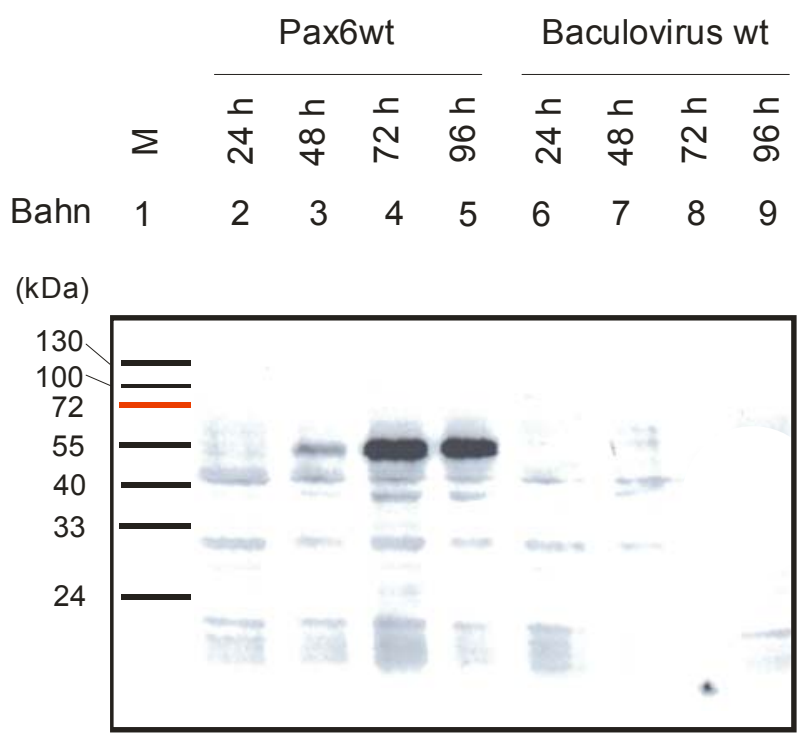

B
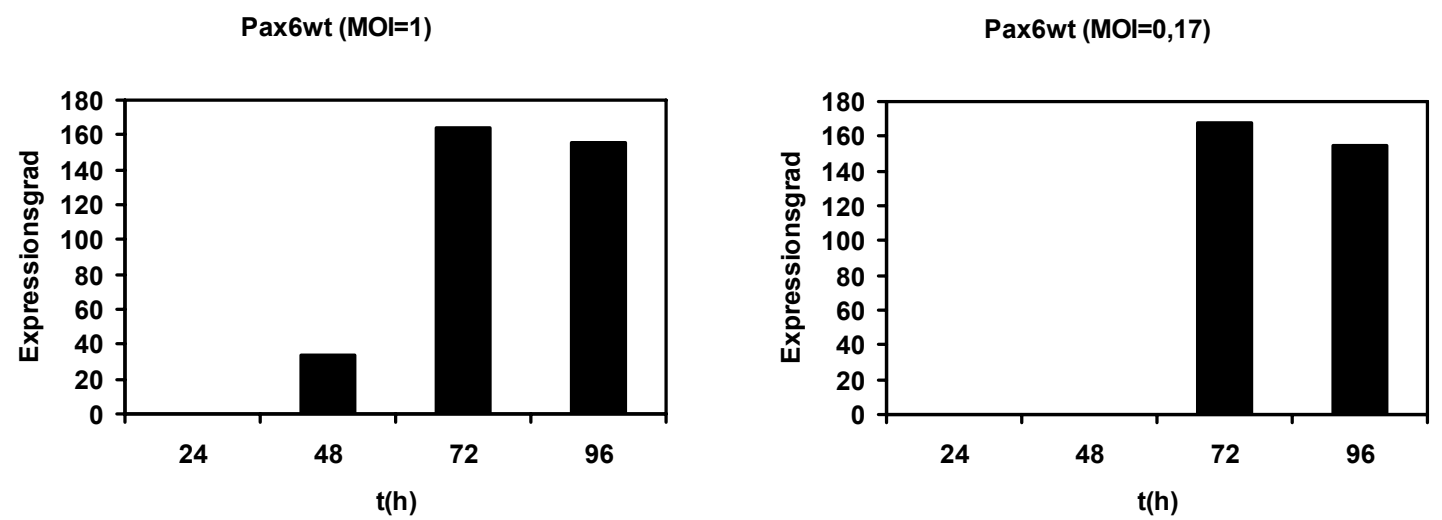

Abb. 3.6: Eine maximale Proteinausbeute von Pax6wt wird $72 \mathrm{~h}$ nach Infektion der Sf9-Zellen mit dem rekombinanten Baculovirus-Stock Bac-Pax6wt erreicht. (A) Sf9-Zellen wurden mit rekombinanten Baculoviren für die Expression von Pax6wt mit einem MOI von 1 infiziert. 24, 48, 72 und $96 \mathrm{~h}$ nach der Infektion wurden Zellextrakte wie unter 2.19.4 beschrieben hergestellt und je $20 \mu \mathrm{l}$ in der SDS-PAGE aufgetrennt. Die Immundetektion erfolgte durch einen Tetra.His-Antikörper gegen den N-terminal fusionierten His-Tag des Proteins (1:1000 Verdünnung in PBS-T $+5 \%(\mathrm{w} / \mathrm{v})$ Magermilchpulver). Als Negativkontrolle wurden die Zellen mit dem Wildtyp Baculovirus infiziert (Bahn 6 bis 9). M, Proteinmarker. (B) Die densitometrische Bestimmung der Bandenintensitäten aus den Immundetektionen erfolgte mit dem Programm BioDocAnalyser (Biometra, Göttingen). Die linke Abbildung zeigt die absoluten Densitometriewerte des unter A dargestellten Immunoblots (MOI=1). Für die rechte Abbildung ist der dazugehörige Immunoblot nicht gezeigt $(\mathrm{MOI}=0,17)$. 
Abbildung 3.6A zeigt eine zeitabhängige Zunahme der Expression von Pax6wt, die nach $72 \mathrm{~h}$ maximal war. Die zur Infektion eingesetzten Virusmengen ( $\mathrm{MOI}=1$ und $\mathrm{MOI}=0,17$ ) führten zu einer gleich hohen Expression von Pax6wt nach 72 h, was densitometrische Auswertungen der Immunoblots ergaben (Abb. 3.6B). Als Kontrolle wurden Sf9-Zellen mit dem Wildtyp Baculovirus infiziert (Abb. 3.6A, Bahn 6 bis 9).

Erwartungsgemäß erhöhte der N-terminale His-Tag die Größe der Proteine um 6 bis 7 kDa, wodurch Pax6wt bei ca. 55 kDa und Pax6PD bei ca. 20 kDa migirierte (Abb. 3.7, Bahn 2 und 3). Die Proteinausbeute war für die Pax6 Paired-Domäne ebenfalls $72 \mathrm{~h}$ nach der Infektion der Sf9-Zellen am höchsten und vergleichbar mit der für Pax6wt (Abb. 3.7).

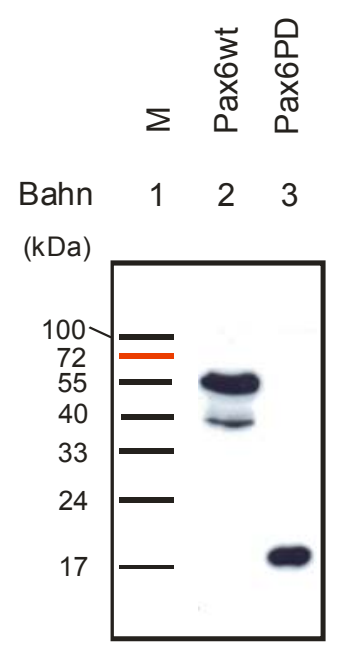

Abb. 3.7: Immundetektion von Pax6wt und Pax6PD im Westernblot. Sf9-Zellen wurden mit den Virusstocks Bac-Pax6wt und Bac-PD mit einem MOI von 1 infiziert. $72 \mathrm{~h}$ nach der Infektion wurden Zellextrakte gewonnen und je $20 \mu \mathrm{l}$ in der SDS-PAGE aufgetrennt. Die Immundetektion erfolgte durch einen Tetra·His-Antikörper. M, Proteinmarker

3.3.3 Charakterisierung der Bindung der rekombinanten Pax6-Proteine an das G1- und G3-Element des Glukagon-Promotors der Ratte

Um zu untersuchen, ob der N-terminale His-Tag oder Sf9-zellspezifische posttranslationale Modifikationen sich auf die Bindung von Pax6wt oder Pax6PD an das G1- oder G3-Element auswirken, wurden EMSA-Experimente mit den rekombinanten Proteinen durchgeführt.

Dazu wurden Sf9-Zellen mit den Virusstocks Bac-Pax6wt und Bac-PD mit einem MOI von 1 infiziert und $72 \mathrm{~h}$ nach der Infektion zu Zellextrakten verarbeitet. Die Expression der rekombinanten Proteine wurde vor dem Einsatz im EMSA mittels Westernblot überprüft (Abb. 3.7). Unterschiedliche Konzentrationen der Pax6wt- und Pax6PD-enthaltenden 
Zellextrakte wurden mit den radioaktiv markierten G3- und G1-Oligonukeotid-Sonden inkubiert.

Das rekombinante Pax6wt-Protein wie auch die Pax6-Paired-Domäne formten einen Komplex mit der G3-Sonde, wobei eine konzentrationsabhängige Abnahme der prozentualen Bindung an die Sonde zu verzeichnen war (Abb. 3.8A, Bahn 2 bis 7). Durch densitometrische Auswertungen konnte bei der höchsten Konzentration $\left(10^{\circ}\right.$ ) von Pax6wt eine Bindung von 88 \% der G3-Sonde errechnet werden. Durch 10-fache und 100-fache Verdünnung der Zellextrakte nahm die prozentuale Bindung der G3-Sonde durch Pax6wt auf $74 \%$ bzw. 17\% ab (Abb. 3.8B). Durch die Pax6-Paired-Domäne wurden 81\% der G3Sonde gebunden. Mit steigender Verdünnung der Zellextrakte nahm die Bindung auf 66\% bei 10 -facher Verdünnung und auf $41 \%$ bei 100 -facher Verdünnung ab. Eine Bindung der Paired-Domäne an die G1-Sonde war nicht nachzuweisen (Abb. 3.8C, Bahn 5 bis 7). Die prozentuale Bindung der G1-Sonde durch Pax6wt war mit 84\% (unverdünnt), 65\% (10fach verdünnt) und 10\% (100-fach verdünnt) etwas geringer als die Bindung von Pax6wt an die G3-Sonde. Als spezifische Kontrollen dienten Zellextrakte aus Sf9-Zellen, die $72 \mathrm{~h}$ zuvor mit dem Wildtyp Baculovirus infiziert wurden (Abb. 3.8A und C, Bac-wt) oder nicht infizierte Zellen (Sf9-Kontrolle). Dabei wurden keine spezifischen Protein-DNA-Komplexe detektiert (Abb. 3.8A und C, Bahn 8 bis 13). 
A

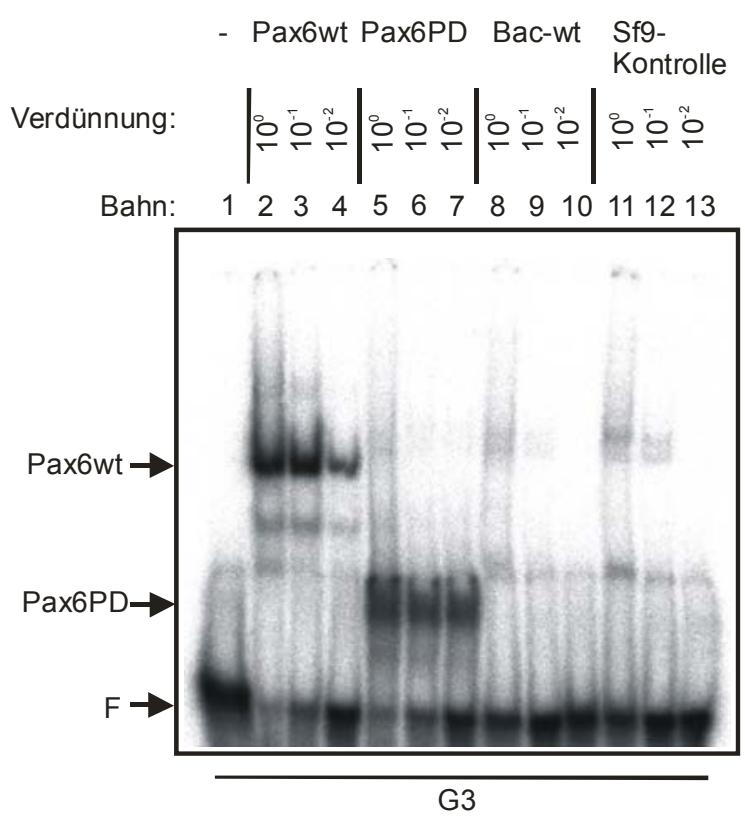

B

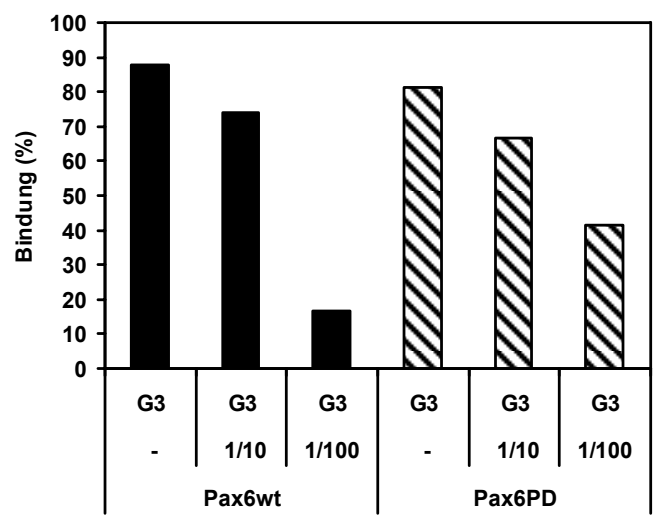

C
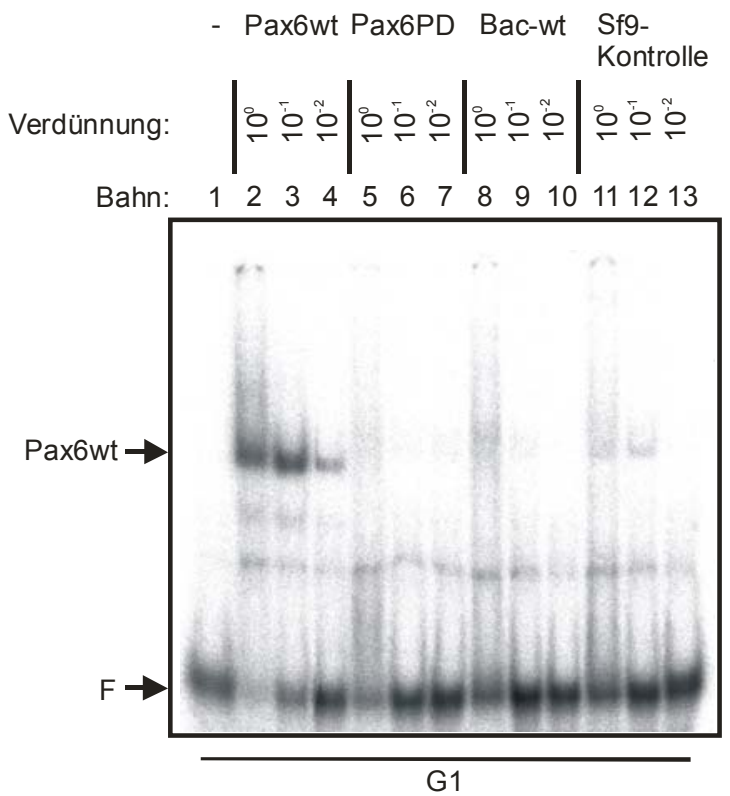

D

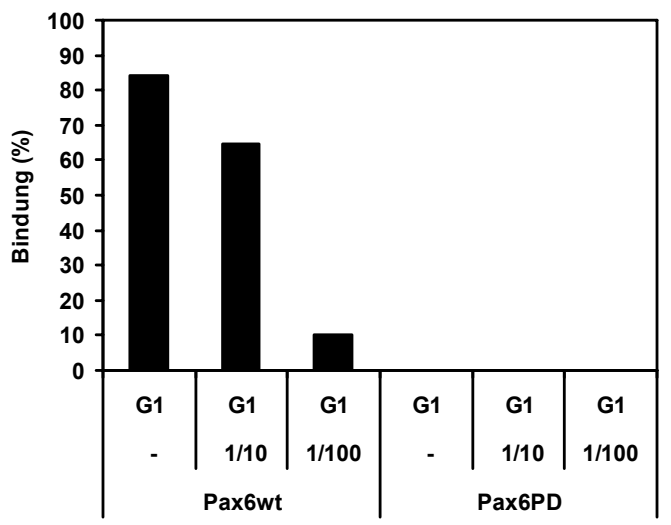

Abb. 3.8: Rekombinantes Pax6-Wildtyp bindet an das G3- und G1-Element des GlukagonPromotors der Ratte. Die rekombinante Pax6-Paired-Domäne formt nur einen Komplex mit dem G3-Element. (A und C) EMSA: Radioaktiv markierte G1- und G3-Oligonukleotid-Sonden wurden mit $5 \mu \mathrm{l}$ der angegebenen Verdünnungen von Zellextrakten aus Sf9-Zellen inkubiert, die 72 h zuvor mit den Virusstocks Bac-Pax6wt, Bac-PD oder dem Wildtyp Baculovirus (Bac-wt) infiziert wurden, oder mit Zellextrakten aus nicht infizierten Zellen (Sf9-Kontrolle). Die Reaktionsansätze wurden auf einem 5 \%igen Polyacrylamidgel unter nicht denaturierenden Bedingungen aufgetrennt. Radioaktiv markierte DNA wurde anschließend autoradiographisch detektiert. Die Pfeile markieren die spezifischen DNA-bindenden Pax6-Proteinkomplexe. $F$, freie Sonde. (B und D) Densitometrische Messung der prozentualen Bindung der G3- und G1-Sonden durch Pax6wt und Pax6PD mit dem Programm TINA Version 2.09g. 


\subsection{Mutation einer putativen Pax6-Homöodomänen-Bindungsstelle im G3- und G1- Element des Glukagon-Promotors der Ratte}

Aus den vorangegangenen Protein-DNA-Bindungsexperimenten ließ sich schließen, dass die Pax6-Paired-Domäne ausreichend für eine Bindung an das G3-Element des Glukagon-Promotors ist. Für die Bindung von Pax6 an das G1-Element konnte gezeigt werden, dass die Homöodomäne zusätzlich notwendig ist.

Im Folgenden sollte untersucht werden, ob die Funktion der Pax6-Homöodomäne bei der Bindung an den Glukagon-Genpromotor und Aktivierung des Glukagon-Gens durch Pax6 in einer zusätzlichen und bestimmten DNA-Bindung liegt. Dies sollte durch DNAMutationsstudien einer putativen Pax6-Homöodomänen-Bindungsstelle im G3- und G1Element experimentell überprüft werden. Die Wirkung dieser Mutationen wurde zu einen auf die Bindung von Pax6 im „Electrophoretic Mobility Shift Assay“ untersucht. Um die funktionelle Bedeutung der Mutationen zu untersuchen, wurden mittels primerless PCR (2.16.2) dieselben Mutationen in das G3- oder das G1-Element des Glukagon-Promotors eingefügt und die Aktivität der entsprechenden Gukagon-Promotor-Reporterfusionsgene in der heterologen Zelllinie JEG-3 durch Expression von Pax6 überprüft. Des Weiteren wurde die Aktivität der Reporterfusionsgene mit mutiertem Glukagon-Promotor in der Glukagon-exprimierenden Pankreasinselzellinie InR1G9 durch endogenes Pax6 getestet.

3.4.1 Annahme einer PH0-artigen („tail-to-tail“) Bindung von Pax6 an das G1- und G3Element des Glukagon-Promotors

Bekannt ist, dass die Bindung von Pax6 an die zwei PISCES-Motive (pancreatic islet cellspecific enhancer sequence) in den Elementen G3 und G1 jeweils über die PairedDomäne erfolgt (Knepel et al., 1991). Damit in Übereinstimmung zeigt das PISCES-Motiv eine hohe Ähnlichkeit mit der DNA-Konsensus-Sequenz für die Bindung der Pax6-PairedDomäne (Epstein et al. 1994a). In Abbildung 3.9 ist die PISCES-Sequenz im G3- und G1Element unterstrichen. In einem „Site-Selection-Assay“ wählte das Drosophila-Protein paired, welches ähnlich wie Pax6 neben einer Paired-Domäne auch eine Homöodomäne besitzt, ein synthetisches Oligonukleotid aus, dessen Sequenz 5' zu einer PairedDomänen-DNA-Bindungsstelle in umgekehrter Orientierung (,tail-to-tail“) eine Homöodomänen-DNA-Bindungsstelle besaß ( $\mathrm{PHO}$-artige Bindung, Jun und Desplan, 1996). Dieses Bindungsszenario wurde als Hypothese für die Bindung von Pax6 an das G3- und G1-Element angenommen. Abbildung 3.9 zeigt ein Alignment des Oligonukleotids, welches durch das Drosophila paired Protein ausgewählt wurde (Site- 
Selection-Assay), zusammen mit der Pax6-Konsensus-Bindungsstelle (Pax6-Konsensus) und dem G3- und G1-Element des Glukagon-Promotors. Davon ausgehend wurde eine putative Pax6-Homöodomänen-Bindungsstelle in G3 und G1 identifiziert, die unmittelbar $5^{\prime}$ an die Bindungsstelle der Paired-Domäne anschließt (rot unterlegte Basen). Zu beachten ist, dass im G1-Element das PISCES-Motiv in umgekehrter Orientierung vorliegt.

Site-Selection

Pax6-Konsensus

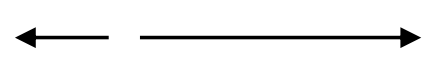

CTTCCAATTAGTCACGCGTGAGTG

$$
\begin{array}{r}
A--T_{T C A C G C}^{A} T_{T}{ }^{C} A-T^{G A}-T^{T} \\
T C
\end{array}
$$

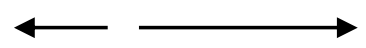

G3

G3PHOmut1

G3PHOmut2

TAGTTTTTCACGCCTGACTGAGATTGAAGGG

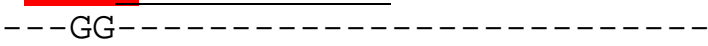

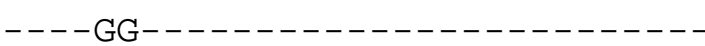

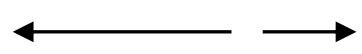

G1

G1PHOmut1

G1PH@mut2

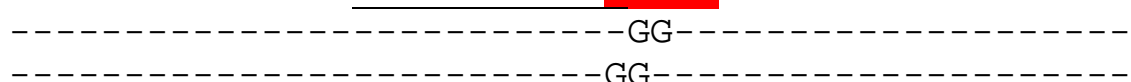

Abb. 3.9: Mutationen in einer putativen Pax6-Homöodomänen-Bindungsstelle im G3- und G1-Element des Glukagon-Promotors. Site-Selection: dieses synthetische Oligonukleotid wurde in einem Site-Selection-Assay durch das Drosophila-Protein paired ausgewählt (Jun und Desplan, 1996); Pax6-Konsensus: Konsensus-Bindungsstelle für das humane und murine Pax6-Protein (Epstein et al., 1994a); Die Mutationen im G3- und G1-Element (PHOmut1/2) sind jeweils unter der Wildtyp-Sequenz dargestellt. Die putativen Homöodomänen-Bindungstellen sind rot unterlegt. Das PISCES-Motiv ist unterstrichen.

Im mutierten G3-Element G3PH0mut1 wurden die Basenpaare -265 und -264 ausgetauscht $(\mathrm{TT} \rightarrow \mathrm{GG}$ ), bei G3PH0mut2 die Basenpaare -264 und -263 (TT $\rightarrow \mathrm{GG}$ ). Analog dazu wurden Mutationen in das G1-Element eingefügt. G1PH0mut1 trägt eine Mutation an Position -72 und -71 (TT $\rightarrow \mathrm{GG}$ ) und G1PH0mut2 an Position -73 und -72 $(A T \rightarrow G G)$. 
3.4.2 Charakterisierung der Bindung von Pax6 und der Pax6-Paired-Domäne an das G3-Element des Glukagon-Promotors mit den Mutationen PHOmut1 und PHOmut2

Pax6wt- und Pax6PD-enthaltende Zellextrakte aus Sf9-Zellen wurden mit den radioaktiv markierten Oligonukleotid-Sonden G3, G3PH0mut1 und G3PH0mut2 inkubiert.

Das rekombinante Pax6wt-Protein wie auch die Pax6-Paired-Domäne formten einen Komplex mit der G3-Sonde (Abb. 3.10A, Bahn 4 und 7). Die Mutationen G3PH0mut1 und G3PH0mut2 führten zu keiner Veränderung der prozentualen Bindung der Sonden durch Pax6wt und Pax6PD (Abb. 3.10A, Bahn 5, 6, 8 und 9). Aus den densitometrischen Messungen der EMSAs konnte errechnet werden, dass $55 \%$ bis $60 \%$ der Sonden G3, G3PH0mut1 und G3PH0mut2 durch Pax6wt und die Pax6 Paired-Domäne gebunden wurden (Abb. 3.10B). Als spezifische Kontrolle dienten Zellextrakte aus Sf9-Zellen, die 72 h zuvor mit dem Wildtyp Baculovirus infiziert wurden (Abb. 3.10A, Bahn 10 bis 12). Dabei wurden keine spezifischen Protein-DNA-Komplexe detektiert.

Abb. 3.10, nächste Seite: Die Mutationen PHOmut1 und PHOmut2 im G3-Element des Glukagon-Promotors haben keinen Einfluss auf die Bindung von Pax6wt und Pax6PD. (A) EMSA: Die radioaktiv markierten Oligonukleotid-Sonden G3, G3PH0mut1 und G3PH0mut2 wurden mit je $5 \mu \mathrm{l}$ Zellextrakt (10-fach verdünnt) aus Sf9-Zellen inkubiert, die $72 \mathrm{~h}$ zuvor mit den Virusstocks Bac-Pax6wt, Bac-PD oder dem Wildtyp Baculovirus (Bac-wt) mit einem MOI von 1 infiziert wurden. Die Reaktionsansätze wurden auf einem 5 \%igen Polyacrylamidgel unter nicht denaturierenden Bedingungen aufgetrennt. Radioaktiv markierte DNA wurde anschließend autoradiographisch detektiert. Die Pfeile markieren die spezifischen DNA-bindenden Pax6Proteinkomplexe. F, freie Sonde. Oben in der Abbildung ist die Sequenz der eingesetzten Sonden gezeigt. (B) Densitomtrische Messung der prozentualen Bindung der Sonden G3, G3PH0mut1 und G3PH0mut2 durch Pax6wt und Pax6PD. Die Ergebnisse sind Mittelwerte und SEM aus 4 unabhängigen Experimenten. 
G3

5 ' - GATCCTGAAGTAGTTITTCACGCCTGACTGAGATTGAAGGGTGTAGC - 3

G3PHOmut1 5' - GATCCTGAAGTAGGGTTTCACGCCTGACTGAGATTGAAGGGTGTAGC - 3'

G3PHOmut2 5' - GATCCTGAAGTAGTGGTTCACGCCTGACTGAGATTGAAGGGTGTAGC - 3 '

A

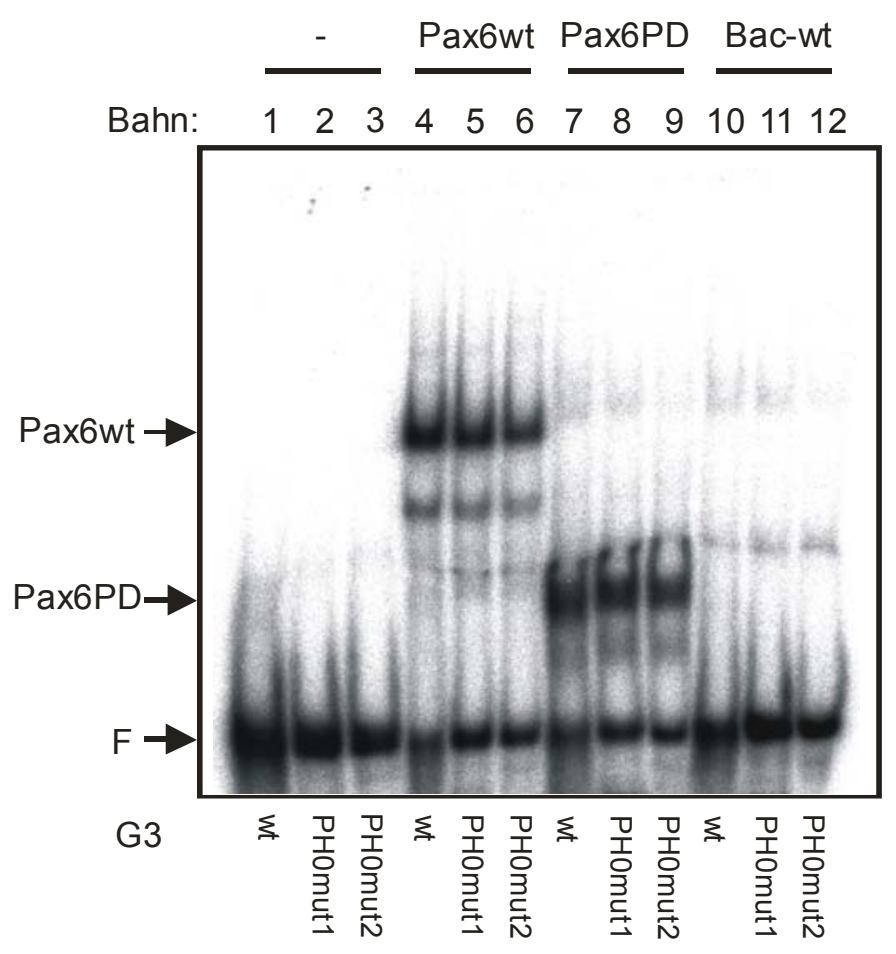

B

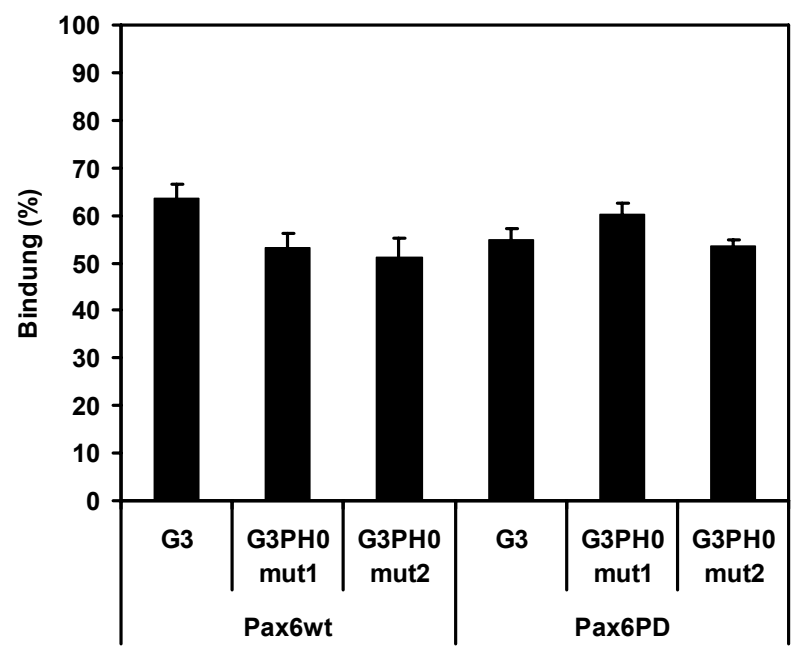


3.4.3 Wirkung der Mutationen PHOmut1 und PHOmut2 im G3-Element auf die Aktivierung des Glukagon-Promotors durch endogenes Pax6 in der pankreatischen Inselzelllinie InR1G9

Um zu untersuchen, welche funktionellen Auswirkungen die Mutationen im G3-Element auf die Aktivierung des Glukagon-Gens durch Pax6 haben, wurden die genannten Mutationen PHOmut1 und PHOmut2 mittels primerless PCR (2.16.2) in das LuciferaseReportergenplasmide -350/-150GluLuc eingefügt. Die daraus resultierenden Konstrukte -350/-150PH0mut1 und -350/-150PH0mut2 sind in Abbildung 3.11A dargestellt.

A

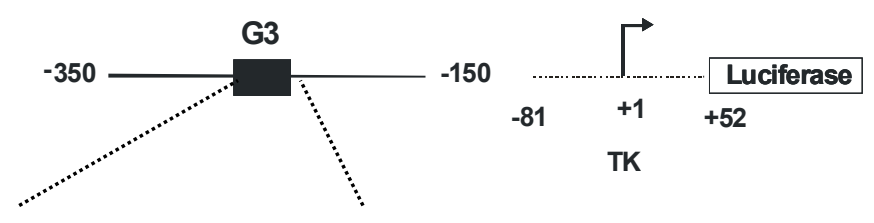

-350/-150GluLuc :

GTTTTTCACGCCTGACTG

-350/-150G3PHOMut1:

GGGTTTCACGCCTGACTG

$-350 /-150 \mathrm{G} 3 \mathrm{PHOMut} 2$ :

GTGGTTCACGCCTGACTG

B

-350GluLuc:

-350(G1m)GluLuc :

-350(G3Am) GluLuc :

$-350($ G1m/G3Am) GluLuc :

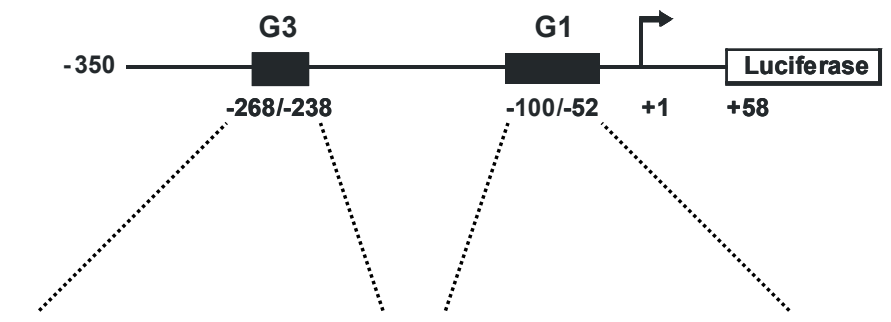

GTTTTTCACGCCTGACTG TTTACAGATGAGAAATTT

GTTTTTCACGCCTGACTG TTTACAGATTAGAAATTT

GTTTTTCAATTATGACTG TTTACAGATGAGAAATTT

GTTTTTCAATTATGACTG TTTACAGATTAGAAATTT

Abb. 3.11: Glukagon-Reporterfusionsgene. (A) Bei dem Reportergen-Plasmid -350/-150GluLuc steht die Expression des Luciferase-Gens unter Kontrolle eines minimalen ThymidinkinasePromotors (TK) (-81 bis +52 , pT81) der mit bp -350 bis -150 der $5^{\prime}$-flankierenden Region des Glukagon-Gens der Ratte fusioniert wurde. $\mathrm{PHO}$-artige Mutationen wurden $5^{\prime}$ des unterstrichenen PISCES-Motivs eingefügt (-350/-150G3PHOmut1 und -350/-150G3PHOmut2). (B) Bei -350GluLuc erfolgt die Expression des Luciferase-Gens unter Kontrolle des Glukagon-Gens der Ratte, die -350 bp der $5^{\prime}$-flankierenden Region und 58 bp des ersten Exons (+58) umfasst. Innerhalb des Glukagon-Promotors wurde die Pax6-Paired-Domänen-DNA-Bindungsstelle in G1 (Punktmutation, G1m) oder G3 (vier-Basenpaar-Mutation, G3Am) oder in G1 und G3 (G1m/G3Am) selektiv mutiert. Die mutierten Basen sind grau unterlegt. 
In dem Reportergen-Plasmid -350GluLuc steht die Expression des Luciferase-Gens unter der Kontrolle von 350 bp der 5 '-flankierende Region des Glukagon-Gens der Ratte (Abb. 3.11B, Schwaninger et al., 1993). In der 3'-Deletionsmutante des Glukagon-Promotors der Ratte -350/-150GluLuc wurde der Glukagon-Promotor vom 3'-Ende her deletiert und mit einem minimalen Thymidin-Kinase-Promotor fusioniert (Fürstenau et al., 1997). Dieses Reportergen-Plasmid enthält nur noch das G3-Element als Pax6Bindungsstelle.

Die Reporterfusionsgene -350GluLuc, -350/-150GluLuc, -350/-150G3PH0mut1 und -350/150G3PH0mut2 wurden transient in die glukagonproduzierende pankreatische Inselzelllinie InR1G9 transfiziert. Um parallel eine Pax6-abhängige Reportergenaktivität zu belegen, wurden zusätzlich die Reportergen-Plasmiden -350(G3m)GluLuc, -350 (G1m)GluLuc und -350(G1m/G3m)GluLuc in die Zellinie InR1-G9 transfiziert. Die in Abbildung 3.11B dargestellten Mutationen in den PISCES-Motiven in G3 und G1 führen zu einem Verlust der Bindung von Pax6 (Knepel et al., 1990; Andersen et al., 1999) und zu einer massiven Abnahme der Glukagon-Promotoraktivität in der Pankreasinselzelllinie InR1G9 (Teichler, Dissertation 2004).

Bezogen auf die Basalaktivität von -350GluLuc, die als 100\% festgelegt wurde, verminderten die Mutationen in den PISCES-Motiven in G3 und G1 die transkriptionelle Aktivität des Luciferase-Gens erwartungsgemäß auf $49 \% \pm 10 \%$ bei $-350(\mathrm{G} 3 \mathrm{~m})$ GluLuc, auf $14 \% \pm 2 \%$ bei -350 (G1m)GluLuc und auf $6 \% \pm 0,7 \%$ bei $-350(\mathrm{G} 1 \mathrm{~m} / \mathrm{G} 3 \mathrm{~m}$ )GluLuc (Abb. 3.12). Die Aktivität von $-350 /-150$ GluLuc betrug $12 \% \pm 2 \%$ verglichen mit -350 GluLuc. Durch die beiden $\mathrm{PHO}$-artigen Mutationen im G3-Element wurde die transkriptionelle Aktivität drastisch um jeweils $75 \%$ verringert (Abb. 3.12). 


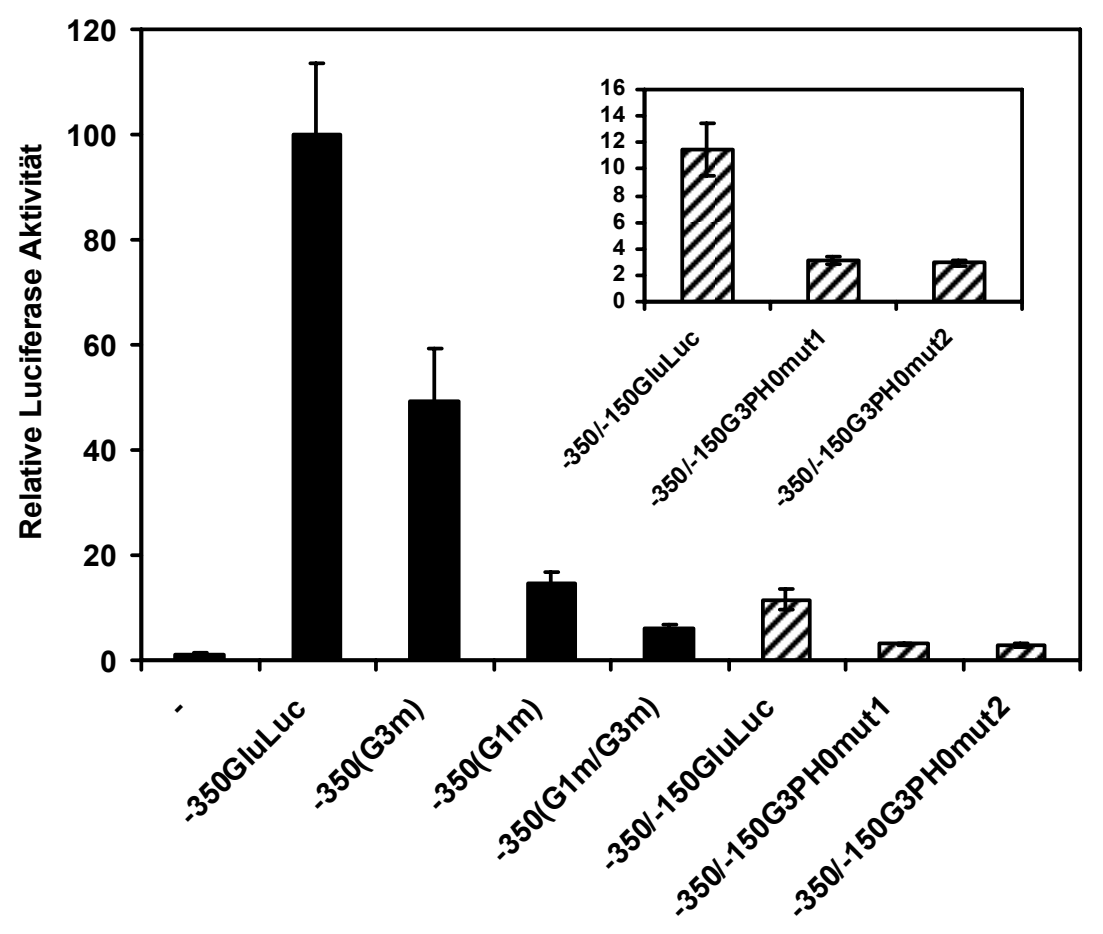

Abb. 3.12: Die Mutationen PHOmut1 und PHOmut2 im G3-Element des Glukagon-Promotors vermindern die Aktivität von -350/-150GluLuc in der glukagonproduzierenden Zelllinie InR1G9. Die Reportergen-Plasmide -350GluLuc, -350(G3m)GluLuc, -350(G1m)GluLuc, -350(G1m/G3m)GluLuc, -350/-150GluLuc, -350/-150G3PHOmut1 und -350/-150G3PH0mut2 (je $2 \mu \mathrm{g} / \mathrm{Schale}$ ) wurden mittels DEAE-Dextran transient in die glukagonproduzierende Zelllinie des a-Phänotyps InR1G9 transfiziert. Die relative Luciferase-Aktivität bezieht sich auf die Aktivität von -350GluLuc, dessen absoluter Wert als 100\% definiert wurde. Die Ergebnisse der Transfektionen sind Mittelwerte und SEM aus drei unabhängigen Experimenten mit Dreifachbestimmung.

3.4.4 Wirkung der Mutation PHOmut1 und PHOmut2 im G3-Element auf die Aktivierung des Glukagon-Promotors durch Pax6 in der heterologen Zelllinie JEG-3

Um die Aktivierung der Glukagon-Promotorfragmente durch exogenes Pax6 in Abwesenheit weiterer a-zellspezifischer Faktoren zu untersuchen, wurden Cotransfektionen in der nicht glukagonproduzierenden und nicht Pax6-exprimierenden humanen Chorionkarzinom-Zelllinie JEG-3 durchgeführt..

Die Luciferase-Reportergen-Plasmide -350GluLuc, -350/-150GluLuc, -350/ -150G3PH0mut1 und -350/-150G3PH0mut2 wurden zusammen mit den Expressionsplasmiden für Pax6-wt, -dHD und -3Ala transient in die heterologe Zelllinie JEG-3 cotransfiziert. Die Pax6-Varianten sind in Abbildung 3.13 oben schematisch dargestellt. Der Expressionsvektor Pax6wt kodiert für das Pax6-Protein der Maus mit der 
Wildtyp-Sequenz. Pax6dHD kodiert für das Pax6-Protein der Maus mit Ausnahme der Homöodomäne. Von der Homöodomäne beibehalten wurden lediglich drei Aminosäuren am Aminoterminus der Homöodomäne, da diese zu einem Motiv gehören, das in der Wachtel als eines von zwei Kernerkennungssignalen des Pax6-Proteins identifiziert wurde (Carriere et al., 1995). Der Expressionsvektor Pax6-3Ala kodiert für das Pax6-Protein der Maus, jedoch wurden 3 Aminosäuren in der Helix 3 zu Alanin mutiert: Valin-47, Serin-50 und Asparagin-51 (Wilson et al., 1995). Diese drei Aminosäuren sind im Drosophila paired-Protein für die DNA-Bindung notwendig. Die beiden letztgenannten Expressionsplasmide wurden ausgewählt, da der Transkriptions-inhibierende Effekt dieser Pax6-Mutationen auf die Glukagon-Gentranskription bereits charakterisiert wurde (Teichler, Dissertation 2004).

Die Aktivität von -350/-150GluLuc wurde durch die Cotransfektion von Pax6wt 12,5-fach stimuliert (Abb. 3.13). Bezogen auf die durch Pax6wt vermittelte Reportergen-Expression von $-350 /-150$ GluLuc $(100 \% \pm 3 \%)$ führten die Mutationen in $-350 /-150 G 3 P H 0 m u t 1$ und -350/-150G3PH0mut2 zu einer drastischen Abnahme der Reportergen-Aktivität auf 35\% \pm 4,7\% bzw. 11,5\% $\pm 1 \%$ (Abb. 3.13, schwarze Säulen). Die Cotransfektion von -350GluLuc führte erwartungsgemäß zu einer synergistischen Aktivierung des Glukagon-Promotors durch Pax6wt über das G3- und G1-Element auf 156\% \pm 4,5\%. Die Deletion der Homöodomäne (dHD) oder die Mutation von 3 Aminosäuren in der Homöodomäne (3Ala) führten zu einer Abnahme der Luciferase-Aktivität bei der Cotransfektion aller Reportergen-Plasmide um 50 bis $70 \%$. Die Basalaktivitäten waren $1,2 \% \pm 0,1 \%$ bei -350 GluLuc, $8,1 \% \pm 1 \%$ bei $-350 /-150$ GluLuc, $1,7 \% \pm 0,3 \%$ bei $-350 /-150$ G3PHOmut 1 und $1,7 \% \pm 0,1 \%$ bei $-350 /-150 G 3 P H 0$ mut 2 . 


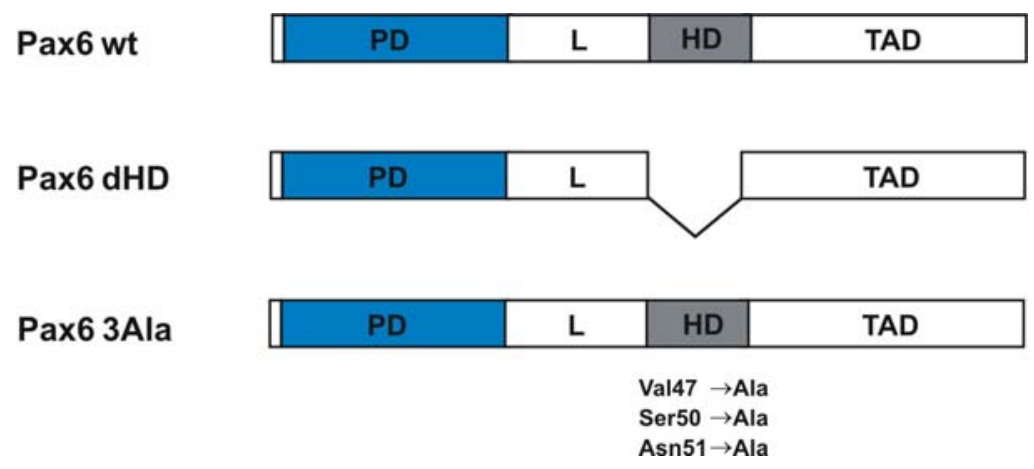

JEG-3

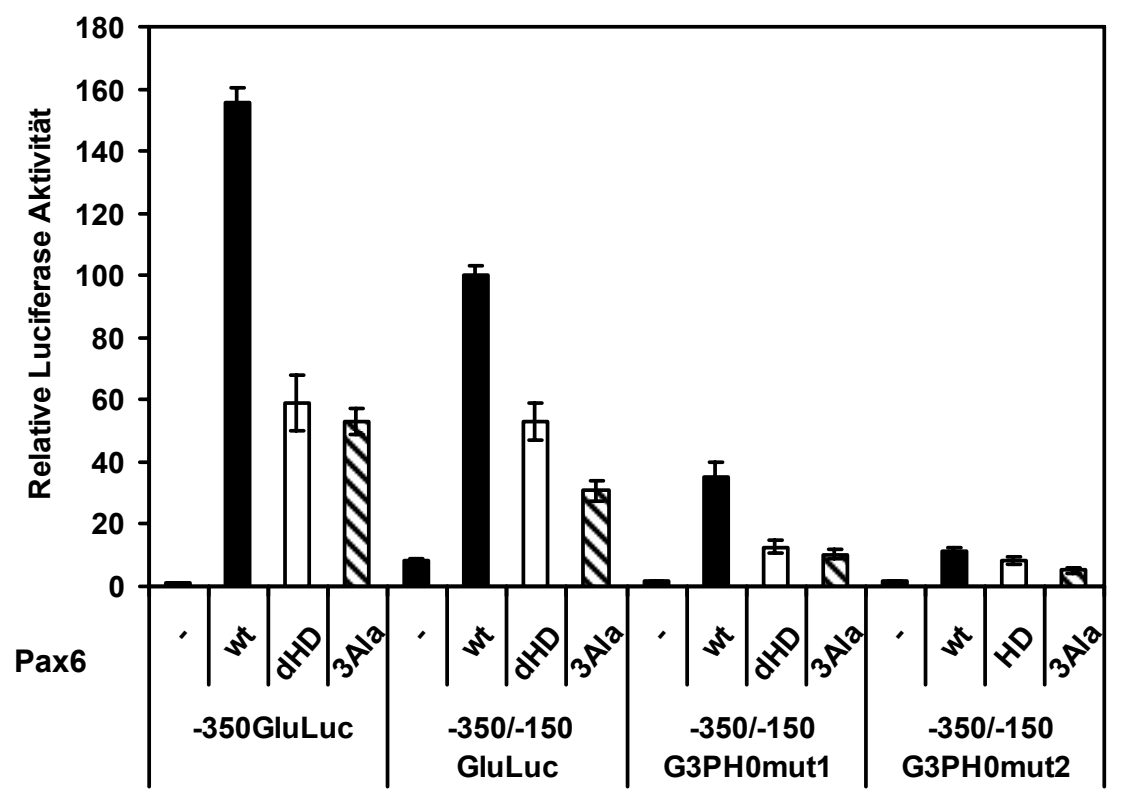

Abb. 3.13: $\mathrm{PHO}$-artige Mutationen in $\mathrm{G} 3$ vermindern die Aktivierung des GlukagonPromotors der Ratte durch Pax6 über das G3-Element in der heterologen Zelllinie JEG-3. Die Reportergen-Plasmide -350GluLuc, -350/-150GluLuc, -350/-150G3PH0mut1 oder -350/ -150G3PH0mut2 (3 $\mathrm{gg} / \mathrm{Sch}$ ale) wurden zusammen mit Expressionsvektoren für Pax6wt (pBATPax6wt), dHD (pBAT-dHD) und 3Ala (pBAT-3Ala) (207 ng/Schale) mittels Calcium-PhosphatPräzipitation transient in die humane Chorionkarzinom-Zelllinie JEG-3 transfiziert. Die LuciferaseAktivität bezieht sich auf die durch Pax6wt induzierte Aktivität des -350/-150GluLuc-Plasmids, dessen absoluter Wert als 100\% definiert wurde. Die Ergebnisse sind Mittelwerte und SEM aus drei unabhängigen Experimenten mit Doppelbestimmung. Die in den Transfektionen eingesetzten Pax6-Varianten sind schematisch in der Abbildung oben dargestellt. Pax6wt (Pax6-Wildtyp), Pax6dHD (Deletion der gesamten Homöodomäne), Pax6-3Ala (Mutation von 3 Aminosäuren, Valin-47, Serin-50, Asparagin-51). PD, Paired-Domäne; L, Linker; HD, Homöodomäne; TAD, Transaktivierungsdomäne. 
3.4.5 Charakterisierung der Bindung von Pax6 und der Pax6-Paired-Domäne an das G1-Element des Glukagon-Promotors mit den Mutationen PHOmut1 und PHOmut2

Pax6wt- und Pax6PD-enthaltende Zellextrakte aus Sf9-Zellen wurden mit den radioaktiv markierten Oligonukleotid-Sonden G1, G1PH0mut1 und G1PH0mut2 inkubiert.

Das rekombinante Pax6wt-Protein formte einen Komplex mit der G1-Sonde (Abb. 3.14A, Bahn 4). Die Mutation in G1PH0mut1 verringerte die prozentuale Bindung der Sonde durch Pax6wt drastisch von $21 \% \pm 4,4 \%$ auf $4,7 \% \pm 2 \%$ (Abb. 3.14A, Bahn 5; Abb. 3.14B). Verglichen mit der Bindung von Pax6wt an G1 führte die Mutation G1PH0mut2 zu keiner Änderung der Bindung der radioaktiv markierten Sonde $(23,2 \% \pm 8,6 \%)$. Durch die Pax6-Paired-Domäne wurde keine der 3 Oligonukleotid-Sonden gebunden (Abb. 3.14A, Bahn 7 bis 9) Als spezifische Kontrolle dienten Zellextrakte aus Sf9-Zellen, die $72 \mathrm{~h}$ zuvor mit dem Wildtyp-Baculovirus infiziert wurden (Abb. 3.14A, Bahn 10 bis 12). Dabei wurden keine spezifischen Protein-DNA-Komplexe detektiert.

\footnotetext{
Abb. 3.14, nächste Seite: Die Mutation PH0mut1 im G1-Element des Glukagon-Promotors verringert die Bindung von Pax6wt an G1. (A) EMSA: Die radioaktiv markierten OligonukleotidSonden G1, G1PH0mut1 und G1PH0mut2 wurden mit je $5 \mu$ l Zellextrakt (10-fach verdünnt) aus Sf9-Zellen inkubiert, die $72 \mathrm{~h}$ zuvor mit den Virusstocks Bac-Pax6wt, Bac-PD oder dem Wildtyp Baculovirus (Bac-wt) mit einem MOI von 1 infiziert wurden. Die Reaktionsansätze wurden auf einem 5 \%igen Polyacrylamidgel unter nicht denaturierenden Bedingungen aufgetrennt. Radioaktiv markierte DNA wurde anschließend autoradiographisch detektiert. Der Pfeil markiert den spezifischen DNA-bindenden Pax6-Proteinkomplex. F, freie Sonde. Oben in der Abbildung ist die Sequenz der eingesetzten Sonden gezeigt. (B) Densitometrische Messung der prozentualen Bindung der Sonden G1, G1PH0mut1 und G1PH0mut2 durch Pax6wt und Pax6PD. Die Ergebnisse sind Mittelwerte und SEM aus 4 unabhängigen Experimenten. Statistik: Anova gefolgt von Student's $t$ test, ${ }^{* *}: p<0,01$.
} 
G1

5’ - GATCGCATTTGAACAAAACCCCATTATTTACAgATGAGAAATTTATATTGTCAG - 3’

G1PHOmut1 5' - GATCGCATTTGAACAAAACCCCATTATTTACAGATGAGAAAGGTATATTGTCAG - 3' G1PH@mut2 5' - GATCGCATTTGAACAAAACCCCATTATTTACAGATGAGAAGGTTATATTGTCAG - 3'

A

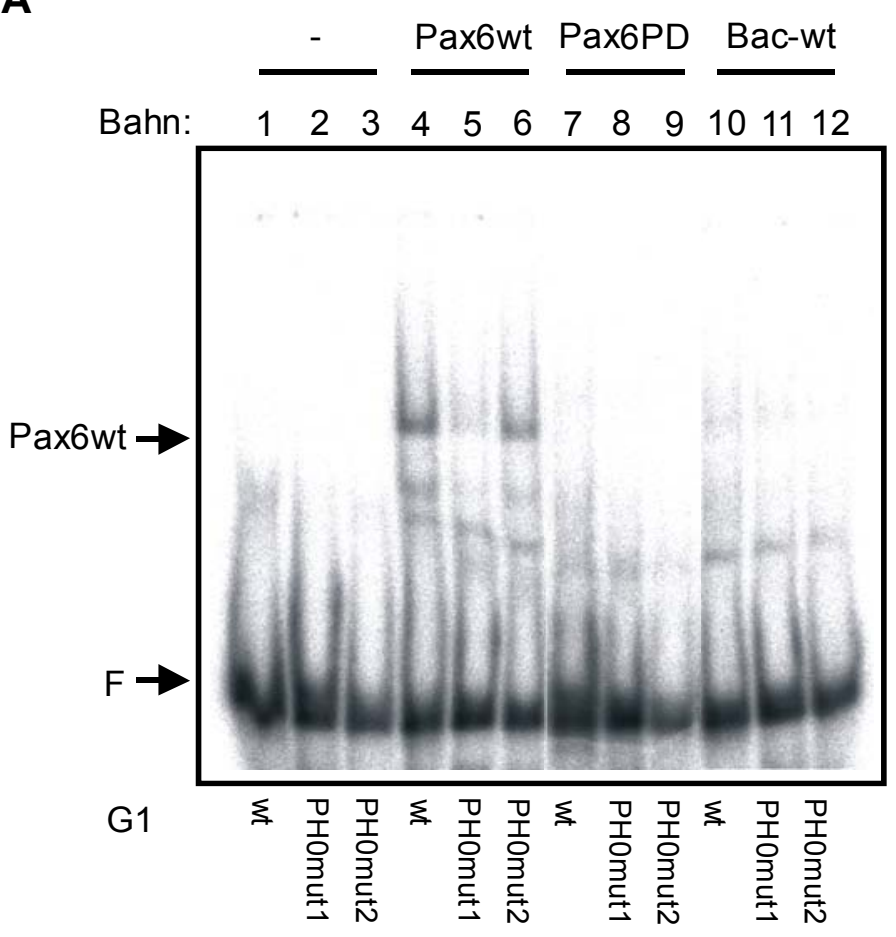

B

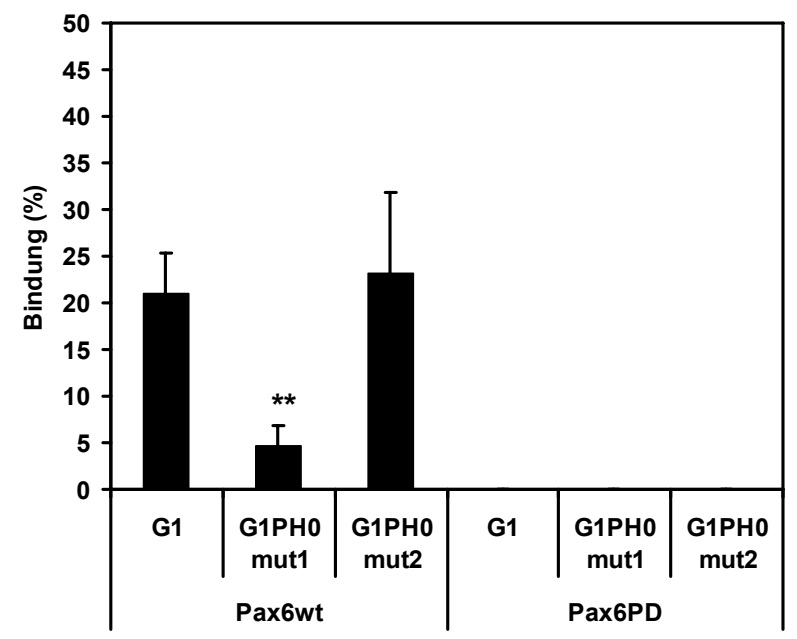


3.4.6 Wirkung der Mutationen PHOmut1 und PHOmut2 im G1-Element auf die Aktivierung des Glukagon-Promotors durch endogenes Pax6 in der pankreatischen Inselzelllinie InR1G9

Die funktionellen Auswirkungen der $\mathrm{PH} 0$-artigen Mutationen im G1-Element auf die Aktivierung des Glukagon-Promotor durch endogenes Pax6 wurden durch Transfektionen der Zelllinie InR1G9 untersucht. Mittels primerless PCR (2.16.2) wurden Mutationen in das Luciferase-Reportergenplasmid -169GluLuc eingefügt. Die daraus resultierenden Konstrukte -169G1PH0mut1 und -169G1PH0mut2 sind in der Abbildung 3.15 dargestellt. In der 5'-Deletionsmutante des Glukagon-Promotors, -169GluLuc, steht die LuciferaseExpression unter der Kontrolle von 169 bp des Glukagon-Promotors der Ratte (Fürstenau et al., 1997). In diesem Konstrukt existiert nur noch die Pax6-Bindungsstelle im G1Element.

-169GluLuc:

-169G1PHOmut1:

-169G1PHOmut2:

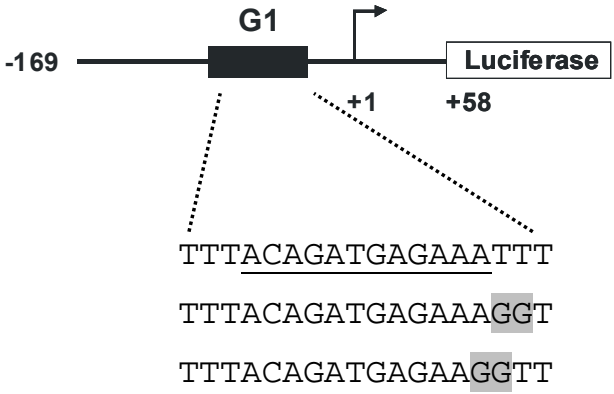

TTTACAGATGAGAAGGTT

Abb. 3.15: Glukagon-Reporterfusionsgene mit den Mutationen PHOmut1 und PHOmut2 im G1-Element. Die Expression des Luciferase-Gens steht unter Kontrolle von 169 bp (-169GluLuc) der 5 '-flankierenden Region des Glukagon-Gens der Ratte und 58 bp des ersten Exons (+58). Im 3 '-Bereich des unterstrichenen reversen PISCES-Motivs wurden $\mathrm{PHO}$-artige Mutationen eingefügt (-169G1PH0mut1 und -169G1PH0mut2). Die mutierten Basen sind grau unterlegt.

Die Reporterfusionsgene -350GluLuc, -169GluLuc, -169G1PH0mut1 und -169G1PH0mut2 wurden transient in die glukagonproduzierende pankreatische Inselzellinie InR1G9 transfiziert. Die Transfektion der Reportergenplasmide $-350(\mathrm{G} 3 \mathrm{~m})$ GluLuc, $-350(\mathrm{G} 1 \mathrm{~m})$ Gluluc und $-350(\mathrm{G} 1 \mathrm{~m} / \mathrm{G} 3 \mathrm{~m})$ GluLuc diente als spezifische Kontrolle und wurde bereits im Kapitel 3.4.3 beschrieben.

Bezogen auf die Basalaktivität von -350GluLuc, die als 100\% festgelegt wurde, betrug die Aktivierung von -169 GluLuc durch endogenes Pax 12\% $\pm 2 \%$ (Abb. 3.16). Die Mutation in -169G1PH0mut1 führte zu einer Abnahme der Luciferase-Aktivität um $75 \%$ auf $3 \% \pm$ 
0,3\%. Die Mutation in -169G1PH0mut2 verringerte die transkriptionelle Aktivität nicht signifikant um ca. $35 \%$ auf $7,5 \% \pm 1,5 \%$.

InR1G9

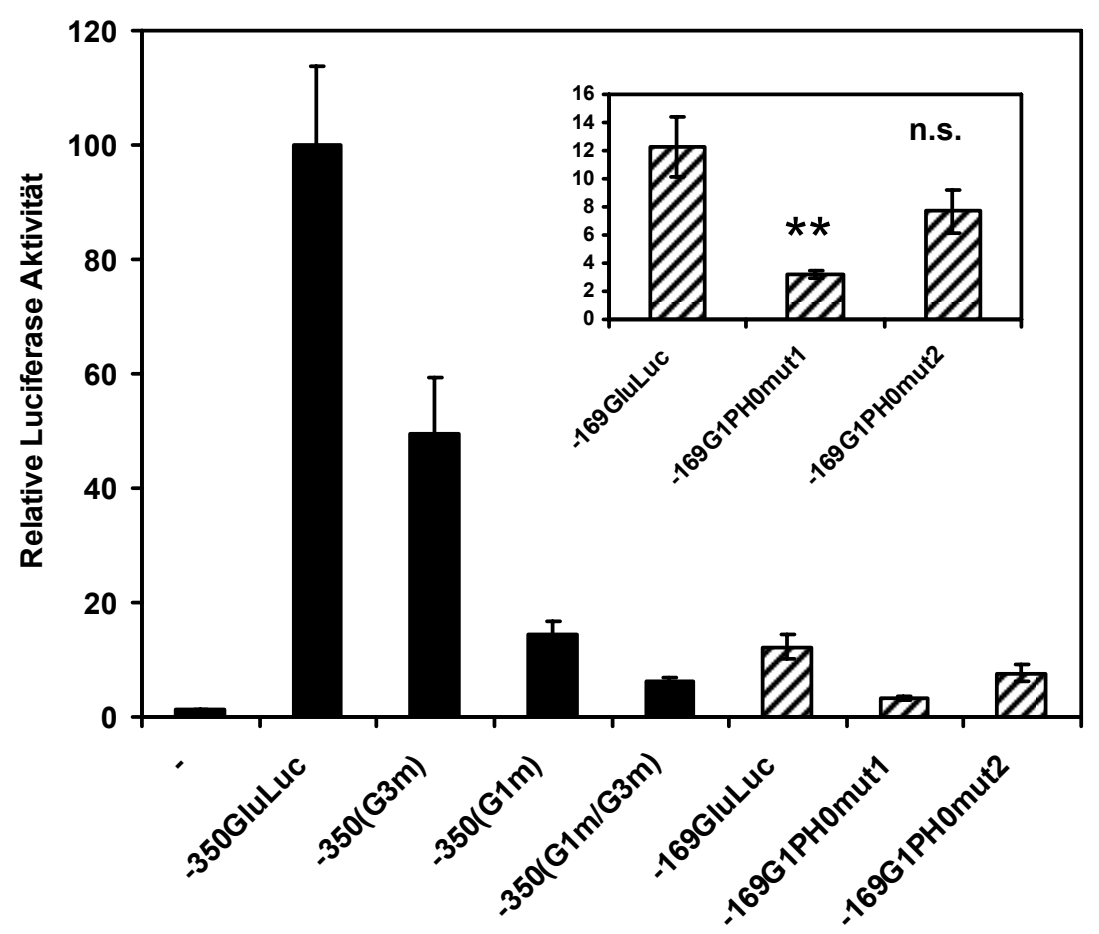

Abb. 3.16: Die Mutationen PHOmut1 und PHOmut2 im G1-Element des Glukagon-Promotors vermindern die Aktivität von -169GluLuc in der glukagonproduzierenden Zelllinie InR1G9. Die Reportergen-Plasmide -350GluLuc, -350(G3m)GluLuc, $\quad-350$ (G1m)GluLuc, -350(G1m/G3m)GluLuc, -169GluLuc, -169G1PH0mut1 und -169G1PH0mut2 (je $2 \mu \mathrm{g} / \mathrm{Schale}$ ) wurden mittels DEAE-Dextran transient in die glukagonproduzierende Zelllinie des a-Phänotyps InR1G9 transfiziert. Die relative Luciferase-Aktivität bezieht sich auf die Aktivität von -350GluLuc, dessen absoluter Wert als 100\% definiert wurde. Die Ergebnisse der Transfektionen sind Mittelwerte und SEM aus drei unabhängigen Experimenten mit Dreifachbestimmung. Statistik: Anova gefolgt von Student's $t$ test, ${ }^{* *}$ : $p<0,01$. n.s.: nicht signifikant.

3.4.7 Wirkung der Mutationen PHOmut1 und PHOmut2 im G1-Element auf die Aktivierung des Glukagon-Promotors durch Pax6 in der heterologen Zelllinie JEG-3

Die Luciferase-Reportergen-Plasmide -350GluLuc, -169GluLuc, -169G1PH0mut1 und -169G1PH0mut2 wurden zusammen mit den Expressionsplasmiden für Pax6-wt, -dHD und -3Ala transient in die heterologe Zelllinie JEG-3 cotransfiziert. 
Die Aktivität von -169GluLuc wurde durch die Cotransfektion von Pax6wt 42-fach stimuliert (Abb. 3.17). Bezogen auf die durch Pax6wt vermittelte Reportergen-Expression von -169GluLuc $(100 \% \pm 2 \%)$ führten die Mutationen in -169G1PH0mut1 und -169G1PH0mut2 zu einer Steigerung der Reportergen-Aktivität auf 306\% \pm 9\% bzw. $215 \% \pm 13 \%$ (Abb. 3.17, schwarze Säulen). Die Cotransfektion von -350GluLuc führte erwartungsgemäß zu einer synergistischen Aktivierung des Glukagon-Promotors durch Pax6wt über das G3- und G1-Element auf 604\% $\pm 48 \%$. Die Deletion der Homöodomäne $(\mathrm{dHD})$ führte zu einer Abnahme der Luciferase-Aktivität bei der Cotransfektion von -169GluLuc, -169G1PH0mut1 oder -169G1PH0mut2 auf etwa das gleiche Niveau von 42\%. Durch die Mutation von 3 Aminosäuren in der Homöodomäne (3Ala) wurde die Reportergenaktivität der oben genannten Konstrukte ebenfalls auf einen vergleichbaren Wert von 22 bis $30 \%$ verringert. Die Basalaktivitäten waren $2,4 \% \pm 0,4 \%$ bei -169 GluLuc, $2,8 \% \pm 0,5 \%$ bei $-169 \mathrm{G} 1 \mathrm{PH} 0$ mut1 und $2,4 \% \pm 0,4 \%$ bei $-169 \mathrm{G} 1 \mathrm{PH} 0$ mut 2 .

JEG-3

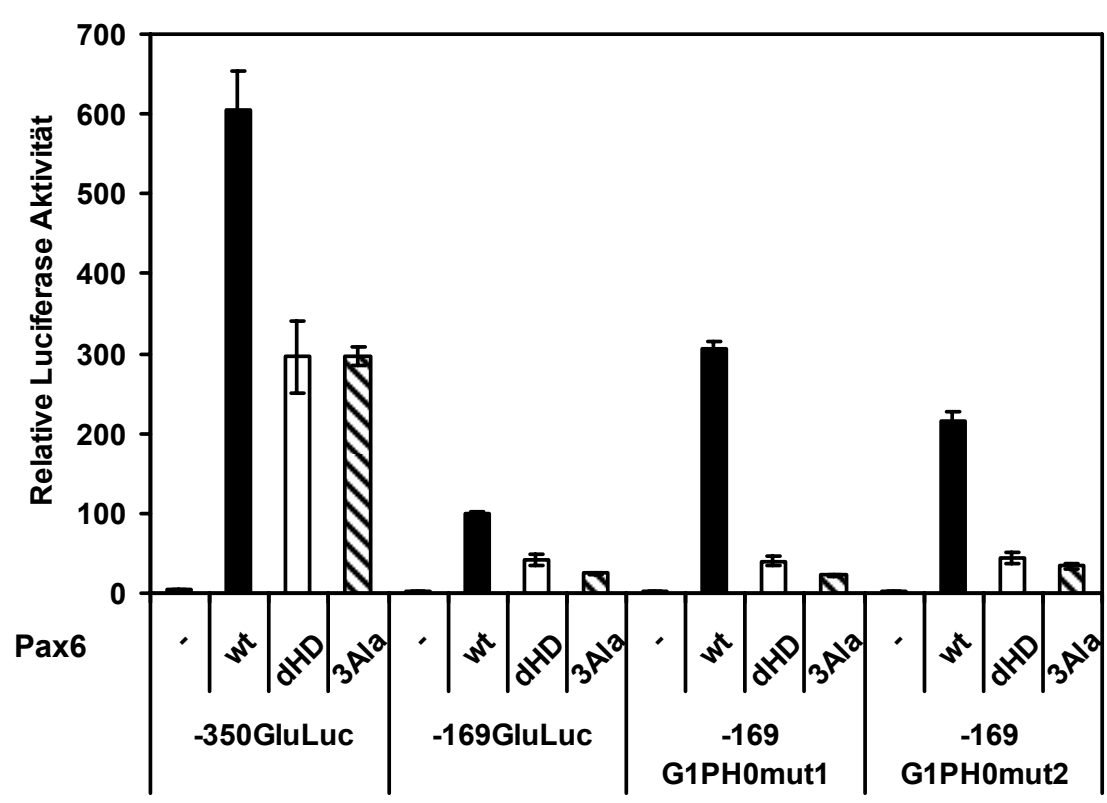

Abb. 3.17: PH0-artige Mutationen in G1 steigern die Aktivierung des Glukagon-Promotors der Ratte durch Pax6 über das G1-Element in der heterologen Zelllinie JEG-3. Die Reportergen-Plasmide -350GluLuc, -169GluLuc, -169G1PH0mut1 oder -169G1PH0mut2 ( $3 \mu \mathrm{g} / \mathrm{Schale}$ ) wurden zusammen mit Expressionsvektoren für Pax6wt (pBAT-Pax6wt), dHD (pBAT-dHD) und 3Ala (pBAT-3Ala) (207 ng/Schale) mittels Calcium-Phosphat-Präzipitation transient in die humane Chorionkarzinom-Zelllinie JEG-3 transfiziert. Die Luciferase-Aktivität bezieht sich auf die durch Pax6wt induzierte Aktivität des -169GluLuc-Plasmids dessen absoluter Wert als 100\% definiert wurde. Die Ergebnisse sind Mittelwerte und SEM aus drei unabhängigen Experimenten mit Doppelbestimmung. 
3.4.8 Wirkung der Mutationen PHOmut1 und PHOmut2 in G1 auf die Kernproteinbindung in Extrakten aus der pankreatischen Inselzelllinie InR1G9 und der heterologen Zelllinie JEG-3 mittels EMSA

Es wurden Kernproteinextrakte (K.E.) aus InR1G9- und JEG-3-Zellen (Schreiber et al., 1989; 2.19.2) hergestellt und im EMSA untersucht. Jeweils $5 \mu \mathrm{g}$ oder $20 \mu \mathrm{g}$ wurden mit den radioaktiv markierten Oligonukleotid-Sonden G1, G1PH0mut1 und G1PH0mut2 inkubiert.

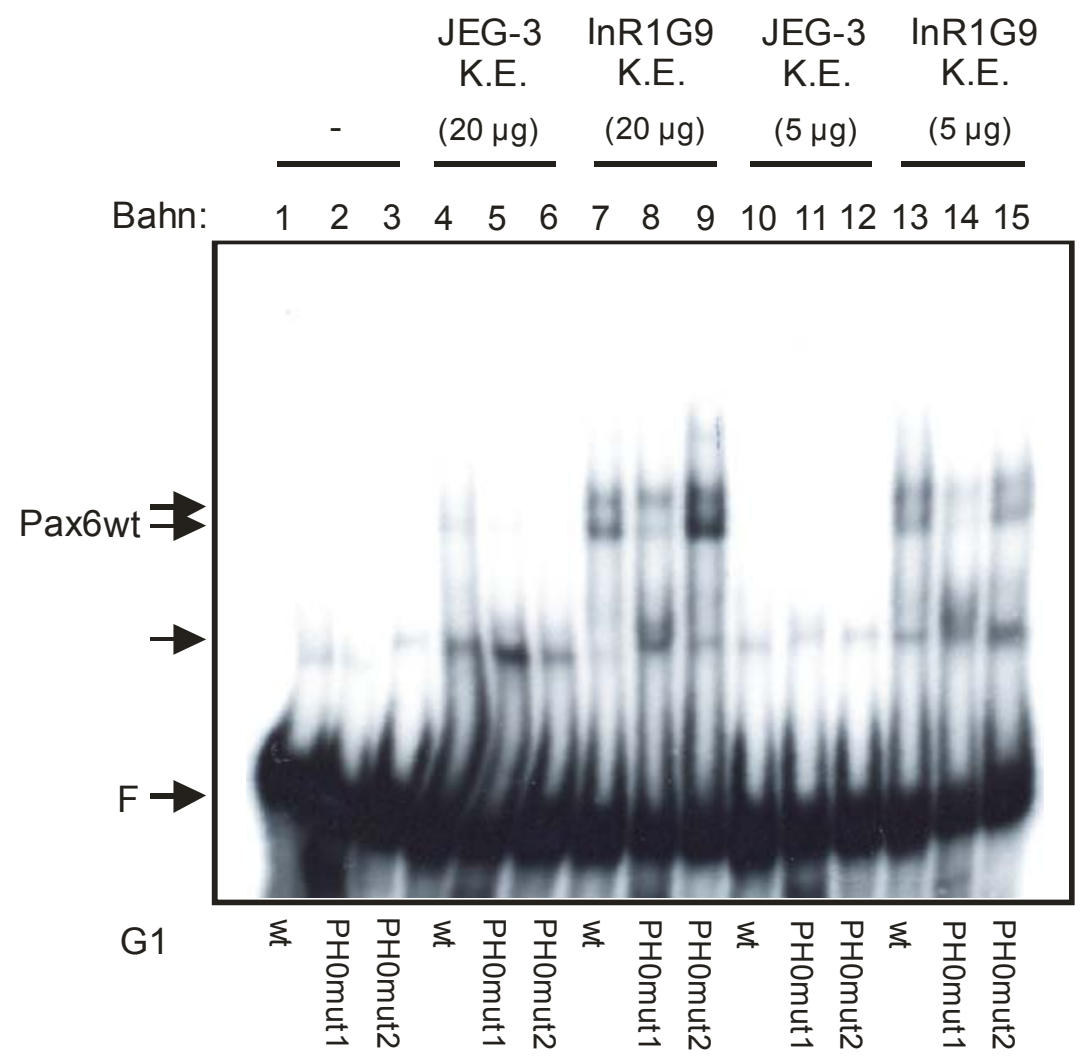

Abb. 3.18: Vergleich von Kernextrakten aus InR1G9- und JEG-3-Zellen auf ihre Bindung an die Sonden G1, G1PHOmut1 und G1PH0mut2. EMSA: Die radioaktiv markierten OligonukeotidSonden G1, G1PH0mut1 und G1PH0mut1 wurden mit $5 \mu$ oder $20 \mu$ Kernproteinextrakten (K.E.) aus der heterologen Zelllinie JEG-3 oder aus der glukagonproduzierenden Zelllinie InR1G9 inkubiert. Die Reaktionsansätze wurden auf einem 5\%igen Polyacrylamidgel unter nicht denaturierenden Bedingungen aufgetrennt. Radioaktiv markierte DNA wurde anschließend autoradiographisch detektiert. Der Doppelpfeil markiert an G1-bindende spezifische Proteinkomplexe aus InR1G9-Zellen. Der einzelne Pfeil markiert Proteine aus JEG-3-Zellen, die an G1, an G1PH0mut1 oder an G1PH0mut2 binden. F, freie Sonde. 
In den Reaktionsansätzen mit $5 \mu \mathrm{g}$ Kernproteinextrakten aus JEG-3-Zellen konnte durch die Mutation G1PH0mut1 und G1PH0mut2 ein Komplex detektiert werden, der langsamer migrierte, als ein Proteinkomplex mit der G1-Sonde (vgl. Abb. 3.18, Bahn 11 und 12 mit Bahn 10). In den Reaktionsansätzen mit $5 \mu \mathrm{g}$ Kernproteinextrakten aus InR1G9-Zellen waren zwei langsamer migrierende Komplexe detektierbar (Abb. 3.18, Bahn 13 und 15), deren Bindung durch die Mutation G1PH0mut1 stark vermindert wurde. Dabei kam es zur Formung eines schneller migrierenden Komplexes mit der Sonde G1PH0mut1 (Bahn 14). Bei der Inkubation mit $20 \mu \mathrm{g}$ Kernproteinextrakt kam es zu einer konzentrationsabhängigen Verstärkung der detektierten Protein-DNA-Komplexe (Bahn 4 bis 9).

\subsection{Bedeutung des N-terminalen $\beta$-Faltblatt-Motivs von Pax6 für die Bindung an den Glukagon-Promotor der Ratte}

3.5.1 In vitro Transkription/Translation von Pax6wt und Pax6 mit deletierter $\beta$-Faltblattstruktur und Darstellung der Expressionsprodukte in der SDS-PAGE

Zur Herstellung des Proteins $\mathrm{d} \beta-P a x 6$ wurde das Expressionsplasmid pcDNA3- $\mathrm{d} \beta P a x 6$ (2.11.1; Tab 2.6) in zellfreien Kaninchen-Retikulozyten-Lysaten unter Verwendung der T7RNA-Polymerase in vitro transkribiert/translatiert (2.19.1). Das Plasmid pcDNA3-dßPax6 kodiert für das Pax6 der Maus, mit Ausnahme der Aminosäuren 2 bis 17.

In Abbildung 3.19 sind die Expressionsprodukte Pax6wt, d $\beta-P a x 6$ und Pax6PD-L-HD in der SDS-PAGE dargestellt. Die Migration von $\mathrm{d} \beta$-Pax6 stimmte mit der berechneten Größe von 45 kDa überein (Abb. 3.19, Bahn 3). Zusätzlich wurden niedermolekulare Degradationsprodukte nachgewiesen. Die schwächere Expression von d $\beta-P a x 6$ im Vergleich zu Pax6wt wurde durch densitometrische Bestimmung der Bandenintensitäten im Mengenverhältnis der Lysate in den EMSA-Experimenten (3.5.2) berücksichtigt. 


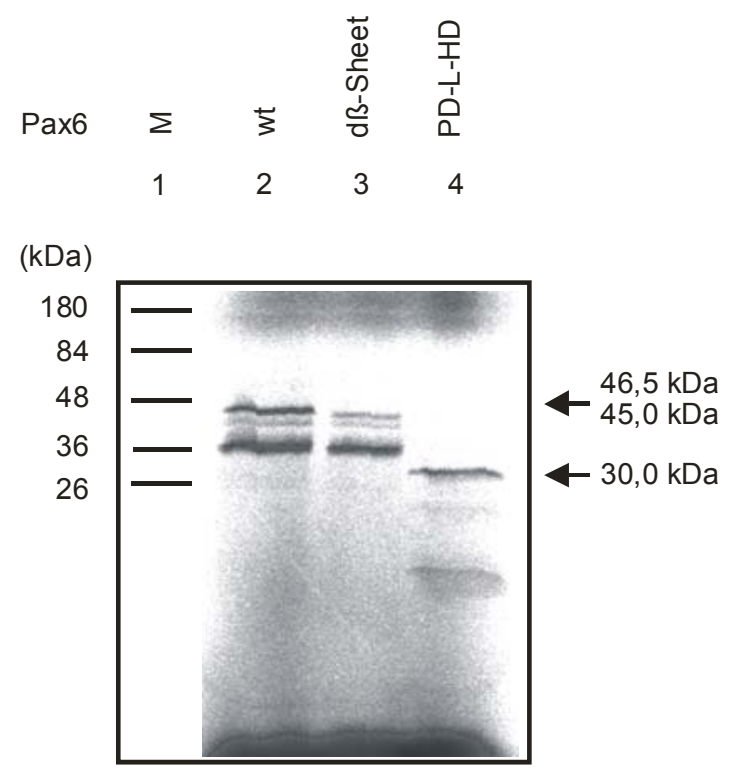

Abb. 3.19: In vitro Transkription/Translation von Pax6wt (46,5 kDa), d $\beta-P a x 6$ (45,0 kDa) und Pax6PD-L-HD $(30,0 \mathrm{kDa})$ in zellfreien Retikulozyten-Lysaten. Für die in vitro Transkription/Translation in Kaninchen-Retikulozyten-Lysaten wurde je $1 \mathrm{\mu g}$ der Expressionsplasmide pcDNA3-Pax6-WT, pcDNA3-dßPax6, und pcDNA3-PD-L-HD unter Verwendung von $\left.{ }^{35} \mathrm{~S}\right]-$ Methionin eingesetzt. Je $5 \mu \mathrm{l}$ der Reaktionsansätze (Bahn 2-4) wurden zusammen mit einem Molekulargewichtsstandard (Bahn 1) mittels SDS-PAGE aufgetrennt. Die Detektion der Proteinbanden erfolgte durch Autoradiographie.

3.5.2 Wirkung der Deletion der $\beta$-Faltblattstruktur von Pax6 auf die Bindung an das G1und G3-Element des Glukagon-Promotors

Retikulozyten-Lysate mit in vitro transkribierten/translatierten Pax6wt, d $\beta-P a x 6$, Pax6PD-L-HD und Pax6PD wurden mit radioaktiv markierten G1- oder G3-OligonukleotidSonden inkubiert.

Bei Inkubation der Proteine Pax6wt und Pax6PD-L-HD mit der G1- und der G3Oligonukleotid-Sonde kam es zu einer verlangsamten Bandenmigration sowohl mit dem G1-Element als auch mit dem G3-Element entsprechend der Größe der Proteine (Abb. 3.20, Bahn 5 bis 8). Die Deletion der $\beta$-Faltblattstruktur in der Pax6 Paired-Domäne führte zu einem Verlust der Bindung sowohl an die G1-, als auch an die G3-Sonde (Abb. 3.20, Bahn 3 und 4). Als Spezifitätskontrolle dienten Ansätze in denen nur Retikulozyten-Lysat ohne Expressionsplasmid mit den Sonden inkubiert wurde (Abb. 3.20, Bahn 11 und 12). 


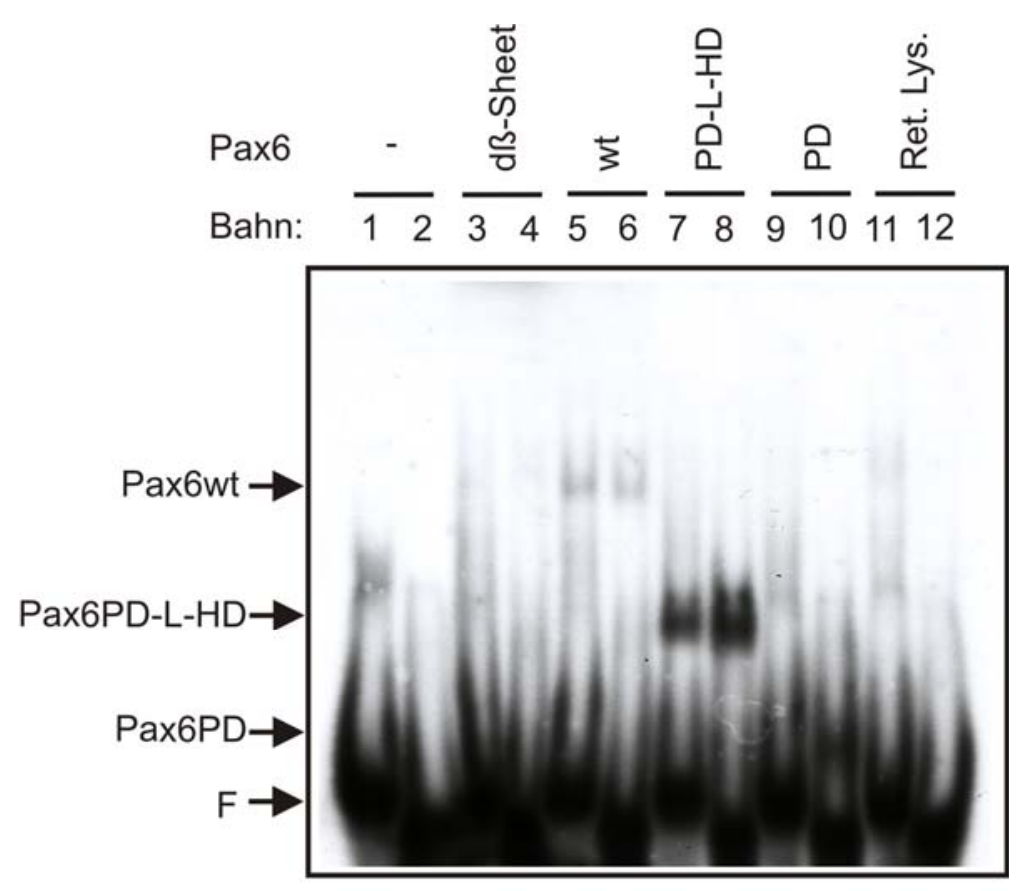

G1 G3 G1 G3 G1 G3 G1 G3 G1 G3 G1 G3

Abb. 3.20: Die $\beta$-Faltblattstruktur im N-terminalen Bereich der Pax6-Paired-Domäne ist für die Bindung von Pax6 an das G1- und G3-Element des Glukagon-Promotors notwendig. EMSA: Die radioaktiv markierten Oligonukleotid-Sonden G1 und G3 wurden mit gleichen Mengen in vitro transkribierten/translatierten d $\beta$-Pax6, Pax6wt, Pax6PD-L-HD und Pax6PD oder mit einem Kontrolllysat ohne Expressionsplasmid (Ret. Lys.) inkubiert. Die Reaktionsansätze wurden auf einem 5 \%igen Polyacrylamidgel unter nicht denaturierenden Bedingungen aufgetrennt. Radioaktiv markierte DNA wurde anschließend autoradiographisch detektiert. Die Pfeile markieren die spezifischen DNA-bindenden Pax6-Proteinkomplexe. F, freie Sonde.

\subsection{Bedeutung der Pax6-Linkerregion für die Aktivierung des Glukagon-Gens der Ratte durch Pax6}

Zwischen den beiden DNA-bindenden Domänen besitzt das Pax6-Protein einen 78 Aminosäure langen Linker dessen Struktur und Funktion weitgehend unbekannt sind.

Um die Bedeutung des Linkers weiter zu charakterisieren, wurden verschiedene Pax6Linkermutanten mittels primerless PCR (2.16.1) erzeugt und in vitro transkribiert/translatiert. Diese Mutanten wurden zum einen auf ihr Bindungsvermögen an das G1- und G3-Element im EMSA untersucht. Die funktionellen Auswirkungen einer Linkermutation für die Regulation der Transkription des Glukagon-Gens im Kontext der 5'flankierenden Region dieses Gens wurde weiterhin mittels transienter Transfektion der heterologen Zelllinie JEG-3 untersucht. 
3.6.1 Herstellung, in vitro Transkription/Translation von Pax6-Linkermutanten und Darstellung der Expressionsprodukte in der SDS-PAGE

Da wenig über die Struktur und Funktion der Linkerregion von Pax6 bekannt ist, wurden für die Mutationen Varianten gewählt, die die Länge des Linkers zwischen der PairedDomäne und der Homöodomäne nicht verändern. So konnte sichergestellt werden, dass mögliche Unterschiede in Protein-DNA-Bindungsstudien nicht durch ein verändertes „Spacing“ zwischen den beiden DNA-Bindedomänen zu Stande kamen. Außerdem wurden die Mutanten ohne die Transaktivierungsdomäne erzeugt, da Pax6 ohne die Transaktivierungsdomäne eine stärkere Bindung an das G1- und G3-Element zeigte (vgl. Abb. 3.3). Mittels primerless PCR (2.16.1) wurden die in Abbildung 3.21 dargestellten Pax6-Linkermutanten erzeugt. Bei dem Protein Pax6PD-Lmut-HD1 ist der N-terminale Bereich des Linkers ('a'), welcher die Aminosäuren von 137 bis 172 umfasst, mit dem Aminosäuren 173 bis 209 umfassenden C-terminalen Bereich des Linkers ('b') vertauscht. Aus eigenen Vergleichen von Pax6-Sequenzen unterschiedlicher Organismen und durch Literaturbefunde (Callaerts et al., 1997) ist bekannt, dass C-terminal der Paired-Domäne als auch N-terminal der Homöodomäne konservierte Regionen im Linker zu finden sind. Diesen Regionen wurden bei der Herstellung der nachfolgenden Konstrukte Beachtung geschenkt.

Bei Pax6PD-Lmut-HD3 wurden die Aminosäuren 198 bis 209 invertiert, um selektiv die konservierte Region N-terminal der Homöodomäne zu mutieren, welche der Aminosäuresequenz DEAQMRLQLKRK entspricht. Pax6PD-Lmut-HD4 stellt ein Konstrukt dar, bei dem die Aminosäuren 153 bis 172 mit den Aminosäuren 173 bis 197 vertauscht wurden. So blieb die konservierte Region N-terminal der Homöodomäne als auch die konservierte Region C-terminal der Paired-Domäne, ein Undecapeptid mit der Sequenz MYDKLRMLNGQ (AS 142 bis 152) erhalten. Abbildung 3.22 stell die Expressionsprodukte dieser Pax6-Varianten dar. Die Proteine Pax6PD-L-HD als auch die Linkermutanten Pax6PD-Lmut-HD1, sowie Pax6PD-Lmut-HD3 und 4 migrierten bei der berechneten Größe von $30 \mathrm{kDa}$ (Abb. 3.22, Bahn 2 bis 5). Zusätzlich wurden niedermolekulare Degradationsprodukte nachgewiesen. 

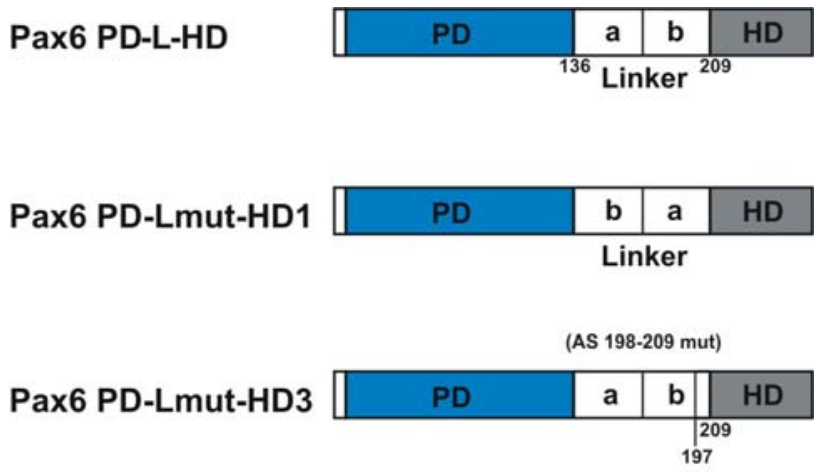

Pax6 PD-Lmut-HD4

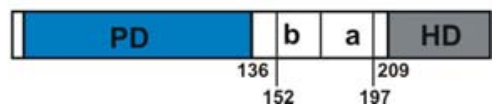

Abb. 3.21: Schematische Darstellung von Pax6 und der generierten Pax6-Linkermutanten. Pax6PD-L-HD (Pax6 Paired-Domäne mit Linker und Homöodomäne); Pax6PD-Lmut-HD1, 3 und 4 (Paired-Domäne mit mutiertem Linker und Homöodomäne 1, 3 und 4). PD, Paired-Domäne; L, Linker; HD, Homöodomäne.
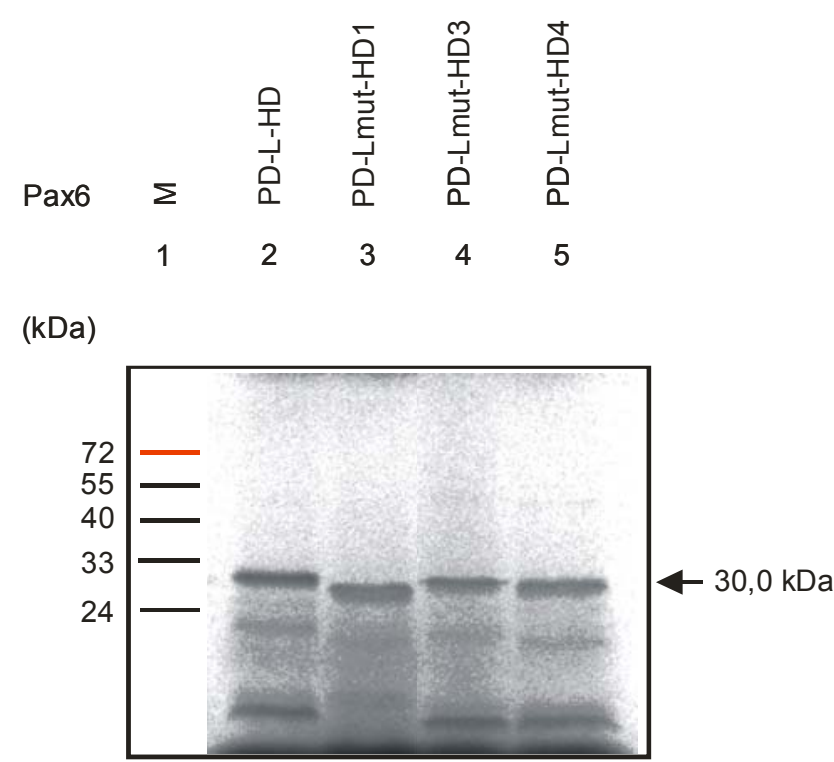

Abb. 3.22: In vitro Transkription/Translation von Pax6PD-L-HD und Pax6PD-Lmut-HD1, 3 und 4 in zellfreien Retikulozyten-Lysaten. Für die in vitro Transkription/Translation in KaninchenRetikulozyten-Lysaten wurde je $1 \mu \mathrm{g}$ der Expressionsplasmide pcDNA3-PD-L-HD sowie pcDNA3PD-Lmut-HD1, 3 und 4 unter Verwendung von $\left[{ }^{35}\right.$ S]-Methionin eingesetzt. Je $5 \mu l$ der Reaktionsansätze (Bahn 2-5) wurden zusammen mit einem Molekulargewichtsstandard (Bahn 1) mittels SDS-PAGE aufgetrennt. Die Detektion der Proteinbanden erfolgte durch Autoradiographie. 
3.6.2 Wirkung von Mutationen in der Pax6-Linkerregion auf die Bindung an das G1- und G3-Element des Glukagon-Promotors der Ratte

Gleiche Mengen Retikulozyten-Lysate mit in vitro transkribierten/translatierten Pax6wt, Pax6PD-L-HD, Pax6PD-Lmut-HD1, Pax6PD-L und Pax6PD wurden mit radioaktiv markierten G1- oder G3-Oligonukleotid-Sonden (2.11.1; Tab.2.1) inkubiert. Spezifische Protein-DNA-Komplexe ließen sich wie unter 3.2.2 beschrieben nachweisen (vgl. auch Abb. 3.3 und 3.4). Zusätzlich konnte eine retardierte Bande bei der Inkubation der G3Oligonukleotid-Sonde mit der Proteinvariante Pax6PD-Lmut-HD1 detektiert werden. Bei der Inkubation dieser Variante mit der G1-Sonde kam es nicht zu einer Bildung eines Protein-DNA-Komplexes (Abb. 3.23, Bahn 7 und 8). Bei der Inkubation eines Kontrolllysats ohne Expressionsplasmid mit den Sonden konnte keine spezifisch retardierte Bande nachgewiesen werden (Abb. 3.23, Bahn 13 und 14).

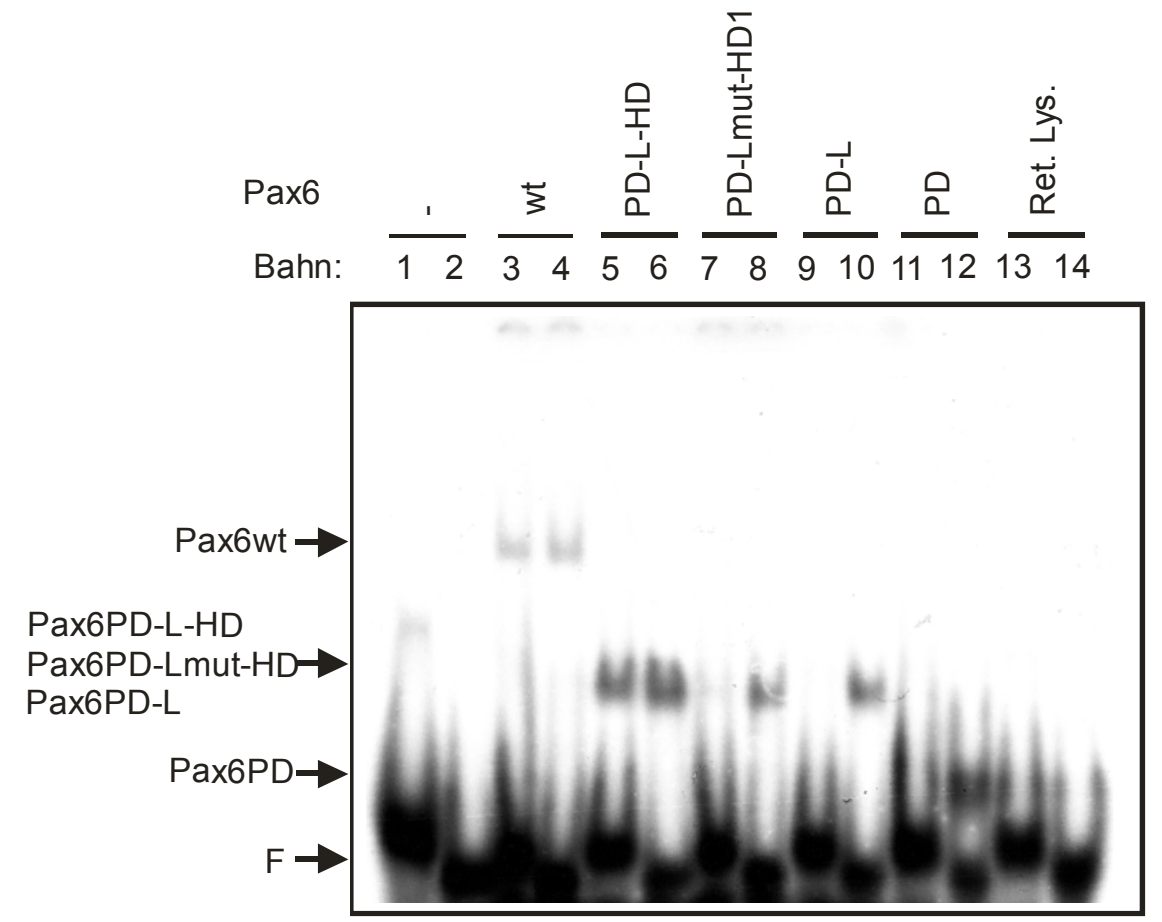

G1 G3 G1 G3 G1 G3 G1 G3 G1 G3 G1 G3 G1 G3

Abb. 3.23: Das in vitro transkribierte/translatierte Pax6-Fragment, in welchem die PairedDomäne und die Homöodomäne über einen mutierten Linker verbunden sind, bindet an das G3-Element, nicht aber an das G1-Element des Glukagon-Promotors. EMSA: Radioaktiv markierte G1- und G3-Oligonukleotid-Sonden wurden mit gleichen Mengen in vitro transkribierten/ translatierten Pax6wt, Pax6PD-L-HD, Pax6PD-Lmut-HD1, Pax6PD-L und Pax6PD oder mit einem Kontrolllysat ohne Expressionsplasmid (Ret. Lys.) inkubiert. Die Reaktionsansätze wurden auf einem $5 \%$ igen Polyacrylamidgel unter nicht denaturierende Bedingungen aufgetrennt. Radioaktiv markierte DNA wurde anschließend autoradiographisch detektiert. die Pfeile markieren die spezifischen DNA-bindenden Pax6-Proteinkomplexe. F, freie Sonde. 
Die Mutation der konservierten Region N-terminal der Homöodomäne (AS 198 - 209; Pax6PD-Lmut-HD3) führte zu einer stark verringerten Bindung an das G1-Element; die Bindung an das G3-Element blieb bestehen (Abb. 3.24A, Bahn 4 und 10; Abb. 3.24B). Für die Pax6-Variante Pax6PD-Lmut-HD4, bei der die konservierten Regionen N-terminal der Homöodomäne wie auch C-terminal der Paired-Domäne erhalten blieben, konnte eine unveränderte Bindung an das G3- und das G1-Element nachgewiesen werden (Abb. 3.24A, Bahn 5 und 11; Abb. 3.24B). Diese Befunde deuten darauf hin, dass nicht nur eine spezifische Länge des Pax6-Linkers sondern auch seine Struktur für die Bindung von Pax6 an das G1-Element notwendig ist. Der konservierten Region N-terminal der Homöodomäne, und möglicherweise auch C-terminal der Paired-Domäne, scheint dabei eine besondere Bedeutung zuzukommen. 
A

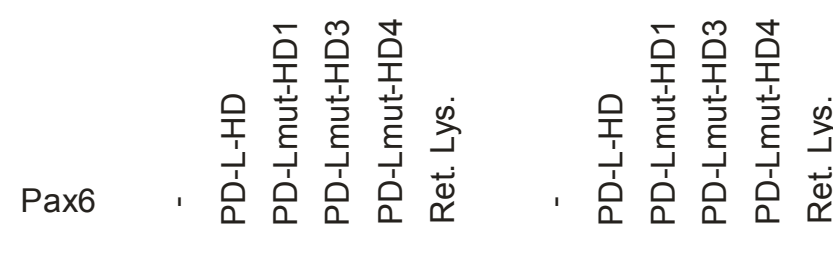

Bahn: $\quad \begin{array}{llllllllllll}1 & 2 & 3 & 4 & 5 & 6 & 7 & 8 & 9 & 10 & 11 & 12\end{array}$

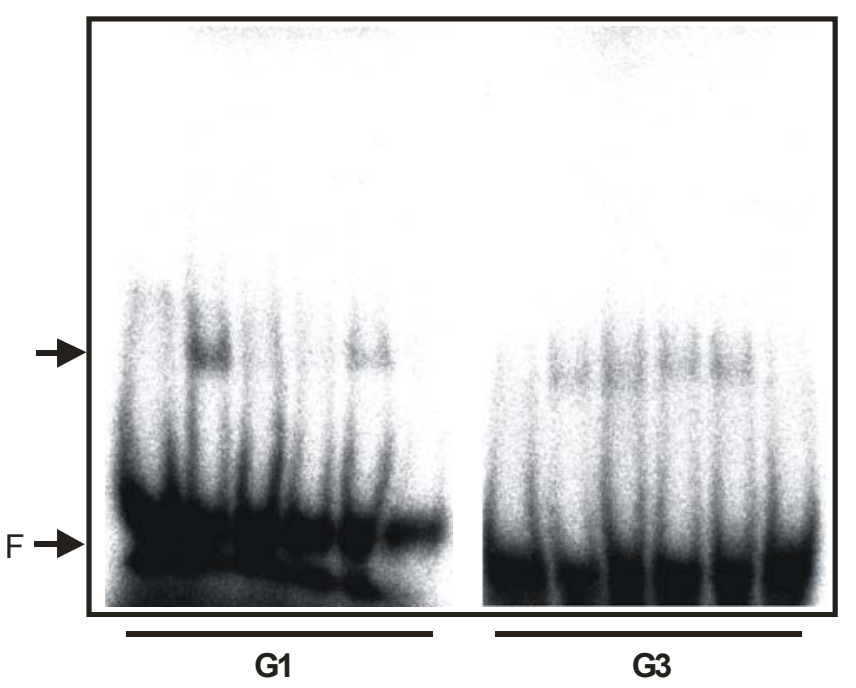

B
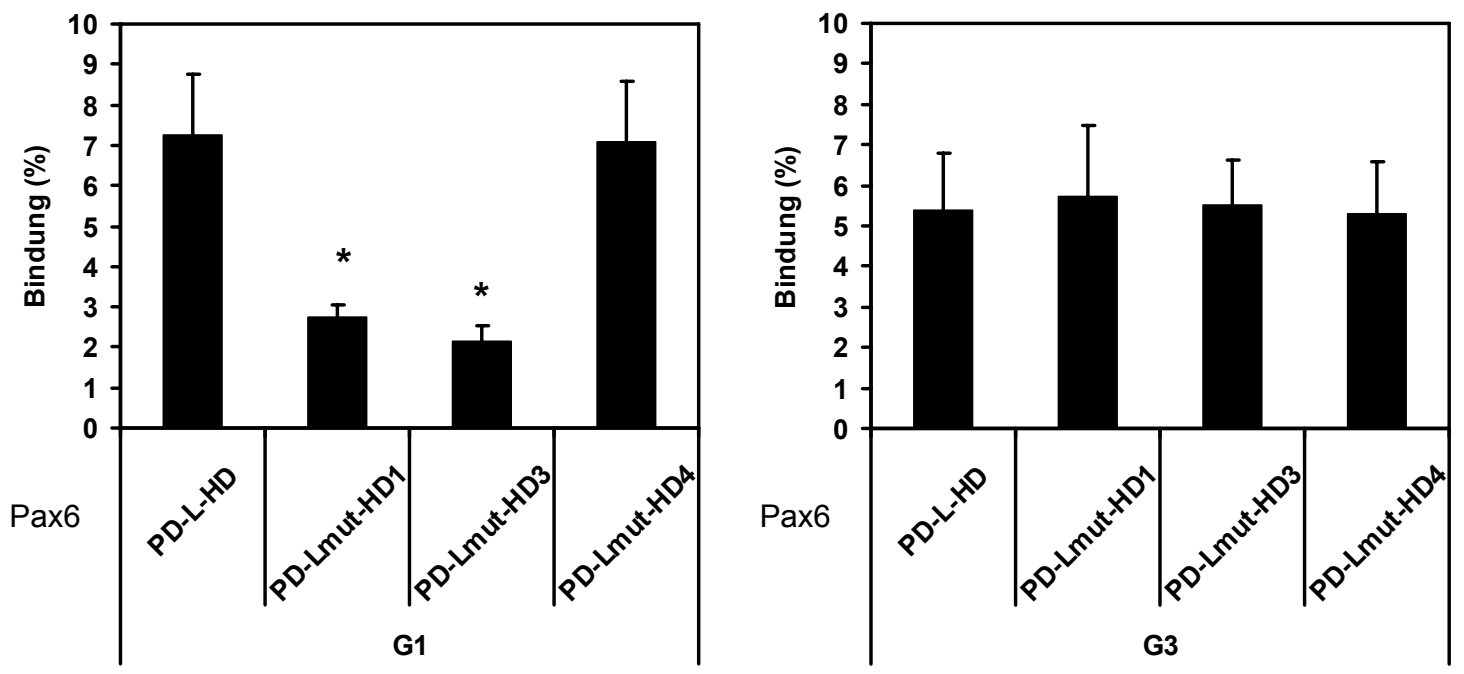

Abb. 3.24: Die Mutation der Aminosäuren 198 bis 209 der Pax6-Linkerregion führt zu einem Verlust der Bindung an das G1-Element des Glukagon-Promotors. (A) EMSA: Radioaktiv markierte G1- und G3-Oligonukleotid-Sonden wurden mit gleichen Mengen in vitro transkribierten/translatierten Pax6PD-L-HD sowie Pax6PD-Lmut-HD1, 3 und 4 oder mit einem Kontrolllysat ohne Expressionsplasmid (Ret. Lys.) inkubiert. Die Reaktionsansätze wurden auf einem 5 \%igen Polyacrylamidgel unter nicht denaturierenden Bedingungen aufgetrennt. Radioaktiv markierte DNA wurde anschließend autoradiographisch detektiert. Der Pfeil markiert die spezifischen DNA-bindenden Pax6-Proteinkomplexe. F, freie Sonde. (B) Densitomtrische Messung der prozentualen Bindung der Sonden durch die Pax6-Varianten. Die Ergebnisse sind Mittelwerte und SEM aus 3 unabhängigen Experimenten. Statistik: Anova gefolgt von Student's $t$ test, *: $p<$ 0,05 . 
3.6.3 Funktionelle Bedeutung der Pax6-Linkerregion für die Aktivierung des GlukagonPromotors der Ratte durch Pax6: Wirkung einer Mutation der Pax6-Linkerregion auf die Aktivierung des Glukagon-Promotors durch Pax6 in der heterologen Zelllinie JEG-3

Um zu untersuchen, welche Auswirkung die Mutation des Pax6-Linkers auf die Aktivierung des Glukagon-Gens über das G1- und G3-Element durch Pax6 hat, wurde das Luciferase-Reportergenplasmide -350GluLuc ausgewählt und zusammen mit $207 \mathrm{ng}$ der Expressionsplasmide für Pax6wt, Pax6Lmut und Pax6dHD in die humane Chorionkarzinomzelllinie JEG-3 cotransfiziert. Mit Hilfe von 5'- und 3'-Deletionsmutanten des 350 bp-Glukagon-Promotorkonstruktes wurde die Wirkung der Mutation des Pax6Linkers auf die Aktivierung des Glukagon-Gens durch Pax6 über das G1-Element oder das G3-Element alleine untersucht. Dazu wurden die Luciferase-Reportergenplasmide -350/-150GluLuc und -169GluLuc ausgewählt und zusammen mit den oben genannten Expressionsplasmiden in die Zelllinie JEG-3 cotransfiziert.

Der Expressionsvektor für Pax6Lmut wurde analog zu den unter 3.6.1 beschriebenen Konstrukten hergestellt und entspricht Pax6PD-Lmut-HD1, allerdings mit Transaktivierungsdomäne (Abb. 3.25, oben). Der Expressionsvektor Pax6dHD kodiert für das Pax6-Protein der Maus mit Ausnahme der Homöodomäne. Er wurde ausgewählt, da der inhibitorische transkriptionelle Effekt dieser Pax6-Mutation auf die GlukagonGentranskription bereits charakterisiert wurde (Teichler, Dissertation 2004).

Die Aktivität von -350GluLuc wurde durch die Cotransfektion von Pax6wt 185-fach stimuliert (Abb. 3.25). Bezogen auf die durch Pax6 vermittelte Reportergen-Expression von -350GluLuc $(100 \% \pm 3 \%)$ führte die Mutation der Pax6-Linkerregion zu einer 45\%igen Abnahme $( \pm 8 \%)$ der Reportergen-Aktivität. Die Deletion der Pax6-Homöodomäne führte zu einer vergleichbaren Reduktion von 55\% $\pm 10 \%$. Bei Cotransfektion von -350/150GluLuc und des Pax6wt-Expressionsvektors wurden 73\% \pm 7\% Reportergen-Aktivität erreicht. Die Mutation der Pax6-Linkerregion wie auch die Deletion der Homöodomäne verringerte die transkriptionelle Aktivität auf 26\%. Die durch Pax6wt vermittelte Reportergen-Aktivität von -169GluLuc betrug $26 \% \pm 2 \%$ und wurde durch die Mutation der Linkerregion oder durch Deletion der Homöodomäne weiter auf 15\% bzw. $7 \%$ verringert. Die Basalaktivitäten waren $0,5 \% \pm 0,07 \%$ bei -350 GluLuc, $2,8 \% \pm 0,5 \%$ bei $-350 /-$ $150 \mathrm{GluLuc}$ und $0,3 \% \pm 0,02 \%$ bei $-169 \mathrm{GluLuc}$. 
Pax6 wt

\begin{tabular}{|l|c|c|c|c|}
\hline PD & $\mathbf{a}$ & $\mathbf{b}$ & HD & TAD \\
\hline
\end{tabular}

Pax6 Lmut

\begin{tabular}{|l|c|c|c|c|}
\hline PD & b & a & HD & TAD \\
\hline \multicolumn{4}{|c|}{ Linker }
\end{tabular}

Pax6 dHD

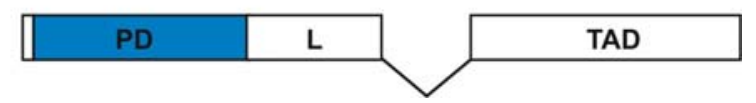

JEG-3

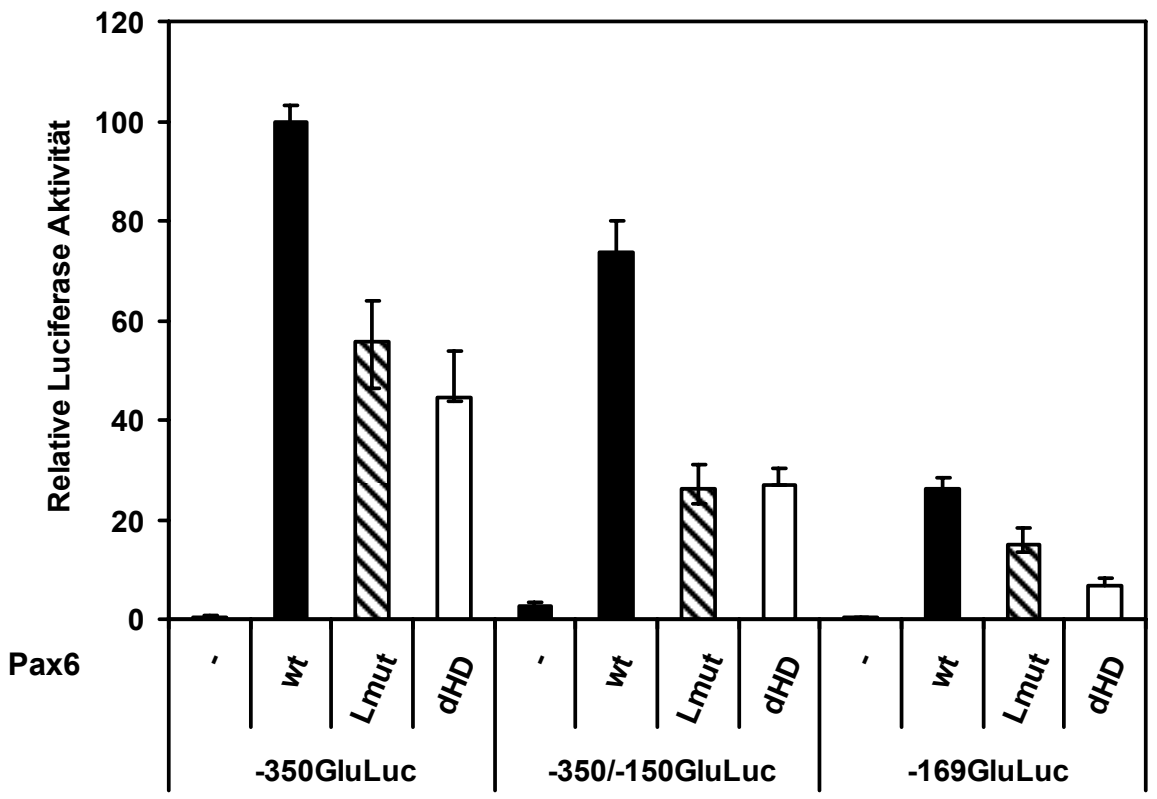

Abb. 3.25: Die Mutation der Pax6-Linkerregion verringert die Aktivierung des GlukagonPromotors durch Pax6 sowohl über das G3-Element als auch über das G1-Element in der heterologen Zelllinie JEG-3. Die Reportergen-Plasmide -350GluLuc, -350/-150GluLuc und -169GluLuc (3 $\mu \mathrm{g} / \mathrm{Sch}$ ale) wurden zusammen mit den Expressionsplasmiden für Pax6wt (pBATPax6wt), Pax6Lmut (pBAT-Pax6Lmut) und dHD (pBAT-dHD) (207 ng/Schale) mittels CalciumPhosphat-Präzipitation transient in die humane Chorionkarzinom-Zelllinie JEG-3 transfiziert. Die Luciferase-Aktivität bezieht sich auf die durch Pax6wt induzierte Aktivität des -350GluLucPlasmids, dessen absoluter Wert als 100\% definiert wurde. Die Ergebnisse sind Mittelwerte und SEM aus drei unabhängigen Experimenten mit Doppelbestimmung. Die in den Transfektionen eingesetzten Pax6-Varianten sind schematisch in der Abbildung oben dargestellt. 
3.6.4 Untersuchung des Expressionsgrades von Pax6 und Pax6-Mutanten in COS-1Zellen

Um zu überprüfen, ob die beobachtete Abnahme der transkriptionellen Aktivität von Pax6 am Glukagon-Gen nach der Mutation der Linkerregion auf einen geringeren Expressionsgrad zurückzuführen ist, wurden Transfektionsstudien in COS-1-Zellen durchgeführt. Aus den transfizierten Zellen wurden Ganzzellextrakte gewonnen (2.19.3) und die Expression von Pax6wt, Pax6Lmut und Pax6dHD mit einem Pax6-spezifischen Antiserum (2.11.5, Rabbit anti-Pax-QNR-Serum12, Carriere et al., 1995) im Westernblot nachgewiesen. In COS-1-Zellen können Plasmide, die einen „SV40 Origin“ enthalten, episomal repliziert werden, was in JEG-3 Zellen nicht möglich ist. Dadurch konnte die Proteinausbeute erhöht werden, um die Pax6-Varianten im Westernblot detektieren zu können.

Der Expressionsgrad von Pax6 mit mutierter Linkerregion entsprach der von Pax6-Wildtyp (Abb. 3.26A, Bahn 2 und 3), was auch durch densitometrische Messungen bestätigt wurde (Abb. 3.26B). Die Expression von Pax6 mit deletierter Homöodomäne war um etwa das Doppelte erhöht und entsprach somit vorherigen Befunden, die den Expressionsgrad und die Kerngängigkeit dieser Pax6-Mutante beschrieben (Teichler, Dissertation 2004). Die Transfektion der COS-1-Zellen mit einem Kontrollvektor lieferte keine zusätzliche Banden (Abb. 3.26A, Bahn 5). 
A

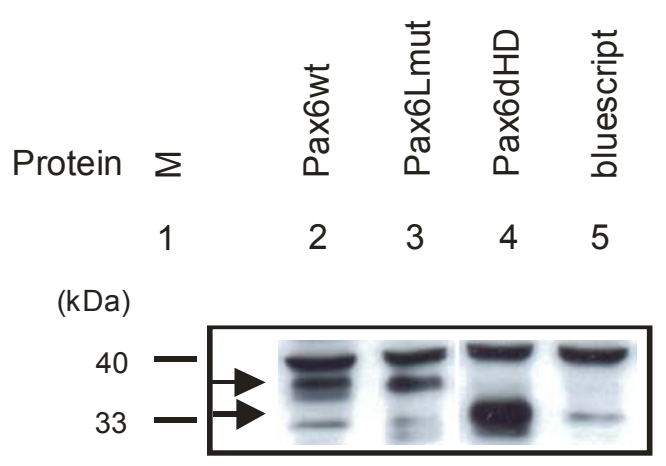

B

Cos-1

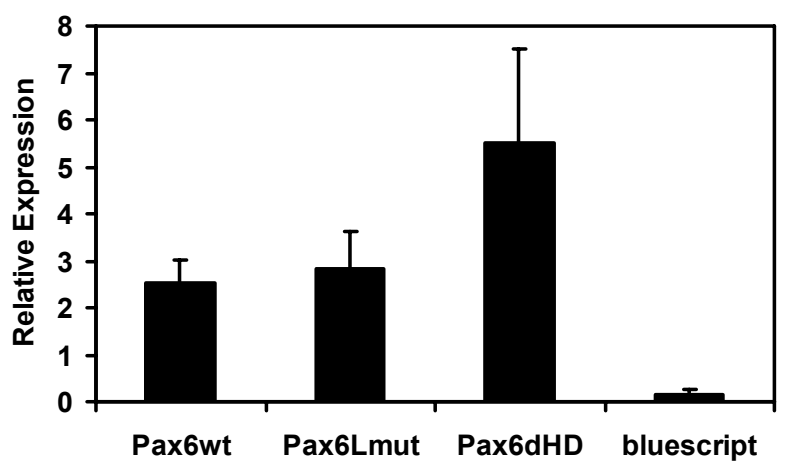

Abb. 3.26: Immunoblot zum Nachweis des Expressionsgrades von Pax6-Wildtyp, Pax6 mit mutierter Linkerregion oder mit deletierter Homöodomäne. COS-1-Zellen wurden mit Expressionsvektoren für Pax6wt (pcDNA3-Pax6-WT), Pax6Lmut (pcDNA3-Pax6Lmut) und dHD (pcDNA3-dHD) mittels DEAE-Dextran transient transfiziert (0,5 $\mu \mathrm{g} /$ Schale). (A) Immunoblot: Die Immundetektion erfolgte durch das Serums anti-Pax-QNR-Serum12 (1:200 verdünnt in PBS-T + $5 \%(\mathrm{w} / \mathrm{v})$ Magermilchpulver). Als Negativkontrolle diente die Transfektion des Plasmids pBluescript (bluescript). (B) Desitometrische Bestimmung der Bandenintensitäten aus den Immundetektionen mit dem Programm BioDocAnalyzer (Biometra, Göttingen). Die Ergebnisse sind Mittelwerte und SEM aus 2 unabhängigen Experimenten mit Doppelbestimmung. 


\section{DISKUSSION}

Der Blutglukosespiegel eines gesunden Menschen schwankt nur in einem geringen Bereich zwischen 4 und $7 \mathrm{mM}$. Um bei stark wechselndem Nahrungsangebot und Energieverbrauch den Blutglukosespiegel in diesen physiologischen Grenzen zu halten, muss die Expression und Sekretion der Pankreasinselhormone Insulin und Glukagon, den Hauptantagonisten der Glukosehomöostase, eng reguliert sein.

Das Peptidhormon Glukagon erhöht die Glukoseabgabe aus der Leber durch Steigerung der Glykogenolyse und Glukoneogenese, sowie durch Hemmung der Glykogensynthese und Glykolyse in den Leberzellen und ist damit für die Aufrechterhaltung ausreichender Blutzuckerspiegel während der Hungerphase notwendig (Unger und Orci 1981a; Unger und Orci 1981b, Jiang und Zhang, 2003; Gelling et al., 2003). Störungen in der GlukagonBiosynthese und -Sekretion tragen zur Pathogenese des Diabetes mellitus bei, der sich durch hyperglykämische Zustände äußert.

Die zellspezifische und nahrungsabhängige Aktivierung des Glukagon-Gens in den $\alpha$ Zellen der Pankreasinseln wird durch eine a-zellspezifische Kombination von Transkriptionsfaktoren bestimmt, unter denen Pax6 eine wichtige Rolle zu spielen scheint (Knepel, 2001). Neben der a-zellspezifischen Aktivierung des Glukagon-Gens wird Pax6 auch mit der blutzuckersenkenden Wirkung der Thiazolidindione, einer neuen Klasse oraler Antidiabetika, in Verbindung gebracht (Schinner et al., 2002). Dennoch ist der molekulare Mechanismus der Regulation der Glukagon-Gentranskription durch Pax6 weitgehend unbekannt. In der vorliegenden Arbeit wird die Rolle der Pax6-Homöodomäne bei der Aktivierung des Glukagon-Gens auf molekularer Ebene, sowie unter funktionellen Aspekten beschrieben. Erstmals betrachtet diese Arbeit auch die Bedeutung der Pax6Linkerregion und deren Einfluss auf die Regulation der Glukagon-Gentranskription.

\subsection{Bedeutung der Pax6-Homöodomäne bei der Bindung von Pax6 an das G1- oder G3-Element des Glukagon-Promotors}

Transkriptionsfaktoren bestehen aus mindestens zwei funktionellen Proteindomänen: Aus einer DNA-bindenden Domäne und einer Transaktivierungsdomäne (Latchman, 1997; Langdon et al., 2001). Interessanterweise besitzt der paired-HomöodomänenTranskriptionsfaktor Pax6, neben seiner Paired-Domäne (Bopp et al., 1986; Treisman et al., 1991) noch eine zweite DNA-bindende Domäne, die Homöodomäne (Walther und 
Gruss, 1991b). Die beiden Pax6-Domänen binden an unterschiedliche DNA-Sequenzen (Epstein et al., 1994a; Wilson et al., 1993), jedoch beide jeweils mit großer Variationsbreite und überlappend mit DNA-Sequenzen, welche von Paired-Domänen bzw. den Homöodomänen anderer Transkriptionsfaktoren gebunden werden (Ritz-Laser et al., 1999; Andersen et al., 1999; Herzig et al., 2000). Wie unter diesen Umständen die spezifische Bindung von Pax6 an bestimmte Zielgene erreicht wird, ist nicht bekannt. Innerhalb des Pax6-Proteins sind die zwei DNA-Bindedomänen am stärksten konserviert, ein Umstand, welcher für einen besonders hohen evolutionären Druck und große funktionelle Bedeutung beider Domänen spricht. Da gegenüber jeweils optimalen synthetischen Bindungsstellen die Affinität der Pax6 Paired-Domäne größer ist als die der Homöodomäne, gilt die Paired-Domäne als die primäre DNA-Bindedomäne von Pax6 (Czerny und Busslinger, 1995). Demgegenüber ist die Bedeutung der Homöodomäne weniger klar. So konnte das dem Pax6 in Drosophila entsprechende Protein eyeless auch ohne Homöodomäne eine Augenbildung induzieren (Punzo et al., 2001). Vier der bisher bekannten neun Pax-Proteine des Menschen (Dahl et al., 1997; Mansouri et al., 1999; Underhill, 2000; Walther et al., 1991b) besitzen keine Homöodomäne. Es gibt aber auch Hinweise auf eine entscheidende Rolle der Pax6-Homöodomäne während der Entwicklung des Nervensystems. In C. elegans wurde eine Pax6-Isoform ohne die PairedDomäne gefunden, welche für die Differenzierung des peripheren Nervensystems essentiell zu sein scheint (Zhang und Emmons, 1995). Außerdem weist die Konservierung der Homöodomänen-Bindungsstelle $\mathrm{P} \underline{3}$ (TAATYNRATTA, mit $\mathrm{Y}=\mathrm{C} / \mathrm{T}, \mathrm{N}=\mathrm{A} / \mathrm{C} / \mathrm{T} / \mathrm{G}$ und $R=A / G$ ) in augenspezifischen Promotoren darauf hin, dass die Pax6-Homöodomäne zur Regulation einiger Zielgene des Pax6-Proteins einen wichtigen Beitrag leisten könnte (Mismer und Rubin, 1989; Fortini und Rubin 1990; Singh et al., 1998).

Sowohl im G1-Element als auch im G3-Element des Glukagon-Promotors gibt es DNABindungsstellen für Homöodomänen-Proteine, die benachbart zu der Pax6-PairedDomänen-Bindungsstelle liegen. Im G1-Element finden sich Bindungsstellen für die Homöodomänen-Proteine Cdx2/3, Brain-4 und IsI-1 (Andersen et al., 1999, Ritz-Laser et al., 1999; Hussain et al., 1997; Wang und Drucker, 1995) (Abb. 1.4). Das G3-Element ist in zwei Domänen unterteilt: in die Bindungsstelle für die Pax6-Paired-Domäne G3A (5'CGCCTGA-3'), welche Teil des PISCES-Motivs ist, und G3B (5'-GATTGAAGGGTGTA3') (Knepel et al., 1990a). G3B zeigt Ähnlichkeiten mit Bindungsstellen von Mitgliedern

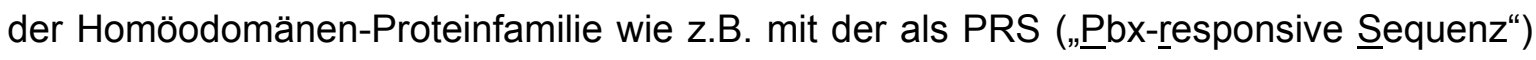
bezeichneten in vitro Bindungsstelle von Pbx (Kamps et al., 1990, Nourse et al., 1990; Lu et al., 1994). Tatsächlich bindet ein Heterodimer aus den Homöodomänen-Proteinen Pbx1/2 (Monica et al., 1991) und dem ubiquitären Homöodomänen-Protein Prep-1 (Berthelsen et al., 1998) an G3B (Herzig et al., 2000). 
In der vorliegenden Arbeit wurde untersucht, auf welche Art und Weise die Pax6Homöodomäne bei der Bindung an das G1-Element und das G3-Element des GlukagonPromotors beiträgt. Dazu wurden Deletionsmutanten des Pax6-Proteins hergestellt (Abb. 3.1) und in Protein-DNA-Bindungsanalysen auf ihre Fähigkeit getestet, an das G1- oder G3-Element zu binden. Dabei zeigte sich, dass die Paired-Domäne von Pax6 alleine ausreichend für eine Bindung an das G3-Element ist. Alle Pax6-Varianten, die mindestens die Paired-Domäne enthalten (Pax6wt, Pax6PD-L-HD und Pax6PD, Abb. 3.3; sowie Pax6PD-L, Abb. 3.4), vermochten an das G3-Element zu binden. Die isolierte Pax6Homöodomäne zeigte keine Bindung an G3. Demgegenüber ist die Pax6-Homöodomäne aber für eine Bindung von Pax6 an das G1-Element notwendig, obwohl sie alleine, wie auch die Paired-Domäne nicht in der Lage ist an G1 zu binden (Abb. 3.3). Das deutet darauf hin, dass die Bindung von Pax6 an G1 eine funktionelle bzw. physikalische Interaktion zwischen der Paired-Domäne und der Homöodomäne erfordert. Damit in Übereinstimmung führte die Deletion der Pax6-Homöodomäne zu einer stark verringerten Bindung an das G1-Element, wohingegen die Bindung an das G3-Element unverändert blieb (Teichler, Dissertation 2004). Auch Ritz-Laser et al. (1999) zeigten, dass an der 5'flankierenden Region des Glukagon-Gens die Pax6-Paired-Domäne für ca. 50\% der halbmaximalen Bindung an G3 ausreichend ist, während nur eine sehr schwache Bindung an G1 zu verzeichnen war. Ein Protein, welches beide DNA-Bindedomänen enthielt (entsprechend der Variante Pax6PD-L-HD, Abb. 3.1, Abb. 3.3) konnte mit hoher Affinität an G1 und G3 binden. Diese Befunde sprechen dafür, dass zumindest für die Bindung von Pax6 an das G1- und G3-Element der Homöodomäne unterschiedliche Bedeutung zukommt. Obwohl die Pax6-Bindungsstellen in den Promotorelementen G1 und G3 eine eindeutige Homologie in ihrer Sequenz zeigen (Abb. 1.6), haben sie nur 8 von 16 Nukleotiden gemeinsam (Philippe et al., 1995), was den funktionellen Unterschied in der Protein-DNA-Interaktion erklären könnte.

Konsistent mit den Bindungsdaten der hier beschriebenen in vitro transkribierten/translatierten Pax6-Proteinvarianten (Abb. 3.2) konnten die in Insektenzellen exprimierten Proteine Pax6wt und Pax6PD (3.3, Abb. 3.7) an das G3Element binden (Abb. 3.8). Im Gegensatz zu Ritz-Laser et al. (1999), die eine sehr schwache Bindung der Pax6 Paired-Domäne an G1 feststellen konnten, war keine Bindung von Pax6PD an das G1-Element zu verzeichnen, obwohl durch dieses Protein ca. $80 \%$ der G3-Sonde gebunden wurden (Abb. 3.8). Grund hierfür sind vermutlich die verschiedenen Expressionssysteme welche zur Proteinproduktion für die Protein-DNABindungsanalysen eingesetzt wurden. So entstammen die Proteine in dieser Arbeit der in vitro Transkription/Translation oder dem Baculovirus-Expressionsvektor-System (BEVS), welches eigens in der Abteilung erfolgreich etabliert wurde (3.3). Ritz-Laser et al. (1999) 
verwendeten zur Herstellung der Proteine die bakterielle Expression von GSTFusionsproteinen.

\subsection{Kooperative Bindung der Homöodomäne und der Paired-Domäne von Pax6 an den Glukagon-Promotor}

Die grundsätzliche Funktion von Pax-Proteinen als Regulatoren der Transkription hängt von einer intakten Funktion ihrer Paired-Domäne ab (Chalepakis et al., 1991; Treisman et al., 1991). Eine Vielzahl von mutierten Allelen von Pax-Genen, die einen loss-of-functionPhenotyp verursachen, kodieren eine Paired-Domäne mit Mutationen, welche die DNABindung des Proteins beeinflussen (Xu et al., 1995). Es wurde auch gezeigt, dass PaxProteine onkogenes Potential haben und die Fähigkeit von Pax3 zur Transformation von der DNA-Bindung der Paired-Domäne abhängt (Chalepakis et al., 1993; Maulbecker und Gruss, 1993).

Strukturdaten zeigen, dass Paired-Domänen aus zwei Subdomänen bestehen; aus der Nterminalen und der C-terminale Subdomäne (Xu et al. 1995) oder anders genannt, der PAI- und RED-Domäne (PAI + RED = PAIRED, Jun und Desplan, 1996). Jede der beiden

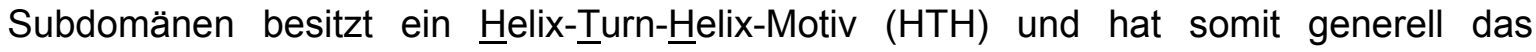
Potential an DNA zu binden. Dennoch geht nur die N-terminale nicht aber die C-terminale Subdomäne des Drosophila paired-Proteins (Prd) DNA-Kontakte ein (Xu et al., 1995). Bei anderen Paired-Domänen, wie bei der von Pax6 trägt auch die C-terminale Subdomäne zu der Gesamtbindung des Proteins an die DNA bei (Xu et al., 1999).

Experimente, welche die spezifische Erkennung von DNA-Sequenzen durch PairedDomänen untersuchten, haben gezeigt, dass unterschiedliche Klassen von PairedDomänen ähnliche DNA-Sequenzen erkennen (Czerny et al., 1993; Epstein et al., 1994a; $\mathrm{Xu}$ et al., 1995; Jun und Desplan 1996). Diese Ergebnisse stimmen mit den Bindungsspezifitäten von anderen konservierten DNA-Bindungsdomänen überein und führen zu der generellen Frage wie strukturell ähnliche Domänen, die ähnliche DNASequenzen erkennen, eine Vielzahl von unterschiedlichen genetischen Programmen steuern können. Die Tatsache, dass die Paired-Domäne eine zweiteilige DNABindedomäne ist und dass sie oftmals mit einer Homöodomäne assoziiert ist deutet darauf hin, dass Pax-Proteine unterschiedliche Kombinationen ihrer DNA-Bindedomänen nutzen, um die Vielfalt in ihrer Funktion zu erlangen.

Die Paired-Domäne und die Homöodomäne von Pax6 können unabhängig voneinander und mit hoher Affinität an spezifische DNA-Sequenzen binden. Für die Bindung an den Glukagon-Genpromotor scheint allerdings eine kooperative Interaktion beider DNA- 
Bindedomänen von Pax6 notwendig zu sein. Zusätzlich müssen die beiden DNABindedomänen in einem Molekül vorliegen, da bei der Inkubation der isolierten PairedDomäne zusammen mit der isolierten Homöodomäne und der G1- oder G3Oligonukeotidsonde keine Bindung an G1 bzw. nur eine Bindung der Paired-Domäne an G3 zu verzeichnen war (Abb. 3.3). Die Pax6-Variante, die beide DNA-Bindedomänen verbunden durch die Linkerregion enthält (Abb. 3.1, Pax6 PD-L-HD), konnte hingegen mit hoher Affinität sowohl an G1 als auch an G3 binden.

Eine kooperative DNA-Bindung der isolierten Paired-Domäne und der Homöodomäne des paired-Proteins von Drosophila konnte an einer $\mathrm{PHO}$-Bindungssstelle beobachtet werden. Allerdings war die beobachtete kooperative Bindung um etwa $50 \%$ schwächer, als wenn beide Domänen zusammen in einem Molekül vorliegen. Des Weiteren wurde gezeigt, dass Paired-Domänen und Homöodomänen aus unterschiedlichen Molekülen interagieren können, um kooperativ an eine spezifische DNA-Sequenz zu binden. So konnte auch die Pax6-Paired-Domäne in Kooperation mit der paired-Homöodomäne an eine $\mathrm{PHO}$ Sequenz binden (P6H0, Jun und Desplan, 1996). Allerdings scheint zumindest im Kontext des paired-Proteins die intermolekulare Interaktion zwischen den Proteindomänen nicht ausreichend zu sein, um ihre biologische Funktion zu vermitteln. In einem „in vivo rescue assay" wurde gezeigt, dass das paired-Protein sowohl eine funktionelle PAI-Domäne wie auch eine Homöodomäne in einem Molekül benötigt, um seine Zielgene aktivieren zu können (Bertuccioli et al., 1996).

Für eine effiziente Bindung von Pax3 an DNA ist das Vorhandensein von zwei DNAErkennungsmotiven notwendig (Chalepakis et al., 1994b). Zum einen das Motiv ATTA für die Homöodomänen-Bindung und das Motiv GTTCC, welches als Paired-DomänenErkennungssequenz dient (Chalepakis et al., 1994c), was auf eine kooperative Bindung beider DNA-Bindedomänen schließen lässt.

\subsection{Funktion der Pax6-Homöodomäne bei der Aktivierung des Glukagon-Gens}

Die Pax6-Homöodomäne scheint nicht nur für die Bindung des Transkriptionsfaktors an den Glukagon-Promotor eine Rolle zu spielen, sondern wird auch für die Aktivierung des Glukagon-Gens durch Pax6 benötigt. So konnte gezeigt werden, dass die Aktivierung des Glukagon-Promotors durch Expression von Pax6 in der heterologen Zelllinie JEG-3 durch Deletion der Homöodomäne drastisch vermindert wird (Abb. 3.13, Abb. 3.17) (Teichler, Dissertation 2004). Die Deletion der Pax6-Homöodomäne vermindert die Aktivierung des Glukagon-Promotors auch dann, wenn durch Deletion entweder das G1- (Abb. 3.17) oder 
das G3-Element (Abb. 3.13) entfernt wird und somit nur noch eine Pax6-Bindungstelle erhalten bleibt (Teichler, Dissertation 2004).

Die Funktion der Pax6-Homöodomäne bei der Aktivierung des Glukagon-Gens durch Pax6 könnte in einer zusätzlichen DNA-Bindung und/oder in Protein-ProteinWechselwirkungen liegen. Für eine zusätzliche DNA-Bindung spricht, dass nicht nur die Deletion der gesamten Homöodomäne, sondern auch die Deletion allein der Helix 3 der Homöodomäne, der so genannten DNA-Erkennungshelix, die Aktivierung des GlukagonGens durch Pax6 vermindert (Teichler, Dissertation 2004). Zum gleichen Effekt führt auch die gezielte Mutation von drei Aminosäuren innerhalb der Helix 3 (Valin-47, Serin-50, Asparagin-51), welche im Drosophila-Protein paired für die DNA-Bindung der Homöodomäne notwendig sind (Wilson et al., 1995) (Abb. 3.13, Abb. 3.17 und Teichler, Dissertation 2004).

In einem „Site-Selection-Assay“ zur Identifizierung von DNA-Bindungsstellen für die Paired- und Homöodomäne des Pax6-verwandten paired-Proteins aus Drosophila, wurde bevorzugt als eins von drei Motiven ein synthetisches Oligonukleotid mit der so genannten PH0-Stelle ausgewählt (Jun und Desplan, 1996). In diesem Oligonukleotid befindet sich im 5'-Bereich zu einer Paired-Domänen-Bindungsstelle in umgekehrte Orientierung („tailto-tail“) und direkt angrenzend (0 bp „spacing“) eine Homöodomänen-Bindungsstelle. Die Sequenz des Oligonukleotids lautet 5'-CAATTAGTCACGC-3', wobei das ATTAKernmotiv unterstrichen ist und das PAI-Kernmotiv (Bindungsstelle der aminoterminalen Subdomäne der Paired-Domäne) hervorgehoben ist. Die PHO-Sequenz wurde sogar vom paired-Protein vor den individuellen optimalen DNA-Bindungsstellen für die Paired- und die Homöodomäne bevorzugt (Jun und Desplan, 1996). Eine PH0-ähnliche Sequenz, PTE („Paired Iarget Element“) genannt, mit benachbarten Erkennungssequenzen für beide DNA-Bindedomänen des paired-Poteins befindet sich im L-Element („late promoter element") des Drosophila-Gens even-skipped (eve) (Fujioka et al., 1996). Die Mutagenese der Bindungsstellen für die paired-Paired-Domäne oder -Homöodomäne, welche zu einer signifikanten Reduktion der in vivo-Aktivität des L-Elements führt, demonstriert die Notwendigkeit beider DNA-Bindedomänen im paired-Protein und dass die $\mathrm{PHO}$-Sequenz essentiell zu sein scheint, um die paired-Funktion in vivo zu vermitteln. Eine Bindung der Pax6-Homöodomäne im 5'-Bereich der Pax6-Paired-Domänen-Bindungsstelle wird weiterhin im Zusammenhang mit dem L1-Gen, welches ein zelluläres Adhäsionsmolekül kodiert, diskutiert (Chalepakis et al., 1994a). Es scheint, dass die Pax6-Paired-Domäne die Basenpaare von 7 bis 26 und die Homöodomäne die Basenpaare von 1 bis 8 der proximalen Pax6-Bindungsstelle L1-170 des L1-Promotors erkennt.

Von diesen Bindungsszenarien ausgehend, konnte durch Sequenzvergleiche der $\mathrm{PHO}-$ Stelle und der murinen bzw. humanen Pax6-Konsensus-Bindungsstelle mit dem G1- und 
G3-Element des Glukagon-Promotors der Ratte eine putative Pax6-HomöodomänenBindungsstelle identifiziert werden (Abb. 3.9). Um zu testen, ob die Funktion der Pax6Homöodomäne bei der Aktivierung des Glukagon-Gens in einer zusätzlichen DNABindung im 5'-Bereich des PISCES-Motivs liegt, wurden Mutationen in die putative Pax6Homöodomänen-Bindungsstelle sowohl im G1- wie auch im G3-Element eingefügt (Abb. 3.9). Entsprechend der angenommen $\mathrm{PHO}$-artigen Natur der Bindung wurden die Mutationen als PHOmut1 und PHOmut2 bezeichnet. Dabei entspricht PHOmut1 einer Mutation, in dem die zentralen TT im ATTA-Kernmotiv der HomöodomänenBindungsstelle durch GG ersetzt wurden. Bei PHOmut2 wurde die Mutation um eine Position näher zum PISCES-Motiv hin verschoben. Aus der Röntgenkristallstruktur des Pax6-Paired-Domänen-DNA-Komplexes (Xu et al., 1999) kann ermittelt werden, dass die Mutationen der Basen in PHOmut1 und PHOmut2 die Paired-Domänen-Bindung theoretisch nicht beeinflussen sollten, da hier nur Kontakte zwischen der Paired-Domäne und dem Phosphatrückgrad der DNA eingegangen werden.

Damit in Übereinstimmung und mit dem Befund, dass die Pax6-Paired-Domäne ausreichend für eine Bindung an das G3-Element ist (Abb. 3.3 und Abb. 3.4), führten $\mathrm{PH} 0$-artige Mutationen in G3 zu keiner signifikanten Veränderung der Bindung von Pax6 oder der isolierten Pax6-Paired-Domäne (Abb. 3.10). Die zusätzliche Bindung der Pax6Homöodomäne im 5'-Bereich der Paired-Domänen-Bindungsstelle scheint aber essentiell für die transkriptionelle Aktivität von Pax6 zu sein, da die Transfektion von LuciferaseReportergenkonstrukten mit PHO-artigen Mutationen im G3-Element (Abb. 3.11) in die glukagonproduzierende Inselzellinie InR1G9 die Aktivierung des Glukagon-Gens durch endogenes Pax6 drastisch verringerte (Abb. 3.12). Auch in Abwesenheit von endogenem Pax6 und anderen a-zellspezifischen Proteinen in der heterologen Zelllinie JEG-3, die sich von einem humanen Chorionkarzinom ableitet (Kohler und Bridson, 1971), konnte ein inhibitorischer Effekt durch die Mutationen G3PHOmut1 und G3PHOmut2 auf die Pax6vermittelte Transkription des Glukagon-Gens festgestellt werden (Abb. 3.13).

Da für die Bindung an das G1-Element beide DNA-Bindedomänen von Pax6 notwendig sind, führten dieselben $\mathrm{PH0}$-artigen Mutationen der putativen Pax6-HomöodomänenBindungsstelle in $\mathrm{G} 1$ zu einer stark verminderten Bindung an G1PH0mut1 (Abb. 3.14). In Übereinstimmung mit diesen Bindungsdaten, kam es zu einer verringerten Aktivierung eines Luciferase-Reporterfusionsgens mit der Mutation G1PH0mut1 (Abb. 3.15) durch endogenes Pax6 nach der Transfektion in die Zelllinie InR1G9 (Abb. 3.16). Im Gegensatz zu den Befunden in der Pax6-exprimierenden, glukagonproduzierenden Zelllinie des aPhänotyps InR1G9, führte die Expression von Pax6 in der heterologen Zelllinie JEG-3 zu einer gesteigerten Aktivität der Glukagon-Reportergen-Plasmide -169G1PH0mut1 und -169G1PH0mut2 (Abb. 3.17). Ein möglicher Grund für diesen Effekt könnte die 
zusätzliche Bindung eines JEG-3-zellspezifischen Proteins im Komplex mit exogenem Pax6 an die mutierten G1-Elemente sein, mit der Folge einer erhöhten transkriptionellen Aktivität des Komplexes. Für einen JEG-3-zellspezifischen Effekt spricht auch, dass durch die Mutation in G1PH0mut1 die Bindung von Pax6 deutlich verringert wird (Abb. 3.14), was eher eine schwächere Aktivierung des Reportergen-Plasmids -169G1PH0mut1 durch exogenes Pax6 erwarten lässt. Tatsächlich konnte in Protein-DNA-Bindungsexperimenten mit Kernextrakten aus JEG-3-Zellen durch die Mutationen G1PH0mut1 und G1PH0mut2 ein neuer Proteinkomplex detektiert werden (Abb. 3.18). Demgegenüber konnten die vorliegenden Bindungsdaten mit Kernextrakten aus InR1G9-Zellen bestätigt werden. Konsistent mit Literaturbefunden konnten zwei Proteinkomplexe an G1 detektiert werden (Abb. 3.18) (Jin und Drucker, 1996; Jin et al., 1997; Andersen et al., 1999; Ritz-Laser et al., 1999). Der schneller migrierende Komplex wurde als Pax6- oder Cdx2/3-Monomer beschrieben, während der langsamere Komplex als Heterodimer aus Pax6 und Cdx2/3 identifiziert wurde (Andersen et al., 1999). Der ternäre Komplex aus Pax6 und Cdx2/3 wurde durch die Mutation G1PH0mut1 verdrängt (Abb. 3.18) was sich in einer verminderten Aktivierung des entsprechenden Reportergenkonstrukts nach der Transfektion in InR1G9-Zellen äußerte (Abb. 3.16).

Zusammenfassend weisen die diskutierten Ergebnisse darauf hin, dass für die Aktivierung des Glukagon-Gens durch Pax6 eine PH0-artige Bindung des Transkriptionsfaktors an den Glukagon-Genpromotor Voraussetzung zu sein scheint. Nicht nur die Deletion oder Mutation der Pax6-Homöodomäne führt zu einer stark verminderten Aktivierung des Glukagon-Gens durch Expression von Pax6 in der heterologen Zellinie JEG-3, sondern auch in einem ähnlich großen Ausmaß die Mutation einer putativen Pax6Homöodomänen-Bindungsstelle im G3-Element der 5'-flankierenden Region des Glukagon-Gens (Abb. 3.13). Zumindest für das G3-Element konnte gezeigt werden, dass die verringerte Aktivierung nicht auf eine Abnahme der Gesamtaffinität von Pax6 an G3 zurückzuführen ist (Abb. 3.10). Vielmehr weisen die vorliegenden Ergebnisse darauf hin, dass durch die $\mathrm{PH} 0$-artige Mutation ein weiterer Bindungsmodus von Pax6 exklusiv über seine Paired-Domäne an die mutierte DNA erzeugt wird (Abb. 4.1.C). 


\subsection{Hypothese zur Regulation der Glukagon-Gentranskription durch die Pax6- Homöodomäne}

Dieses hypotetische Modell zur Regulation der Glukagon-Gentranskription durch Pax6 nimmt zum einen eine DNA-induzierte Konformationsänderung des Pax6-Proteins an und weist auf eine bedeutende regulatorische Rolle der Homöodomäne hin.

A

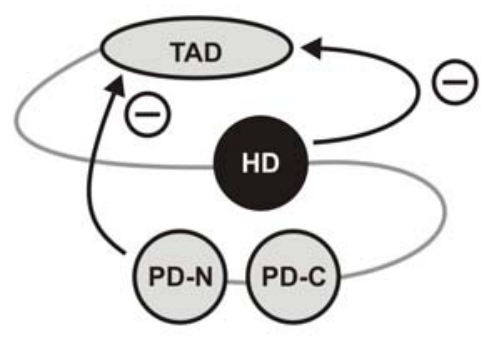

C

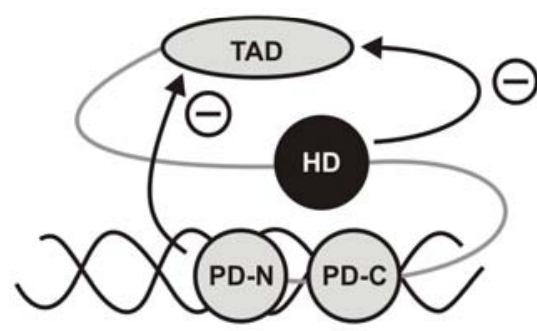

\begin{tabular}{|l|l|}
\hline PHOmut GGGT & PISCES \\
\hline
\end{tabular}

G3
B

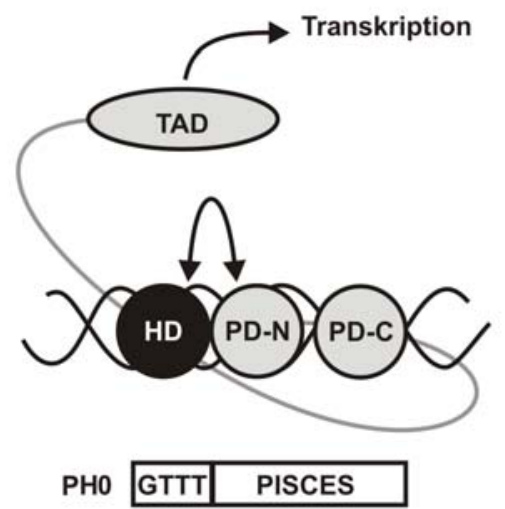

D
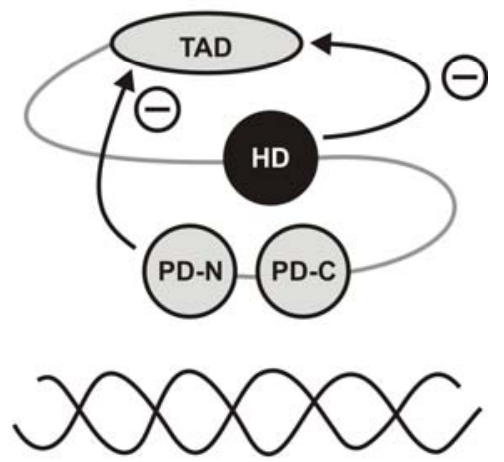

PHOmut ACCT

G1

Abb. 4.1: Modell zur Funktion der Pax6-Homöodomäne bei der Aktivierung des GlukagonGens durch Pax6. (A) Im nicht DNA-gebundenen Zustand unterliegt die carboxyterminale Transaktivierungsdomäne von Pax6 durch Protein-Protein-Wechselwirkungen einer Hemmung durch die Paired- und die Homöodomäne. (B) Nach der Bindung von Pax6 über seine PairedDomäne an das PISCES-Motiv und durch die Interaktion der Homöodomäne im direkt angrenzenden Bereich $5^{\prime}$ von PISCES, kommt es zu einer Neukonformation von Pax6 am Glukagon-Genpromotor (PHO-artige Bindung). Dadurch wird die Transaktivierungsdomäne aus ihrer Hemmung entlassen und aktiv. (C) Durch die Mutation der putativen HomöodomänenBindungsstelle (PHOmut) in $\mathrm{G} 3$ wird die Bindung der Pax6-Homöodomäne unterbunden und es entsteht ein neuer Bindungsmodus, der eine geringere transkriptionelle Aktivität aufweist. (D) Durch die Mutation PHOmut in G1 wird die kooperative Bindung beider DNA-Bindedomänen von Pax6 unterbunden. PD-N, aminoterminale Subdomäne der Paired-Domäne; PD-C, carboxyterminale Subdomäne der Paired-Domäne; HD, Homöodomäne, TAD, Transaktivierungsdomäne; PISCES, „pancreatic islet cell-specific enhancer sequence“. 
Im nicht DNA-gebundenen Zustand (Abb. 4.1A) unterliegt die carboxyterminale Transaktivierungsdomäne von Pax6 über intramolekulare Protein-ProteinWechselwirkungen einer Hemmung sowohl durch die Homöodomäne als auch durch die Paired-Domäne. Durch die Bindung von Pax6 an die DNA kommt es zu einer Konformationsänderung des Proteins wodurch die Transaktivierungsdomäne aus ihrer Hemmung entlassen wird und die Transkription steigert (Abb. 4.1B). Dabei bindet Pax6 über seine Paired-Domäne an das PISCES-Motiv im G3-Element des GlukagonPromotors. Auch wenn die Homöodomäne nicht unbedingt zur Gesamtaffinität von Pax6 am G3-Element beiträgt, so ermöglicht ihre Bindung im 5'-Bereich des PISCES-Motivs erst die transkriptionell aktive Neukonformation von Pax6. Durch die Mutation der putativen Pax6-Homöodomänen-Bindungsstelle (PHOmut) in $\mathrm{G} 3$ kommt es zu einem Verlust der Bindung der Homöodomäne, wodurch ein neuer Bindungsmodus entsteht, der transkriptionell weniger aktiv ist (Abb. 4.1C). Durch die PH0-artige Mutation in G1 kommt es zu einem Verlust der Bindung von Pax6, da die kooperative Bindung der Homöodomäne zusammen mit der Paired-Domäne nicht mehr möglich ist (Abb. 4.1D).

Eine DNA-induzierte Konformationsänderung wie in dem vorgestellten Modell konnte für Pax3 gezeigt werden. Apuzzo et al. (2004) stellten durch Einfügen von Schnittstellen für den Faktor Xa in das Pax3-Protein fest, dass durch die Bindung von Pax3 an DNA die Zugänglichkeit für den Faktor Xa herabgesetzt wurde. Daraus schlossen sie auf eine kompaktere und geschütztere Struktur von DNA-gebundenem Pax3 im Gegensatz zu freiem Pax3. Die DNA-Bindung der Pax3-Paired-Domäne verursachte dabei nicht nur eine Strukturänderung in der Paired-Domäne sondern ebenso in der Homöodomäne und umgekehrt (Apuzzo et al., 2004), was die funktionelle Abhängigkeit beider DNABindedomänen von Pax3 voneinander verdeutlicht.

Das vorliegende Modell zur Funktion der Homöodomäne beruht auf der Annahme einer direkten intramolekularen Interaktion zwischen der Pax6-Homöodomäne, der Pax6Paired-Domäne und der Pax6-Transaktivierungsdomäne (Abb. 4.1).

Tatsächlich ist die Pax6-Homöodomäne zu direkten Protein-Protein-Interaktionen in der Lage. So vermag sie mit der eigenen Paired-Domäne (Mikkola et al., 2001; Jun und Desplan, 1996), mit Homöodomänen anderer Proteine (Mikkola et al, 2001) oder mit Proteinen wie dem TATA-Box-bindenden Protein (TBP) (Cvekl, 1999) direkt zu interagieren. Der Befund, dass ein Fusionsprotein Gal4-Pax6-Transaktivierungsdomäne eine größere transkriptionelle Aktivität an einem synthetischen GAL4-Reportergen besitzt als ein Fusionsprotein, welches zusätzlich die Pax6-Homöodomäne beinhaltet (Mikkola et al, 2001), kann als funktioneller Hinweis auf eine Interaktion der Pax6-Homöodomäne mit der Pax6-Transaktivierungsdomäne gewertet werden. Diese Befunde sprechen für eine 
DNA-unabhängige inhibitorische Wirkung der Pax6-Homöodomäne durch Hemmung der Aktivität der Transaktivierungsdomäne und werden durch die hier vorgestellte Hypothese (Abb. 4.1A) widergespiegelt.

Bei der PH0-artigen DNA-Bindung von Pax6 könnte auch eine Interaktion zwischen der Pax6-Homöodomäne und N-terminalen Bereichen der Pax6-Paired-Domäne zu einer Stabilisierung der Bindung beitragen. In dem vorgeschlagenem Modell bindet die Pax6Homöodomäne unmittelbar im 5'-Bereich der Paired-Domänen-Bindungsstelle an die DNA. Dadurch liegen die beiden DNA-bindenden Domänen so dicht beieinander, dass Protein-Protein-Wechselwirkungen zwischen der Paired-Domäne und der Homöodomäne möglich wären. Die ersten Aminosäurereste der N-terminalen Subdomäne der PairedDomäne formen ein $\beta$-Hairpin mit darauf folgendem $\beta$-Turn (Abb. 1.2). Dieses Strukturmotiv könnte über Wechselwirkungen mit der DNA und durch intramolekulare Protein-Protein-Interaktionen zur Stabilisierung einer PHO-artigen Bindung an das G3oder G1-Element beitragen. Dafür spricht der Befund, dass die Deletion des $\beta$-FaltblattMotivs (Aminosäure 2 bis 17 des Pax6-Proteins) zu einem Verlust der Bindung von Pax6 an das G1- und G3-Element führt (Abb. 3.20) und dementsprechend zu einem Zusammenbruch der transkriptionellen Aktivität des Pax6-Proteins am GlukagonGenpromotor in der heterologen Zelllinie JEG-3 (Dibaj, unveröffentlicht). Das $\beta$-HairpinMotiv überspannt die kleine Furche der DNA und geht Kontakte mit dem ZuckerPhosphat-Rückrad beider DNA-Stränge ein. Der folgende $\beta$-Turn (Aminosäure 13 bis 16) besetzt die kleine Furche der DNA und geht wichtige Basenkontakte ein (Xu et al., 1995; Xu et al., 1999). Entwicklungsstörungen, die durch „Missense-Mutationen“ innerhalb oder in der Nähe des $\beta$-Hairpin- und $\beta$-Turn-Motivs der Pax-Proteine hervorgerufen werden, weisen auf eine wichtige Funktion der N-terminalen Paired-Domänen-Region hin. (Balling et al., 1988; Baldwin et al., 1992; Tassabehji et al., 1993; Vogan et al., 1993). Beachtenswerterweise scheinen Mutationen in diesen Strukturen bei Pax3 nicht nur die Paired-Domänen-Bindung sondern auch die Bindung der Homöodomäne zu beeinflussen (Underhill et al., 1995; Underhill und Gros, 1997; Fortin et al., 1997), was als Hinweis auf eine funktionelle bzw. physikalische Interaktion zwischen beiden Domänen gewertet werden kann.

Ebenso führen „Missense-Mutationen“ in anderen Bereichen der Paired-Domäne zu einer veränderten Homöodomänen-Funktion im Pax6-Protein (Singh et al., 2000; Mishra et al., 2002). Außerdem beeinflussen Deletionen oder Mutationen in der Pax6Transaktivierungsdomäne die Homöodomänen-Funktion (Singh et al., 1998; Singh et al., 2001).

Die Homöodomäne und die Paired-Domäne von Pax6 können auch ohne eine DNABindung miteinander interagieren (Mikkola et al., 2001). Überraschenderweise vermittelt 
die Helix 3 der Homöodomäne, welche die Erkennungshelix für die spezifische DNABindung ist, auch die Protein-Protein-Interaktion mit der Paired-Domäne (Bruun et al., 2005). Die Wechselwirkung beruht dabei zum größten Teil DNA-unabhägig auf elektrostatischen Kräften zwischen sauren Resten in der ersten und zweiten Helix der Cterminalen Subdomäne der Paired-Domäne und basischen Resten in der dritten Helix der Homöodomäne. Die MH1-Domäne des Transkriptionsfaktors Smad3 Interagiert ebenfalls mit der C-terminale Subdomäne von Pax6, wodurch die Autoregulation des Pax6Promotors P1 gehemmt wird. Die durch TGF $\beta$ induzierte Translokation von Smad3 in den Nukleus hemmt dadurch die Pax6-Promotor-Aktivität durch TGF $\beta$, indem die Interaktion von Smad3 mit der C-terminalen Subdomäne von Pax6 die DNA-Bindung durch dessen Paired-Domäne unterbindet (Grocott et al., 2007).

Diese Befunde stehen im Einklang mit dem vorgestellten Modell (Abb. 4.1), wobei erst durch die Bindung der Pax6-Homöodomäne zusammen mit der Paired-Domäne in einer $\mathrm{PHO}$-artigen Konformation an die DNA eine Interaktion zwischen dem N-terminalen Bereich der Paired-Domäne und der Homöodomäne ermöglicht wird.

Eine PHO-artige Bindung wird auch durch andere Literaturbefunde bestärkt. Zum einen durch den schon erwähnte Aspekt, dass eine $\mathrm{PHO}$-Sequenz vom Drosophila pairedProtein vor den individuellen optimalen DNA-Bindungsstellen für die Paired- und die Homöodomäne bevorzugt wird (Jun und Desplan, 1996). Weiterhin ist das "Spacing“ zwischen den DNA-Bindungsstellen von entscheidender Bedeutung. Durch das Einfügen von 2 bp ( $\mathrm{PH} 2)$ anstatt der 0 bp ( $\mathrm{PHO})$ oder einer umgekehrten Orientierung der beiden Bindungsstellen (HP2) nahm die Bindungsaffinität von paired dramatisch ab (Jun und Desplan, 1996). Für die POU-spezifische Domäne und die POU-Homöodomäne von Oct1, die zusammen als POU-Domäne bezeichnet werden, ist aus der Röntgenkristallstruktur bekannt, dass sie mit direkt benachbarten (0 bp „spacing“) DNA-Erkennungssequenzen interagieren (Klemm et al., 1994). Dabei kommt es zu keinen Protein-Protein-Kontakten zwischen den beiden unabhängigen DNA-Bindedomänen, trotzdem aber resultiert die Separation beider DNA-Bindungsstellen durch die Insertion von 1 oder 2 bp in einer geringeren Bindungsaffinität der POU-Domäne von Oct-1 (van Leeuwen et al., 1997).

\subsection{Die Pax6-Linkerregion zwischen den beiden DNA-Bindedomänen ist für die Aktivierung des Glukagon-Gens durch Pax6 notwendig}

Die vorangegangenen Befunde deuten auf eine wesentliche Funktion der Pax6Linkerregion hin. Um die kooperative Bindung beider DNA-Bindedomänen an das G1oder G3-Element zu vermitteln, müssen beide Domänen in einem Molekül durch den 
Pax6-Linker verbunden vorliegen (4.2, Abb. 3.3). In der vorliegenden Arbeit wurden durch Untersuchungen der Pax6-Linkerregion erstmals Einblicke in die Funktion dieser Region im Pax6-Protein ermöglicht.

Über die Linkerregion des Pax6-Proteins ist bis heute wenig bekannt. Die flexible Region umfasst mit 78 Aminosäuren den Bereich von Aminosäure 132 bis 209 des humanen bzw. murinen Pax6-Proteins (Abb. 1.1) und ist reich an Glutamin und Glycin. Die Länge des Pax6-Linkers ist unter den Spezies variable und wenig konserviert. Durch eigene Vergleiche von Pax6-Sequenzen unterschiedlicher Organismen und durch Literaturbefunde (Callaerts et al., 1997), konnten Sequenzähnlichkeiten in der Linkerregion in den Bereichen N-terminal der Homöodomäne und C-terminal der PairedDomäne identifiziert werden. Im Durchschnitt sind acht von zwölf Aminosäuren im Nterminalen Bereich der Homöodomäne konserviert. Eine beachtenswerte Ausnahme stellt die entsprechende Region von Pax6 aus Dugesia tigrina dar, in der nur zwei der genannten zwölf Aminosäuren konserviert sind. Eine zusätzliche konservierte Region im Linker der meisten Pax6-Proteine konnte C-terminal der Paired-Domäne identifiziert werden. Ein Undecapeptid mit der Konsensus-Sequenz MYDKLRMLNGQ. Dieses Sequenzmotiv findet sich nicht im Pax6-Linker von Phallusia mammillata und Dugesia tigrina und ist wenig konserviert in Caenorhabditis elegans (vier von elf Aminosäuren sind identisch). Eine funktionelle Signifikanz für dieses Peptid ist unbekannt. In einer funktionellen Untersuchung in Drosophila melanogaster konnte Pax6 aus Phallusia mammillata die ektopische Augenbildung induzieren, was demonstriert, dass zumindest für diese Funktion das Undecapeptid nicht essentiell ist (Callaerts et al., 1997).

Methodischer Ansatz zur Untersuchung der Funktion der Linkerregion war zum einen die Herstellung unterschiedlicher Varianten von Pax6 mit Mutationen in der Linkerregion und die Charakterisierung ihrer Bindungseigenschaften an das G1- und G3-Element des Glukagon-Genpromotors. Weiterhin wurde die Rolle des Pax6-Linkers über die Ebene der Bindungsstudien hinaus auch unter funktionellen Aspekten charakterisiert.

Die Protein-DNA-Bindungsexperimente zeigten, dass neben der Homöodomäne auch dem Pax6-Linker eine wichtige Rolle bei der Bindung an das Promotorelement G1 zukommt: Die Variante Pax6PD-L (Abb. 3.1) zeigte eine Bindung an G3 nicht aber an G1 (Abb. 3.4). Zur Bindung von Pax6 an G1 muss neben der Paired-Domäne sowohl die Linkerregion als auch die Homöodomäne im Proteinkontext enthalten sein. Zur weiteren Charakterisierung des Linkers wurden die Varianten Pax6PD-Lmut-HD1, 3 und 4 hergestellt (Abb. 3.21, Abb. 3.22). Bei dem Protein Pax6PD-Lmut-HD1 wurde der Linker in der Mitte geteilt und der N-terminale Teil (Bereich a) mit dem C-terminalen Teil (Bereich b) vertauscht (Abb. 3.21). Auf diese Weise bleibt sowohl die Länge des Linkers als auch dessen Aminosäurezusammensetzung erhalten. Durch diese Mutation ging die Bindung 
an das Promotorelement G1 verloren (Abb. 3.23). Damit zeigt die Mutante Pax6PD-LmutHD1 ein ähnliches Bindungsmuster an G1 und G3 wie die Mutante Pax6PD-L, die die native Linkersequenz, aber keine Homöodomäne besitzt. Dieser Befund deutet darauf hin, dass nicht nur eine spezifische Länge der Pax6-Linkerregion wichtig ist um eine kooperative Bindung der Paired-Domäne und der Homöodomäne zu vermitteln, sondern auch eine spezifische Aminosäuresequenz. Auf den besonderen Stellenwert der konservierten Region im N-terminalen Bereich der Homöodomäne weisen folgende Befunde hin: Allein durch die Invertierung der zwölf Aminosäuren umfassenden konservierten Region mit der Sequenz DEAQMRLQLKRK ging die Bindung des entsprechenden Proteins Pax6PD-Lmut-HD3 an das G1-Element verloren (Abb. 3.24). Wenn hingegen die konservierten Regionen im Linker erhalten bleiben (vgl. 3.5.1 und Abb. 3.21) und nur der Bereich dazwischen mutiert ist (entsprechend der Variante Pax6PD-LmutHD4) war eine Bindung sowohl an das G3- als auch an das G1-Element zu verzeichnen (Abb. 3.24).

Da durch die Mutation in Pax6PD-Lmut-HD3 wiederum weder die Länge noch die Aminosäurezusammensetzung verändert wurde, scheint der Bereich des Linkers welcher das Peptid DEAQMRLQLKRK umfasst, mehr als nur strukturelle Funktion zu haben. Gegen einen Beitrag zur direkten DNA-Bindung spricht allerdings, dass die Homöodomäne des Drosophila paired-Proteins sowohl mit 17 Aminosäuren N-terminal der Homöodomäne als auch ohne unverändert und mit hoher Affinität an die KonsensusBindungsstelle P3 bindet (Wilson et al., 1993; Wilson et al., 1995). Die Pax6-Linkerregion N-terminal der Homöodomäne könnte aber durch Protein-Protein-Interaktionen mit der Paired-Domäne zur Stabilisierung einer PH0-artigen Bindung von Pax6 an den GlukagonPromotor beitragen. Bei der von Jun und Desplan (1996) postulierten Bindung des pairedProteins an eine PHO-Bindungsstelle sind Protein-Protein-Kontakte zwischen dem Nterminalen Arm der Homöodomäne oder der angrenzenden konservierten Region des Linkers und der zweiten Helix der Paired-Domäne möglich, was für die vorgeschlagene Theorie spricht. Durch die Mutationen in den Proteinen Pax6PD-Lmut-HD1 und Pax6PDLmut-HD3 fält diese Interaktion weg und eine $\mathrm{PHO}$-artige Bindung von Pax6 durch die Kooperation beider DNA-Bindedomänen ist nicht mehr möglich. Diese Vermutung wird auch durch die funktionellen Untersuchungen unterstützt. Die Mutation der Pax6Linkerregion führte, wie auch die Deletion der Homöodomäne, zu einer deutlichen Verminderung der Pax6-vermittelten Aktivierung des Glukagon-Genpromotors in der Zelllinie JEG-3 (Abb. 3.25). Die bei diesen Experimenten eingesetzte Mutante Pax6-Lmut entspricht dem Konstrukt Pax6-PD-Lmut-HD1, allerdings mit Transaktivierungsdomäne (Abb. 3.25). In Western-Blot-Experimenten konnte gezeigt werden, dass die verminderte 
Aktivierung des Glukagon-Genpromotors nicht auf eine verringerte Expression der eingesetzten Pax6-Varianten zurückzuführen ist (Abb. 3.26).

Diese Ergebnisse zeigen, dass am Promotorelement G3 die korrekte Aminosäuresequenz der Linkerregion für die volle transkriptionsaktivierende Wirkung von Pax6 erforderlich ist. Während für die Bindung von Pax6 an das G3-Element schon die Paired-Domäne alleine diese Funktion vermitteln kann, ist in Hinblick auf die Transkriptionsaktivierung durch Pax6 auch eine korrekte Anordnung und Sequenz der Linkerregion sowie das Vorhandensein der Homöodomäne wichtig. Am G1-Element ist die Linkerregion zusammen mit der Homöodomäne sowohl für die Pax6-Bindung als auch für die Transkriptionsaktivierung essentiell.

Für die Pax3-Bindung scheint die Linkerregion größere Variabilität zuzulassen. Für eine effiziente Bindung von Pax3 ist sowohl die Paired- und die Homöodomäne notwendig, als auch ihre DNA-Erkennungsmotive GTTCC und ATTA. Allerdings sind sowohl die Länge der Linkerregion im Pax3-Protein als auch der Winkel zwischen den beiden DNAErkennungsmotiven in der Doppelhelix variabel (Chalepakis et al., 1994b).

Demgegenüber zeigen Studien mit POU-Proteinen, dass die Sequenz, welche die POUspezifische Domäne von der POU-Homöodomäne trennt, die DNA-Bindungsspezifität der POU-Domäne zu beeinflussen scheint (Herr und Cleary, 1995). Im Fall des POU-Proteins Oct-1 ist gezeigt worden, dass sowohl die Länge als auch die Aminosäurezusammensetzung der Linkerregion zusätzlich zu ihrer verbindenden Funktion für die DNA-Bindungsaffinität und DNA-Bindungsspezifität wichtig ist (van Leeuween et al., 1997).

Fortin et al. (1998) konnten durch die Konstruktion von chimären Proteinen, in dem die Pax3-Homöodomäne und die Pax3-Linkerregion graduell durch die entsprechende Sequenz des Homöodomänen-Proteins Phox ersetzt wurde, Hinweise auf die Funktion der Linkerregion erlangen. Die durch die Pax3-Paired-Domäne regulierte Bindung der Homöodomäne wurde unterbunden, wenn die Pax3-Homöodomäne inklusive der $18 \mathrm{~N}$ terminal angrenzenden Aminosäuren durch die entsprechende Phox-Sequenz ersetzt wurde. Das chimäre Protein, in dem die Pax3-Homöodomäne alleine durch die von Phox ersetzt wurde, konnte unvermindert an die DNA binden. Die $\mathrm{N}$-terminal der Homöodomäne gelegene Linkersequenz scheint also auch im Pax3-Protein bei der kooperativen DNA-Interaktion der beiden DNA-Bindedomänen eine entscheidende Rolle zu spielen. 


\subsection{Vergleichendes Modeling einer PH0-artigen Bindung von Pax6 an das G3- Element des Glukagon-Genpromotors}

Obwohl eine Röntgenkristallstruktur der Pax6-Paired-Domäne zusammen mit der Homöodomäne bisher noch nicht beschrieben ist, wurden unterschiedliche Versuche unternommen, die Bindung beider Domänen an DNA oder die Protein-Protein-Interaktion zwischen den beiden Domänen vorherzusagen (Jun und Desplan, 1996; Xu et al., 1999; Garvie et al., 2001; Bruun et al., 2005).

Durch Modeling der Struktur beider Domänen des Drosophila paired-Proteins an eine $\mathrm{PH} 0-$ Stelle, die auch in der vorliegenden Arbeit als Vorhersage der Bindung von Pax6 an den Glukagon-Promotor herangezogen wurde (Abb. 3.9), konnte gezeigt werden, dass diese Art der Bindung generell möglich erscheint (Jun und Desplan, 1996). Dabei binden jeweils die Erkennungshelices beider Domänen (Helix 3 der N-terminalen Subdomäne der Paired-Domäne und Helix 3 der Homöodomäne) an gegenüberliegende Bereiche der DNA-Doppelhelix. Für das paired-Protein sind Protein-Protein-Kontakte in dieser Bindungskonformation zwischen der zweiten Helix der Paired-Domäne und dem Nterminalen Arm der Homöodomäne oder den angrenzenden konservierten Bereichen der Linkerregion möglich.

Für die DNA-Bindung an den Promotor L1 eines zellulären Adhäsionsmoleküls ist sowohl die Pax6 Paired- als auch die Homöodomäne notwendig. In „Footprinting-Experimenten“ konnte gezeigt werden, dass die Homöodomäne die DNA im 5'-Bereich direkt angrenzend an die Bindungsstelle der N-terminalen Subdomäne von Pax6 schützt (Chalepakis et al., 1994a). Das Modeling dieser PH0-artigen Bindungskonformation der beiden Pax6-DNA-Bindedomänen stellt dar, dass die Homöodomäne und die N-terminale Pax6 Helix-Turn-Helix-Einheit mit der großen Furche der DNA-Doppelhelix interagieren können und beide jeweils an gegenüberliegende Bereiche der DNA binden. Der erste $\beta$ Turn und die Schleife zwischen der $\alpha$-Helix 2 und 3 der Paired-Domäne sind dem Nterminalen Arm der Homöodomäne am nächsten (Chalepakis et al., 1994a; Xu et al., 1999). Protein-Protein-Interaktionen zwischen diesen Strukturen sind vorstellbar.

Weiterhin wurde gezeigt, dass die Pax5-Paired-Domäne ETS-DNA-Bindedomänen an die DNA-Bindungsstelle der C-terminalen Subdomäne von Pax5 rekrutieren kann und einen Komplex an einem B-Zell-spezifischen Promotor bildet (Fitzsimmons, 1996). Die Pax6 Paired-Domäne weist ebenfalls überlappende DNA-Bindungsspezifitäten mit Mitgliedern der Ets-Familie auf und kann ebenfalls potenziell mit diesen interagieren (Plaza et al., 1994). Aus der Tatsache, dass die Paired-Domänen von Pax5 und Pax6 76\% Sequenzidentität zeigen und alle der DNA-kontaktierenden Aminosäurereste konserviert sind, schlossen Xu et al. (1999), dass die Struktur und die DNA-Bindung beider Proteine 
nahezu identische sein sollte. In dem von innen vorgeschlagene Model bindet die ETSDomäne an die DNA direkt angrenzend zu der Bindungsstelle der Pax6 C-terminalen Subdomäne.

Mit einer Röntgenkristallstruktur eines ternären Komplexes aus der Pax5-Paired-Domäne, der ETS-Domäne von Ets-1 und DNA wurde allerdings gezeigt, dass die Bindung von Ets-1 N-terminal von Pax5 erfolgt (Garvie et al., 2001; Pufall und Graves et al., 2002). Ets-1-Aminosäurereste kontaktieren dabei das $\beta$-Hairpin-Motiv und die zweite $\alpha$-Helix der N-terminalen Subdomäne von Pax5. Für diese Interaktion spricht auch, dass Mutationen in dem $\beta$-Hairpin-Motiv die Rekrutierung von Ets-1 verhindern oder die DNA-Bindung von Pax5 unterbinden (Fitzsimmons et al., 2001, Wheat et al., 1999). Zusätzlich zu Pax5 können noch Pax2, Pax3 und mit Vorbehalt Pax6 Ets-Proteine rekrutieren und der Komplex durch Interaktion von Ets mit dem $\beta$-Hairpin der Paired-Domäne an DNA binden (Wheat et al., 1999). Der hohe Grad der Sequenzkonservierung des $\beta$-Hairpin-Motivs in verschiedenen Pax-Proteinen und auch in Pax-Proteinen unterschiedlichster Spezies, deutet auf eine funktionelle Rolle für die DNA-Bindung und Protein-Protein-Interaktion dieser Struktur hin.

Zusammenfassend untermauern die Literaturbefunde und die Ergebnisse der vorliegenden Arbeit die Hypothese der PH0-artigen Bindung von Pax6 an den GlukagonPromotor. Auch eine Interaktion zwischen der Homöodomäne bzw. der angrenzenden Linkerregion und N-terminalen Bereichen der Paired-Domäne scheint wahrscheinlich. Die von Garvie et al. (2001) veröffentlichte Röntgenkristallstruktur des Komplexes aus Pax5, Ets-1 und DNA wurde zu einem vergleichenden Modeling der Bindung der Pax6Homöodomäne an einen Komplex aus der Pax6-Paired-Domäne und dem G3-Element des Glukagon-Genpromotors herangezogen. Abbildung 4.2 zeigt, dass eine Bindung der Homöodomäne direkt angrenzend an die Bindungsstelle der Paired-Domäne möglich ist. Die dritte Helix der Pax6-Homöodomäne, die DNA-Erkennungshelix, bindet an die große Furche der DNA mit der Sequenz TAGTTTTTCACGCCTGACTGAGATTGAAGGG, wobei die Homöodomänen-Bindungsstelle unterstrichen ist. Am angrenzenden gegenüberliegenden Bereich der DNA bindet die Pax6-Paired-Domäne mit ihren beiden Subdomänen. $\mathrm{Zu}$ erkennen ist, dass das $\beta$-Hairpin der $\beta$-Faltblattstruktur den $\mathrm{N}$ terminalen Bereichen der Homöodomäne am nächsten ist. 


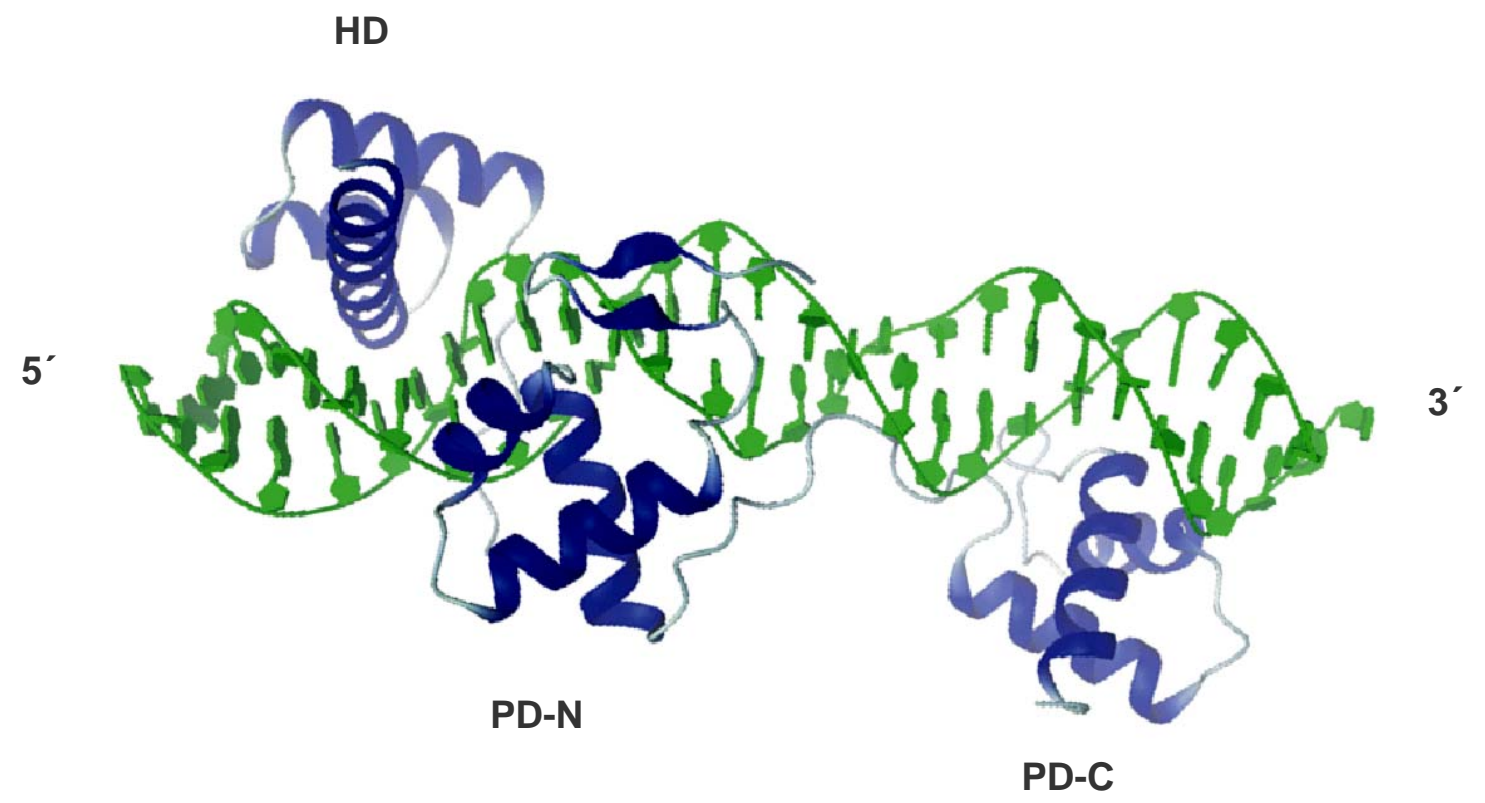

Abb. 4.2: Vergleichendes Modeling der Bindung der Pax6-Homöodomäne an das G3Element des Glukagon-Genpromotors. Die Pax6-Homöodomäne bindet direkt angrenzend im 5 '-Bereich der Paired-Domänen-Bindungsstelle an den gegenüberliegenden Bereich der DNA mit der Sequenz TAGTTTTTCACGCCTGACTGAGATTGAAGGG. Das Motiv GTTT der putativen Homöodomänen-Bindungsstelle ist unterstrichen. HD, Pax6-Homöodomäne; PD-N, aminoterminale Subdomäne, PD-C, carboxyterminale Subdomäne der Pax6-Paired-Domäne. Nach R. Krätzner: Homologie-basiertes Modeling nach der Röntgenkristallstruktur des Komplexes aus Pax5, Ets-1 und DNA (Garvie et al., 2001). 


\section{$5 \quad$ ZUSAMMENFASSUNG}

Das Peptidhormon Glukagon erhöht die Glukoseabgabe aus der Leber und ist damit für die Aufrechterhaltung ausreichender Blutzuckerspiegel während der Hungerphase notwendig. Störungen in der Glukagon-Biosynthese und -Sekretion tragen zur Pathogenese des Diabetes mellitus bei, der sich durch hyperglykämische Zustände äußert. Die zellspezifische und nahrungsabhängige Aktivierung des Glukagon-Gens in den a-Zellen der Langerhans'schen Inseln des Pankreas wird auf transkriptionellem Niveau reguliert, wobei der Transkriptionsfaktor Pax6 eine essentielle Rolle spielt. Pax6 bindet in vitro über seine Paired-Domäne an das PISCES-Motiv im G1- und G3-Element des Glukagon-Genpromotors und aktiviert synergistisch die Transkription des GlukagonGens. Pax6 besitzt noch eine weitere DNA-Bindedomäne, die Homöodomäne, deren Funktion weitgehend unbekannt ist. Vorangegangene Untersuchungen in der Arbeitsgruppe hatten durch interne Deletion und gezielte Mutation der Pax6Homöodomäne zeigen können, dass die Pax6-Homöodomäne für die Aktivierung des Glukagon-Gens durch Pax6 notwendig ist, vermutlich durch Bindung an das G3- und G1Element. Wo und wie diese Bindung erfolgt, blieb unbekannt. Die vorliegende Arbeit sollte zum besseren Verständnis der molekularen Mechanismen der Regulation der GlukagonGentranskription durch die Pax6-Homöodomäne beitragen.

Durch DNA-Sequenzvergleiche konnte im G1- und G3-Element des Glukagon-Promotors eine putative Pax6-Homöodomänen-Bindungsstelle in reverser Orientierung und direkt angrenzend im 5'-Bereich des PISCES-Motivs (PHO) identifiziert werden. Zwei zentrale Basen der putativen Pax6-Homöodomänen-Bindungsstelle wurden in G3 bzw. G1 mutiert (PHOmut1). Mit Hilfe von durch in vitro Transkription/Translation oder im Baculovirussystem hergestellten Proteinen konnte im „Electrophoretic Mobility Shift Assay“ bestätigt werden, dass die Pax6-Paired-Domäne für die Bindung an das G3Element ausreichend ist, wohingegen für die Bindung an das G1-Element die Pax6Paired-Domäne mit Linker und Homöodomäne notwendig ist. Die Mutation PHOmut1 hatte keine Wirkung auf die Bindung von Pax6-Wildtyp und Pax6-Paired-Domäne an G3, verminderte jedoch massiv die Bindung von Pax6-Wildtyp an G1. In transienten Transfektionsstudien mit Reporterfusionsgenen verminderte die Mutation PHOmut1 drastisch die transkriptionelle Aktivierung am G1-Element durch endogenes Pax6 in der a-Zelllinie InR1G9. Ebenso verminderte die Mutation PH0mut1 stark die transkriptionelle Aktivierung am G3-Element durch endogenes Pax6 in der a-Zelllinie InR1G9 oder durch exprimiertes Pax6 in der heterologen Zelllinie JEG-3. Durch Mutationsstudien der Pax6- 
Linkerregion konnte demonstriert werden, dass der Linker notwendig für Aktivierung des Glukagon-Gens durch Pax6 ist. Ein entscheidender Beitrag kommt dabei einer 12 Aminosäure-langen konservierten Region N-terminal der Pax6-Homöodomäne zu, die möglicherweise durch Protein-Protein-Interaktionen mit N-terminalen Bereichen der Pax6Paired-Domäne zu der kooperativen Bindung beider DNA-Bindedomänen am GlukagonGenpromotor beiträgt.

Diese Befunde sprechen für eine PH0-artige Bindung der Pax6-Homöodomäne an das G3- und G1-Element des Glukagon-Gens. Bemerkenswerterweise ist diese kooperative Bindung der Pax6-Homöodomäne für die Aktivierung der Transkription auch dort (an G3) notwendig, wo die Bindung der Pax6-Homöodomäne nicht zur Gesamtaffinität der Bindung von Pax6 beiträgt. Es wird daher postuliert, dass die kooperative Bindung der Pax6-Homöodomäne mit der Pax6-Paired-Domäne sowohl am G1- als auch G3-Element des Glukagon-Gens eine Neufaltung von Pax6 in eine transkriptionell aktive Konformation induziert. 


\section{SUMMARY}

The peptide hormone glucagon increases glucose output from the liver and thus maintains sufficient blood glucose levels during the fasting state. Malfunctions in biosynthesis and secretion of glucagon contribute to the pathogenesis of diabetes type 2 . The cell-specific activation of the glucagon gene in the a-cells of pancreatic islets is caused by multiple transcription factors among those Pax6 seems to be crucial. Pax6 binds in vitro through its paired domain to the PISCES-motif, present in the proximal promoter element G1 and the more distal enhancer like element G3 of the glucagon gene promoter and activates the glucagon gene transcription synergistically. In addition, Pax6 contains a homeodomain as a second DNA binding domain whose function is unclear. Previous studies revealed that the Pax6 homeodomain contributes to the activation of glucagon gene transcription but the mechanism is still unclear. The aim of this work was to investigate the molecular mechanisms of the Pax6 homeodomain acting on the regulation of glucagon gene transcription.

Alignment of DNA sequences revealed a putative Pax6 homeodomain binding site in the G1 and G3 element adjacent directly and in reverse orientation to the region $5^{\prime}$ to the PISCES-motif, suggesting a so called PH0-like binding of Pax6 to the glucagon gene promoter. In this putative Pax6 homeodomain binding site, two central base pairs in G1 and G3 were mutated (PHOmut1). Using deletion mutants of the Pax6 protein (produced by in vitro transcription/translation and by the baculovirus expression system) it was shown by electrophoretic mobility shift assays, that the paired domain is sufficient for the interaction with the G3 element, whereas the binding to $\mathrm{G} 1$ requires the linker region and the homeodomain in addition. The mutation PHOmut1 had no effect on the binding of Pax6 wildtyp and the Pax6 paired domain to $\mathrm{G} 3$, but decreased the binding of Pax6 wildtyp to $\mathrm{G} 1$ dramatically. In transient transfections with reporter fusion genes it was shown, that the mutation PH0mut1 in G1 decreased the activation of the glucagon gene promoter by endogenous Pax6 in the a-cell line InR1G9. Likewise the mutation PH0mut1 in $\mathrm{G} 3$ reduced the activation of the glucagon gene in InR1G9 cells as well as in the heterologous cell line JEG-3 by expression of Pax6. Furthermore, it was shown that the Pax6 linker region is essential for the function of Pax6 in the activation of the glucagon gene. A conserved region of twelve amino acids in the linker located $\mathrm{N}$-terminally to the homeodomain was identified as an important sequence for DNA-binding and function of Pax6. 
These results suggest a PH0-like binding of the Pax6 homeodomain to the elements G1 and G3 of the glucagon gene promoter. Noteworthy, the cooperative binding of the Pax6 homeodomain is even necessary for the activation of transcription on the G3 element, although the homeodomain does not contribute to the binding of Pax6 to G3. A model assumes that the cooperative binding of the Pax6 homeodomain and the Pax6 paired domain to $\mathrm{G} 1$ and $\mathrm{G} 3$ induces a conformational change of the Pax6 protein resulting in an increased glucagon gene transcription. 


\section{$7 \quad$ LITERATURVERZEICHNIS}

Alberts, B., Bray, D., Lewis, J., Raff, M., Roberts, K. \& Watson, J. D. (1994) Molecular Biology of the Cell, $3^{\text {rd }}$ edn. 401-474, Garland Publishing, New York.

Andersen, F. G., Jensen, J., Heller, R. S., Petersen, H. V., Larsson, L. I., Madsen, O. D. \& Serup, P. (1999) Pax6 and Cdx2/3 form a functional complex on the rat glucagon gene promoter G1-element. FEBS Lett. 445: 306-310.

Apuzzo, S., Abdelhakim, A., Fortin, A. S. \& Gros, P. (2004) Cross-talk between the paired domain and the homeodomain of Pax3: DNA binding by each domain causes a structural change in the other domain, supporting interdependence for DNA Binding. $J$. Biol. Chem. 279: 33601-33612.

Ashcroft, F. M. \& Ashcroft, S. J. H. (1992) Insulin-Molecular biology to pathology. IRL Press, Oxford, New York, Tokio.

Ausubel, F. M., Brent, R., Kingston, R. E., Moore, O. D., Seidman, F.G., Smith, J.A. \& Struhl, K. (1987) Current protocols in molecular biology. Vol1. New York, Chichester, Brisbane, Toronto, Singapur: Wiley-Intersciences.

Balling, R., Deutsch, U. \& Gruss, P. (1988) Undulated, a mutation affecting the development of the mouse skeleton, has a point mutation in the paired box of Pax 1. Cell 55: 531-535.

Baldwin, C. T., Hoth, C. F., Amos, J. A., da-Silva, E. O. \& Milunsky, A. (1992) An exonic mutation in the HuP2 paired domain gene causes Waardenburg's syndrome. Nature 355: 637-638.

Baum, J., Simons, B. E. Jr., Unger, R. H. \& Madison, L. L. (1962) Localization of glucagon in the alpha cells in the pancreatic islet by immunofluorescent technics. Diabetes 11: 371-374. 
Beimesche, S., Neubauer, A., Herzig, S., Grzeskowiak, R., Dietrich, T., Cierny, I., Scholz, D., Alejel, T. \& Knepel, W. (1999) Tissue-specific transcriptional activity of a pancreatic islet cell-specific enhancer sequence/Pax6-binding site determined in normal adult tissues in vivo using transgenic mice. Mol. Endocrinol. 13: 718-728.

Berthelsen, J., Zappavigna, V., Mavilio, F. \& Blasi, F. (1998) Prep1, a novel functional partner of Pbx proteins. EMBO J. 17:1423-1433.

Bertuccioli, C., Fasano, L., Jun, S., Wang, S., Sheng, G. \& Desplan, C. (1996) In vivo requirement for the paired domain and homeodomain of the paired segmentation gene product. Development 122: 2673-2685.

Billeter, M., Qian, Y., Otting, G., Müller, M., Gehring, W. J. \& Wüthrich, K. (1990) Determination of the three-dimensional structure of the Antennapedia homeodomain from Drosophila in solution by $1 \mathrm{H}$ nuclear magnetic resonance spectroscopy. J. Mol. Biol. 214:183-197.

Blank, V. \& Andrews, N. C. (1997) The Maf transcription factors: regulators of differentiation. Trends Biochem. Sci. 22: 437-441.

Bonner-Weir, S. (1991) Anatomy of the islet of Langerhans, 15-27. In E. Samols (Hrsg.), The endocrine pancreas, Raven Press, New York.

Bopp, D., Burri, M., Baumgartner, S., Frigerio, G. \& Noll, M. (1986) Conservation of a large protein domain in the segmentation gene paired and in functionally related genes of Drosophila. Cell 47: 1033-1040.

Bradford, M. M. (1976) A rapid and sensitive method for a quantitation of microgram quantities of protein utilizing the principle of protein-dye binding. Anal. Biochem. 72: 248254.

Bruun, J. A., Thomassen, E. I., Kristiansen, K., Tylden, G., Holm, T., Mikkola, I., Bjorkoy, G. \& Johansen, T. (2005) The third helix of the homeodomain of paired class homeodomain proteins acts as a recognition helix both for DNA and protein interactions. Nucleic Acids Res. 33: 2661-2675. 
Calkhoven, C. F. \& Ab, G. (1996) Multiple steps in the regulation of transcription-factor level and activity. Biochem. J. 317: 329-342.

Callaerts, P., Halder, G. \& Gehring W. J. (1997) PAX-6 in development and evolution. Annu. Rev. Neurosci. 20: 483-532.

Calzone, F. J., Lee, J. J., Le, N., Britten, R. J. \& Davidson, E. H. (1988) Developmental appearance of factors that bind specifically to cis-regulatory sequences of a gene expressed in the sea urchin embryo. Genes Dev. 2: 1074-1088.

Carbonell, L. F., Klowden, M. J. \& Miller, L. K. (1985) Baculovirus-mediated expression of bacterial genes in dipteran and mammalian cells. J. Virol. 56: 153-160.

Carriere, C., Plaza, S., Caboche, J., Dozier, C., Bailly, M., Martin, P. \& Saule, S. (1995) Nuclear localization signals, DNA binding, and transactivation properties of quail Pax-6 (Pax-QNR) isoforms. Cell Growth Differ. 6: 1531-1540.

Chalepakis, G., Fritsch, R., Fickenscher, H., Deutsch, U., Goulding, M. \& Gruss, P. (1991) The molecular basis of the undulated/Pax-1 mutation. Cell 66: 873-884.

Chalepakis, G., Temblay, P. \& Gruss, P. (1992) Pax genes, mutants and molecular function. J. Cell. Sci. Suppl. 16: 61-67.

Chalepakis, G., Stoykova, A., Wijnholds, J., Tremblay, P. \& Gruss, P. (1993) Pax: Gene regulators in the developing nervous system. J. Neurobiol. 24: 1367-1384.

Chalepakis, G., Wijnholds, J., Giese, P., Schachner, M. \& Gruss, P. (1994a) Characterization of Pax-6 and Hoxa-1 binding to the promoter region of the neural cell adhesion molecule L1. DNA Cell Biol. 13: 891-900.

Chalepakis, G., Wijnholds, J. \& Gruss, P. (1994b) Pax-3-DNA interaction: flexibility in the DNA binding and induction of DNA conformational changes by paired domains. Nucleic Acids Res. 22: 3131-3137.

Chalepakis, G., Goulding, M., Read, A., Strachan, T. \& Gruss, P. (1994c) Molecular basis of splotch and Waardenburg Pax-3 mutations. Proc. Natl. Acad. Sci. USA 91: 36853689. 
Chester, N. \& Marshak, D. R. (1993) Dimethyl sulfoxid-mediated primer $\mathrm{T}_{\mathrm{m}}$ reduction: a method for analyzing the role of renaturation temperature in the polymerase chain reaction. Anal. Biochem. 209: 284-290.

Cubitt, A. B., Heim, R., Adams, S. R., Boyd, A. E., Gross, L. A. \& Tsien, R. Y. (1995) Understanding, improving and using green fluorescent proteins. Trends Biochem. Sci. 20: 448-455.

Cvekl, A. \& Piatigorsky, J. (1996) Lens development and crystallin gene expression: many roles for Pax-6. Bioessays 18: 621-630.

Cvekl, A., Kashanchi, F., Brady, J. N., Piatigorsky, J. (1999) Pax-6 interactions with TATA-box-binding protein and retinoblastoma protein. Invest. Ophthalmol. Vis. Sci. 40: 1343-1350.

Czerny, T., Schaffner, G. \& Busslinger, M. (1993) DNA sequence recognition by Pax proteins: bipartite structure of the paired domain and its binding site. Genes Dev. 7: 20482061.

Czerny, T. \& Busslinger, M. (1995) DNA-binding and transactivation properties of Pax-6: three amino acids in the paired domain are responsible for the different sequence recognition of Pax-6 and BSAP (Pax-5). Mol. Cell. Biol. 15: 2858-2871.

Dagert, M. \& Ehrlich, S. D. (1979) Prolonged incubation in calcium chloride improves the competence of Escherichia coli cells. Gene 6: 23-28.

Dahl, E., Koseki, H. \& Balling, R. (1997) Pax genes and organogenesis. Bioessays 19: 755-765.

De Wet, J. R., Wood, K. V., De Luca, M., Helinski, 0. R. \& Subramani, S. (1987) Firefly luciferase gene; structure and expression in mammalian cells. Mol. Cell. Biol. 7: 725-737.

Drucker, D. J. \& Asa, S. (1988) Glucagon gene expression in vertebrate Brain. J. Biol. Chem. 263: 13475-13478.

Drucker, D. J. (1998) Glucagon-like peptides. Diabetes 47: 159-169. 
Drucker, D. J., Philippe, J., Jepeal, L. \& Habener J. F. (1987) Glucagon gene 5'flanking sequences promote islet cell-specific gene transcription. J. Biol. Chem. 262: 15659-15665.

Duncan, M. K., Haynes, J. I., Cvekl, A. \& Piatigorsky, J. (1998) Dual roles for Pax-6: a transcriptional repressor of lens fiber cell-specific beta-crystallin genes. Mol. Cell. Biol. 18: 5579-5586.

Dynan, W. S. (1989) Modularity in promoters and enhancers. Cell 58: 1-4.

Efrat, S., Teitelman, G., Anwar, M., Ruggiero, D. \& Hanahan, D. (1988) Glucagon gene regulatory region directs oncoprotein expression to neurons and pancreatic alpha cells. Neuron 1: 605-613.

Epstein, J., Cai, J., Glaser, T., Jepeal, L. \& Maas, R. (1994a) Identification of a Pax paired domain recognition sequence and evidence for DNA-dependent conformational changes. J. Biol. Chem. 269: 8355-8361.

Epstein, J.A., Glaser, T., Cai, J., Jepeal, L., Walton, D. S. \& Maas, R. L. (1994b) Two independent and interactive DNA-binding subdomains of the Pax6 paired domain are regulated by alternative splicing. Genes Dev. 8: 2022-2034.

Fitzsimmons, D., Hodsdon, W., Wheat, W., Maira, S. M., Wasylyk, B. \& Hagman, J. (1996) Pax-5 (BSAP) recruits Ets proto-oncogene family proteins to form functional ternary complexes on a B-cell-specific promoter. Genes Dev. 10: 2198-2211.

Fitzsimmons, D., Lutz, R., Wheat, W., Chamberlin, H. M. \& Hagman, J. (2001) Highly conserved amino acids in Pax and Ets proteins are required for DNA binding and ternary complex assembly. Nucleic Acids Res. 29: 4154-4165.

Fortin, A. S., Underhill, D. A. \& Gros, P. (1997) Reciprocal effect of Waardenburg syndrome mutations on DNA binding by the Pax-3 paired domain and homeodomain. Hum. Mol. Genet. 6: 1781-1790.

Fortin, A. S., Underhill, D. A. \& Gros, P. (1998) Helix 2 of the paired domain plays a key role in the regulation of DNA-binding by the Pax-3 homeodomain. Nucleic Acids Res. 26: 4574-4581. 
Fortini M. E. \& Rubin, G. M. (1990) Analysis of cis-acting requirements of the Rh3 and Rh4 genes reveals a bipartite organization to rhodopsin promoters in Drosophila melanogaster. Genes Dev. 4: 444-463.

Frankel, A. D., \& Kim, P. S. (1991) Modular structure of transcription factors: implications for gene regulation. Cell 65: 717-719.

Frigerio, G., Burri, M., Bopp, D., Baumgartner, S. \& Noll, M. (1986) Structure of the segmentation gene paired and the Drosophila PRD gene set as part of a gene network. Cell 47: 735-746.

Fujioka, M., Miskiewicz, P., Raj, L., Gulledge, A. A., Weir, M. \& Goto, T. (1996) Drosophila Paired regulates late even-skipped expression through a composite binding site for the paired domain and the homeodomain. Development 122: 2697-2707.

Fürstenau, U., Schwaninger, M., Blume, R., Kennerknecht, I. \& Knepel, W. (1997) Characterization of a novel protein kinase $\mathrm{C}$ response element in the glucagon gene. Mol. Cell. Biol. 17: 1805-1816.

Garvie, C. W., Hagman, J. \& Wolberger, C. (2001) Structural studies of Ets-1/Pax5 complex formation on DNA. Mol. Cell 8: 1267-1276.

Gehring, W. J., Affolter, M., \& Burglin, T. (1994) Homeodomain proteins. Annu. Rev. Biochem. 63: 487-526.

Gehring, W. J. \& Ikeo, K. (1999) Pax6: mastering eye morphogenesis and eye evolution. Trends Genet. 15: 371-377.

Gelling, R. W., Du, X. Q., Dichmann, D. S., Romer, J., Huang, H., Cui, L., Obici, S., Tang, B., Holst, J. J., Fledelius, C., Johansen, P. B., Rossetti, L., Jelicks, L. A., Serup, P., Nishmura, E. \& Charron, M. J. (2003) Lower blood glucose, hyperglucagonemia, and pancreatic alpha cell hyperplasia in glucagon receptor knockout mice. Proc. Natl. Acad. Sci. USA 100: 1438-1443.

Glaser, T., Walton, D. S. \& Maas, R. L. (1992) Genomic structure, evolutionary conservation and aniridia mutations in the human PAX6 gene. Nature Genet. 2: 232-239. 
Gluzman, Y. (1981) SV40-transformed simian cells support the replication of early SV40 mutants. Cell 23: 175-182.

Greene, R. J. \& Guarente, L. (1987) Subcloning. Methods Enzymol. 152: 512-521.

Grocott, T., Frost, V., Maillard, M., Johansen, T., Wheeler, G. N., Dawes, L. J., Wormstone, I. M. \& Chantry, A. (2007) The MH1 domain of Smad3 interacts with Pax6 and represses autoregulation of the Pax6 P1 promoter. Nucleic Acids Res. (Epub ahead of print) 1-12.

Grzeskowiak, R., Amin, J., Oetjen, E. \& Knepel, W. (2000) Insulin responsiveness of the glucagon gene conferred by interactions between proximal promoter and more distal enhancer-like elements involving the paired-domain transcription factor Pax6. J. Biol. Chem. 275: 30037-30045.

Habener, J. F., Drucker, D. J., Mojsov, S., Knepel, W. \& Philippe, J. (1991) Biosynthesis of glucagon. In: Samols E. ed. The endocrine pancreas. New York: Raven Press. 53-71.

Halder, G., Callaerts, P. \& Gehring, W. J. (1995) Induction of ectopic eyes by targeted expression of the eyeless gene in Drosophila. Science 267: 1788-1792.

Heim, R., Prasher, D. C. \& Tsien, R. Y. (1994) Wavelength mutations and posttranslational autoxidation of green fluorescent protein. Proc. Natl. Acad. Sci. USA 91: 12501-12504

Herr, W. \& Cleary, M. A. (1995) The POU domain: versatility in transcriptional regulation by a flexible two-in-one DNA-binding domain. Genes Dev. 9: 1679-1693.

Herzig, S., Fuzesi, L. \& Knepel, W. (2000) Heterodimeric Pbx-Prep1 homeodomain protein binding to the glucagon gene restricting transcription in a cell type-dependent manner. J. Biol. Chem. 275: 27989-27999.

Hill, R. E., Favor, J., Hogan, B. L. M., Ton, C. C. T., Saunders, G. F., Hanson, I. M., Prosser, J., Jordan, T., Hastie, N. D. \& van Heyningen, V. (1991) Mouse Small eye results from mutations in a paired-like homeobox-containing gene. Nature 354: 522-525. 
Hittner, H. M. (1989) Aniridia. In "The glaucomas" (R. Rich, M. B. Shields \& T. Krupin, Eds.), pp. 869-884. Mosby, St. Louis.

Hussain, M. A., Lee, J., Miller, C. P. \& Habener, J. F. (1997) POU domain transcription factor brain 4 confers pancreatic alpha-cell-specific expression of the proglucagon gene through interaction with a novel proximal promoter G1 element. Mol. Cell. Biol. 17: 71867194.

Jiang, G. \& Zhang, B. B. (2003) Glucagon and regulation of glucose metabolism. Am. J. Physiol. Endocrinol. Metab. 284: 671-678.

Jin, T. \& Drucker, D. J. (1996) Activation of proglucagon gene transcription through a novel promoter element by the caudal-related homeodomain protein cdx-2/3. Mol. Cell. Biol. 16: 19-28.

Jin, T., Trinh, D. K., Wang, F. \& Drucker, D. J. (1997) The caudal homeobox protein cdx-2/3 activates endogenous proglucagon gene expression in InR1-G9 islet cells. Mol. Endocrinol. 11: 203-209.

Johnson, P. F. \& McKnight, S. L. (1989) Eukaryotic transcriptional regulatory proteins. Annu. Rev. Biochem. 58: 799-839.

Jordan, T., Hanson, I., Zaletayev, D., Hodgson, S., Prosser, J., Seawright, A., Hastie, N. \& van Heyningen, V. (1992) The human PAX6 gene is mutated in two patients with aniridia. Nature Genet. 1: 328-332.

Jun, S. \& Desplan, C. (1996) Cooperative interactions between paired domain and homeodomain. Development 122: 2639-2650.

Kamps, M. P., Murre, C., Sun, X. H. \& Baltimore, D. (1990) A new homeobox gene contributes the DNA binding domain of the $t(1 ; 19)$ translocation protein pre-B ALL. Cell 60: 547-555.

Kissinger, C. R., Liu, B. S., Martin-Blanco, E., Kornberg, T. B. \& Pabo C. O. (1990) Crystal structure of an engrailed homeodomain-DNA complex at 2.8 A resolution: a framework for understanding homeodomain-DNA interactions. Cell 63: 579-590. 
Klemm, J. D., Rould, M. A., Aurora, R., Herr W. \& Pabo, C. O. (1994) Crystal structure of the Oct-1 POU domain bound to an octamer site: DNA recognition with tethered DNAbinding modules. Cell 77: 21-32.

Knepel, W., Chafitz, J. \& Habener, J. F. (1990a) Transcriptional activation of the rat glucagon gene by the cyclic AMP-responsive element in pancreatic islet cells. Mol. Cell. Biol. 10: 6799-804.

Knepel, W., Jepeal, L., \& Habener, J. F. (1990b) A pancreatic islet cell-specific enhancer-like element in the glucagon gene contains two domains binding distinct cellular proteins. J. Biol. Chem. 265: 8725-8735.

Knepel, W., Vallejo, M., Chafitz, J. A. \& Habener, J. F. (1991) The pancreatic isletspecific glucagon G3 transcription factors recognize control elements in the rat somatostatin and insulin-I genes. Mol. Endocrinol. 5: 1457-1466.

Knepel, W. (1993) Transcriptional control of pancreatic islet hormones gene expression. Exp. Clin. Endocrinol. 101: 39-45.

Knepel, W. (2001) The $\alpha$-cell and regulation of glucagon gene transcription. In "Molecular Basis of Endocrine Pancreas Development and Function" (Hrsg. Hussain, M. A., Miller, C. P., Habener, J. F.) Kluwer Academic Publishers, Boston: 67-89.

Kohler, P. O. \& Bridson, W. E. (1971) Isolation of hormone-producing clonal lines of human choriocarcinoma. J. Clin. Endocrinol. Metab. 32: 683-687.

Laemmli, U. K. (1970) Cleavage of structural proteins during the assembly of the head of bacteriophage T4. Nature 227: 680-685.

Langdon, R. C., Burr, T., Pagan-Westphal, S. \& Hochschild, A. (2001) A chimeric activator of transcription that uses two DNA-binding domains to make simultaneous contact with pairs of recognition sites. Mol. Microbiol. 41: 885-896.

Latchman, D. S. (1997) Transcription factors: an overview. Int. J. Biochem. Cell Biol. 29: 1305-1312.

Lefebvre, P. J. (1995) Glucagon and its family revisited. Diabetes Care 18: 715-730. 
Lu, Q., Wright, D. D. \& Kamps, M. P. (1994) Fusion with E2A converts the Pbx1 homeodomain protein into an constitutive transcriptional activator in human leukemias carrying the $\mathrm{t}(1 ; 19)$ translocation. Mol. Cell. Biol. 14: 3938-3948.

Liu, J. J., Kao, W. W. \& Wilson, S. E. (1999) Corneal epithelium-specific mouse keratin K12 promoter. Exp. Eye Res. 68: 295-301.

Mansouri, A., Goudreau, G. \& Gruss, P. (1999) Pax genes and their role in organogenesis. Cancer Res. 59: 1707-1709.

Marquardt, T., Ashery-Padan, R., Andrejewski, N., Scardigli, R., Guillemot, F. \& Gruss, P. (2001) Pax6 is required for the multipotent state of retinal progenitor cells. Cell 105: 43-55.

Matsunami, H. \& Takeichi, M. (1995) Fetal brain subdivisions defined by R- and Ecadherin expressions: evidence for the role of cadherin activity in region-specific, cell-cell adhesion. Dev. Biol. 172: 466-478.

Matsuo, T., Osumi-Yamashita, N., Noji, S., Ohuchi, H., Koyama, E., Myokai, F., Matsuo, N., Taniguchi, S., Doi, H., Ninomiya, Y., Fujiwara, M., Watanabe, T. \& Eto, K. (1993) A mutation in the Pax-6 gene in rat small eye is associated with impaired migration of midbrain crest cells. Nature Genet. 3: 299-304.

Maulbecker, C. C. \& Gruss, P. (1993) The oncogenic potential of Pax genes. EMBO J. 12: 2361-2367.

Meech, R., Kallunki, P., Edelman, G. M. \& Jones, F. S. (1999) A binding site for homeodomain and Pax proteins is necessary for L1 cell adhesion molecule gene expression by Pax-6 and bone morphogenetic proteins. Proc. Natl. Acad. Sci. USA 96: 2420-2425.

Mikkola, I., Bruun, J. A., Holm, T. \& Johansen, T. (2001) Superactivation of Pax6mediated transactivation from paired domain-binding sites by DNA-independent recruitment of different homeodomain proteins. J. Biol. Chem. 276: 4109-4118. 
Mishra, R., Gorlov, I. P., Chao, L. Y., Singh, S. \& Saunders G. F. (2002) PAX6, paired domain influences sequence recognition by the homeodomain. J. Biol. Chem. 277: 4948849494.

Mismer, D. \& Rubin, G. M. (1989) Definition of cis-acting elements regulating expression of the Drosophila melanogaster ninaE opsin gene by oligonucleotide-directed mutagenesis. Genetics 121: 77-87.

Mitchell P. J. \& Tijan, R. (1989) Transcriptional regulation in mammalian cells by sequence-specific DNA binding proteins. Science 245: 371-378.

Monica, K., Galili, N:, Nourse, J., Saltman, D. \& Cleary, M. L. (1991) PBX2 and PBX3, new homeobox genes with extensive homology to the human proto-oncogene PBX1. Mol. Cell. Biol. 11: 6149-6157.

Morel, C., Cordier-Bussat, M. \& Philippe, J. (1995) The upstream promoter element of the glucagon gene, G1 confers pancreatic alpha cell-specific expression. J. Biol. Chem. 270: 3046-55.

Mullis, K. B. \& Faloona, F. A. (1987) Specific synthesis of DNA in vitro via a polymerasecatalyzed chain reaction. Methods Enzymol. 155: 335-350.

Nelson, L. B., Spaeth, G. L., Nowinski, T. S., Margo, C. E. \& Jackson, L. (1984) Aniridia. A review. Surv. Ophthalmol. 28: 621-642.

Nourse, J., Mellentin, J. D., Galili, N., Wilkinson, J., Stanbridge, E., Smith, S. D. \& Cleary, M. L. (1990) Chromosomal translocation $t(1 ; 19)$ results in synthesis of a homeobox fusion mRNA that codes for a potential chimeric transcription factor. Cell 60: 535-545.

O'Reilly, D. R., Miller, L. K. \& Luckow, V. A. (1992) Baculovirus expression vectors: a laboratory manual. Freemann and Company, New York.

Otting, G., Qian, Y. Q., Billeter, M., Müller, M., Affolter, M., Gehring, W. J. \& Wüthrich, K. (1990) Protein-DNA contacts in the structure of a homeodomain-DNA complex determined by nuclear magnetic resonance spectroscopy in solution. EMBO J. 9: 30853092. 
Page, M. J. \& Rodgers, B. C. (1995) Selection of recombinant baculoviruses by visual screening. Methods Mol. Biol. 39: 107-127.

Philippe, J., Drucker, D. J., Knepel, W., Jepeal, L., Misulovin, Z. \& Habener, J. F. (1988) Alpha-cell-specific expression of the glucagon gene is conferred to the glucagon promoter element by the interactions of DNA-binding proteins. Mol. Cell. Biol. 8: 48774888.

Philippe, J. (1989) Glucagon gene transcription is negatively regulated by insulin in a hamster islet cell line. J. Clin. Invest. 84: 672-677.

Philippe, J., Morel, C. \& Cordier-Bussat, M. (1995) Islet-specific proteins interact with the insulin-response element of the glucagon gene. J. Biol. Chem. 270: 3039-3045.

Phillips, C. L., Vershon, A. K., Johnson, A. D. \& Dahlquist, F. W. (1991) Secondary structure of the homeodomain of yeast alpha 2 repressor determined by NMR spectroscopy. Genes Dev. 5: 764-772.

Plaza, S., Grevin, D., MacLeod, K., Stehelin, D. \& Saule, S. (1994) Pax-QNR/Pax-6, a paired- and homeobox-containing protein, recognizes Ets binding sites and can alter the transactivating properties of Ets transcription factors. Gene Expr. 4: 43-52.

Ptashne, M. (1988) How eukaryotic transcriptional activators work. Nature 335: 683-689.

Pufall, M. A. \& Graves, B. J. (2002) Ets-1 flips for new partner Pax-5. Structure 10: $11-14$.

Punzo, C., Kurata, S. \& Gehring, W. J. (2001) The eyeless homeodomain is dispensable for eye development in Drosophila. Genes Dev. 15: 1716-1723.

Qian, Y, Q., Ottinger, G., Billeter, M., Müller, M., Gehring, W. \& Wüthrich, K. (1994) Nuclear magnetic resonance solution structure of the fushi tarazu homeodomain from Drosophila and comparison with the Antennapedia homeodomain. J. Mol. Biol. 238: 333-345. 
Quiring, R., Walldorf, U., Kloter, U. \& Gehring, W. J. (1994) Homology of the eyeless gene of Drosophila to the Small eye gene in mice and Aniridia in humans. Science 265: 785-789.

Regulski, M., Harding, K., Kostriken, R., Karch, F., Levine M. \& McGinnis, W. (1985) Homeo box genes of the Antennapedia and bithorax complexes of Drosophila. Cell 43: 71-80.

Ritz-Laser, B., Estreicher, A., Klages N., Saule, S. \& Philippe, J. (1999) Pax-6 and $\mathrm{Cdx}-2 / 3$ interact to activate glucagon gene expression on the $\mathrm{G} 1$ control element. J. Biol. Chem. 274: 4124-4132.

Saiki, R. K., Gelfand, D. H., Stoffel, S., Scharf, S. J., Higuchi, R., Horn, G. T., Mullis, K. B. \& Erlich, H. A. (1988) Primer-directed enzymatic amplification of DNA with a thermostable DNA polymerase. Science 239: 487-491.

Sambrook, J., Fritsch, E. F. \& Maniatis, T. (1989) Molecular cloning. A laboratory manual ( $2^{\text {nd }}$ Ed.). Cold Spring Harbor Laboratory Press, Cold Spring Harbor, USA.

Sander, M., Neubüser, A., Kalamaras, J., Ee, H. C., Martin, G. R. \& German, M. S. (1997) Genetic analysis reveals that PAX6 is required for normal transcription of pancreatic hormone genes and islet development. Genes Dev. 11: 1662-1673.

Sanger, F., Nicklen, S. \& Coulson, A. R. (1977) DNA sequencing with chain-terminating inhibitors. Proc. Natl. Acad. Sci. USA 74: 5463-5467.

Scardigli, R., Schuurmans, C., Gradwohl, G. \& Guillemot, F. (2001) Crossregulation between Neurogenin2 and pathways specifying neuronal identity in the spinal cord. Neuron 31: 203-217.

Schafer, B. W., Czerny, T., Bernasconi, M., Genini, M. \& Busslinger, M. (1994) Molecular cloning and characterization of a human PAX-7 cDNA expressed in normal and neoplastic myocytes. Nucleic Acids Res. 22: 4574-4582. 
Schinner, S., Dellas, C., Schröder, M., Heinlein, C. A., Chang, C., Fischer, J. \& Knepel, W. (2002) Repression of glucagon gene transcription by peroxisome proliferatoractivated receptor gamma through inhibition of Pax6 transcriptional activity. J. Biol. Chem. 277: 1941-1948.

Schreiber, E., Matthias P., Müller, M. M. \& Schaffner, W. (1989) Rapid detection of octamer binding proteins with 'mini-extracts', prepared from a small number of cells. Nucleic Acids Res. 17: 6419.

Schwaninger, M., Lux, G., Blume, R., Oejen, E., Hidaka, H. \& Knepel, W. (1993) Membrane depolarization and calcium influx induce glucagon gene transcription in pancreatic islet cells through the cyclic AMP-responsive element. J. Biol. Chem. 268: 5168- 5177.

Shaw, M. W., Falls, H. F. \& Neel, J. V. (1960) Congenital aniridia. Am. J. Hum. Genet. 12: 389-415.

Simpson, T. I. \& Price, D. J. (2002) Pax6; a pleitropic player in development. Bioassays 24: 1041-1051.

Singh, S., Tang, H. K., Lee, J. Y. \& Saunders, G. F. (1998) Truncation mutations in the transactivation region of PAX6 result in dominant-negative mutants. J. Biol. Chem. 273: 21531-21541.

Singh, S., Stellrecht, C. M., Tang, H. K. \& Saunders, G. F. (2000) Modulation of PAX6 homeodomain function by the paired domain. J. Biol. Chem. 275: 17306-17313.

Singh, S., Chao, L. Y., Mishra, R., Davies, J. \& Saunders, G. F. (2001) Missense mutation at the C-terminus of PAX6 negatively modulates homeodomain function. Hum. Mol. Genet. 10: 911-918.

Stemmer, W. P., Crameri, A., Ha, K. D., Brennan, T. M. \& Heyneker, H. L. (1995) Single-step assembly of a gene and entire plasmid from large numbers of oligodeoxyribonucleotides. Gene 164: 49-53. 
St-Onge, L., Sosa-Pineda, B., Chowdhury, K., Mansouri, A. \& Gruss, P. (1997) Pax6 is required for differentiation of glucagon-producing alpha-cells in mouse pancreas. Nature 387: 406-409.

Stuart, E. T., Kioussi, C. \& Gruss, P. (1994) Mammalian Pax genes. Annu. Rev. Genet. 28: 219-236.

Stümpel, F., Scholtka, B., Hunger, A. \& Jungermann, K. (1998) Enteric glucagon 37 rather than pancreatic glucagon 29 stimulates glucose absorption in rat intestine. Gastroenterology 115: 1-10.

Takaki, R., Ono, J., Nakamura, M., Yokogawa, Y., Kumae, S., Hiraoka, T., Yamaguchi, K., Hamaguchi, K. \& Uchida, S. (1986) Isolation of glucagon-secreting cell lines by cloning insulinoma cells. In Vitro Cell. Dev. Biol. 22: 120-126.

Tang, H. K., Singh, S. \& Saunders, G. F. (1998) Dissection of the transactivation function of the transcription factor encoded by the eye developmental gene Pax6. J. Biol. Chem. 273: 7210-7221.

Tassabehji, M., Read, A. P., Newton, V.E., Patton, M., Gruss, P., Harris, R. \& Strachan, T. (1993) Mutations in the PAX3 gene causing Waardenburg syndrome type 1 and type 2. Nat. Genet. 3: 26-30.

Teichler, S. (2004) Bedeutung der Homöodomäne des Transkriptionsfaktors Pax6 für die Aktivierung des Glukagon-Gens durch Pax6. Dissertation, Universität Göttingen.

Throsby, M., Homo-Delarche, F., Chevenne, D., Goya, R., Dardenne, M., \& Pleau, J. M. (1998) Pancreatic hormone expression in the murine thymus: localization in dendritic cells and macrophages. Endocrinology 139: 2399-2406.

Treisman, J., Harris, E. \& Desplan, C. (1991) The paired box encodes a second DNAbinding domain in the paired homeo domain protein. Genes Dev. 5: 594-604.

Underhill, D. A. (2000) Genetic and biochemical diversity in the Pax gene family. Biochem. Cell. Biol. 78: 629-638. 
Underhill, D. A., Vogan, K. J. \& Gros, P. (1995) Analysis of the mouse Splotch-delayed mutation indicates that the Pax-3 paired domain can influence homeodomain DNA-binding activity. Proc. Natl. Acad. Sci. USA 92: 3692-3696.

Underhill, D. A. \& Gros, P. (1997) The paired-domain regulates DNA binding by the homeodomain within the intact Pax-3 protein. J. Biol. Chem. 272: 14175-14182.

Unger, R. H. \& Orci, L. (1981a) Glucagon and the A-cell: physiology and pathophysiology (first of two parts). N. Engl. J. Med. 304:1518-1524.

Unger, R. H. \& Orci, L. (1981b) Glucagon and the A-cell: physiology and pathophysiology (second of two parts). N. Engl. J. Med. 304: 1575-1580.

van Leeuwen, H. C., Strating, M. J., Rensen, M., de Laat, W. \& van der Vliet, P. C. (1997) Linker length and composition influence the flexibility of Oct-1 DNA binding. EMBO J. 16: 2043-2053.

Vaughn, J. L., Goodwin, R. H., Tompkins, G. J. \& McCawley, P. (1977) The establishment of two cell lines from the insect Spodoptera frugiperda (Lepidoptera; Noctuidae). In Vitro 13: 213-217.

Vogan, K. J., Epstein, D. J., Trasler, D. G. \& Gros, P. (1993) The splotch-delayed (Spd) mouse mutant carries a point mutation within the paired box of the Pax-3 gene. Genomics 17: 364-369.

Vogelstein, B. \& Gillespie, D. (1979) Preparative and analytical purification of DNA from agarose. Proc. Natl. Acad. Sci. USA 76: 615-619.

Walther, C. \& Gruss, P. (1991a) Pax-6, a murine paired box gene, is expressed in the developing CNS. Development 113: 1435-1449.

Walther, C., Guenet, J. L., Simon, D., Deutsch, U., Jostes, B., Goulding, M. D., Plachov, D., Balling, R. \& Gruss, P. (1991b) Pax: a murine multigene family of paired box containing genes. Genomics 11: 424-434. 
Wang, M. \& Drucker, D. J. (1995) The LIM domain homeobox gene isl-1 is a positive regulator of islet cell-specific proglucagon gene transcription. J. Biol. Chem. 270: 1264612652.

Wheat, W., Fitzsimmons, D., Lennox, H., Krautkramer, S. R., Gentile, L. N., Mclntosh, L. P. \& Hagman, J. (1999) The highly conserved beta-hairpin of the paired DNA-binding domain is required for assembly of Pax-Ets ternary complexes. Mol. Cell. Biol. 19: 22312241.

Wilson, D., Sheng, G., Lecuit, T., Dostatni, N. \& Desplan, C. (1993) Cooperative dimerization of paired class homeo domains on DNA. Genes Dev. 7: 2120-2134.

Wilson, D. S., Guenther, B., Desplan, C. \& Kuriyan, J. (1995) High resolution crystal structure of a paired (Pax) class cooperative homeodomain dimer on DNA. Cell 82: 709719.

Xu, W., Rould, M. A., Jun, S., Desplan, C. \& Pabo, C. O. (1995) Crystal structure of a paired domain-DNA complex at $2.5 \mathrm{~A}$ resolution reveals structural basis for Pax developmental mutations. Cell 80: 639-650.

Xu, H. E., Rould, M. A., Xu, W., Epstein, J. A., Maas, R. L. \& Pabo, C. O. (1999) Crystal structure of the human Pax6 paired domain-DNA complex reveals specific roles for the linker region and carboxy-terminal subdomain in DNA binding. Genes Dev. 13: 12631275 .

Zhang, Y. \& Emmons, S. W. (1995) Specification of sense-organ identity by a Caenorhabditis elegans Pax-6 homologue. Nature 377: 55-59. 


\section{DANKSAGUNG}

Mein besonderer Dank gilt Herrn Prof. Dr. W. Knepel für die Überlassung des Dissertationsthemas, die fachliche Unterstützung in allen Phasen dieser Arbeit sowie für die konstruktiven Diskussionen.

Herrn Prof. Dr. R. Hardeland danke ich für die bereitwillige Betreuung der Arbeit seitens der Biologischen Fakultät und sein wissenschaftliches Interesse am Fortgang dieser Arbeit.

Bei Herrn PD Dr. W. Kramer bedanke ich mich für die Bereitschaft, das Korreferat für diese Arbeit zu übernehmen.

Für die nette Betreuung und wissenschaftlichen Anregungen, sowie für zahlreiche Tipps und Tricks im Laboralltag gilt mein besonderer Dank auch Herrn Dr. Ralf Krätzner.

Dr. Elke Oetjen und Dr. Ulrike Böer sei für wertvolle fachliche Diskussionen gedankt.

Ein ganz herzliches Dankeschön geht an die Truppe aus Labor 206: an Corinna Dickel ohne deren tatkräftige Unterstützung manches nicht machbar gewesen wäre, sowie an Andrei und Sanjeev für das nette Arbeitsklima und hilfreiche Ratschläge in vielen Belangen.

Allen Mitgliedern der Abteilung Molekulare Pharmakologie speziell auch Doris, Roland, Irmgard, Julia, Miranda und Anna danke ich für die Hilfsbereitschaft und eine nette Arbeitsatmosphäre.

Nicht zuletzt danke ich meiner Familie, insbesondere meinem Vater, der mir vieles ermöglicht hat. 


\section{LEBENSLAUF}

\section{Persönliche Daten}

Name:

Geburtsdatum:

Geburtsort:

Staatsangehörigkeit:

Familienstand:

\section{Schulbildung}

1983 - 1987

1987 - 1989

1989 - 1996

\section{Zivildienst}

1996 - 1997

Hochschulbildung

1997 - 2003

1999

$2002-2003$

Jan. 2003 - Sep. 2003

\section{Dissertation}

Mai 2004

Mai 2007

\section{Marcel Grapp}

25.09.1976

Göttingen

deutsch

ledig
Grundschule in Hardegsen

Orientierungsstufe der KGS Moringen

Otto-Hahn-Gymnasium in Göttingen,

Abschluss: Allgemeine Hochschulreife

Zivildienst in den Göttinger Werkstätten für Behinderte (WfB)

Studium der Biologie an der Georg-August-Universität zu Göttingen mit den Fächern: Mikrobiologie, Pharmakologie \& Toxikologie und Immunologie

Vordiplomsprüfung mit den Fächern Mikrobiologie, Botanik, anorganische Chemie und Physik

Diplomarbeit im Institut für Mikrobiologie und Genetik in Göttingen, Titel:

„Mutantenerzeugung in Methanosarcina mazei Gö1“

Abschlussnote: „mit Auszeichnung“

Wissenschaftlicher Mitarbeiter im

Institut für Mikrobiologie und Genetik in Göttingen
Beginn der experimentelle Arbeiten zur vorliegenden Dissertation im Zentrum Pharmakologie und Toxikologie, Abteilung Molekulare Pharmakologie in Göttingen unter der Leitung von Herrn Prof. Dr. W. Knepel im Rahmen des SFB 402 der Deutschen Forschungsgemeinschaft „Molekulare und Zelluläre Hepatogastroenterologie“

Abgabe der vorliegenden Dissertation 